UNIVERSITAT JAUME I

ESCOLA DE DOCTORAT DE LA UNIVERSITAT JAUME I

PROGRAMA DE DOCTORAT EN TECNOLOGIES INDUSTRIALS I MATERIALS

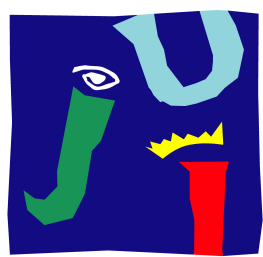

UNIVERSITAT

JAUME•I

\title{
NUMERICAL FORMULATION OF PHYSICAL PHENOMENA IN NANOPARTICLES FOR THEIR APPLICATION TO NANOFLUIDS
}

\section{A dissertation presented by Josep Forner Escrig for the Degree of} Doctor of Philosophy

AUTHORED BY: Josep Forner Escrig

SUPERVISED BY: Roberto Palma Guerrero Rosa Mondragón Cazorla 



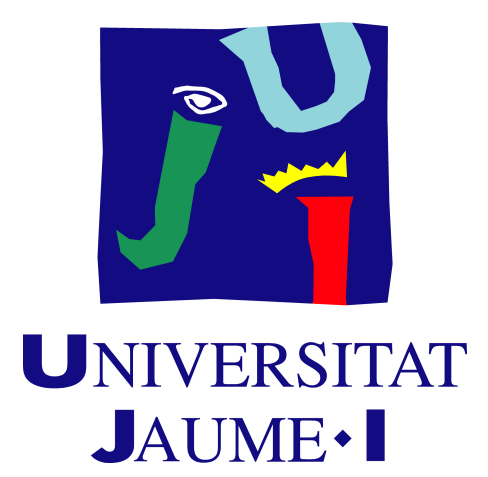

PROGRAMA DE DOCTORAT EN TECNOLOGIES INDUSTRIALS I MATERIALS ESCOLA DE DOCTORAT DE LA UNIVERSITAT JAUME I

\section{FORMULACIÓ NUMĖRICA DE FENÒMENS FÍSICS EN NANOPARTÍCULES PER A LA SEUA APLICACIÓ EN NANOFLUIDS}

\footnotetext{
Memòria presentada per Josep Forner Escrig per a optar al grau de doctor per la Universitat Jaume I
}
AUTOR
DIRECTOR
DIRECTORA
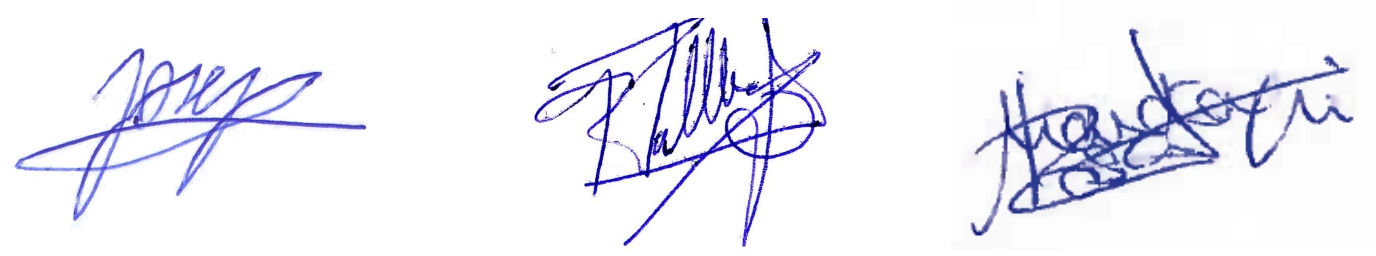



\section{Funding}

\section{Pre-doctoral contract:}

- Ayuda para contratos predoctorales para la formación de doctores FPI-Ministerio de Economía, Industria y Competitividad de España, convocatoria 2017, dentro del marco del Programa Estatal de Promoción del Talento y su Empleabilidad del Plan Estatal de Investigación Científica y Técnica y de Innovación 2013-2016 (Ref. BES-2017-080217).

$1^{\text {st }}$ July $2018-30^{\text {th }}$ June 2021

\section{Research stay:}

- Zienkiewicz Centre for Computational Engineering, Swansea University, Wales (United Kingdom).

$2^{\text {nd }}$ September $2019-16^{\text {th }}$ December 2019

Funded by Ayuda a la movilidad predoctoral para la realización de estancias breves en centros de $I+D$ 2017, associated to Ayuda para contratos predoctorales para la formación de doctores FPI - Ministerio de Economía, Industria y Competitividad de España, convocatoria 2017 (Ref. BES-2017-080217). 



\section{Compendium of publications}

- J. Forner-Escrig, R. Palma and R. Mondragón. Finite element formulation to study thermal stresses in nanoencapsulated phase change materials for energy storage, Journal of Thermal Stresses, vol. 43, no. 5, pp. 543-562, 2020.

DOI: $10.1080 / 01495739.2020 .1718045$

- J. Forner-Escrig, R. Mondragón, L. Hernández, R. Palma. Mechanical reliability analysis of nanoencapsulated phase change materials combining Monte Carlo technique and the finite element method, Submitted for publication.

- J. Forner-Escrig, N. Navarrete, R. Palma, D. La Zara, A. Goulas, D. Valdesueiro, J. R. van Ommen, L. Hernández, R. Mondragón. Numerical modelling of the mechanical reliability of multi-coated nanoencapsulated phase change materials with improved thermal performance, Submitted for publication.

- J. Forner-Escrig, R. Mondragón, L. Hernández, R. Palma. Non-linear finite element modelling of light-to-heat energy conversion applied to solar nanofluids, International Journal of Mechanical Sciences, vol. 188, pp. 105952, 2020.

DOI: $10.1016 /$ j.ijmecsci.2020.105952

This thesis has been accepted by the co-authors of the publications listed above that have waived the right to present them as a part of another $\mathrm{PhD}$ thesis. 

To my family 



\section{Acknowledgements}

Firstly, I would like to thank my supervisors: Quique, for thinking of me as a candidate for the pre-doctoral contract I have held and for laying the foundations of the research developed during these years; unfortunately, we did not have time for more...; Roberto, for encouraging me into the fascinating world of research and for helping me delve into the world of multiphysics, thermodynamics and numerical methods; Rosa, for your invaluable help in introducing me into the world of nanofluids and for making me more aware of experimental research. I am very grateful to both Roberto and Rosa for being my PhD directors and for their guidance, help and support and all the time they have devoted to me throughout this research experience.

I want to thank the entities which participated in the funding of my thesis during this time: Ministerio de Economía, Industria y Competitividad de España and Fondo Social Europeo for the pre-doctoral contract in the FPI programme (Ref. BES-2017-080217) and the mobility grant for research stays corresponding to this contract, both of them associated to the project ENE2016-77694-R, awarded by Ministerio de Economía y Competitividad de España.

I would also like to express my deep gratitude to Prof. Antonio J. Gil from Swansea University for accepting me into his research group during my research stay and for finding time for our fruitful discussions about numerical methods and continuum mechanics. Also thanks to all the people I met in Swansea, they made me feel at home.

Furthermore, I would like to thank Leo, Nuria and the rest of the Multiphase Fluids research Group from Universitat Jaume I for their gentle help and collaboration during this thesis. I must thank the Continuum Mechanics and Theory of Structures scientific area of Universitat Jaume I as well for their kind support and help during all this time, for providing me with a computer and all the necessary equipment to develop my research and for having the opportunity to teach my first lessons in the domain of structural mechanics. Finally, I would also like to thank all the people from the Department of Mechanical Engineering and Construction from Universitat Jaume I who always have a nice and encouraging word to say to me.

I wish to thank all my dear friends for their support and interest during all this time. It is unfair just to name a few but space is limited and I must apologise in advance for omissions. A special mention is devoted to Aitor and Andrei for their great plans and the fun we have together. Of course I cannot forget to thank my friends at university: Oscar, Raquel, Carlos J., Dani, Josep C., Ester, Carlos D., Jorge and Marc for making the everyday routine much more enjoyable and for the fun we have during lunches... and dinners! Thanks to all of you for helping me clear my mind when I was stuck at my research work.

Finalment, m'agradaria donar les gràcies de tot cor a la meua família pel seu 
amor i recolzament incondicional. Moltes gràcies a tots els meus oncles, ties, cosins, cosines, nebots i nebodes pel seu afecte, interés i suport al llarg de la tesi. Una menció especial mereixen els meus avis $i$ àvies per la seua estima, gran cor $i$ el coneixement que m'han transmés. Estic segur que els haguera fet tant de comboi com a mi haver pogut veure el resultat d'aquest treball. Desgraciadament, el temps no ha permés que estiguen tots ells ací avui... També vull donar les gràcies al meu germà Jaume per la seua estima, ajuda i totes les hores $i$ bons moments que hem passat junts des de menuts $i$ per les que encara queden... Per últim, no podria estar més agraït als meus pares, Josep $i$ Lola, pel seu amor, pel seu enorme suport $i$ ajuda (i no sols en matemàtiques), per la seua paciència i per totes les oportunitats que m'han donat $i$ sacrificis que han fet perquè puga formar-me com a persona $i$ professionalment. També són ells qui m'han inculcat el sentit de la responsabilitat $i$ la cultura del treball i l'esforç $i$ és gràcies a ells que sempre intente donar el màxim de mi en tot allò que faig. A tots vosaltres, moltíssimes gràcies! 


\section{Contents}

$\begin{array}{lll}\text { Funding } & \text { I }\end{array}$

$\begin{array}{ll}\text { Compendium of publications } & \text { III }\end{array}$

$\begin{array}{ll}\text { Acknowledgements } & \text { VII }\end{array}$

$\begin{array}{lll}\text { Abstract } & \text { XIII }\end{array}$

$\begin{array}{ll}\text { List of Figures } & \text { XIX }\end{array}$

$\begin{array}{ll}\text { List of Tables } & \text { XXIII }\end{array}$

$\begin{array}{lll}\text { Nomenclature } & \text { XXV }\end{array}$

Chapter 1: Structure 1

Chapter 2: Introduction $\quad 3$

2.1 Concentrated Solar Power Plants . . . . . . . . . . . . . . . . . . 4

2.2 Nanofluids . . . . . . . . . . . . . . . . . . . . . . . 6

2.3 Outline of theoretical background . . . . . . . . . . . . . . 12

2.3.1 Thermodynamics .................. . . 12

2.3.1.1 Equilibrium Thermodynamics . . . . . . . . . . 14

2.3.1.2 Non-Equilibrium Thermodynamics . . . . . . . . 15

2.3.2 Continuum Mechanics . . . . . . . . . . . . . . . . . 17

2.3.3 Electromagnetism . . . . . . . . . . . . . . . . . 18

2.3.4 Finite Element Method . . . . . . . . . . . . . . . 19

2.4 List of assumptions . . . . . . . . . . . . . . . . . . . . . . . 22

2.5 Objectives . . . . . . . . . . . . . . . . . . . . 23

Chapter 3: Finite element formulation to study thermal stresses in nanoencapsulated phase change materials for energy storage $\quad 25$

3.1 Introduction . . . . . . . . . . . . . . . . 26

3.2 Theoretical formulation . . . . . . . . . . . . . . . . . . 28

3.2.1 Balance equations . . . . . . . . . . . . . . . . . . . 28

3.2.1.1 Mechanical balances . . . . . . . . . . . . . 29

3.2.1.2 Energy balance . . . . . . . . . . . . . . . . 29

3.2.2 Constitutive equations . . . . . . . . . . . . . . . . . . 29

3.2.2.1 Thermomechanical constitution . . . . . . . . . 29

3.2.2.2 Heat conduction . . . . . . . . . . . . 30

3.2.3 Boundary conditions . . . . . . . . . . . . . . . . . 31

3.3 Outline of numerical phase change schemes . . . . . . . . . . . . 31 
3.3.1 Equivalent heat capacity scheme . . . . . . . . . . . . . 31

3.3.2 Heat source scheme . . . . . . . . . . . . . . . . . . . 31

3.3.3 Enthalpy scheme . . . . . . . . . . . . . . . . 32

3.4 Finite element formulation . . . . . . . . . . . . . . . . . . . 32

3.4.1 Weak forms . . . . . . . . . . . . . . . 32

3.4.2 Discretisation . . . . . . . . . . . . . . . 33

3.4 .3 Residuals . . . . . . . . . . . . . . . . 33

3.4.4 Assembled tangent matrix . . . . . . . . . . . . . . 34

3.5 Validations . . . . . . . . . . . . . . . . . . . 34

3.6 Analyses of thermal stresses in nePCMs . . . . . . . . . . . . 37

3.6.1 Temperature and Rankine's equivalent stress distributions . . 38

3.6.2 Analysis of the shell thickness . . . . . . . . . . . . . . 41

3.7 Conclusions . . . . . . . . . . . . . . . . . 43

Appendix to Chapter $3 \quad 44$

A. Tangent matrices . . . . . . . . . . . . . . . . 44

B. Analytical solution . . . . . . . . . . . . . . 45

Chapter 4: Mechanical reliability analysis of nanoencapsulated phase change materials combining Monte Carlo technique and the finite $\begin{array}{ll}\text { element method } & 47\end{array}$

4.1 Introduction . . . . . . . . . . . . . . . . . . . . . 48

4.2 Outline of the problem . . . . . . . . . . . . . . . . 50

4.2.1 Description of the nanoparticle . . . . . . . . . . . 50

4.2.2 Description of the finite element model . . . . . . . . . . . 51

4.3 Probabilisitic analysis . . . . . . . . . . . . . . . 52

4.3.1 Distribution functions and sample generation . . . . . . . 53

4.3.2 Uncertainty and Sensitivity Analyses . . . . . . . . . . . 53

4.3 .3 Probability of Failure . . . . . . . . . . . . . . . . 54

4.4 Results . . . . . . . . . . . . . . . . . . 55

4.4.1 Uncertainty analysis . . . . . . . . . . . . . 55

4.4 Sensitivity analysis . . . . . . . . . . . . . . 58

4.4.3 Probability of failure of nePCMs . . . . . . . . . . . 59

4.5 Conclusions . . . . . . . . . . . . . . . . . . 62

Chapter 5: Numerical modelling of the mechanical reliability of multi-coated nanoencapsulated phase change materials with im$\begin{array}{lr}\text { proved thermal performance } & \mathbf{6 5}\end{array}$

5.1 Introduction . . . . . . . . . . . . . . . . . . 66

5.2 Materials and methods . . . . . . . . . . . . . . . 67

5.2 .1 Materials ..................... 67

5.3 Characterisation techniques ................... 71

5.3.1 Thermogravimetric analysis, TGA . . . . . . . . . . 71

5.3.2 Differential scanning calorimetry, DSC . . . . . . . . . . 72

5.4 Numerical tool . . . . . . . . . . . . . . . . . . . . 72

5.4.1 Model description . . . . . . . . . . . . . . . 72

5.4 Probability of failure . . . . . . . . . . . . . 72

5.5 Results . . . . . . . . . . . . . . . . . . 73

5.5.1 Thermal stability . . . . . . . . . . . . . 73 
5.5.2 Enthalpy decrease . . . . . . . . . . . . . . . . 74

5.5.3 Probability of failure . . . . . . . . . . . . . 75

5.6 Conclusions . . . . . . . . . . . . . . . . . . . . . . . 78

Chapter 6: Non-linear finite element modelling of light-to-heat en$\begin{array}{lr}\text { ergy conversion applied to solar nanofluids } & 81\end{array}$

6.1 Introduction . . . . . . . . . . . . . . . . . . 82

6.2 Theoretical formulation . . . . . . . . . . . . . . . . . . 84

6.2.1 Electromagnetism . . . . . . . . . . . . . . . 85

6.2.2 Thermodynamics . . . . . . . . . . . . . . . . 85

6.2.2.1 Equilibrium thermodynamics (ET) . . . . . . . 85

6.2.2.2 Non-equilibrium thermodynamics (NET) . . . . . . 86

6.2.3 Boundary conditions . . . . . . . . . . . . . . . 89

6.3 Finite element formulation . . . . . . . . . . . . . . . . . . 89

6.3.1 Weak forms . . . . . . . . . . . . . . . . 8 89

6.3.2 Discretisations . . . . . . . . . . . . . . . . . . . 89

6.3.3 Residuals ........................... 90

6.3 .4 Tangent matrices . . . . . . . . . . . . . . . . . . . 990 90

6.4 Results . . . . . . . . . . . . . . . . . . . . 91

6.4.1 One-dimensional validation . . . . . . . . . . . . . . 91

6.4 .2 Three-dimensional simulation . . . . . . . . . . . . 93

6.4.3 Light-to-heat conversion for different NPs . . . . . . . . . . . 95

6.4.4 Evolution of temperature increase with concentration . . . . . 97

6.5 Conclusions . . . . . . . . . . . . . . . . . . . 98

$\begin{array}{lr}\text { Appendix to Chapter } 6 & 99\end{array}$

A. Static and high-frequency relative permittivity . . . . . . . . 99

B. Debye relaxation law . . . . . . . . . . . . . . 99

C. Tangent matrices . . . . . . . . . . . . . 100

D. One-dimensional analytical solution . . . . . . . . . . 101

$\begin{array}{ll}\text { Chapter 7: General discussion and conclusions } & 103\end{array}$

$\begin{array}{ll}\text { Chapter 8: Gaps and future research works } & 107\end{array}$

$\begin{array}{lr}\text { Chapter 9: Scientific production } & 109\end{array}$

9.1 Journal Contributions . . . . . . . . . . . . . . . . . . . . . 109

9.2 Book Chapters . . . . . . . . . . . . . . . . . . . . 109

9.3 Contribution to International Conferences . . . . . . . . . . . . . . . 110

$\begin{array}{ll}\text { Bibliography } & 111\end{array}$ 



\section{Abstract}

This thesis presents a numerical formulation grounded on continuum physics to study different coupled phenomena, such as thermomechanics and high-frequency thermoelectricity, in nanoparticles (NPs) for their applications to nanofluids (NFs) for both thermal energy storage and direct solar absorption applications.

This work falls within the current scope of energy transition from conventional fossil fuel sources towards alternative energy ones to fight against global warming. The use of renewable energies appears to be the solution for reducing polluting emissions and thus, constitutes a research field which concentrates great efforts these days. Among all the existing renewable energies, the focus is put on solar thermal energy, in which solar radiation is harvested by Concentrated Solar Power (CSP) plants to convert it into electricity. Since a major drawback of solar energy is its intermittence due to weather conditions, Thermal Energy Storage (TES) systems are commonly incorporated to mitigate this inconvenience.

One of the technologies under research for TES systems is the use of nanofluids. Commonly, base fluids with poor thermal properties are combined with metallic oxide NPs in order to enhance the thermal properties of the nanofluid. Recently, metallic nanoencapsulated Phase Change Materials (nePCMs), exhibiting a core@shell structure, were proposed as the solid medium to take advantage of the latent heat storage in addition to the sensible heat storage. It was observed that one of the issues arising in nePCMs was the eventual failure of the shell when subjected to thermal processes and then, the leakage of the molten core, which is not confined anymore.

Therefore, the need for a rigorous analysis of the failure of the shell of nePCMs has motivated the formulation of a thermomechanical model with phase change in this thesis. This thermodynamically consistent model, discretised within the Finite Element (FE) method and implemented in a research code, allows to predict the thermal stresses arising during thermal processes. Then, the numerical tool is used to predict the failure of spherical and cylindrical nePCMs for different pairs of core@shell materials ( $\mathrm{Sn} @ \mathrm{SnO}_{2}$ and $\mathrm{Al} @ \mathrm{Al}_{2} \mathrm{O}_{3}$ ) and to assess the influence of the shell thickness on the energy density capability and mechanical strength of nePCMs.

As experiments and real applications are not exempt from uncertainties, the formulation of a probabilistic numerical tool appears to be of capital importance to incorporate measurement dispersion into the numerical analysis. For this purpose, a tool combining the FE thermomechanical model with Monte Carlo techniques is developed: i) to identify the physical parameters exerting a major influence on the mechanical failure of the shell and on the energy density capability of the nePCM, ii) to predict its probability of failure and iii) to select the optimal materials for industrial applications.

The developed numerical probabilistic tool is used to analyse the probabil- 
ity of failure of double-coated nePCMs synthesised by Atomic Layer Deposition $\left(\mathrm{Sn} @ \mathrm{SnO}_{2} @ \mathrm{SiO}_{2}\right.$ and $\mathrm{Sn} @ \mathrm{SnO}_{\mathrm{Al}_{2} \mathrm{O}_{3}}$ ) to better understand the thermomechanical behaviour of multi-coated nePCMs.

With regard to solar collector technology, Direct Absorption Solar Collectors (DASC) are currently under research as an alternative to reduce thermal losses between the absorbing surfaces and the Heat Transfer Fluid (HTF) by directly absorbing solar radiation within the fluid itself. Then, the use of NPs for DASC appears to be as another relevant application of nanofluids to increase the efficiency of these volumetric collectors in solar thermal energy applications. In this thesis, a thermodynamically consistent, monolithic and time-dependent thermoelectric model is formulated and implemented in the FE code in order to predict the temperature increase undergone by the NPs. The capabilities of the present formulation were analysed by simulating the temperature increase for different optically excited NPs (gold, silver and graphite) and by varying the NP concentration in the nanofluid.

In summary, the numerical tools developed during this thesis can be used as a virtual laboratory to predict experimental results and to identify the physical characteristics of the NPs required to obtain an optimal performance of the nanofluids while reducing the number of experimental tasks to be performed. 


\section{Resum}

Aquesta tesi presenta una formulació numèrica basada en física de medis continus per a estudiar diferents fenòmens acoblats, com la termomecànica i la termoelectricitat d'altes freqüències, en nanopartícules (NPs) per a aplicacions en nanofluids (NFs), tant per a emmagatzemament d'energia tèrmica com per a aplicacions d'absorció solar directa.

Aquest treball s'emmarca dins del context actual de transició energètica des dels combustibles fòssils convencionals cap a fonts d'energia alternativa per a lluitar contra l'escalfament global. L'ús d'energies renovables sembla ser la solució per a reduir emissions contaminants i llavors, constitueix un camp de recerca que concentra grans esforços actualment. Entre totes les energies renovables existents, l'èmfasi recau sobre l'energia solar tèrmica, en la qual la radiació solar és captada a través de plantes de Concentració d'Energia Solar (CSP), que permeten convertir aquesta energia en electricitat. Com que un dels grans desavantatges de l'energia solar és la seua intermitència a causa de les condicions meteorològiques, normalment s'incorporen sistemes d'Emmagatzemament d'Energia Tèrmica (TES) per a mitigar aquest inconvenient.

Una de les tecnologies que es troba en investigació per a sistemes TES és l'ús de nanofluids. Normalment, es combinen fluids base amb propietats tèrmiques pobres amb NPs d'òxids metàl-lics per a millorar les propietats tèrmiques del nanofluid. Recentment, Materials de Canvi de Fase nanoencapsulats (nePCMs), que posseeixen una estructura nucli@escorça, han sigut emprats com a component sòlid per a aprofitar la seua capacitat d'emmagatzemament de calor latent a més del sensible. S'ha observat que un dels problemes que sorgeixen en els nePCMs és la possible fallada de l'escorça quan es troba sotmesa a processos tèrmics, la qual cosa dóna lloc a fugues del material del nucli que es troba fos i llavors, deixa d'estar confinat.

Per tant, la necessitat de realitzar una anàlisi rigorosa de la fallada de l'escorça dels nePCMs ha motivat la formulació d'un model termomecànic amb canvi de fase en aquesta tesi. Aquest model termodinàmicament consistent i discretitzat amb el mètode dels elements finits (FE) ha sigut implementat en un codi numèric de recerca, la qual cosa permet predir les tensions tèrmiques que sorgeixen durant els processos tèrmics. Llavors, aquesta eina numèrica és utilitzada per a predir la fallada de nePCMs esfèrics i cilíndrics per a diferents combinacions de materials nucli@escorça $\left(\mathrm{Sn} @ \mathrm{SnO}_{2}\right.$ i $\left.\mathrm{Al} @ \mathrm{Al}_{2} \mathrm{O}_{3}\right)$ i per a determinar la influència que el gruix de l'escorça exerceix sobre la capacitat d'emmagatzemament d'energia i sobre la resistència mecànica dels nePCMs.

Com que els experiments i aplicacions reals no estan exempts d'incertesa, la formulació d'una eina numèrica probabilista adquireix una importància capital per a incorporar la dispersió de mesura en l'anàlisi numèrica. Per aquest motiu, s'ha creat una ferramenta que combina el model FE termomecànic amb tècniques de Monte 
Carlo amb l'objectiu de: i) identificar els paràmetres físics que exerceixen una major influència en la fallada mecànica de l'escorça i en la capacitat d'emmagatzemament energètic del nePCM, ii) predir la seua probabilitat de fallada i iii) seleccionar els materials òptims per a aplicacions industrials.

L'eina numèrica probabilista que s'ha desenvolupat en la tesi és utilitzada per a analitzar la probabilitat de fallada de nePCMs sintetitzats amb doble encapsulament mitjançant la tècnica de Atomic Layer Deposition $\left(\mathrm{Sn} @ \mathrm{SnO}_{2} @ \mathrm{SiO}_{2}\right.$ i $\mathrm{Sn} @ \mathrm{SnO} @$ $\mathrm{Al}_{2} \mathrm{O}_{3}$ ) per a comprendre millor el comportament termomecànic d'aquests nePCMs multiencapsulats.

Pel que fa a la tecnologia de col-lectors solars, actualment s'investiguen Col-lectors Solars d'Absorció Directa (DASC) com una alternativa per a reduir les pèrdues tèrmiques existents entre les superfícies d'absorció i el Fluid de Transferència de Calor (HTF), mitjançant l'absorció directa de la radiació solar al si del propi fluid. Llavors, l'ús de NPs per a DASC es revela com una altra aplicació rellevant dels nanofluids amb el fi d'incrementar l'eficiència d'aquests col-lectors volumètrics en aplicacions d'energia solar tèrmica. En aquesta tesi, s'ha formulat i posteriorment implementat en un codi $\mathrm{FE}$ un model termodinàmicament consistent, monolític $\mathrm{i}$ en el domini temporal per a predir els increments de temperatura que tenen lloc en les NPs. Les prestacions de la present formulació han sigut analitzades mitjançant la simulació dels increments de temperatura en diferents NPs (or, argent i grafit) excitades òpticament i fent variar la concentració de NPs en el nanofluid.

En resum, les eines numèriques desenvolupades durant aquesta tesi poden ser utilitzades com una mena de laboratori virtual per a predir resultats experimentals i identificar les característiques físiques de les NPs necessàries per a obtenir una prestació òptima dels nanofluids al mateix temps que permet reduir el nombre d'experiments a realitzar. 


\section{Resumen}

Esta tesis presenta una formulación numérica basada en física de medios continuos para estudiar diferentes fenómenos acoplados, como la termomecánica y la termoelectricidad de altas frecuencias, en nanopartículas (NPs) para aplicaciones en nanofluidos (NFs), tanto para almacenamiento de energía térmica como para aplicaciones de absorción solar directa.

Este trabajo se enmarca en el contexto actual de transición energética desde los combustibles fósiles convencionales hacia fuentes de energía alternativa para luchar contra el calentamiento global. El uso de energías renovables parece ser la solución para reducir emisiones contaminantes y por ello, constituye un campo de investigación que concentra grandes esfuerzos actualmente. Entre todas las energías renovables existentes, el énfasis recae sobre la energía solar térmica, en la que la radiación solar es captada a través de plantas de Concentración de Energía Solar (CSP), que permiten convertir esta energía en electricidad. Como una de las grandes desventajas de la energía solar es su intermitencia a causa de las condiciones meteorológicas, normalmente se incorporan sistemas de Almacenamiento de Energía Térmica (TES) para mitigar este inconveniente.

Una de las tecnologías que se está investigando para sistemas TES es el uso de nanofluidos. Normalmente, se combinan fluidos base con propiedades térmicas pobres con NPs de óxidos metálicos para mejorar las propiedades térmicas del nanofluido. Recientemente, Materiales de Cambio de Fase nanoencapsulados (nePCMs), que poseen una estructura núcleo@corteza, han sido empleados como componente sólido para aprovechar su capacidad de almacenamiento de calor latente además del sensible. Se ha observado que uno de los problemas que surgen en los nePCMs es el posible fallo de la corteza cuando se encuentra sometida a procesos térmicos, lo que da lugar a fugas del material del núcleo que se encuentra fundido y por tanto, deja de estar confinado.

De este modo, la necesidad de realizar un análisis riguroso del fallo de la corteza de los nePCMs ha motivado la formulación de un modelo termomecánico con cambio de fase en esta tesis. Este modelo termodinámicamente consistente y discretizado mediante el método de los elementos finitos (FE) ha sido implementado en un código numérico de investigación, lo que nos permite predecir las tensiones térmicas que surgen durante los procesos térmicos. Por ello, esta herramienta numérica es utilizada para predecir el fallo de nePCMs esféricos y cilíndricos para diferentes combinaciones de materiales núcleo@corteza $\left(\mathrm{Sn} @ \mathrm{SnO}_{2}\right.$ y $\left.\mathrm{Al} @ \mathrm{Al}_{2} \mathrm{O}_{3}\right)$ y para determinar la influencia que el espesor de la corteza ejerce sobre la capacidad de almacenamiento de energía y sobre la resistencia mecánica de los nePCMs.

Como los experimentos y aplicaciones reales no están exentos de incertidumbre, la formulación de una herramienta numérica probabilista adquiere una importancia capital para incorporar la dispersión de medida en el análisis numérico. Por este 
motivo, se ha creado una herramienta que combina el modelo FE termomecánico con técnicas de Monte Carlo con el objetivo de: i) identificar los parámetros físicos que ejercen una mayor influencia en el fallo mecánico de la corteza y en la capacidad de almacenamiento energético del nePCM, ii) predecir su probabilidad de fallo y iii) seleccionar los materiales óptimos para aplicaciones industriales.

La herramienta numérica probabilista que se ha desarrollado en la tesis es utilizada para analizar la probabilidad de fallo de nePCMs sintetizados con doble encapsulamiento mediante la técnica de Atomic Layer Deposition $\left(\mathrm{Sn} @ \mathrm{SnO}_{2} @ \mathrm{SiO}_{2}\right.$ y $\mathrm{Sn} @ \mathrm{SnO} @ \mathrm{Al}_{2} \mathrm{O}_{3}$ ) para comprender mejor el comportamiento termomecánico de estos nePCMs multiencapsulados.

En lo que respecta a la tecnología de colectores solares, actualmente se investigan Colectores Solares de Absorción Directa (DASC) como una alternativa para reducir las pérdidas térmicas existentes entre las superficies de absorción y el Fluido de Transferencia de Calor (HTF), mediante la absorción directa de la radiación solar en el seno del propio fluido. Por tanto, el uso de NPs para DASC se revela como otra aplicación relevante de los nanofluidos con el fin de incrementar la eficiencia de estos colectores volumétricos en aplicaciones de energía solar térmica. En esta tesis, se ha formulado y posteriormente implementado en un código FE un modelo termodinámicamente consistente, monolítico y en el dominio temporal para predecir los incrementos de temperatura que tienen lugar en las NPs. Las prestaciones de la presente formulación han sido analizadas mediante la simulación de los incrementos de temperatura en diferentes NPs (oro, plata y grafito) excitadas ópticamente y haciendo variar la concentración de NPs en el nanofluido.

En resumen, las herramientas numéricas desarrolladas durante esta tesis pueden ser utilizadas como una especie de laboratorio virtual para predecir resultados experimentales e identificar las características físicas de las NPs necesarias para obtener una prestación óptima de los nanofluidos al mismo tiempo que permite reducir el número de experimentos a realizar. 


\section{List of Figures}

Figure 2.1 Solar energy flowchart. . . . . . . . . . . . . . . 4

Figure 2.2 Scheme of CSP plants with parabolic troughs (left) and with heliostats (right). Figures from [8]. . . . . . . . . . 5

Figure 2.3 Scheme of a conventional solar collector configuration (left) and of a volumetric collector (right). Figures from [10]. . . . 6

Figure 2.4 Samples of nanofluids. Figures obtained at the Nanofluids Laboratory at Universitat Jaume I (Castelló de la Plana, Spain). 7

Figure 2.5 Flowchart of the different types of nanofluids according to their base fluid, working temperature and application. . . . . 7

Figure 2.6 Thermal energy storage mechanisms over a thermal cycle, where $\Delta T_{\text {supercooling }}$ refers to the temperature difference existing in phase change materials between crystallisation and melting. . . . . . . . . . . . . . . . . 8

Figure 2.7 Images of tin nanoencapsulated phase change materials. Figures obtained at the Nanofluids Laboratory at Universitat Jaume I (Castelló de la Plana, Spain). . . . . . . . . . . . . 9

Figure 2.8 Spectrum of PCM candidates according to their values of melting temperature and phase change enthalpy. Figure from $[20] \ldots \ldots \ldots \ldots$. . . . . . . . . . . . . 10

Figure 2.9 Diagram of interaction between mechanical, thermal and electric field in the present thesis. . . . . . . . . . . . . . . 12

Figure 2.10 Thermodynamic universe of a system of domain $\Omega$, delimited from its surroundings $\Omega^{\infty}$ by the boundary $\Gamma$ with outward normal $\underline{n} . \ldots \ldots \ldots$

Figure 2.11 Description of motion showing Lagrangian $(\Omega)$ and Eulerian $\left(\Omega^{\prime}\right)$ configurations. . . . . . . . . . . . . 18

Figure 2.12 Discretisation of a continuum domain by the finite element method. An eight-noded hexahedral element is represented beneath. . . . . . . . . . . . . . . . 20

Figure 3.1 Sketch of phase change of a pure substance (left) and of an alloy (right). Enthalpy $H$ vs. temperature $T$. . . . . . . 27

Figure 3.2 Geometry and boundary conditions of the one-dimensional domain used for the validation of the numerical model. The domain is mechanically free and $T=T_{0}$ at $y=0$ while it is fixed and $T=T_{i}$ at $y=L_{y} \ldots \ldots \ldots \ldots \ldots$ 
Figure 3.3 Comparison of analytical and numerical temperature distributions (left column) and axial displacement (right column) for three different times. The three phase change schemes are considered: heat capacity (top row), heat source (middle row) and enthalpy (bottom row). Analytical solutions in lines and numerical in solid circles. . . . . . . . . . . . . . . . 36

Figure 3.4 Cross-section sketch of the geometry of nanoencapsulated phase change materials: spherical (left) and cylindrical (right). Both are composed of a core of diameter $d-2 e_{\text {shell }}$, filled with a phase change material, and of a shell of thickness $e_{\text {shell }}$ to encapsulate it. . . . . . . . . . . . . . . 38

Figure 3.5 Temperature (K) and maximum Rankine's equivalent stress (MPa) distributions developed at the shell for spherical and cylindrical nanoencapsulated phase change materials (nePCMs). . . . . . . . . . . . . . . . . . 40

Figure 3.6 Evolution with time of Rankine's equivalent stress at the nanoparticle shell for $\mathrm{Sn} @ \mathrm{SnO}_{2}$ and $\mathrm{Al} @ \mathrm{Al}_{2} \mathrm{O}_{3}$ cylindrical (Cyl) and spherical (Sph) nanoencapsulated phase change materials. 41

Figure 3.7 Influence of shell thickness $\left(e_{\text {shell }}\right)$ on a) energy density and

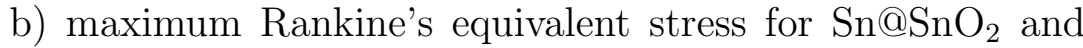
$\mathrm{Al} @ \mathrm{Al}_{2} \mathrm{O}_{3}$ spherical (Sph) and cylindrical (Cyl) nanoencapsulated phase change materials. . . . . . . . . . . . . . 42

Figure 4.1 Geometry of the ellipsoidal nanoencapsulated phase change material with the three semi-axes $a_{\text {semi }}, b_{\text {semi }}$ and $c_{\text {semi }}$ of the outer ellipsoid and the shell thickness $e_{\text {shell }} . \ldots$. . . . . . 50

Figure 4.2 Flowchart of the probabilistic numerical tool. . . . . . . . . . 52

Figure 4.3 Histogram of Rankine's equivalent stress for $\mathrm{Sn}_{\mathrm{S}} \mathrm{SnO}_{2}$ neP$\mathrm{CMs}$ (left) and $\mathrm{Al} @ \mathrm{Al}_{2} \mathrm{O}_{3}$ nePCMs (right) with their respective mean value $\mu$ and standard deviation $\sigma . \ldots . . . .56$

Figure 4.4 Histogram of energy density for $\mathrm{Sn} @ \mathrm{SnO}_{2}$ nePCMs (left) and $\mathrm{Al} @ \mathrm{Al}_{2} \mathrm{O}_{3}$ nePCMs (right) with their respective mean value $\mu$ and standard deviation $\sigma \ldots \ldots \ldots \ldots . \ldots . \ldots 57$

Figure 4.5 Convergence of Monte Carlo simulation. . . . . . . . . . . . 57

Figure 4.6 Standardized Regression Coefficients (SRC) in absolute value for $\mathrm{Sn} @ \mathrm{SnO}_{2}$ (top) and $\mathrm{Al} @ \mathrm{Al}_{2} \mathrm{O}_{3}$ (bottom) nanoencapsulated phase change materials. Notation in Table 4.1. . . . . . 58

Figure 4.7 Deterministic (top) and probabilistic (bottom) failure criteria compared against the maximum Rankine's equivalent stress

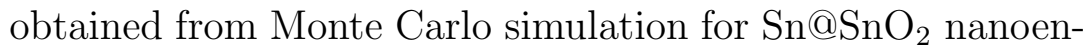
capsulated phase change materials. . . . . . . . . . . 60

Figure 4.8 Deterministic (top) and probabilistic (bottom) failure criteria compared against the maximum Rankine's equivalent stress obtained from Monte Carlo simulations for $\mathrm{Al} @ \mathrm{Al}_{2} \mathrm{O}_{3}$ nanoencapsulated phase change materials. . . . . . . . . . 61

Figure 5.1 TEM images of $\mathrm{Sn} @ \mathrm{SnO}$ (left) and multi-coated $\mathrm{Sn}_{\mathrm{SnO}} \mathrm{SnO}_{2} \mathrm{SiO}_{2}$

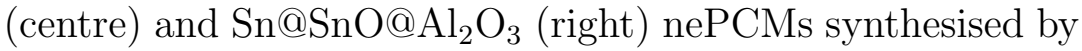
ALD technique after 50 cycles. . . . . . . . . . . 68 
Figure 5.1 TGA analysis of $\mathrm{Sn} @ \mathrm{SnO}, \mathrm{Sn} @ \mathrm{SnO}_{2} @ \mathrm{SiO}_{2}$ and $\mathrm{Sn} @ \mathrm{SnO} @ \mathrm{Al}_{2} \mathrm{O}_{3}$ nanoencapsulated phase change materials subjected to different number of ALD cycles. . . . . . . . . . . . . 74

Figure 5.2 Evolution of the phase change enthalpy $(\mathrm{H})$ decrease with thermal cycling in nitrogen $\left(\mathrm{N}_{2}\right)$ atmosphere for $\mathrm{Sn} @ \mathrm{SnO}$, $\mathrm{Sn} @ \mathrm{SnO}_{2} @ \mathrm{SiO}_{2}$ and $\mathrm{Sn} @ \mathrm{SnO} @ \mathrm{Al}_{2} \mathrm{O}_{3}$ nePCMs subjected to different number of ALD cycles. . . . . . . . . . . . 75

Figure 5.3 Deterministic (left) and probabilistic (right) failure criteria compared against the maximum Rankine's equivalent stress obtained from Monte Carlo simulation for a) $\mathrm{Sn} @ \mathrm{SnO}$, b) $\mathrm{Sn} @ \mathrm{SnO}_{2} @ \mathrm{SiO}_{2}$ and c) $\mathrm{Sn} @ \mathrm{SnO} @ \mathrm{Al}_{2} \mathrm{O}_{3}$ nanoencapsulated phase change materials. . . . . . . . . . . . . . 76

Figure 5.4 Evolution of the probability of failure (POF) of the inner and outer shells and of the enthalpy $(\mathrm{H})$ decrease with the outer shell thickness of multi-coated a) $\mathrm{Sn} @ \mathrm{SnO}_{2} @ \mathrm{SiO}_{2}$ and b) $\mathrm{Sn} @ \mathrm{SnO} @ \mathrm{Al}_{2} \mathrm{O}_{3}$ nanoencapsulated phase change materials. 77

Figure 6.1 Geometry and boundary conditions of the one-dimensional domain used for the validation of the numerical model. . . . . 91

Figure 6.2 Comparison of the steady-state analytical and numerical distributions of temperature (left) and voltage (right) along the one-dimensional domain shown in Figure 6.1 for three different values of prescribed voltage $V_{2}=\{0.05,0.1,0.2\}(\mathrm{V})$ at the right end of the geometry. . . . . . . . . . . . . . 92

Figure 6.3 Geometry and boundary conditions of the three-dimensional simulation. . . . . . . . . . . . . . . 93

Figure 6.4 Temperature increase across the diameter of a gold nanoparticle centred at $x=0$ (see Figure 6.3) for four different values of amplitude of sinusoidal excitation $\sin (\omega t)=$ $\{0.31,-0.60,0.82,-0.96\}$ at four different times $t=\{20,40,60$, $80\}(n s)$. The nanoparticle is $20(\mathrm{~nm})$ in diameter and is irradiated by a laser flux of $5 \times 10^{4}\left(\mathrm{~W} / \mathrm{cm}^{2}\right)$ at a wavelength $\lambda=400(\mathrm{~nm}) . \ldots \ldots \ldots \ldots$

Figure 6.5 Time evolution of the temperature increase of different nanofluids for a laser flux $I_{\text {laser }}=5 \times 10^{4}\left(\mathrm{~W} / \mathrm{cm}^{2}\right)$ at a wavelength $\lambda=400(\mathrm{~nm})$ for four different volumetric concentrations $\phi=\{0.0034,0.0065,0.016,0.052\}(\%)$. The media considered for simulation are only water $\left(\mathrm{H}_{2} \mathrm{O}\right)$ and three different nanofluids composed of: gold nanoparticles dispersed in water $\left(\mathrm{Au}+\mathrm{H}_{2} \mathrm{O}\right)$, silver nanoparticles dispersed in water $(\mathrm{Ag}+$ $\left.\mathrm{H}_{2} \mathrm{O}\right)$ and graphite nanoparticles dispersed in water $\left(\mathrm{G}+\mathrm{H}_{2} \mathrm{O}\right) .96$

Figure 6.6 Evolution of the dimensionless temperature increase in relation to the volumetric concentration of the NPs in the nanofluid for three different nanofluids composed of: gold nanoparticles dispersed in water $\left(\mathrm{Au}+\mathrm{H}_{2} \mathrm{O}\right)$, silver nanoparticles dispersed in water $\left(\mathrm{Ag}+\mathrm{H}_{2} \mathrm{O}\right)$ and graphite nanoparticles dispersed in water $\left(\mathrm{G}+\mathrm{H}_{2} \mathrm{O}\right)$ for a laser flux $I_{\text {laser }}=5 \times$ $10^{4}\left(\mathrm{~W} / \mathrm{cm}^{2}\right)$ at a wavelength $\lambda=400(\mathrm{~nm}) \ldots \ldots . \ldots 97$ 



\section{List of Tables}

Table 2.1 Summary of milestones of this thesis treated in each chapter. . 24

Table 3.1 Material properties of tin (Sn) and aluminium (Al). Subscripts $s$ and $l$ refer to solid and liquid phases, respectively. . . . . . . 35

Table 3.2 Maximum relative error (\%) of temperature $(T)$ and axial displacement $(v)$ for each phase change numerical scheme: $h c$ (heat capacity), hs (heat source), e (enthalpy). . . . . . . 37

Table 3.3 Material properties of $\mathrm{SnO}_{2}$ and $\mathrm{Al}_{2} \mathrm{O}_{3}$. . . . . . . . . . . . 38

Table 4.1 Summary of material and geometrical properties of $\mathrm{Sn}_{\mathrm{SnO}} \mathrm{Sn}_{2}$ and $\mathrm{Al} @ \mathrm{Al}_{2} \mathrm{O}_{3}$ (core@shell) nanoencapsulated phase change materials (nePCMs). SRC is the abbreviation of standardised regression coefficients used in the sensitivity analysis and $\sigma$ is the standard deviation for each of the properties with respect to their mean values. . . . . . . . . . . . . . . . 51

Table 5.1 Summary of shell thickness combinations with respect to the number of atomic layer deposition (ALD) cycles for $\mathrm{Sn} @ \mathrm{SnO}_{2} @$ $\mathrm{SiO}_{2}$ and $\mathrm{Sn} @ \mathrm{SnO} @ \mathrm{Al}_{2} \mathrm{O}_{3}$ (core@inner_shell@outer_shell) nanoencapsulated phase change materials. . . . . . . . . . . 68

Table 5.2 Summary of material and geometrical properties for $\mathrm{Sn}_{\mathrm{SnO}} @$ $\mathrm{SiO}_{2}$ (core@inner_shell@outer_shell)nnanoencapsulated phase change materials (nePCMs). $\sigma$ is the standard deviation for each of the properties with respect to their mean values. . . . . 69

Table 5.3 Summary of material and geometrical properties for $\mathrm{Sn} @ \mathrm{SnO} @$ $\mathrm{Al}_{2} \mathrm{O}_{3}$ (core@inner_shell@outer_shell)nanoencapsulated phase change materials (nePCMs). $\sigma$ is the standard deviation for each of the properties with respect to their mean values. . . . 70

Table 6.1 Material properties for different materials. . . . . . . . . . 92 



\section{Nomenclature}

\section{Mathematical notation}

Symbol

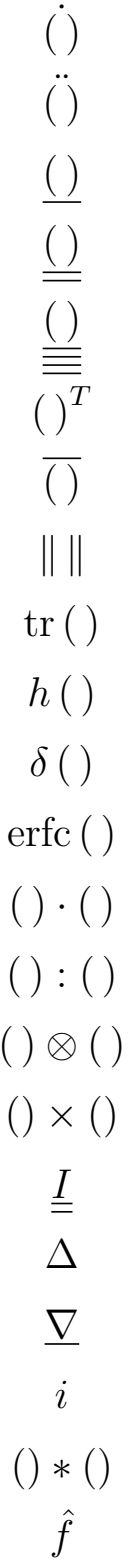

\section{Description}

First time derivative

Second time derivative

First-order tensor

Second-order tensor

Fourth-order tensor

Transpose

Prescribed value

Euclidean norm

Trace

Heaviside step function

Dirac delta function

Complementary error function

Dot product

Double contraction product

Tensor product

Cross product

Identity tensor

Increment

Nabla operator

Imaginary unit

Convolution product

Fourier transform of function $f$ 
List of variables

$\underline{\text { Symbol }}$

$\rho$
$\underline{u}$
$u, v, w$

$\underline{\underline{\sigma}}$

$\underline{f}$

$\underline{t}$

$\sigma_{t}$

c

C

T

$\mathcal{E}_{v}$

$\mathcal{I}_{v}$

$\underline{j}_{F}$

$\underline{Y}$

$\underline{\underline{L}}$

$\mathcal{E}$

$\underline{j}_{\mathcal{E}}$

$\mathcal{Q}$

$\mathcal{W}$

$\mathcal{K}$

$\mathcal{P}$

$\mathrm{u}$

$\mathcal{U}$

$\mathrm{s}$

$\mathcal{S}$

$\underline{j_{s}}$

\section{Description}

Mass density

Displacement field

Components of $\underline{u}$ in $\mathrm{x}, \mathrm{y}, \mathrm{z}$

directions

Cauchy stress tensor

Body force vector

Traction vector

Tensile strength

Specific heat capacity

Heat capacity

Temperature

Set of ET extensive variables

Set of ET intensive variables

Set of NET fluxes

Set of NET driving forces

Phenomenological first-order material properties

$$
\text { Total energy }
$$

Total energy flux

Heat exchange

Work

Kinetic energy

Potential energy

Specific internal energy

Internal energy

Specific entropy

Entropy

Entropy flux

\section{$\underline{\text { SI Units }}$}

$\mathrm{kg} / \mathrm{m}^{3}$

$\mathrm{m}$

m

$$
\begin{aligned}
& \mathrm{N} / \mathrm{m}^{2} \\
& \mathrm{~N} / \mathrm{m}^{3} \\
& \mathrm{~N} / \mathrm{m}^{2} \\
& \mathrm{~N} / \mathrm{m}^{2}
\end{aligned}
$$

$\mathrm{J} /(\mathrm{kg} \cdot \mathrm{K})$

$\mathrm{J} /\left(\mathrm{m}^{3} \cdot \mathrm{K}\right)$

K

$\mathrm{J} / \mathrm{m}^{3}$

$\mathrm{W} / \mathrm{m}^{2}$

$\mathrm{J} / \mathrm{m}^{3}$

$\mathrm{J} / \mathrm{m}^{3}$

$\mathrm{J} / \mathrm{m}^{3}$

$\mathrm{J} / \mathrm{m}^{3}$

$\mathrm{J} / \mathrm{kg}$

$\mathrm{J} / \mathrm{m}^{3}$

$\mathrm{J} /(\mathrm{kg} \cdot \mathrm{K})$

$\mathrm{J} /\left(\mathrm{m}^{3} \cdot \mathrm{K}\right)$

$\mathrm{W} /\left(\mathrm{m}^{2} \cdot \mathrm{K}\right)$ 


\begin{tabular}{|c|c|c|}
\hline$\sigma_{s}$ & Entropy production & $\mathrm{W} /\left(\mathrm{m}^{3} \cdot \mathrm{K}\right)$ \\
\hline$H$ & Enthalpy & $\mathrm{J} / \mathrm{m}^{3}$ \\
\hline $\mathcal{F}$ & $\begin{array}{l}\text { Thermomechanical } \\
\text { Helmholtz energy }\end{array}$ & $\mathrm{J} / \mathrm{m}^{3}$ \\
\hline $\mathcal{G}$ & $\begin{array}{l}\text { Thermoelectrical } \\
\text { Gibbs-like energy }\end{array}$ & $\mathrm{J} / \mathrm{m}^{3}$ \\
\hline$\underline{q}$ & Heat flux vector & $\mathrm{W} / \mathrm{m}^{2}$ \\
\hline$r$ & Heat source/sink & $\mathrm{W} / \mathrm{m}^{3}$ \\
\hline$L$ & Latent heat & $\mathrm{J} / \mathrm{kg}$ \\
\hline$t$ & Time & s \\
\hline$\underline{\underline{\underline{\underline{\underline{C}}}}}$ & Elasticity tensor & $\mathrm{N} / \mathrm{m}^{2}$ \\
\hline$\underline{\underline{\varepsilon}}$ & $\begin{array}{c}\text { Infinitesimal strain } \\
\text { tensor }\end{array}$ & - \\
\hline$\underline{\beta}$ & Thermoelasticity tensor & $\mathrm{N} /\left(\mathrm{m}^{2} \cdot \mathrm{K}\right)$ \\
\hline $\bar{E}$ & Young's modulus & $\mathrm{N} / \mathrm{m}^{2}$ \\
\hline$\nu$ & Poisson's ratio & - \\
\hline$\lambda$ & Lamé's first parameter & $\mathrm{N} / \mathrm{m}^{2}$ \\
\hline$\mu$ & Lamé's second parameter & $\mathrm{N} / \mathrm{m}^{2}$ \\
\hline$K$ & Bulk modulus & $\mathrm{N} / \mathrm{m}^{2}$ \\
\hline$p$ & Pressure & $\mathrm{N} / \mathrm{m}^{2}$ \\
\hline$\alpha^{\prime}$ & $\begin{array}{c}\text { Thermal expansion } \\
\text { coefficient }\end{array}$ & $1 / \mathrm{K}$ \\
\hline$\underline{\underline{\kappa}}$ & $\begin{array}{c}\text { Thermal conductivity } \\
\text { tensor }\end{array}$ & $\mathrm{W} /(\mathrm{m} \cdot \mathrm{K})$ \\
\hline$\beta$ & Thermal diffusivity & $\mathrm{m}^{2} / \mathrm{s}$ \\
\hline$E_{d}$ & Energy density & $\mathrm{J} / \mathrm{m}^{3}$ \\
\hline$V$ & Volume & $\mathrm{m}^{3}$ \\
\hline$\phi$ & Volumetric concentration & - \\
\hline$\omega$ & Excitation pulsation & $\mathrm{rad} / \mathrm{s}$ \\
\hline$\lambda$ & Wavelength & $\mathrm{m}$ \\
\hline$\underline{E}$ & Electric field & $\mathrm{V} / \mathrm{m}$ \\
\hline$V$ & Voltage & $\mathrm{V}$ \\
\hline$\underline{D}$ & Electric displacement & $\mathrm{C} / \mathrm{m}^{2}$ \\
\hline
\end{tabular}




\begin{tabular}{|c|c|c|}
\hline$\underline{P}$ & Polarisation vector & $\mathrm{C} / \mathrm{m}^{2}$ \\
\hline$\epsilon_{0}$ & Vacuum permittivity & $\mathrm{F} / \mathrm{m}$ \\
\hline$\epsilon_{r}$ & $\begin{array}{l}\text { Complex relative } \\
\text { permittivity }\end{array}$ & - \\
\hline$\epsilon^{\prime}$ & $\begin{array}{l}\text { Real part of complex } \\
\text { relative permittivity }\end{array}$ & - \\
\hline$\epsilon^{\prime \prime}$ & $\begin{array}{l}\text { Imaginary part of } \\
\text { complex relative } \\
\text { permittivity }\end{array}$ & - \\
\hline$\epsilon_{s}$ & $\begin{array}{l}\text { Static relative } \\
\text { permittivity }\end{array}$ & - \\
\hline$\epsilon_{\infty}$ & $\begin{array}{l}\text { High-frequency relative } \\
\text { permittivity }\end{array}$ & - \\
\hline$n$ & Complex refractive index & - \\
\hline$c_{\text {light }}$ & Speed of light & $\mathrm{m} / \mathrm{s}$ \\
\hline$\tau$ & Relaxation time & s \\
\hline$\underline{j}$ & Free electric current & $\mathrm{A} / \mathrm{m}^{2}$ \\
\hline$\underline{\underline{\gamma}}$ & $\begin{array}{l}\text { Electrical conductivity } \\
\text { tensor }\end{array}$ & $1 /(\Omega \cdot \mathrm{m})$ \\
\hline$\underline{H}$ & Magnetic field & $\mathrm{A} / \mathrm{m}$ \\
\hline$\underline{B}$ & Magnetic induction & $\mathrm{kg} /\left(\mathrm{s}^{2} \cdot \mathrm{A}\right)$ \\
\hline$\underline{S}$ & Poynting vector & $\mathrm{W} / \mathrm{m}^{2}$ \\
\hline$I_{\text {laser }}$ & RMS value of laser flux & $\mathrm{W} / \mathrm{m}^{2}$ \\
\hline$N$ & $\begin{array}{c}\text { Number of Monte Carlo } \\
\text { evaluations }\end{array}$ & - \\
\hline$M$ & Model & - \\
\hline$\xi_{j}$ & $\begin{array}{c}\text { Random variable of the } \\
\text { model }\end{array}$ & - \\
\hline$\phi_{i}$ & Outputs of the model & - \\
\hline$\theta$ & Regression Coefficients & - \\
\hline$\Theta$ & $\begin{array}{c}\text { Standardized Regression } \\
\text { Coefficients }\end{array}$ & - \\
\hline$\Psi$ & Random Error & - \\
\hline$G\left(\xi_{j}\right)$ & Limit state function & - \\
\hline$f_{\xi_{j}}()$ & $\begin{array}{l}\text { Joint probability density } \\
\text { function of } \xi_{j}\end{array}$ & - \\
\hline
\end{tabular}




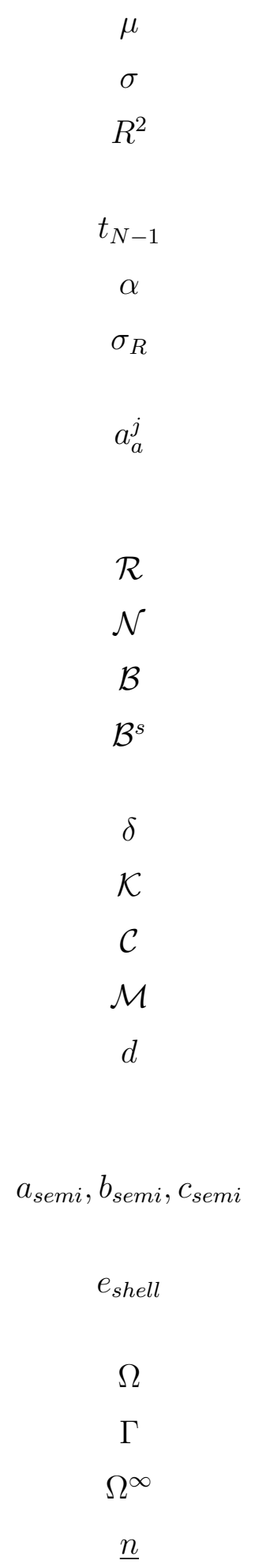

\author{
Mean \\ Standard Deviation \\ Coefficient of \\ determination \\ Student's t-distribution \\ Risk / significance level \\ Maximum Rankine's \\ equivalent stress
}

$\mathrm{N} / \mathrm{m}^{2}$

Nodal values at a generic

node $a$ for each degree of freedom $j$

Residual

Shape functions

Discretised gradients

Discretised mechanical

gradient matrix

Virtual operator

Tangent stiffness matrix

Tangent capacity matrix

Tangent mass matrix

Outer diameter of a spherical/cylindrical $\mathrm{NP} / \mathrm{nePCM}$

Outer semi-axes of an ellipsoidal nePCM

Shell thickness of a nePCM

$\mathrm{m}$

Domain

Boundary

Thermodynamic universe

Outward normal vector to the boundary of the domain 
Abbreviations and Acronyms

$\underline{\text { Symbol }}$

CSP

PV

TES

DASC

NP

NF

nePCM

SPR

ALD

wt.

Sn

$\mathrm{SnO}$

$\mathrm{SnO}_{2}$

$\mathrm{Al}$

$\mathrm{Al}_{2} \mathrm{O}_{3}$

$\mathrm{SiO}_{2}$

$\mathrm{Au}$

$\mathrm{Ag}$

G

$\mathrm{H}_{2} \mathrm{O}$

$\mathrm{A} @ \mathrm{~B}$

ET

NET

PDE

FE

NR

dof

hot

RMS

$\mathrm{MC}$

\section{Description}

Concentrated Solar Plants

Photovoltaic

Thermal Energy Storage

Direct Absorption Solar Collectors

Nanoparticle

Nanofluid

Nanoencapsulated phase change material

Surface Plasmon Resonance

Atomic Layer Deposition

Weight

Tin

Tin(II) oxide

Tin(IV) oxide

Aluminium

Alumina

Silica

Gold

Silver

Graphite

Water

Material A encapsulated in Material B

Equilibrium Thermodynamics

Non-Equilibrium Thermodynamics

Partial Differential Equation

Finite Element

Newton-Raphson

Degree of Freedom

High order terms

Root Mean Square

Monte Carlo 
LHS

UA

SA

SRC

POF

CI

CV

SE

\section{Subscripts}

$\underline{\text { Symbol }}$

$s$

$l$

ref

m

$n+1$

n

e

$c$

$d l$

NF
Latin Hypercube Sampling

Uncertainty Analysis

Sensitivity Analysis

Standardised Regression Coefficients

Probability of Failure

Confidence Interval

Coefficient of Variation

Standard Error $\underline{\text { Description }}$

Solid

Liquid

Reference

Melting

Current time instant

Previous time instant

Element

Critical point

Dimensionless

Nanofluid

\section{Superscripts}

$\underline{\text { Symbol }}$

$s$

$h c$

$h s$

e

$r$

$i$

\section{Description}

Symmetric

Equivalent heat capacity phase change scheme

Heat source phase change scheme

Enthalpy phase change scheme

Reversible

Irreversible 



\section{Chapter 1: Structure}

Considering that the present thesis is made by compendium of publications, a breakdown of the results discussed in each chapter is provided next, detailing the topics covered in each one of them.

- Chapter 2: Introduction.

This chapter deals with an introductory state of the art on nanofluids, that has led to the present thesis, as well as an outline of conceptual background, necessary to better understand the theoretical and numerical formulations developed in this work.

- Chapter 3: Finite element formulation to study thermal stresses in nanoencapsulated phase change materials for energy storage.

In this chapter, a thermodynamically consistent thermomechanical model with phase change is formulated to predict thermal stress arising in nePCMs during thermal processes, which may contribute to the mechanical failure of the nePCM shell. Three regularisation schemes are presented to deal with phase change numerically. After validation of the model with analytical results, it is used to study thermal stresses in spherical and cylindrical nePCMs made of two different pairs of core@shell materials ( $\mathrm{Sn} @ \mathrm{SnO}_{2}$ and $\mathrm{Al} @ \mathrm{Al}_{2} \mathrm{O}_{3}$ ). Finally, an analysis of influence of shell thickness on both mechanical strength and energy density capability is performed as well.

- Chapter 4: Mechanical reliability analysis of nanoencapsulated phase change materials combining Monte Carlo technique and the finite element method.

This chapter deals with the formulation of a probabilistic numerical tool to incorporate measurement uncertainty into the thermomechanical performance analysis of nePCMs. This probabilistic numerical tool is created by combining Monte Carlo techniques with a FE model and is used to optimise the design of nePCMs. More precisely, the objective of this probabilistic tool is to help to identify the physical parameters having a major influence on the shell failure of nePCMs and on their energy density storage. Furthermore, this numerical tool is also used to predict the probability of failure of nePCMs by deterministic and probabilistic criteria.

- Chapter 5: Numerical modelling of the mechanical reliability of multi-coated nanoencapsulated phase change materials with improved thermal performance.

In this chapter, the probabilistic numerical tool developed in this thesis is used to study the mechanical reliability of double-coated nePCMs $\left(\mathrm{Sn} @ \mathrm{SnO}_{2} @ \mathrm{SiO}_{2}\right.$ 
and $\mathrm{Sn} @ \mathrm{SnO} @ \mathrm{Al}_{2} \mathrm{O}_{3}$ ) experimentally synthesised by the cutting-edge technique of ALD in order to assess the effect of the second coating on their mechanical performance. Furthermore, the samples were thermally characterised to determine their loss of enthalpy and to study any existing relationship between it and the mechanical failure of the shell.

- Chapter 6: Non-linear finite element modelling of light-to-heat energy conversion applied to solar nanofluids.

This chapter deals with the theoretical and numerical formulation of a highfrequency time-domain thermoelectric model to account for instantaneous dissipation and to predict the temperature increase undergone by optically excited NPs for their use in solar nanofluids. Once the model is validated against analytical results, simulations of the time-evolving temperature increase produced by $\mathrm{Au}, \mathrm{Ag}$ and graphite NPs dispersed in water are performed. Finally, the influence of NP concentration on the temperature increase undergone by the nanofluid is also studied.

- Chapter 7: Conclusions.

In this chapter, a summary of the main results obtained through this thesis is presented along with the research objectives that have been accomplished.

- Chapter 8: Gaps and future research works.

This chapter deals with possible research lines to continue and extend the work performed during the thesis. 


\section{Chapter 2: Introduction}

Development of society is intrinsically related to generation and use of energy from the beginning of history, though an upsurge has been experienced since the Industrial Revolution. The primary energy sources, used since then to make possible significant progress in terms of technological development, have deeply influenced the energy generation since the subsequent years until the present. Fossil fuels such as coal, petroleum or natural gas were the main energy sources that powered that development and still these days play a predominant role as primary energy sources worldwide. In 2018, only $18 \%$ of total final energy consumption was not due to fossil fuels [1].

Not only these conventional energy sources are limited in time (and estimated to last no more than 50-100 years from now [2]) but the exclusive use of these sources during decades by humankind is at the origin of the global warming and degradation of our ecosystem nowadays. Consequently, a progressive increase in the average temperature of oceans and land surfaces has been registered since that period of intense industrialisation. For this reason, currently, international entities such as the Intergovernmental Panel on Climate Change (IPCC) stress the need to keep global warming below $1.5{ }^{\circ} \mathrm{C}$ to avoid irreversible damage on the ecosystem [3] and to preserve the environment for the future generations.

This context highlights the need for transition from the aforementioned conventional energy sources to renewable ones, as occurring since the last decades. In 2018, the total amount of electricity generated from renewable sources was 6586 TWh, which represents an increase of $6.1 \%$ with regard to renewable generation of electricity in 2017 [4]. On this ground, efforts in research are concentrated in reaching the objectives established by the European Commission in the 2030 climate 86 energy framework [5]:

- At least $40 \%$ cuts in greenhouse emissions, with respect to 1990 levels.

- At least $32 \%$ share for renewable energy.

- At least $32.5 \%$ improvement in energy efficiency.

With respect to different alternative and renewable energy sources, solar energy deserves a special mention because it represents a massive and reliable energy source. According to [6], it is estimated that the Sun needs a little more than one hour and a half to irradiate the necessary amount of energy to satisfy the one-year worldwide energetic demand nowadays.

In order to harvest solar energy, two main technologies co-exist: photovoltaic (PV) and solar thermal. The former converts solar radiation directly into electricity by using semiconductor materials while the latter transfers the incoming solar energy 
into a medium to produce thermal energy, which can be stored for later use or directly used to generate electricity. With regard to solar thermal energy, solar collectors are the devices used to harvest solar radiation and they can be classified into two main categories:

- Concentrating solar collectors. This type of collectors presents concave reflecting surfaces to focus the solar radiation into a small area, which permits to augment the energy flux. Technologies which fall within this category are parabolic dish reflectors, heliostat field collectors, linear Fresnel reflectors and parabolic trough collectors.

- Non-concentrating solar collectors. These collectors only have a fixed position and hence, do not track the Sun's position. Non-concentrating collectors present a constant area for absorbing solar radiation and the most usual configurations of these collectors are: flat plate, compound parabolic and evacuated tube collectors.

Figure 2.1 summarises the different types of solar energy and collector technologies to harvest solar radiation. One of the main applications of solar thermal energy can be found in Concentrated Solar Power (CSP) plants, which are treated in further detail in Section 2.1.

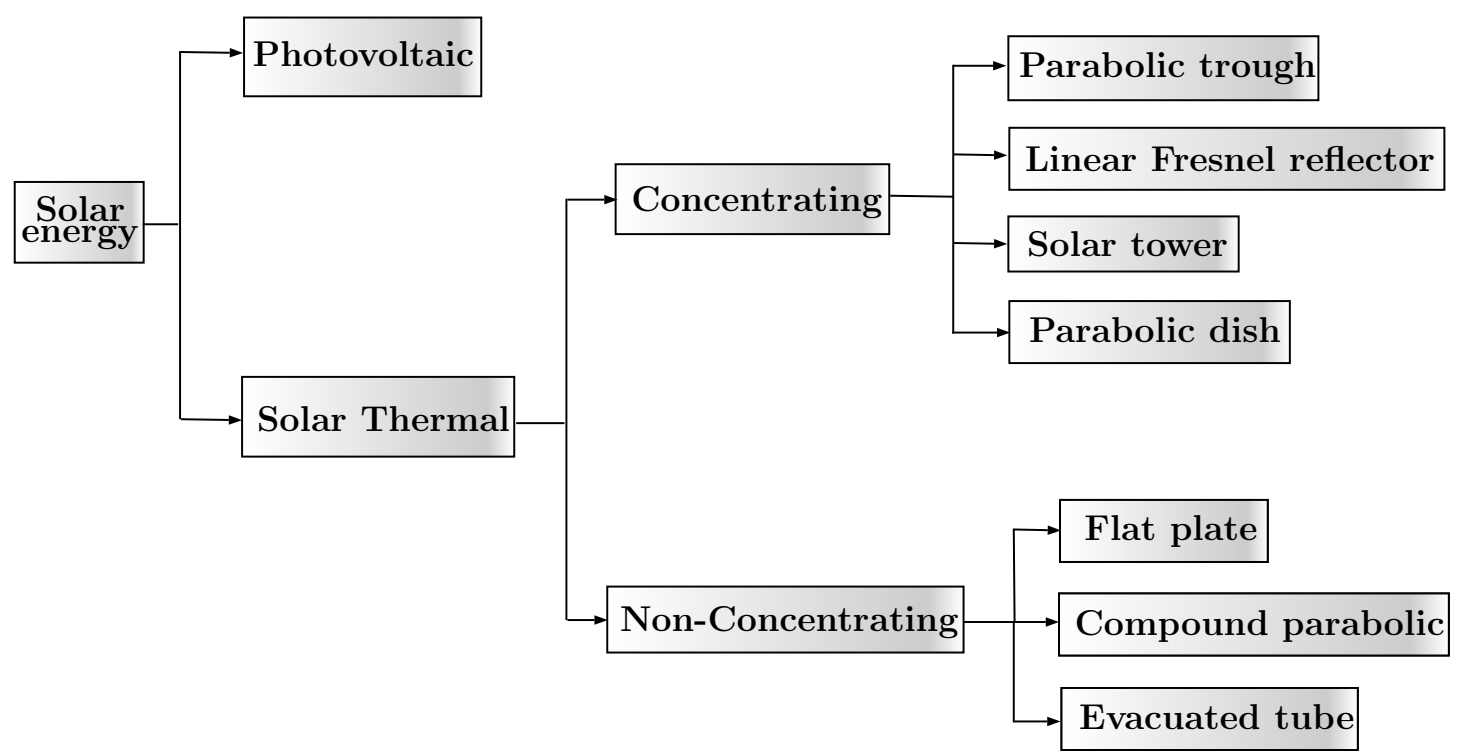

Figure 2.1: Solar energy flowchart.

\subsection{Concentrated Solar Power Plants}

In CSP plants, collectors (absorbing surfaces) are irradiated by solar energy, which is then transferred to a Heat Transfer Fluid (HTF) and is transported to a heat exchanger for steam generation in a secondary circuit. This steam is finally used to feed a turbine and to produce electricity. One of the features that make CSP plants stand out from most of renewable energy technologies is the possibility to incorporate Thermal Energy Storage (TES) equipment to store energy to be used 
when energy generation is lower than demand and being able to supply this energy when necessary. Therefore, CSP plants with TES systems can contribute to mitigate gaps between energy demand and supply.

With regard to collector technology used in CSP applications, four different configurations can be found [7], as shown in Figure 2.1:

- Parabolic troughs: parallel rows of curved mirrors concentrate solar radiation along a single axis while moving to track Sun's position.

- Linear Fresnel reflectors: long rows of flat or slightly curved mirror reflect solar radiation onto a linear fixed receiver.

- Solar towers: different small reflectors (called heliostats) focus solar flux on the top of a fixed tower.

- Parabolic dishes: they focus solar radiation at a single point, situated above the centre of the dish while following Sun's position.

Parabolic troughs and solar towers are the most widespread CSP configurations and they are shown in Figure 2.2 for further detail.
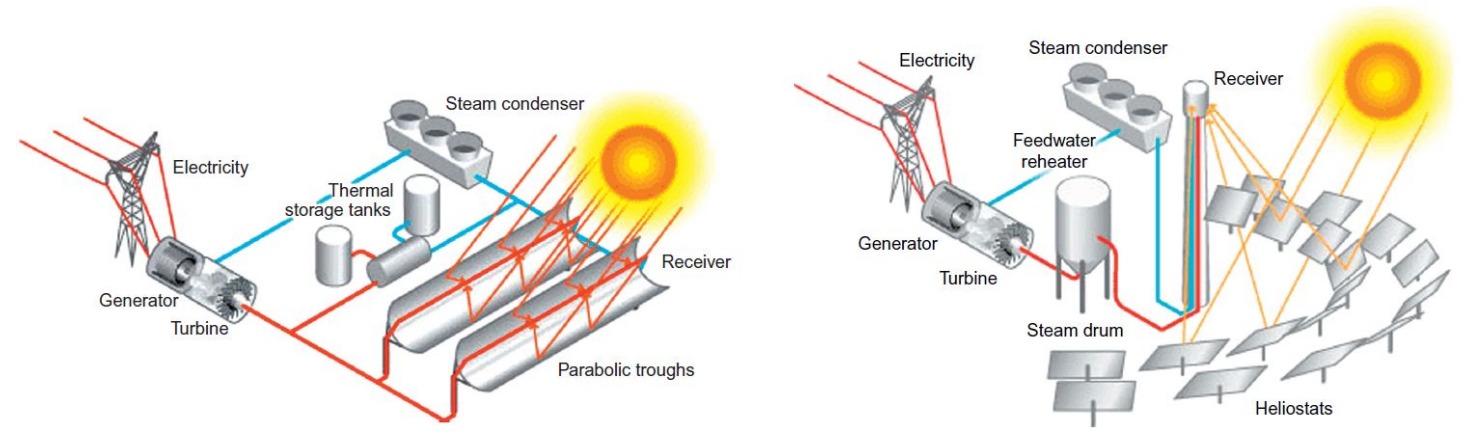

Figure 2.2: Scheme of CSP plants with parabolic troughs (left) and with heliostats (right). Figures from $[8]$.

The main feature of these collectors is that they normally present concave reflecting surfaces to focus solar radiation onto a small area, which permits to augment the effective energy flux and achieve higher temperatures than the ones obtained for instance for non-concentrating applications. However, depending on the configuration of the concentrating collectors, different working temperatures can be achieved. For example, as stated in [9], the maximum operation temperature achieved for linear concentration configurations is around $400{ }^{\circ} \mathrm{C}$ while it is above $500{ }^{\circ} \mathrm{C}$ for collectors concentrating radiation at a single point. Consequently, depending on the reached temperatures, different heat transfer fluids can be used such as thermal oils or molten salts.

TES systems in CSP plants may have different configurations [9], although the most widespread TES technology is based on a storage fluid flowing between a hot and a cold storage tank (active storage). Energy is stored in the hot tank fluid and released to the heat transfer fluid when energy demand exceeds generation. Then, the cold TES fluid is stored in the cold tank. One of the most common TES fluid used in CSP plants is a molten salt known as solar salt, which is made of $\mathrm{NaNO}_{3}$ and $\mathrm{KNO}_{3}\left(60: 40\right.$ wt.\%) and with a melting temperature $T_{m}=493.15 \mathrm{~K}$. If the 
storage fluid is also used as HTF, it receives the name of direct-active storage while if a heat exchanger is needed when the HTF and the storage medium are different, the system is referred as indirect-active. Consequently, one of the main features of these storage fluids for their use in TES applications is their ability to store energy through sensible storage capability. The sensible storage capability of TES systems depends on both the specific heat and the temperature difference undergone by the storage medium. Since specific heat of molten salts tends to be low, one of the possible solutions to overcome this limitation consists in adding solids in suspension within the base fluid. When the size of these solids falls within the nanometric scale, these colloidal dispersions are named nanofluids and they are presented in more detail in Section 2.2.

Although concentrating solar collectors present a better performance than their non-concentrating counterparts in terms of effective incident flux, the thermal efficiency of both technologies could be enhanced because significant heat losses occur between the absorbing surface of the collector and the HTF circulating in the power plant. A technical solution to this problem consists in using volumetric collectors, which directly absorb the energy from the incoming solar radiation. For this purpose, special surfaces, which permit light to enter the liquid but prevent it from escaping, are used. Two examples of conventional and volumetric collector technologies are depicted in Figure 2.3.
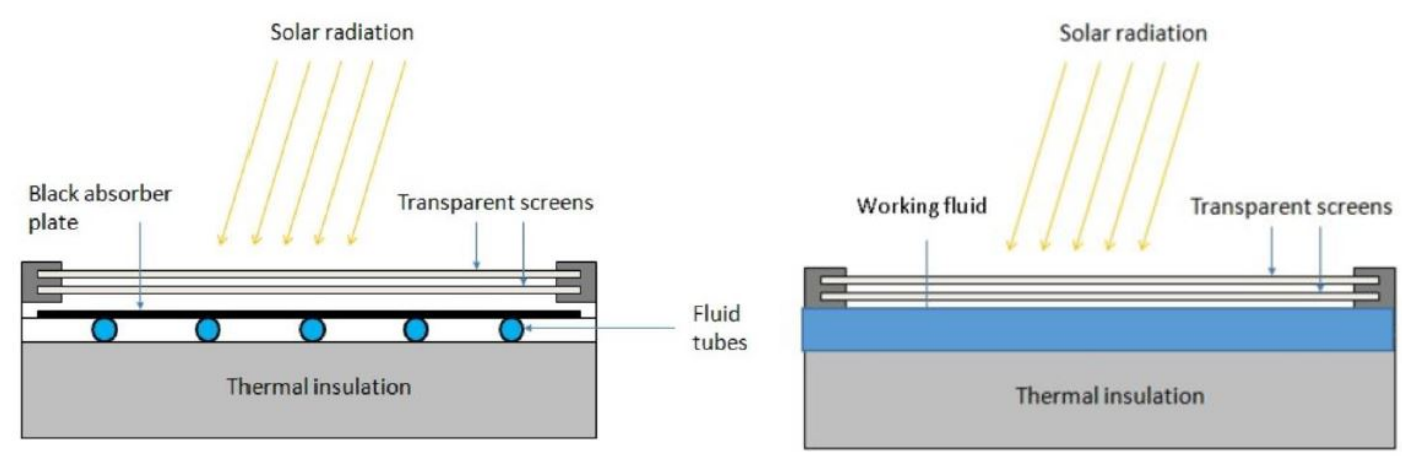

Figure 2.3: Scheme of a conventional solar collector configuration (left) and of a volumetric collector (right). Figures from [10].

On this ground, the use of nanoparticles (NPs) in dispersion within a fluid has recently attracted attention for their use in Direct Absorption Solar Collectors (DASC). Given the importance of this application, a new branch of nanofluids, which receive the name of solar nanofluids, is currently under research, as detailed in Section 2.2.

\subsection{Nanofluids}

Nanofluid is the name given to the colloidal dispersion of NPs (particles whose size is not larger than $100 \mathrm{~nm}$ in diameter) within a base fluid [11]. The main advantage of these nanofluids, due to the Brownian motion of NPs inside the base fluid, is that they combine the transport properties of the fluid with the good thermal properties of NPs, which are normally made of metals or metal oxides. The addition of micrometric particles into a fluid with the aim of improving their thermal 
properties was already studied by Maxwell [12] in 1873 but the main concern was the lack of stability of the suspensions due to the large size of the solid components used at that time. Indeed, the homogeneous combination of properties of solid and liquid media in a nanofluid is possible as long as the solid material size falls within the nanometric scale, which is the threshold size range from which colloidal stability cannot be guaranteed and may lead to problems of sedimentation and agglomeration of particles, which could produce clogging in flow systems. Some nanofluid samples can be observed in Figure 2.4 and a flowchart summarising the different types of nanofluids according to their base fluid, working temperature and application is shown in Figure 2.5.

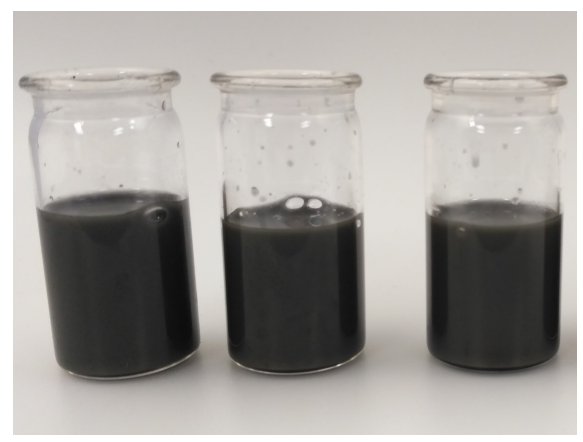

Figure 2.4: Samples of nanofluids. Figures obtained at the Nanofluids Laboratory at Universitat Jaume I (Castelló de la Plana, Spain).

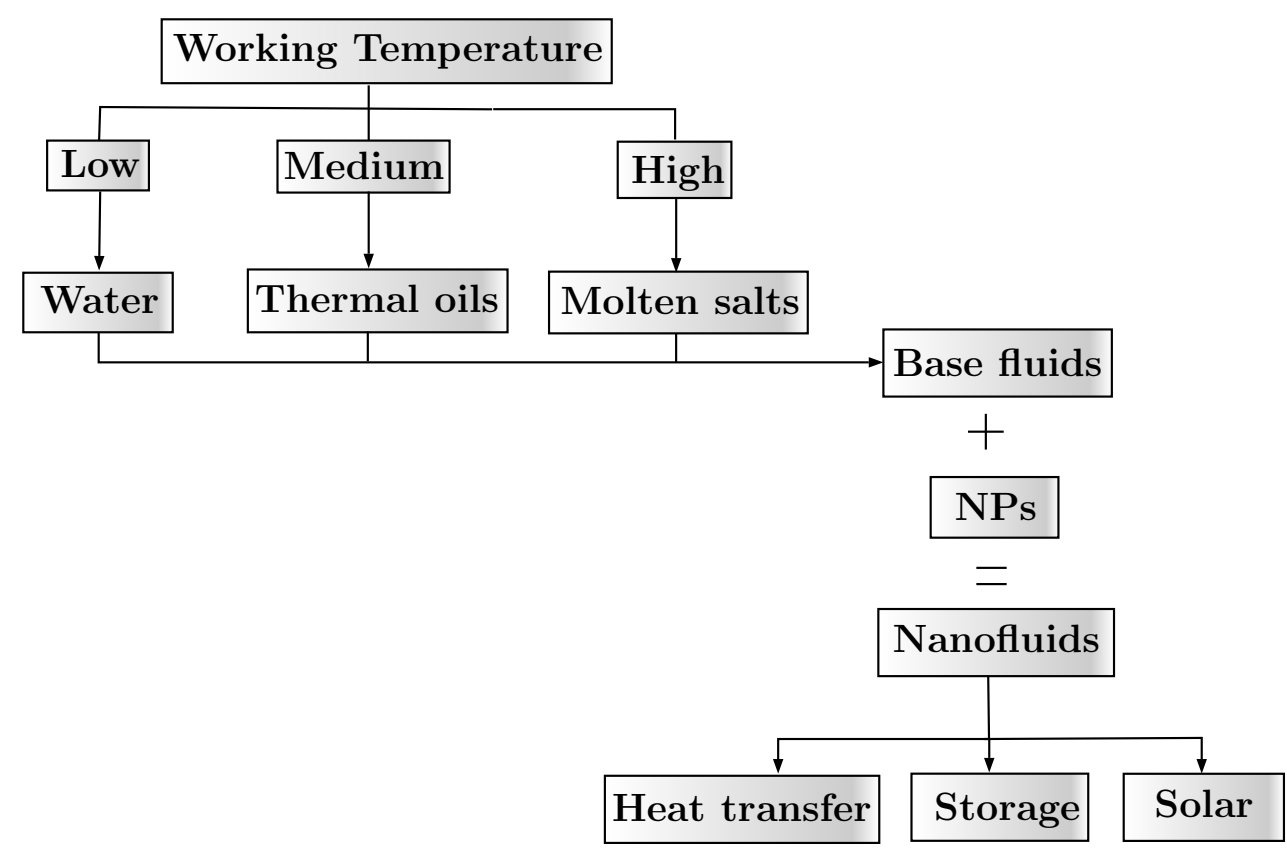

Figure 2.5: Flowchart of the different types of nanofluids according to their base fluid, working temperature and application.

Some of the more relevant properties of nanofluids for their use for TES applications are: viscosity, thermal conductivity and specific heat.

- Regarding viscosity, the load of NPs within the base fluid during the synthesis of nanofluids contributes to increase their viscosity. Then, increasing the res- 
istance of the fluid to flow through a system causes an increment in its cost of operation.

- The excellent thermal conductivity of solids with respect to liquid media explains why the NPs used in nanofluids permit to speed up the cycles of charge and discharge of energy in TES systems and to increase the heat transfer coefficient of HTFs.

- With respect to specific heat of nanofluids, this material property is related to their ability to store energy through sensible heat storage. Normally, sensible heat is the predominant storage mechanism in nanofluids and is determined by both specific heat and the temperature difference undergone by the storage medium. It has been observed experimentally that since solid NPs possess lower specific heat than the base fluid in which they are dispersed, the specific heat of the nanofluid decreases according to the mixture rule, which is the case for water or oils, not permitting to improve its storage capability. However, exceptional enhancements of specific heat in nanofluids were registered when ionic liquids such as molten salts were used as the base fluid [13, 14].

Apart from sensible heat storage, the other physical mechanism to improve the energy storage capability of a medium consists in exploiting its latent heat storage. In this vein, the use of a Phase Change Material (PCM) exhibiting a transition between two different states of matter in the working temperature range of a desired application is of remarkable interest for TES purposes. PCMs are normally based on cycles of melting and solidification -absorption and release of energy, respectively; see Figure 2.6 for further detail of thermal storage with variation of temperature over a heating-cooling cycle. Indeed, latent heat (or phase change enthalpy) is the necessary amount of energy to change matter from its solid to liquid phase and vice versa. Therefore, PCMs can act as thermal regulators since they permit to store energy temporarily and free it in periods of high demand.

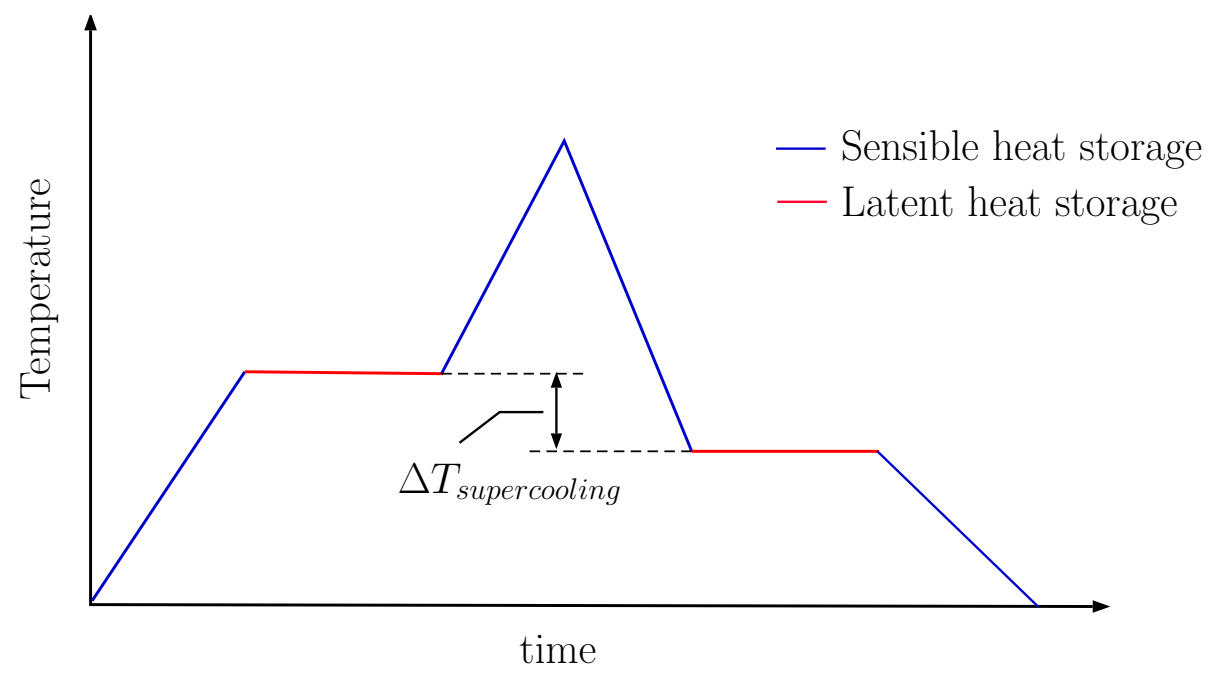

Figure 2.6: Thermal energy storage mechanisms over a thermal cycle, where $\Delta T_{\text {supercooling }}$ refers to the temperature difference existing in phase change materials between crystallisation and melting.

Recently, nanoencapsulated PCMs were proposed as the solid component of the nanofluids in order to boost their energy storage performance with the contribution 
of latent heat storage in addition to the sensible one [15-18]. However, some difficulties arise in the use of PCMs in nanofluids. More precisely, the use of PCMs demands some sort of encapsulation to prevent their leakage when molten. For this reason, a surrounding shell possessing a higher melting temperature than the PCM must be engineered around it. Otherwise, the different nanometric PCMs that are present in a nanofluid would collapse and would produce bigger drops of molten PCM that would settle down during their solidification, which would make the nanofluid lose its working principle. These core@shell nanostructures commonly receive the name of nanoencapsulated phase change materials (nePCMs). Samples of nePCMs can be observed in Figure 2.7.
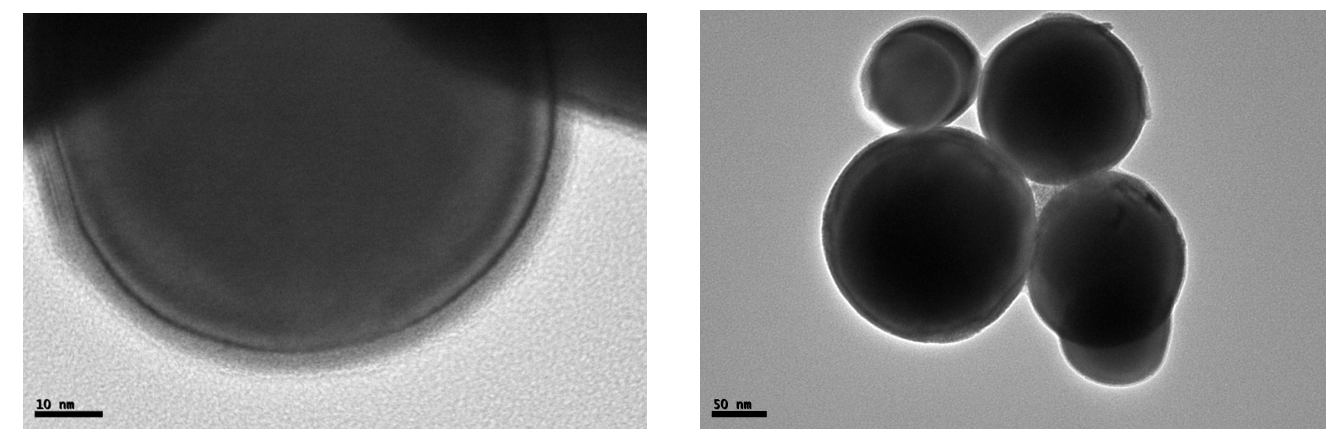

Figure 2.7: Images of tin nanoencapsulated phase change materials. Figures obtained at the Nanofluids Laboratory at Universitat Jaume I (Castelló de la Plana, Spain).

Although different materials could be used as PCMs, their selection criteria is based on their values of melting temperature, which must be close to the desired working temperature, and of phase change enthalpy, which is directly related to the latent heat capability of the storage medium. Figure 2.8 depicts the spectrum of eventual PCM candidates according to their values of melting temperature and phase change enthalpy. Then, metals are commonly used as PCMs in nanofluids for high temperature applications. Furthermore, metals not only have high thermal conductivities, which permit to speed up the cycles of energy charge and discharge in TES applications, but also normally possess high mass densities, which permits to reduce the load of NPs in dispersion in the nanofluid while still enhancing its mass related properties. There exist sundry chemical and physicochemical encapsulation techniques to synthesise nePCM shells such as Atomic Layer Deposition (ALD), emulsion polymerisation, in situ polymerisation, interfacial polymerisation, sol-gel techniques, etc. [19]. Nevertheless, metallic nePCMs can be also self-encapsulated by an oxide layer [17], naturally formed by passivation, that permits to confine the core in liquid state while also avoiding chemical routes for the synthesis of these shells. Examples of metallic materials used for nePCMs can be for instance tin, aluminium or metallic alloys.

One of the issues experimentally encountered in nanofluids containing nePCMs when subjected to thermal processes is their loss of enthalpy, which might be originated by further oxidation of the nePCM core. The cause of this phenomenon may be the mechanical failure of the nePCM shells due to thermal stresses arising during thermal processes, as reported in [17]. Then, owing to the shell failure, the liquid core of the nePCM cannot be confined anymore and the nanofluid loses its properties. Therefore, more studies are needed to gain further comprehension into this phenomenon in order to avoid the shell failure for synthesising mechanically 


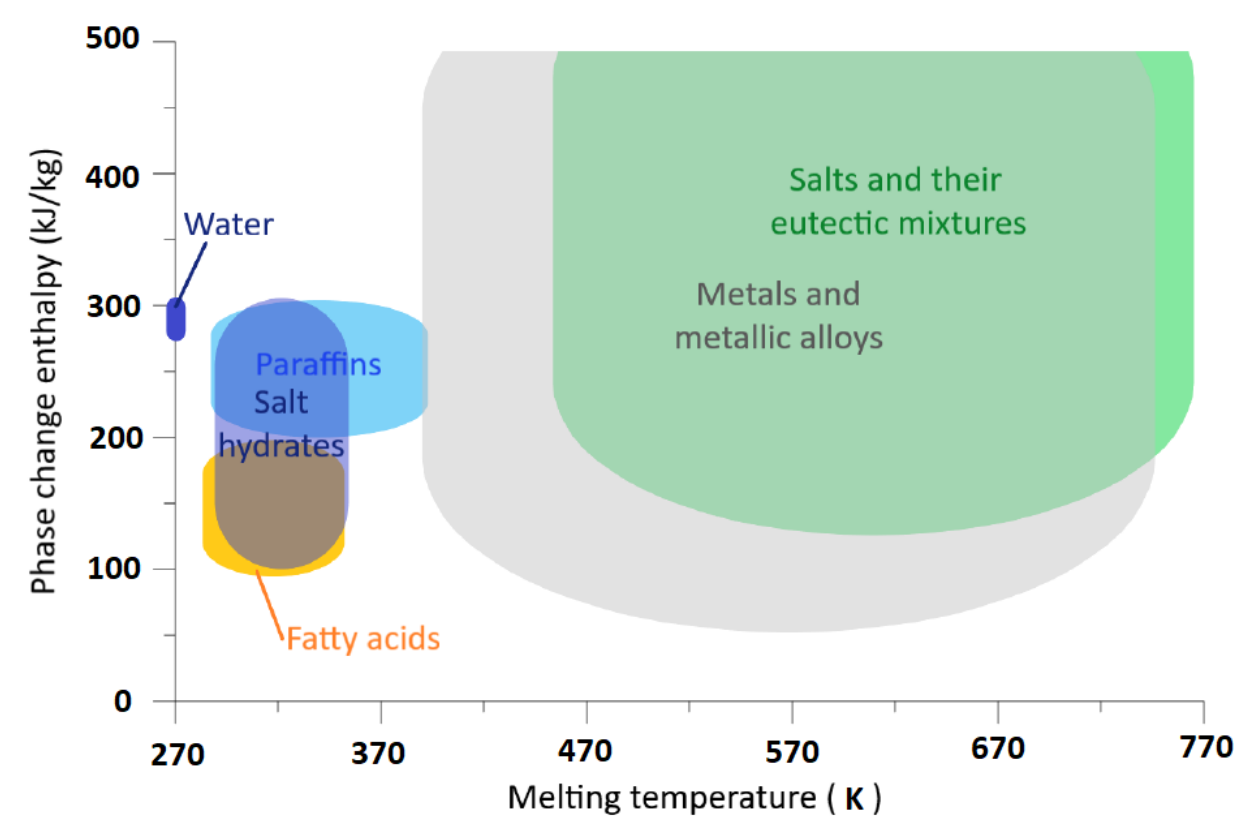

Figure 2.8: Spectrum of PCM candidates according to their values of melting temperature and phase change enthalpy. Figure from [20].

reliable nePCMs.

Regarding direct solar absorption applications, a specific branch of nanofluids, named solar nanofluids [21] is under research. The key feature of solar nanofluids is that a considerable enhancement in the coefficient of absorption of the nanofluid can be achieved with the addition of small loads of NPs in the base fluid, which permits to avoid problems of colloidal stability and viscosity increase in the nanofluid. Since the enhanced absorption capability of solar nanofluids relies on the optical properties of the NPs, their material selection is of major importance for direct absorption applications. More specifically, the absorption spectrum of the NP must be in coincidence with the emission spectrum of solar radiation. Different materials appear in literature as possible candidates for their use as NPs in solar nanofluids. The case of some metallic NPs made of gold or silver are of special relevance since an outstanding photothermal conversion has been observed due to their surface plasmon resonance (SPR). SPR is a collective oscillation of conduction electrons when illuminated by a light source of a determined wavelength, which permits to maximise the absorption at a specific wavelength range [22]. Another important family of materials for direct absorption of solar radiation is carbon structures (graphite, carbon nanotubes, graphene, graphene oxide, etc.), which does not present any absorption peak in its spectrum, unlike the aforementioned metallic NPs, but, in turn, possess remarkable absorption throughout its full spectrum. In short, the addition of the adequate NPs to a base fluid can increase the efficiency of volumetric collectors due to the light-induced heating produced by optically excited NPs. Therefore, a good understanding of the physical phenomena occurring around the NPs is necessary to master the temperature increase undergone by solar nanofluids in order to select the optimal material for industrial applications.

To sum up, the rigorous analysis of some of the aforementioned issues such as the failure of nePCM shells, the consideration of uncertainty measurement into the performance analysis of nePCMs or the prediction of the temperature increase un- 
dergone by optically excited nanofluids, highlights the need for the formulation of theoretical models and for the development of numerical tools, which can contribute to systematically assess the performance of NPs and predict their behaviour for their use in nanofluids. Despite the existence of numerical and simulation works in the context of nanofluids [23-26], the traditional modelling approach has normally consisted in studying the nanofluid as exhibiting averaged material properties between those of the base fluid and those of NPs. These works put their focus of study in modelling the nanofluid as a whole by making use of different numerical techniques such as Computational Fluid Dynamics (CFD), which is a valid approach for assessing the overall performance of a nanofluid for a desired application. However, this approach does not permit to study local phenomena in nanofluids, which is the aim of study of this thesis, since the local description of the medium is lost because of the definition of the nanofluid as a homogenised system. More recently, further attention has been attracted by the study of more local phenomena like mesoscopic and microscopic interactions, which has led to the use of other numerical techniques such as the Lattice Boltzmann method or Molecular Dynamics. However, these microscopic frameworks are more interested in the study of the discrete movement of molecules and their interactions, which falls beyond the scope of this thesis, which mainly focuses in providing a framework to study phenomena occurring at NPs from the continuum multiphysics formalism. Therefore, the novelty of the present thesis lies in the formulation of thermodynamically consistent theoretical models and the development of numerical tools by using the Finite Element (FE) method for the study of local phenomena occurring at NPs in nanofluids and for their application to material selection for NPs and to predict their behaviour. Further detail of the theoretical and numerical models developed in the present thesis are presented in Section 2.3. 


\subsection{Outline of theoretical background}

This section introduces the theoretical and numerical concepts for the formulation and development of the models in the present thesis.

\subsubsection{Thermodynamics}

Thermodynamics is the branch of physics which deals with the interactions between all forms of energy. In particular, Figure 2.9 shows a diagram of interaction among the three physical fields studied in this thesis: mechanical, thermal and electric (in rectangles), which are related by the principal material properties (in ellipses) and coupling effects (in double-boundary ellipses) considered in the theoretical models.

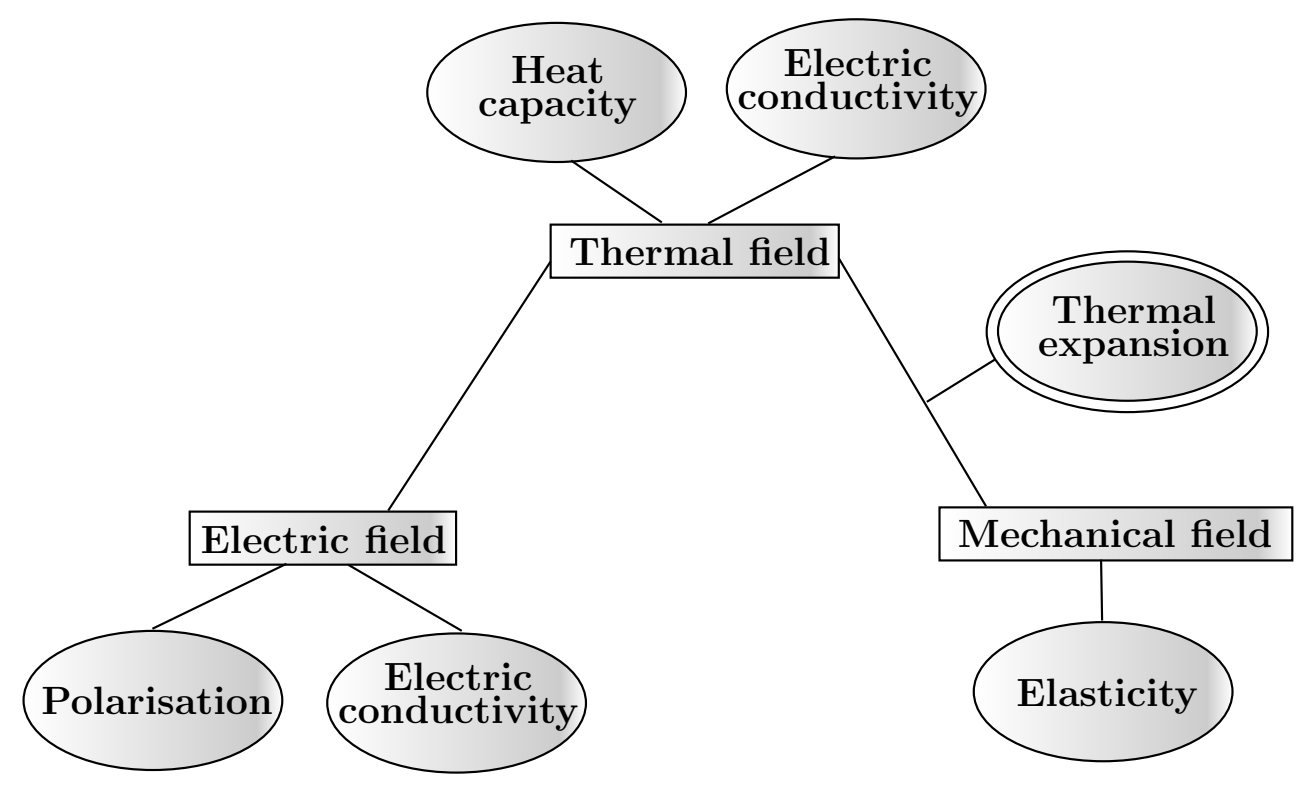

Figure 2.9: Diagram of interaction between mechanical, thermal and electric field in the present thesis.

For the study of thermodynamics, it is first necessary to review some concepts with regard to the definition of a system. A thermodynamic system, as that shown in Figure 2.10, is a portion or body of matter of domain $\Omega$ and delimited from its surroundings $\Omega^{\infty}$ by the boundary $\Gamma$ with an outward normal vector $\underline{n}$. The union of a system with its surroundings is known as thermodynamic universe.

According to the relation of thermodynamic systems with their surroundings, there are three types of thermodynamic systems:

- Isolated system: exchanges neither matter nor energy with its surroundings.

- Closed system: exchanges energy but not matter.

- Open system: exchanges both matter and energy.

For the description of interactions in the context of thermodynamics, it is necessary to distinguish between the next two categories of thermodynamic variables: 


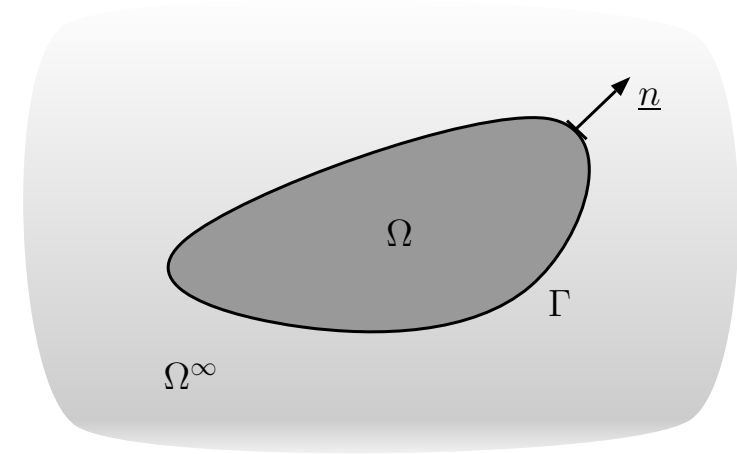

Figure 2.10: Thermodynamic universe of a system of domain $\Omega$, delimited from its surroundings $\Omega^{\infty}$ by the boundary $\Gamma$ with outward normal $\underline{n}$.

- Extensive variables $\left(\underline{\mathcal{E}}_{v}\right)$ : their magnitude is additive for subsystems composing the thermodynamic system, i.e. extensive variables depend upon the size of the system.

- Intensive variables $\left(\underline{\mathcal{I}}_{v}\right)$ : their magnitude is independent of the size or amount of matter in the system.

A thermodynamic interaction can be defined as the product of a pair of extensive and intensive variables, which receives the name of energetically conjugated variables and are mathematically expressed as: $\underline{\mathcal{E}}_{v} \cdot \underline{\mathcal{I}}_{v}$. In terms of the study of interactions between different physical fields, intensive and extensive variables are also known as causes and effects, respectively.

In order to physically model real applications, thermodynamics copes with processes rather than states. Therefore, a thermodynamic process can be defined as the energetic evolution of a system from an initial to a final state [27]. According to this definition, processes can be classified into two main categories:

- Reversible processes: thermodynamic systems can be returned to their initial configuration by performing infinitesimal changes to the system through its surroundings. In practice, perfectly reversible processes do not exist. However, if the system undergoing changes responds much faster than the prescribed change itself, the deviation from reversibility is not significant.

- Irreversible processes: thermodynamic systems cannot be restored to their initial configuration due to energy losses during the changes performed to the system.

The study of reversible and irreversible processes by the physicist community has led to the formulation of different frameworks to study thermodynamics. However, this thesis focuses on two of the most used frameworks in the context of continuum physics modelling: equilibrium and non-equilibrium thermodynamics, related to reversible and irreversible phenomena, respectively. They are presented in further detail in the forthcoming sections. 


\subsubsection{Equilibrium Thermodynamics}

Equilibrium Thermodynamics (ET) [28] is the branch of thermodynamics that studies transformations of energy and matter in a state of balance. In ET, the state of a system is considered uniform and defined by macroscopic magnitudes.

Despite the fact that ET deals with the four laws of thermodynamics, the present thesis focuses explicitly only on the first and the second ones.

\section{First law of thermodynamics}

This law states that the total energy of an isolated system is conserved. In other words, energy cannot be either created or destroyed but only transformed from one form to another. Total energy $\mathcal{E}$ of a system is defined as the sum of the kinetic energy $\mathcal{K}$, potential energy $\mathcal{P}$ and internal energy $\mathcal{U}$ :

$$
\mathcal{E}=\mathcal{K}+\mathcal{P}+\mathcal{U}
$$

Kinetic energy represents the energy due to the motion of the described system while potential energy designates the energy of the system when it is subjected to the action of an external force field (for instance, gravity). Internal energy accounts for the diverse kinetic energies of the microscopic movement of atoms that constitute matter as well as the potential energy of interaction between elementary particles.

The conservation of internal energy follows the classical structure of a conservation law:

$$
\dot{\mathcal{E}}=-\underline{\nabla} \cdot \underline{j}_{\mathcal{E}}
$$

where the term on the right-hand side of (2.2) represents the exchange of internal energy flux $\underline{j}_{\mathcal{E}}$ through the boundary of the system.

For the $\overline{d e s c r i p t i o n}$ of phenomenology without transfer of matter, the first principle of thermodynamics is often recast into the following differential form:

$$
\mathrm{d} \mathcal{U}=\mathrm{d} \mathcal{Q}+\mathrm{d} \mathcal{W}
$$

where $\mathcal{Q}$ and $\mathcal{W}$ represent heat exchange and work, respectively. The last term in (2.3) can be expanded as the product of extensive and intensive variables, which permits to re-express the first law of thermodynamics as follows:

$$
\mathrm{d} \mathcal{U}=\mathrm{d} \mathcal{Q}+\underline{\mathcal{I}}_{v} \cdot \mathrm{d} \underline{\mathcal{E}}_{v},
$$

where $\underline{\mathcal{I}}_{v}$ and $\underline{\mathcal{E}}_{v}$ stand for vectors containing the necessary intensive and extensive variables to describe the phenomenology of the thermodynamic system under consideration.

\section{Second law of thermodynamics}

The second law states the irreversibility of natural processes and permits to define the infinitesimal heat transfer $\mathrm{d} \mathcal{Q}$ as follows:

$$
\mathrm{d} \mathcal{Q}=T \mathrm{~d} \mathcal{S}
$$


where $T$ and $\mathcal{S}$ denote temperature and entropy, respectively. Then, substitution of (2.5) into (2.4) permits to arrive to Euler's equation in infinitesimal form:

$$
\mathrm{d} \mathcal{U}=T \mathrm{~d} \mathcal{S}+\underline{\mathcal{I}}_{v} \cdot \mathrm{d} \underline{\mathcal{E}}_{v} .
$$

Euler's equation (2.6) is used to derive the balance laws for the theoretical formulations presented in the next chapters of the thesis. Depending on the phenomenology considered in the system of interest, different terms will arise from the product of internal and external variables in (2.6).

\section{Constitutive equations}

Another relevant aspect within the context of ET is the definition of material behaviour through constitutive equations, also known as equations of state within the context of thermodynamics. Whilst balance laws are valid independently of the specific features of the medium under study, material behaviour must be carefully particularised for the phenomenology which is of interest.

Therefore, in order to derive the constitutive equations of a specific medium, an energy functional including the relevant variables of state must be defined. For instance, in order to describe thermomechanical and thermoelectrical phenomena, energy functionals must be formulated as depending on the following variables, respectively:

$$
\mathcal{U}_{\text {thermomech }}(\underline{\underline{\varepsilon}}, \mathcal{S}), \quad \mathcal{U}_{\text {thermoelect }}(\underline{D}, \mathcal{S})
$$

where $\underline{\underline{\varepsilon}}$ and $\underline{D}$ represent the small strain tensor and electric displacement, which characterise mechanical and electric energy functionals, respectively.

Since in the context of the present thesis, models are formulated to describe phenomena occurring at NPs for their application to nanofluids, the assumptions of small strain, displacements and rotations are made for the mechanical field, as indicated in Section 2.3.2, without affecting the validity of the modelling of the rest of physical fields. Then, these assumptions permit to obtain an expression of the energetic functional describing material behaviour by formulating a Taylor's series expansion around the considered equilibrium configuration.

The mathematical detail of constitutive equations can be found in the following chapters of the thesis.

\subsubsection{Non-Equilibrium Thermodynamics}

Non-Equilibrium Thermodynamics (NET) [29] is the discipline of thermodynamics that deals with interactions which do not occur under equilibrium conditions. More precisely, this formalism permits the description of transport phenomena as well as chemical reactions. In NET, the state of the system is not uniform and varies locally due to distributions of representative magnitudes of the described phenomenology imposed over the thermodynamic system by dissipative thermodynamic fluxes. In the NET framework, intensive and extensive variables are commonly denoted as driving forces $\underline{Y}$ and fluxes $\underline{j}_{F}$, respectively [30].

NET deals with thermodynamic magnitudes in out-of-equilibrium systems. Therefore, a priori, it cannot be guaranteed that the classical definitions of ET magnitudes such as temperature, entropy, etc. are still valid within the NET framework. This 
theoretical issue can be overcome by the local equilibrium hypothesis [31]. Since the described system is out of equilibrium globally, the original system can be mentally split into cells (also called material points), which are large enough to neglect microscopic fluctuations but sufficiently small to consider that equilibrium in each individual cell is a good approximation. In short, the focus is put on each material point of the system rather than in the global system in the NET formalism. Then, the local equilibrium hypothesis states that at an instant of time, equilibrium can be achieved at each material point of a system. However, the state of equilibrium is different at each material point and can change with time. The main consequence of this hypothesis is that the same thermodynamic magnitudes defined within the ET formalism are also valid in the NET framework.

Therefore, this result together with the continuum hypotheses, which states that matter is continuously distributed in a system, permits to re-express thermodynamic magnitudes in continuum form:

$$
\mathcal{U}=\int_{\Omega} \rho \mathrm{u} \mathrm{d} \Omega, \quad \mathcal{S}=\int_{\Omega} \rho \mathrm{s} \mathrm{d} \Omega,
$$

where $\mathrm{u}$ and $\mathrm{s}$ denote specific internal energy and specific entropy, respectively.

Expression of magnitudes in a continuum form results in a more amenable notation for the subsequent formulation of balance laws in the following chapters.

\section{Transport equations}

Transport equations are the analogous counterparts of constitutive equations but within the context of NET and they account for dissipative phenomena in the medium of interest. In order to derive the equations governing dissipation phenomena, it is necessary to recast the energy balance into the form of an entropy balance, which reads as follows:

$$
\int_{\Omega} \rho \dot{\mathrm{s}} \mathrm{d} \Omega=-\int_{\Omega} \underline{\nabla} \cdot \underline{j_{s}} \mathrm{~d} \Omega+\int_{\Omega} \sigma_{s} \mathrm{~d} \Omega,
$$

where $\underline{j}_{s}$ and $\sigma_{s}$ represent entropy flux and entropy production, respectively. The entropy production can be generally written as the product of driving forces $\underline{Y}$ and fluxes $\underline{J}_{F}$ :

$$
\sigma_{s}=\underline{J}_{F} \cdot \underline{Y} \geq 0 .
$$

Entropy production must be always positive or equal to zero to satisfy the second law of thermodynamics. Notice that the case where $\sigma_{s}=0$ corresponds to the limit case of reversible processes.

Then, transport equations can be obtained by formulating an expression relating a flux with a driving force, as in (2.10). As a first and good approximation, it is assumed that fluxes and driving forces are linearly related through an expression of the following form:

$$
\underline{J}_{F}=\underline{\underline{L}} \cdot \underline{Y}
$$

where $\underline{\underline{L}}$ denotes phenomenological first-order material properties, which must satisfy some restrictions [29, 31]: 
- Material symmetry (Curie's law). It states that causes cannot have more elements of symmetry than the effects they produce [31]. In other words, Curie's law forbids the coupling between fluxes and driving forces of different tensorial order in isotropic systems and within the linear regime of transport equations.

- Sign of phenomenological coefficients. A restriction on the sign of phenomenological coefficients arises from the second law of thermodynamics, as it can be seen from substitution of (2.11) into (2.10), which gives rise to the following quadratic form:

$$
\sigma_{s}=\underline{\underline{L}} \cdot \underline{Y} \cdot \underline{Y} \geq 0
$$

According to algebra results, the necessary and sufficient conditions for $\sigma_{s} \geq 0$ can be guaranteed by satisfying the following conditions, expressed in indicial notation:

$$
\begin{array}{ll}
L_{i i} & \geq 0, \\
L_{i i} L_{j j} & \geq \frac{1}{4}\left(L_{i j}+L_{j i}\right)^{2} .
\end{array}
$$

- Onsager-Casimir's reciprocal relations. The reciprocal relation between tensorial phenomenological coefficients is written as follows:

$$
L_{i j}= \pm\left(L_{j i}\right)^{T}
$$

These symmetry properties are commonly used for the study of coupled irreversible phenomena since the determination of a cross-coefficient $L_{i j}$ avoids the need for another experiment to characterise its reciprocal coefficient $L_{j i}$. Notice that the validity of this reciprocity is satisfied only for linear flux-driving forces relations.

A theoretical formulation obtained through the formalisms of ET and NET and respecting all the aforementioned restrictions in these sections is said to be thermodynamically consistent.

\subsubsection{Continuum Mechanics}

The study of the motion in the context of continuum mechanics classically distinguishes between two different descriptions:

- Lagrangian configuration. It is also known as the initial configuration of the medium and is considered as the fixed reference state from which motion is described. This is commonly the approach retained for modelling continuum solid mechanics.

- Eulerian configuration. It also receives the name of current configuration and studies the motion of the medium under study from the perspective of the moving/deformed medium. This is normally the modelling approach retained by the fluid mechanics community. 
Figure 2.11 shows both Lagrangian $(\Omega)$ and Eulerian $\left(\Omega^{\prime}\right)$ descriptions, where $\underline{X}$ and $\underline{x}$ denote position vectors of a point in the initial and current configurations and $\underline{u}=\underline{x}-\underline{X}$ represents the displacement field.

The study of the mechanical field in the present thesis assumes the small strain theory. This assumption implies that no distinction exists between Lagrangian and Eulerian configurations since the current state of (small) deformation is close enough to the reference state and any difference between them is negligible: $|\underline{u}|<<|\underline{X}|$.

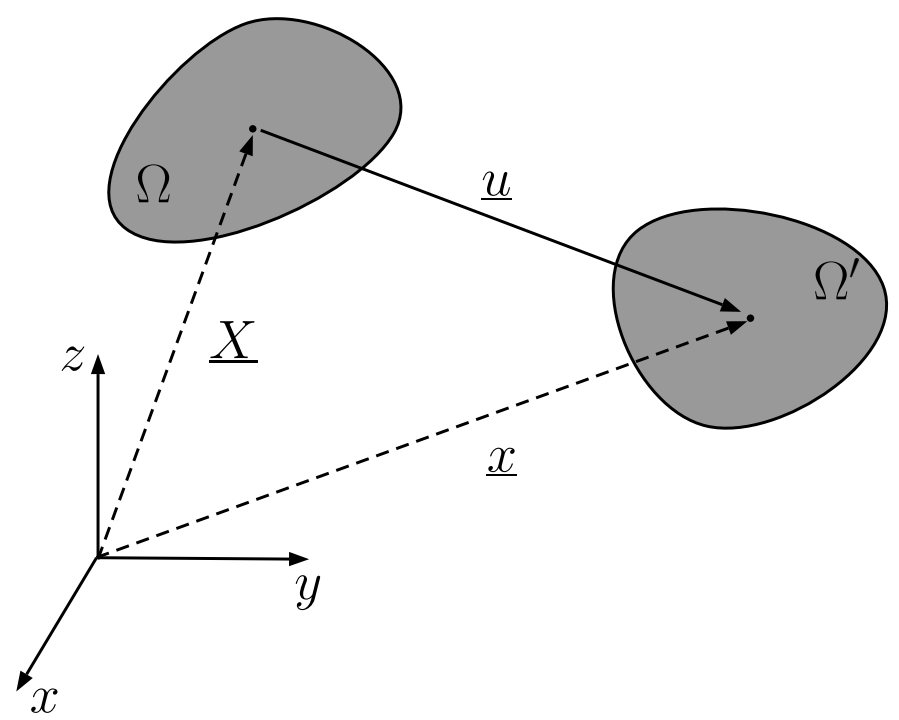

Figure 2.11: Description of motion showing Lagrangian $(\Omega)$ and Eulerian $\left(\Omega^{\prime}\right)$ configurations.

In order to study the mechanical equilibrium state of a medium, two different balances must be presented:

\section{Linear momentum balance}

The linear momentum balance is written in local form as follows:

$$
\rho \underline{\ddot{u}}=\underline{\nabla} \cdot \underline{\underline{\sigma}}+\underline{f},
$$

where $\rho, \underline{u}, \underline{\underline{\sigma}}$ and $\underline{f}$ represent mass density, displacement field, Cauchy stress tensor and body force vector, respectively.

\section{Angular momentum balance}

The angular momentum balance is automatically satisfied by the symmetry of the Cauchy stress tensor: $\underline{\underline{\sigma}}=\underline{\underline{\sigma}}^{T}$, see [32].

\subsubsection{Electromagnetism}

Electromagnetism is the discipline which focuses on the study of interactions between electric $\underline{E}$ and magnetic $\underline{H}$ fields with their sources, namely, free electric charges $\rho_{q}$ and free electric currents $\underline{j}$. The description of electromagnetism is based on four empirical equations called Maxwell's laws, which can be formulated as [30]:

$$
\underline{\nabla} \cdot \underline{D}=\rho_{q}, \quad \underline{\nabla} \cdot \underline{B}=0, \quad \underline{\nabla} \times \underline{E}=-\underline{\dot{B}}, \quad \underline{\nabla} \times \underline{H}=\underline{j}+\underline{\dot{D}},
$$


where $\underline{B}$ denotes the magnetic induction. As observed, from left to right, first and second equations (called Gauss' electric and magnetic laws) relate the corresponding physical field with their scalar sources, while third and fourth (Faraday's and Ampère's laws) with their vector sources. Notice that the magnetic field is solenoidal, namely, it has zero divergence: there are no scalar sources or sinks.

The electromagnetic constitutive equations are:

$$
\underline{D}=\epsilon_{0} \underline{E}+\underline{P}, \quad \underline{B}=\mu_{0} \underline{H}+\underline{M},
$$

where $\epsilon_{0}, \mu_{0}, \underline{P}$ and $\underline{M}$ represent vacuum permittivity, vacuum permeability, polarisation and magnetisation vectors, respectively.

The present thesis focuses exclusively on electric field and magnetic field is not considered in further developments.

\section{Electric charge balance}

The electric charge balance, which governs the evolution of the electric field, is derived from Ampère's law and by using a vector calculus property claiming that the divergence of the curl is always zero for any vector field:

$$
\underline{\nabla} \cdot(\underline{j}+\underline{\dot{D}})=0 \text {. }
$$

\subsubsection{Finite Element Method}

Analytical solutions to Partial Differential Equations (PDEs) governing the behaviour and evolution of systems can only be obtained for rather simple and limited cases of study. Therefore, in order to obtain solutions to real problems, numerical methods appear to be the only available solution. Despite the fact that diverse numerical methods exist in literature for the solution of PDEs, the Finite Element (FE) method [33, 34] will be used in this thesis for its robustness and applicability for the solution of complex non-linear problems in science and engineering.

The solution of a boundary-value problem by the FE method consists in formulating a weak statement of the strong form of the problem of interest and then approximating the solution of these weak forms by FE discretisations. An outline of the steps necessary to develop a FE formulation is presented below:

i) The continuum domain of study is divided into different subdomains, generally called elements in the FE context, which are connected at nodal points, at which the numerical solution of the problem is interpolated. See Figure 2.12.

ii) The strong form of the governing equations are re-expressed in their corresponding weak statements by means of the Bubnov-Galerkin method, in which both weighting and test functions belong to the same function spaces.

iii) A set of FE functions (or shape functions) is chosen to approximate the solution of the weak equations and introduced into the governing equations to obtain the residuals (or equations) to be solved.

iv) The solution of the problem is obtained by solving a system of equations numerically. In the case of time-evolving systems, the discretised problem must be solved both spatially and temporally. 


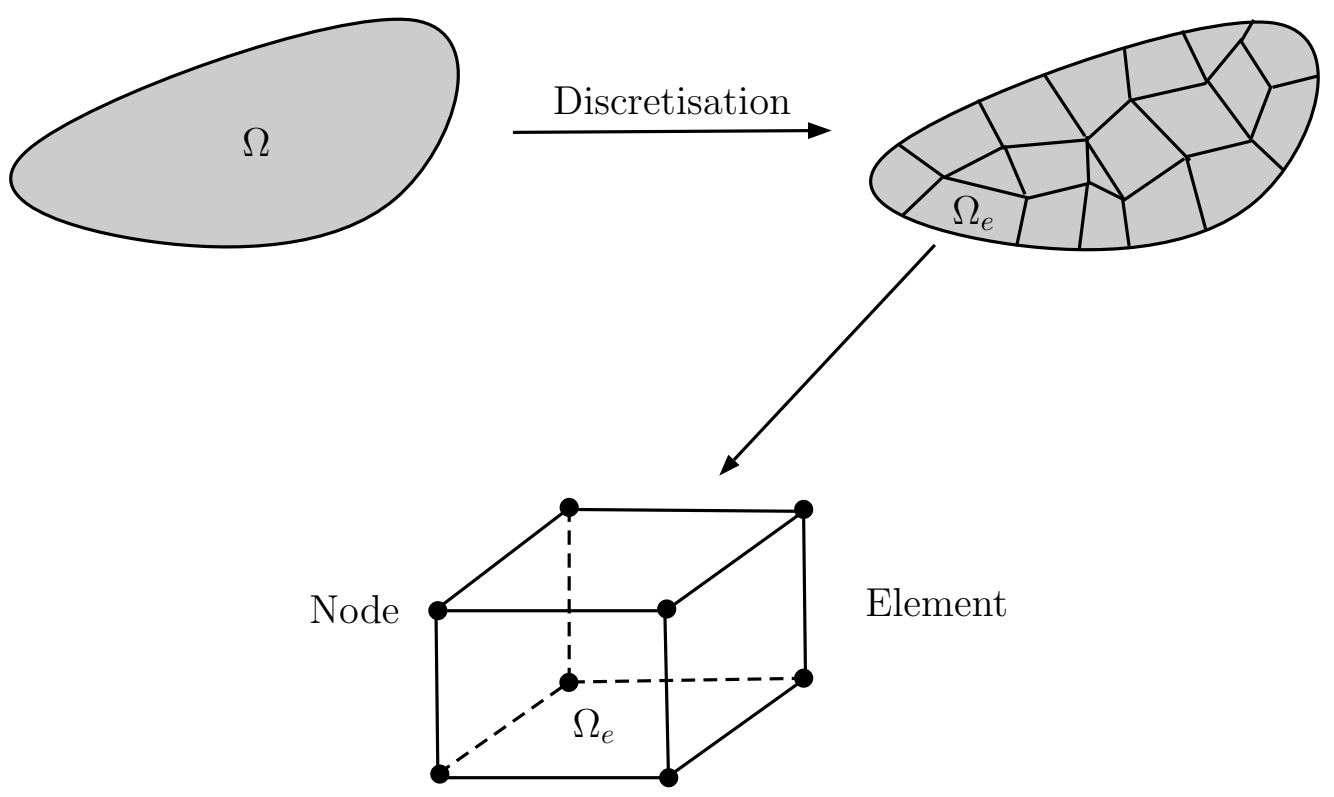

Figure 2.12: Discretisation of a continuum domain by the finite element method. An eight-noded hexahedral element is represented beneath.

Given the large size of the system of equations to be treated for the solution of a problem and the tedium of manually repeating this solution process repeatedly, numerical problems are solved computationally. The research code FEAP [35] is used for the numerical implementation of the models formulated in the present thesis.

Different techniques and strategies are available in the literature for the numerical solution of the equations governing a specific problem. In the framework of this thesis, Newton-Raphson and Newmark implicit time scheme are used to solve the problem spatially and temporally, respectively.

\section{Newton-Raphson}

Newton-Raphson (NR) is a root-finding algorithm used to solve the residual equation $\mathcal{R}$ and it is mathematically expressed as:

$$
\mathcal{R}_{i}^{k+1}=\mathcal{R}_{i}^{k}+\left.\frac{\partial \mathcal{R}_{i}}{\partial g_{j}}\right|^{k} d g_{j}^{k}=0,
$$

where superscripts and subscripts refer to NR iterations and indicial notation of tensors, respectively. In this case, $g_{j}$ denotes a variable at the current time instant $t_{n+1}$ and the preceding $d$ denotes a Newton-Raphson increment.

Equation (2.19) is normally re-expressed alternatively in the FE context as:

$$
\left.\left(c_{1} \mathcal{K}_{i j}+c_{2} \mathcal{C}_{i j}+c_{3} \mathcal{M}_{i j}\right)\right|^{k} d g_{j}^{k}=\mathcal{R}_{i}^{k},
$$

where $c_{1}, c_{2}$ and $c_{3}$ are constants depending on the time scheme and $\mathcal{K}_{i j}, \mathcal{C}_{i j}$ and $\mathcal{M}_{i j}$ are the tangent stiffness, capacity and mass matrices, which are defined as follows:

$$
\mathcal{K}_{i j}=-\frac{\partial \mathcal{R}_{i}}{\partial g_{j}}, \quad \mathcal{C}_{i j}=-\frac{\partial \mathcal{R}_{i}}{\partial \dot{g}_{j}}, \quad \mathcal{M}_{i j}=-\frac{\partial \mathcal{R}_{i}}{\partial \ddot{g}_{j}}
$$


The system of equations in (2.20) is solved iteratively until a threshold error value is reached and convergence is then attained. Depending on the definition of the problem, several evaluations of the residual by the NR method may be required until reaching convergence. The solution update through the different NR iterations is performed as follows:

$$
g_{j}^{k+1}=g_{j}^{k}+d g_{j}^{k} .
$$

Then, when convergence is guaranteed, solution values are updated for the last time, the numerical solution moves a time step $\Delta t$ forward and a new NR iteration can start.

\section{Newmark implicit time scheme}

Newmark family of time integrators cover different possibilities to discretise PDEs in time domain. From the different existing possibilities, the focus is put only on the Newmark implicit scheme since it is the algorithm used in the present thesis.

Newmark formulas define the relationship between increments in a magnitude and increments in their first and second time derivatives (velocities and accelerations) as follows:

$$
\begin{aligned}
& d g_{i}=\beta \Delta t^{2} d \ddot{g}_{i}, \\
& d \dot{g}_{i}=\gamma \Delta t d \ddot{g}_{i},
\end{aligned}
$$

where $\beta$ and $\gamma$ denote Newmark's scalar parameters and $\Delta t$ represents the time increment.

According to (2.23), the aforementioned coefficients $c_{1}, c_{2}$ and $c_{3}$ depending on the time integrator can be determined for Newmark methods:

$$
c_{1}=1, \quad c_{2}=\frac{\gamma}{\beta \Delta t}, \quad c_{3}=\frac{1}{\beta \Delta t^{2}},
$$

The specific values of coefficients $\beta$ and $\gamma$ depend on the desired Newmark algorithm from this time scheme family. For the simulations performed in this thesis, an implicit time scheme is used by choosing $\beta=\frac{1}{4}$ and $\gamma=\frac{1}{2}$.

The detail of the derivation of FE formulations for specific studies can be found in the following chapters of this thesis. 


\subsection{List of assumptions}

This section presents the assumptions made for the theoretical and numerical modelling throughout the present thesis:

- The hypotheses of small displacements, rotations and strains are used for the mechanical field.

- Fluid media are assumed to behave like a liquid at rest.

- Phase change models are only considered for pure substances.

- The domain of study for thermomechanic problems consists of a single nePCM. Therefore, the effect of interactions between nano-sized particles, external forces and flow conditions of the fluid media in which nePCMs are dispersed are not taken into account in the present modelling.

- Constant material properties are considered for each of the studied physical fields (mechanical, thermal and electric) and for each of the states of matter under study, namely solid and liquid.

- Biot coupling is not considered in the thermal field.

- Dispersion in material parameters is assumed to be normally distributed for the reliability analysis.

- A high-frequency and time-based thermoelectric formulation is adopted for the study of light-to-heat phenomena in NPs.

- The domain of study for thermoelectric problems consists of a single NP surrounded by the fluid medium in which the particle is suspended. 


\subsection{Objectives}

The present thesis aims to propose numerical formulations of physical phenomena such as thermomechanics and high-frequency thermoelectricity involving NPs in nanofluids to gain further comprehension into these phenomena. Then, these numerical tools can be used as a virtual laboratory to predict the behaviour and select the optimal NPs for their use in nanofluids.

One of the key points of the present work consists in formulating a thermodynamically consistent model dealing with thermomechanics and phase change for the study of thermal stresses arising in nePCMs when exposed to thermal processes, which may lead to the failure of the nePCM shells. For this purpose, the proposed model is formulated by making use of continuum physics theories and by applying the technique of the FE method to discretise the equations to be solved numerically. With this numerical tool, predictions on the mechanical resistance and energy density capability of nePCMs can be performed for different geometries and pairs of core@shell materials.

As experiments and real applications are not exempt from uncertainties, which are experimentally unavoidable during the process of measurement and characterisation, the formulation of a probabilistic numerical tool seems to be of special interest to include measurement dispersion into the numerical analysis. Consequently, a tool combining the FE thermomechanical model with Monte Carlo techniques is also developed in this thesis to help in the selection of optimal nePCM materials, which play a major role on the performance of the nanofluid. The aim of developing this probabilistic tool consists in identifying the physical parameters exerting a major influence on the mechanical failure of the shells and on energy density capability of the nePCMs as well as predicting their probability of failure by considering deterministic and probabilistic failure criteria.

Recently, multi-layered nePCMs synthesised by the cutting-edge technology of Atomic Layer Deposition (ALD) were reported to exhibit an enhanced mechanical and thermal performance compared to their single coated counterparts. With the aim of gaining comprehension into the mechanical behaviour of these nanocapsules, the numerical probabilistic tool developed in this thesis is applied to study the eventual failure of experimentally synthesised nePCMs with double coating.

The use of NPs for DASC is another relevant application of nanofluids to increase the efficiency of volumetric collectors in solar thermal energy applications. The difficulty of experimentally measuring the temperature increase undergone by the NPs highlights the need for a numerical model to predict this temperature increase and to obtain an optimal solar nanofluid. Therefore, one of the aims of the present thesis involves formulating a thermodynamically consistent thermoelectric model in time domain to consider instantaneous dissipation. Then, the numerical implementation of the model, discretised by the FE method, can be used to predict the temperature increase for different optically excited NPs and to assess the influence of NP concentration in the nanofluid.

The partial objectives of this thesis, which allow to control and assess the study of physical phenomena involving NPs for their application in nanofluids, are the following:

- Formulation of numerical models to gain comprehension into thermomechanical phenomena and phase change taking place at nePCMs for TES purposes. 
- Analysis of mechanical failure for different nePCM geometries and for different pairs of core@shell materials.

- Study of the influence of shell thickness on the mechanical strength and energy density storage of nePCMs.

- Development of a probabilistic numerical tool to incorporate measurement uncertainty in the numerical analysis of nePCMs.

- Identification of the material and/or geometrical parameters having a major influence on the mechanical failure of nePCM shells and on energy density of nePCMs.

- Prediction of the probability of failure of nePCMs undergoing thermal processes.

- Application of the numerical tools to predict the thermomechanical behaviour of multi-layered experimentally synthesised nePCMs.

- Formulation of numerical models to gain comprehension into high-frequency thermoelectric phenomena occurring at NPs for their use in solar nanofluids for DASC.

- Assessment of the temperature increase predicted for NPs made of different materials and by varying the concentration of NPs in solar nanofluids.

A summary of the main milestones of this thesis is presented in Table 2.1.

Table 2.1: Summary of milestones of this thesis treated in each chapter.

\begin{tabular}{|c|c|c|c|c|}
\hline Milestone & Chapter 3 & Chapter 4 & Chapter 5 & Chapter 6 \\
\hline \multicolumn{5}{|c|}{ Formulation of models and development of numerical tools } \\
\hline Thermomechanics & $x$ & $x$ & $x$ & \\
\hline Thermoelectricity & & & & $x$ \\
\hline $\mathrm{MC}$ & & $x$ & $x$ & \\
\hline \multicolumn{5}{|c|}{ Overcoming issues with thermal storage } \\
\hline Shell failure & $x$ & $x$ & $x$ & \\
\hline Energy density & $x$ & $x$ & $x$ & \\
\hline Shell thickness & $x$ & $x$ & $x$ & \\
\hline POF & & $x$ & $x$ & \\
\hline \multicolumn{5}{|c|}{ Overcoming issues with solar absorption } \\
\hline Temperature increase & & & & $x$ \\
\hline NP concentration & & & & $x$ \\
\hline
\end{tabular}




\title{
Chapter 3: Finite element formu- lation to study thermal stresses in nanoencapsulated phase change ma- terials for energy storage
}

\begin{abstract}
Nanoencapsulated phase change materials (nePCMs) -which are composed of a core with a phase change material and of a shell that envelopes the core-are currently under research for heat storage applications. Mechanically, one problem encountered in the synthesis of nePCMs is the failure of the shell due to thermal stresses during heating/cooling cycles. Thus, a compromise between shell and core volumes must be found to guarantee both mechanical reliability and heat storage capacity. At present, this compromise is commonly achieved by trial and error experiments or by using simple analytical solutions. On this ground, the current work presents a thermodynamically consistent and three-dimensional finite element (FE) formulation considering both solid and liquid phases to study thermal stresses in nePCMs. Despite the fact that there are several phase change FE formulations in the literature, the main novelty of the present work is its monolithic coupling-no staggered approaches are required- between thermal and mechanical fields. Then, the FE formulation is implemented in a computational code and it is validated against one-dimensional analytical solutions. Finally, the FE model is used to perform a thermal stress analysis for different nePCM geometries and materials to predict their mechanical failure by using the Rankine's criterion.
\end{abstract}




\subsection{Introduction}

One of the major concerns that society faces currently for its development is producing and supplying energy. In fact, evolution of mankind has been closely related to a progressive increase in energy consumption through history [36]. Therefore, research in energy production appears to be crucial for society. Concerning the production of energy, two different paths seem to arise: searching and exploiting new sources of energy or optimising the existing facilities of energy production processes to gain in efficiency. In connection with this last alternative, a considerable amount of research in thermal energy storage is being carried out [37-40]. More precisely, in this field, heat storage systems based on phase change materials are continuously attracting attention, see $[15,16,18,41]$ for more details. These materials change from one state of matter to another one by releasing or absorbing energy and, consequently, they act as regulators: allow storing energy temporarily and freeing it when necessary.

A main application of phase change materials can be found at concentrated solar power plants [42], where they are used together with heat transfer fluids for storing energy. A way for improving the thermal efficiency of these plants consists of adding nanoencapsulated phase change materials (nePCMs) to the heat transfer fluid or to the thermal storage fluid. This mixture, commonly known as nanofluid [11], enables not only to improve the efficiency of heat transfer [43] but also to store energy to overcome the mismatch between supply and demand of energy [40]. Nevertheless and despite the fact that nePCMs have a direct impact in the thermal efficiency and heat storage, their synthesis becomes a difficult task.

From a mechanical point of view and due to the thermal stresses which appear in heating/cooling cycles [17], one of the major problems to synthesise nePCMs arises in determining the thickness of the shell which confines the phase change material (core) given that a compromise between mechanical reliability and heat storage must be achieved. Both mechanical and thermal capabilities can be measured by the encapsulation ratio $\eta$, which is defined as the ratio between the volume of the nePCM core and that of the whole nePCM (core + shell):

- $\eta \approx 1$ implies high thermal efficiency but low mechanical reliability,

- $\eta<<1$ produces high reliability and low thermal efficiency.

Furthermore, increasing the size of the nanoparticle as a way of enhancing its heat storage capacity is discarded given that the colloidal stability of the nanofluid is not guaranteed as early as a threshold value of the nanoparticle radius is overcome $[44,45]$.

Owing to the complexity that this problem entails, different scientific and technical communities are involved in its study. Therefore, together with experimentation, numerical simulations appear to be suitable to gain in understanding while trying to reduce the number and the cost of experiments to be conducted.

Despite the fact that there are several numerical models in the literature concerning different aspects of nanoparticles, their scope of study is rarely devoted to describe the thermomechanical behaviour of the nePCMs. For instance, the thermal behaviour of the shell is accurately described in [46], but it does not consider the influence of the thermal stresses on the shell. 
Regarding phase change without mechanical interactions, a great variety of numerical schemes are available in the literature; for instance, [47, 48] use the finite difference method and $[49,50]$ the finite element (FE) method. According to [51-54], materials exhibit two different behaviours when changing their state of matter from solid to liquid or vice versa, see the schematic enthalpy variation for both phase change cases shown in Figure 3.1:

- Pure substances present a sharp change in their value of enthalpy $H$, see Figure 3.1 (left), which represents $H$ versus temperature $T$ and the two matter states: solid and liquid.

- Alloys present a smoother variation of $H$, see Figure 3.1 (right), since both phases co-exist at the same time when the temperature $T \in\left[T_{s}, T_{l}\right]$, where $T_{s}$ and $T_{l}$ denote solidus and liquidus temperature [55], respectively. The transition zone is commonly referred as mushy zone.

Numerically, pure substances result more problematic than alloys given that the latent heat released/absorbed leads to a discontinuity in enthalpy. In the framework of the $\mathrm{FE}$, a direct element integration in the presence of jump discontinuities produces errors, which can be solved by regularisation techniques [50].
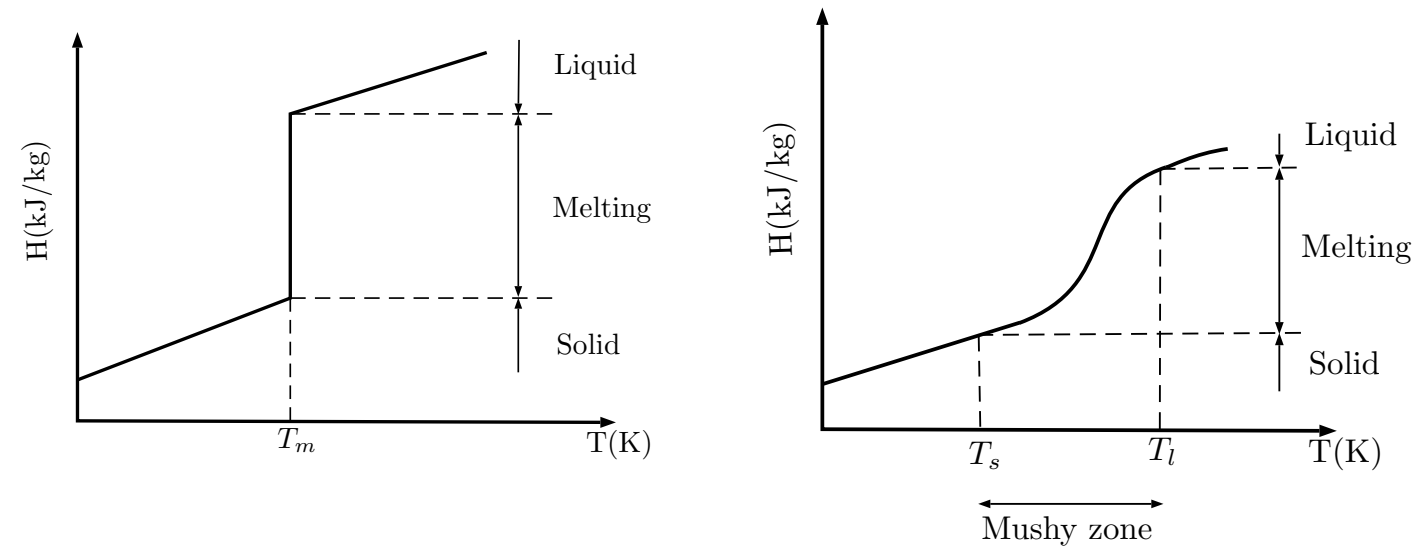

Figure 3.1: Sketch of phase change of a pure substance (left) and of an alloy (right). Enthalpy $H$ vs. temperature $T$.

In addition and according to [51-54], there are basically two families of numerical schemes to numerically solve phase change:

- Tracking domain schemes, for which the phase change interface is continuously tracked.

- Fixed domain schemes, for which the phase change is calculated after the calculation of temperature distributions.

On the one hand, the first scheme is accurate for pure substances but not suitable for alloys. Besides, this method often requires mesh adaptivity or geometric transformations to determine the phase change interface. On the other hand, the second scheme is suitable for both pure and alloy substances and it is easier to implement than tracking methods [49].

Finally, a thermomechanical FE formulation with phase change is reported in [56]. However, this work uses a staggered approach: first a thermal analysis is 
performed to obtain the temperature distributions and then a mechanical analysis is conducted. Therefore, the computational time increases and the accuracy and robustness decreases.

In this context, the current work presents a three-dimensional and thermodynamically consistent formulation applied to thermo-elastic phase change pure substances. For this purpose, linear momentum and energy balances are stated and the constitutive equations are obtained from a thermodynamic potential, specifically, from the Helmholtz's potential. Then, the governing equations are discretised in the context of the FE method [33], which is more robust than the finite difference method. In particular, a monolithic (no staggered approach is required) and displacement-based formulation by using eight-noded elements with four degrees of freedom per node is considered. With regard to phase change, a fixed domain scheme is adopted and three implicit numerical schemes -equivalent heat capacity, heat source and enthalpy- with regularisation techniques are implemented and tested by using one-dimensional analytical solutions extended by the authors of the present work.

Finally, the numerical tool developed in the present work is applied to study phase change in nePCMs in order to determine their temperature distribution and asses their mechanical strength. In particular, two nePCM geometries (spherical and cylindrical) and two pair of core@shell materials $\left(\mathrm{Sn} @ \mathrm{SnO}_{2}\right.$ and $\left.\mathrm{Al} @ \mathrm{Al}_{2} \mathrm{O}_{3}\right)$ are simulated and the Rankine's criterion is used to predict the mechanical failure of the nePCM shell.

The current work assumes linear elasticity for the solid phase given that, from an experimental point of view, the plastic behaviour of the shell should be avoided. For the liquid phase and since the core volume is reduced: i) advection terms are neglected in a first and good approximation as was also adopted in [56] for modelling welding processes, and ii) the liquid behaves like a liquid at rest, as assumed in [57]. Constant material properties are considered in each state of matter (solid and liquid). Experimentally, material properties exhibit temperature-dependency, but the lack of data and the dispersion in the measurements reported in literature make the constancy assumption a reasonable modelling choice.

\subsection{Theoretical formulation}

Mathematically, the thermomechanical phase change problem is expressed by a set of two coupled differential equations, called governing equations, which are composed of balance and constitutive equations and of boundary conditions.

\subsubsection{Balance equations}

Consider a body of domain $\Omega$, boundary $\Gamma$ and its outward normal $\underline{n}$ containing solid and liquid phases. In order to model the current thermomechanical phase change problem, three balance equations must be considered: linear and angular momentum balances and energy balance. 


\subsubsection{Mechanical balances}

Linear and angular momentum balances for both solid and liquid phases may be expressed as:

$$
\rho \underline{\ddot{u}}=\underline{\nabla} \cdot \underline{\underline{\sigma}}+\underline{f}, \quad \underline{\underline{\sigma}}=\underline{\underline{\sigma}}^{T},
$$

where $\rho, \underline{\ddot{u}}, \underline{\sigma}, f$ denote mass density, acceleration, Cauchy stress tensor and body force vector, respectively. Besides, the stress tensor is directly related to the traction vector $\underline{t}$ by the Cauchy relation: $\underline{t}=\underline{\sigma} \cdot \underline{n}$.

Finally, the angular momentum balance is automatically satisfied by the symmetry of the Cauchy stress tensor, as expressed in the right equation of (3.1).

\subsubsection{Energy balance}

For the sake of convenience, the energy balance is expressed in terms of enthalpy $H$, which is defined as [53]:

$$
H=\int_{T_{r e f}}^{T} \rho c \mathrm{~d} T^{\prime}+\rho L h\left(T-T_{m}\right),
$$

where $c, L$ denote heat capacity and latent heat, respectively; $T_{r e f}, T_{m}$ are reference temperature at which enthalpy is calculated and melting temperature, respectively; and $h\left(T-T_{m}\right)$ is the Heaviside step function, which reads:

$$
h\left(T-T_{m}\right)=\left\{\begin{array}{lll}
0 & \text { if } \quad T<T_{m} \\
1 & \text { if } \quad T \geq T_{m}
\end{array}\right.
$$

Finally, the energy balance may be expressed as:

$$
\frac{d H}{d t}=-\underline{\nabla} \cdot \underline{q}+r
$$

where $\underline{q}$ and $r$ denote heat flux and heat source/sink, respectively.

\subsubsection{Constitutive equations}

In this section, constitutive equations are obtained by consistent thermodynamic approaches based on equilibrium and non-equilibrium theories, see [30, 58, 59] for more details.

\subsubsection{Thermomechanical constitution}

The material constitution for the solid phase is calculated from the Helmholtz energy potential $\mathcal{F}$, which is obtained by combining the first and second law of thermodynamics, by assuming that only reversible processes are considered, by applying a Legendre transformation to exchange the entropy $S$ by T, and by assuming a natural state $\mathcal{F}\left(T=T_{r e f}, \underline{\underline{\varepsilon}}=\underline{\underline{0}}\right)=0$ for which the body is undeformed and at a reference 
temperature $T_{\text {ref }}$ :

$$
\begin{gathered}
\mathcal{F}(T, \underline{\underline{\varepsilon}})=\mathcal{F}\left(T_{r e f}, \underline{\underline{0}}\right)+\frac{\partial \mathcal{F}\left(T_{r e f}, \underline{\underline{0}}\right)}{\partial T}\left(T-T_{r e f}\right)+\frac{\partial \mathcal{F}\left(T_{r e f}, \underline{\underline{0}}\right)}{\partial \underline{\underline{\varepsilon}}}: \underline{\underline{\varepsilon}} \\
+\frac{1}{2}\left[\frac{\partial^{2} \mathcal{F}\left(T_{r e f}, \underline{\underline{0}}\right)}{\partial T^{2}}\left(T-T_{r e f}\right)^{2}+\underline{\underline{\varepsilon}}: \frac{\partial^{2} \mathcal{F}\left(T_{r e f}, \underline{\underline{0}}\right)}{\partial \underline{\underline{\varepsilon}}^{2}}: \underline{\underline{\varepsilon}}+2\left(T-T_{r e f}\right) \frac{\partial^{2} \mathcal{F}\left(T_{r e f}, \underline{\underline{0}}\right)}{\partial T \partial \underline{\underline{\varepsilon}}}: \underline{\underline{\varepsilon}}\right] \\
+h o t=-\frac{1}{2} \frac{\rho c}{T_{r e f}}\left(T-T_{r e f}\right)^{2}+\frac{1}{2} \underline{\underline{\varepsilon}}: \underline{\underline{\underline{C}}}: \underline{\underline{\varepsilon}}+\left(T-T_{r e f}\right) \underline{\underline{\beta}}: \underline{\underline{\varepsilon}}+h o t
\end{gathered}
$$

where $\underline{\underline{\varepsilon}}=\underline{\nabla}^{s} \underline{u}$ denotes small strain tensor, $\underline{u}$ the displacement vector with Cartesian components $\underline{u}=(u, v, w), \underline{\nabla}^{s}$ the symmetric part of the displacement gradient and hot is the abbreviation for high-order terms.

The three first terms in the Taylor expansion of (3.5) vanish since the natural state is zero and there are neither initial stresses nor initial variation of entropy, respectively. Furthermore, Biot coupling [60] is not considered in the current work: a one way thermoelastic coupling is assumed. Finally, $\underline{\underline{\underline{C}}}$ and $\underline{\underline{\beta}}$ denote fourth-order elastic and second-order thermoelastic tensors, respectively, which are explicitly expressed as:

$$
\underline{\underline{\underline{\underline{C}}}}=\frac{\partial^{2} \mathcal{F}\left(T_{r e f}, \underline{\underline{0}}\right)}{\partial \underline{\underline{\varepsilon}}^{2}}=\lambda \underline{\underline{I}} \otimes \underline{\underline{I}}+2 \mu \underline{\underline{\underline{\underline{I}}}}, \quad \underline{\underline{\beta}}=\frac{\partial^{2} \mathcal{F}\left(T_{r e f}, \underline{\underline{0}}\right)}{\partial T \partial \underline{\underline{\varepsilon}}}=(3 \lambda+2 \mu) \alpha^{\prime} \underline{\underline{I}},
$$

where $\underline{\underline{I}}, \underline{\underline{I}}^{s}$ denote second- and symmetric part fourth-order identity tensors, respectively [61], and the Lamé parameters are expressed as:

$$
\lambda=\frac{E \nu}{(1+\nu)(1-2 \nu)}, \quad \mu=\frac{E}{2(1+\nu)},
$$

where $E, \nu$ and $\alpha^{\prime}$ denote Young's modulus, Poisson's ratio and thermal expansion coefficient, respectively.

Finally, the constitutive equation for both solid $\underline{\underline{\sigma_{s}}}$ and liquid $\underline{\underline{\sigma_{l}}}$ phases is obtained by a standard equilibrium thermodynamics approach [28] to obtain:

$$
\underline{\underline{\sigma_{s}}}=\frac{\partial \mathcal{F}}{\partial \underline{\underline{\varepsilon}}}=\underline{\underline{\underline{C}}}: \underline{\underline{\varepsilon}}-\underline{\underline{\beta}}\left(T-T_{r e f}\right), \quad \underline{\underline{\sigma_{l}}}=\frac{1}{3} \operatorname{tr}\left(\underline{\underline{\sigma_{s}}}\right) \underline{\underline{I}},
$$

where it is assumed that the liquid phase change material inside the shell behaves like a liquid at rest (hydrostatics) and then the deviatoric part of stresses in the liquid is not present, as indicated in [57].

\subsubsection{Heat conduction}

From a phenomenological point of view, heat flux and its driving force - the gradient of temperature- are related in a first and good approximation by [28]:

$$
\underline{q}=-\underline{\underline{\kappa}} \cdot \underline{\nabla} T
$$

where $\underline{\underline{\kappa}}=\kappa \underline{\underline{I}}$ denotes the isotropic thermal conductivity tensor. 


\subsubsection{Boundary conditions}

The boundary conditions are composed of Dirichlet (also known as first-type) or Neumann (second-type) expressions:

$$
\begin{array}{ll}
\text { Dirichlet: } \quad \underline{u}=\underline{\bar{u}} ; \quad T=\bar{T}, \\
\text { Neumann: } \quad \underline{\underline{\sigma}} \cdot \underline{n}=\underline{\bar{t}} ; \quad \underline{q} \cdot \underline{n}=\bar{q},
\end{array}
$$

where $\underline{\underline{u}}, \bar{T}, \bar{t}$ and $\bar{q}$ are the prescribed displacements, temperature, traction vector and thermal flux, respectively.

\subsection{Outline of numerical phase change schemes}

This section briefly describes the three different numerical phase change schemes used in the current work, namely: equivalent heat capacity $h c$, heat source $h s$ and enthalpy $e$ schemes.

\subsubsection{Equivalent heat capacity scheme}

In this scheme, the rate of enthalpy is calculated by directly applying the chain rule to $(3.2)$ :

$$
\frac{d H}{d t}=\frac{d H}{d T} \frac{d T}{d t}=\rho \underbrace{\left[c+L \delta\left(T-T_{m}\right)\right]}_{c(T)} \dot{T},
$$

where $\delta$ denotes the Dirac delta function. Introducing (3.11) in (3.4), the energy balance becomes:

$$
\rho c(T) \dot{T}=-\underline{\nabla} \cdot \underline{q}+r .
$$

From a numerical point of view and according to [53, 54], a numerical regularisation is performed and $c(T)$ reads:

$$
c(T)=\left\{\begin{array}{lll}
c_{s} & \text { if } \quad T<T_{s}, \\
\frac{c_{s}+c_{l}}{2}+\frac{L}{2 \epsilon} & \text { if } \quad T_{s} \leq T \leq T_{l}, \\
c_{l} & \text { if } \quad T>T_{l},
\end{array}\right.
$$

where $c_{s}$ and $c_{l}$ denote heat capacity for solid and liquid phases, respectively, $\epsilon$ is the regularisation parameter, which ensures the correct integration of the $\delta$ function, and $T_{s}=T_{m}-\epsilon$ and $T_{l}=T_{m}+\epsilon$ represent temperatures for solid and liquid phases, respectively.

\subsubsection{Heat source scheme}

This scheme directly performs the derivative of (3.2) with respect to time:

$$
\frac{d H}{d t}=\rho c \dot{T}+\frac{d}{d t}\left[\rho L h\left(T-T_{m}\right)\right]
$$


Now, by applying a backward first-order finite difference with time step $\Delta t$ to the second term on the right-hand side of (3.14) and introducing it into (3.4), the energy balance becomes:

$$
\Delta t \rho c \dot{T}=-\underline{\nabla} \cdot \underline{q} \Delta t+r \Delta t-\rho L\left(h_{n+1}-h_{n}\right),
$$

where $h_{n+1}$ and $h_{n}$ denote the regularised Heaviside step function at current time $n+1$ and at previous time $n$, respectively. This regularisation form at the current time (obviously analogous for $h_{n}$ ) may be expressed as [62]:

$$
h_{n+1}=\left\{\begin{array}{lll}
0 & \text { if } & T_{n+1}<T_{s}, \\
\frac{T_{n+1}-T_{s}}{T_{l}-T_{s}} & \text { if } & T_{s} \leq T_{n+1} \leq T_{l}, \\
1 & \text { if } & T_{n+1}>T_{l} .
\end{array}\right.
$$

\subsubsection{Enthalpy scheme}

In this scheme, the rate of enthalpy is directly discretised by using a backward first-order finite difference scheme. Then, the energy balance of (3.4) becomes:

$$
\frac{H_{n+1}-H_{n}}{\Delta t}=-\underline{\nabla} \cdot \underline{q}_{n+1}+r_{n+1},
$$

where $H_{n+1}$ and $H_{n}$ denote the regularised enthalpy at current and previous time, respectively. The regularised enthalpy at the current time (similar for previous time) may be expressed as [53, 63]:

$$
H_{n+1}= \begin{cases}\rho c_{s}\left(T_{n+1}-T_{r e f}\right) & \text { if } \quad T_{n+1}<T_{s}, \\ \rho c_{s}\left(T_{s}-T_{r e f}\right)+\frac{\rho L\left(T_{n+1}-T_{s}\right)}{T_{l}-T_{s}} & \text { if } \quad T_{s} \leq T_{n+1} \leq T_{l}, \\ \rho c_{s}\left(T_{m}-T_{r e f}\right)+\rho L+\rho c_{l}\left(T_{n+1}-T_{m}\right) & \text { if } \quad T_{n+1}>T_{l} .\end{cases}
$$

\subsection{Finite element formulation}

This section presents a variational formulation, based on the FE method [33], to numerically solve the balance equations (3.1), (3.12),(3.15) and (3.17).

\subsubsection{Weak forms}

Since the strong forms are second-order differential functions of the degrees of freedom $\underline{u}$ and $T$, these forms are multiplied in the whole domain by arbitrary test (also called weight) functions $\delta \underline{u}$ and $\delta T$ in order to obtain an amenable displacementbased FE formulation. Then, the divergence theorem is applied to the gradient term of both strong forms and the Neumann boundary conditions of (3.10) are enforced to calculate the weak forms, which are first-order differential equations of the degrees of freedom.

Finally, the mechanical weak form becomes:

$$
\int_{\Omega} \delta \underline{u} \cdot(\rho \underline{\ddot{u}}-\underline{f}) \mathrm{d} \Omega+\int_{\Omega} \underline{\underline{\nabla}} \delta \underline{u}: \underline{\underline{\sigma}} \mathrm{d} \Omega-\oint_{\Gamma} \delta \underline{u} \cdot \underline{\underline{\sigma}} \cdot \underline{n} \mathrm{~d} \Gamma=0 .
$$


The three thermal weak forms -one for each phase change scheme- read:

$$
\begin{aligned}
& \int_{\Omega} \delta T\left[\rho c+\rho L \delta\left(T-T_{m}\right)\right] \dot{T} \mathrm{~d} \Omega-\int_{\Omega} r \delta T \mathrm{~d} \Omega-\int_{\Omega} \underline{\nabla} \delta T \cdot \underline{q} \mathrm{~d} \Omega+\int_{\Gamma} \delta T \underline{q} \cdot \underline{n} \mathrm{~d} \Gamma=0, \\
& \int_{\Omega}\left[\underline{\nabla} \delta T \cdot \underline{q} \Delta t+\delta T r \Delta t-\delta T \Delta t \rho c \dot{T}-\delta T \rho L\left(h_{n+1}-h_{n}\right)\right] \mathrm{d} \Omega-\int_{\Gamma} \delta T \underline{q} \cdot \underline{n} \mathrm{~d} \Gamma=0, \\
& \int_{\Omega}\left[\underline{\nabla} \delta T \cdot \underline{q} \Delta t+\delta \operatorname{Tr} \Delta t-\delta T\left(H_{n+1}-H_{n}\right)\right] \mathrm{d} \Omega-\int_{\Gamma} \delta T \underline{q} \cdot \underline{n} \mathrm{~d} \Gamma=0 .
\end{aligned}
$$

\subsubsection{Discretisation}

In order to obtain numerical solutions in the framework of the FE method, the continuum domain $\Omega$ is discretised by $n$ three-dimensional eight-noded brick elements of domain $\Omega_{e}$ and boundary $\Gamma_{e}$. For this purpose, an isoparametric interpolation by using standard shape functions of Lagrange-type $\mathcal{N}$ is adopted to interpolate the global coordinates, the test functions and the four degrees of freedom:

$$
\begin{array}{lll}
\underline{u} \approx \underline{\mathcal{N}_{a}} a \frac{u}{a} ; & T \approx \mathcal{N}_{a} a_{a}^{T} ; & \delta \underline{u} \approx \underline{\mathcal{N}_{a}} \delta a \frac{u}{a}, \\
\delta T \approx \mathcal{N}_{a} \delta a_{a}^{T} ; & \underline{\nabla^{s}} \underline{u} \approx \underline{\underline{\mathcal{B}_{a}}} a_{a} ; & \underline{\nabla} T \approx \underline{\mathcal{B}_{a}} a_{a}^{T} \\
\underline{\underline{\nabla}} \delta \underline{\underline{u}} \approx \underline{\underline{\mathcal{B}_{a}}} \delta a \underline{\underline{\underline{u}}} \delta T \approx \underline{\mathcal{B}_{a}} \delta a_{a}^{T}, &
\end{array}
$$

where the Einstein summation convention is used; $a_{a}^{j}$ denotes the nodal values at a generic node $a$ for each degree of freedom $j=(u, v, w, T)$; and $\underline{\mathcal{B}}^{s}$ and $\underline{\mathcal{B}}$ denote the discretised form of the symmetric gradient of displacements and gradient of temperature, respectively.

\subsubsection{Residuals}

Despite the linearity of the problem, a residual-based formulation is adopted in the present work for the sake of completeness. For it, by introducing (3.21) in (3.19), the mechanical residual reads:

$$
\mathcal{R}_{b}^{\underline{u}}=-\int_{\Omega_{e}} \underline{\underline{\mathcal{B}_{b}}} \underline{\underline{\sigma}} \underline{\underline{\sigma}} \mathrm{d} \Omega_{e}-\int_{\Omega_{e}} \underline{\mathcal{N}_{b}} \rho \underline{\mathcal{N}_{j}} \ddot{a}_{j}^{u} \mathrm{~d} \Omega_{e}+\int_{\Omega_{e}} \underline{\mathcal{N}_{b}} \underline{f} \mathrm{~d} \Omega_{e}+\int_{\Gamma_{e}} \underline{\mathcal{N}_{b}} \underline{\underline{\sigma}} \underline{n} \underline{\mathrm{d}} \Gamma_{e},
$$

where the constitutive equation of $\underline{\underline{\sigma}}$ depends on the phase, namely, solid $\underline{\underline{\sigma_{s}}}$ or liquid $\underline{\underline{\sigma_{l}}}$, mathematically:

$$
\underline{\underline{\sigma}} \rightarrow\left\{\begin{array}{l}
\underline{\underline{\sigma_{s}}}=\underline{\underline{\underline{\underline{C}}}}:\left[\underline{\underline{\mathcal{B}_{i}}} a_{i}^{u}\right]-\underline{\underline{\beta}}\left(\mathcal{N}_{i} a_{i}^{T}-T_{r e f}\right) \\
\underline{\underline{\sigma_{l}}}=\frac{1}{3} \operatorname{tr}\left(\underline{\underline{\sigma_{s}}}\right) \underline{\underline{I}} .
\end{array}\right.
$$


Likewise, by introducing (3.21) in (3.20), the thermal residuals for each phase change scheme become:

$$
\begin{gathered}
\mathcal{R}_{b}^{T, h c}=-\int_{\Omega_{e}} \mathcal{N}_{b}\left[\rho c+\rho L \delta\left(T-T_{m}\right)\right] \mathcal{N}_{j} \dot{a}_{j}^{T} \mathrm{~d} \Omega_{e}+\int_{\Omega_{e}} \underline{\mathcal{B}}_{b} \underline{q} \mathrm{~d} \Omega_{e} \\
+\int_{\Omega_{e}} r \mathcal{N}_{b} \mathrm{~d} \Omega_{e}-\int_{\Gamma_{e}} \mathcal{N}_{b} \underline{q} \underline{n} \mathrm{~d} \Gamma_{e} \\
\mathcal{R}_{b, n+1}^{T, h s}=\int_{\Omega_{e}}\left[\underline{\mathcal{B}}_{b} \underline{q} \Delta t+\mathcal{N}_{b} r \Delta t-\mathcal{N}_{b} \Delta t \rho c \mathcal{N}_{j} \dot{a}_{j}^{T}-\mathcal{N}_{b} \rho L\left(h_{n+1}-h_{n}\right)\right] \mathrm{d} \Omega_{e} \\
\quad-\int_{\Gamma_{e}} \mathcal{N}_{b} \underline{q} \underline{n} \mathrm{~d} \Gamma_{e}, \\
\mathcal{R}_{b, n+1}^{T, e}=\int_{\Omega_{e}}\left(\underline{\mathcal{B}}_{b} \underline{q} \Delta t+\mathcal{N}_{b} r \Delta t-\mathcal{N}_{b} H_{n+1}+\mathcal{N}_{b} H_{n}\right) \mathrm{d} \Omega_{e}-\int_{\Gamma_{e}} \mathcal{N}_{b} \underline{q} \underline{n} \mathrm{~d} \Gamma_{e},
\end{gathered}
$$

where, as commented, the indexes $h c, h s$ and $e$ refer to the phase change schemes. The discretised form of the heat flux of (3.9) becomes $\underline{q}=-\underline{\underline{\kappa}} \underline{B}_{j} a_{j}^{T}$.

\subsubsection{Assembled tangent matrix}

This section presents the final assembled and monolithic matrices at generic nodes $a, b$ for the schemes $k=\{h c, h s\}$ :

$$
\left[\begin{array}{cc}
\mathcal{K}_{a b}^{\underline{u} u}+c_{3} \mathcal{M}_{a b}^{\underline{u} u} & \mathcal{K}_{a b}^{\underline{u} T} \\
0 & \mathcal{K}_{a b}^{T T}+c_{2} \mathcal{C}_{a b}^{T T}
\end{array}\right]\left[\begin{array}{l}
\mathrm{d} a_{b}^{\underline{u}} \\
\mathrm{~d} a_{b}^{T}
\end{array}\right]=\left[\begin{array}{c}
\underline{\mathcal{R}}_{b}^{\underline{u}} \\
\mathcal{R}_{b}^{T, k}
\end{array}\right]
$$

and for the case $e$ :

$$
\left[\begin{array}{cc}
\mathcal{K}_{a b}^{\underline{u} u}+c_{3} \mathcal{M}_{a b}^{\underline{u} u} & \mathcal{K}_{a b}^{\underline{u} T} \\
0 & \mathcal{K}_{a b}^{T T}
\end{array}\right]\left[\begin{array}{l}
\mathrm{d} a_{b}^{\underline{u}} \\
\mathrm{~d} a_{b}^{T}
\end{array}\right]=\left[\begin{array}{l}
\underline{\mathcal{R}}_{b}^{\underline{u}} \\
\mathcal{R}_{b}^{T, e}
\end{array}\right]
$$

where $\mathcal{K}, \mathcal{C}$ and $\mathcal{M}$ denote stiffness, capacity and mass matrices, respectively, and they are explicitly calculated in the Section Appendix A. In addition, the coefficients $c_{2}$ and $c_{3}$ are scalar quantities, which result from linearising the Newmark relations, see [64].

Finally, the numerical formulation is implemented into the research code FEAP [35], which belongs to the University of California at Berkeley (USA). This software holds dummy routines, called user elements, that permit to introduce new modular elements as that of the present work.

\subsection{Validations}

This section presents several comparisons between analytical and numerical solutions in order to check the correct implementation of the numerical formulation. For this 
purpose, available closed solutions in the literature, which solve phase change problems, are extended by the authors of the current work by including the mechanical field, see Section Appendix B.

Figure 3.2 shows the geometry and boundary conditions of the numerical model used for the validations. A fixed-free rod of length $L_{y}\left(L_{y}>>L_{x}, L_{z}\right)$ at an initial temperature $T_{i}$ is considered and a time-dependent temperature $T_{0}$ is prescribed at the free-end. Since $T_{0}>T_{m}>T_{i}$, the phase change interface will move progressively towards the fixed-end.

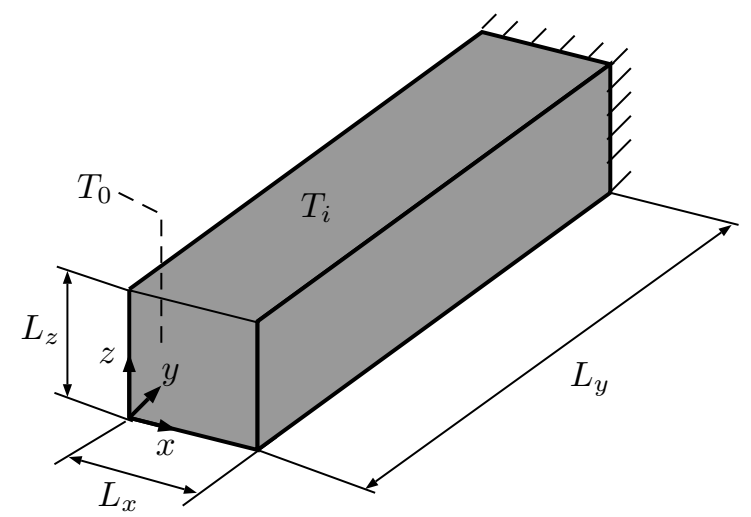

Figure 3.2: Geometry and boundary conditions of the one-dimensional domain used for the validation of the numerical model. The domain is mechanically free and $T=T_{0}$ at $y=0$ while it is fixed and $T=T_{i}$ at $y=L_{y}$.

Table 3.1: Material properties of tin $(\mathrm{Sn})$ and aluminium (Al). Subscripts $s$ and $l$ refer to solid and liquid phases, respectively.

\begin{tabular}{|c|c|c|c|}
\hline \multirow{2}{*}{ Property } & Sn & Al & Unit \\
\hline$\rho_{s}$ & 7280 & 2681 & $\mathrm{~kg} / \mathrm{m}^{3}$ \\
\hline$\rho_{l}$ & 6800 & 2365 & $\mathrm{~kg} / \mathrm{m}^{3}$ \\
\hline$c_{s}$ & 230 & 959.11 & $\mathrm{~J} /(\mathrm{kg} \cdot \mathrm{K})$ \\
\hline$c_{l}$ & 257 & 1085.95 & $\mathrm{~J} /(\mathrm{kg} \cdot \mathrm{K})$ \\
\hline$\kappa_{s}$ & 65 & 240 & $\mathrm{~W} /(\mathrm{m} \cdot \mathrm{K})$ \\
\hline$\kappa_{l}$ & 31 & 93 & $\mathrm{~W} /(\mathrm{m} \cdot \mathrm{K})$ \\
\hline$E$ & 43.3 & 70 & $\mathrm{GPa}$ \\
\hline$\nu$ & 0.33 & 0.33 & - \\
\hline$\alpha^{\prime}$ & $2 \times 10^{-5}$ & $2.1 \times 10^{-5}$ & $1 / \mathrm{K}$ \\
\hline$T_{m}$ & 498.65 & 933.15 & $\mathrm{~K}$ \\
\hline$L$ & 60.627 & 395.60 & $\mathrm{~kJ} / \mathrm{kg}$ \\
\hline
\end{tabular}

For the validations, material properties are those of tin $(\mathrm{Sn})$, which are obtained from [65-69] and summarised in Table 3.1, and the values $T_{0}=573.15(\mathrm{~K})$ and $T_{i}=303.15(\mathrm{~K})$ are considered. In addition, Table 3.1 reports the material properties of aluminium $(\mathrm{Al})$, obtained from [65] and used in Section 3.6 for further analyses. 

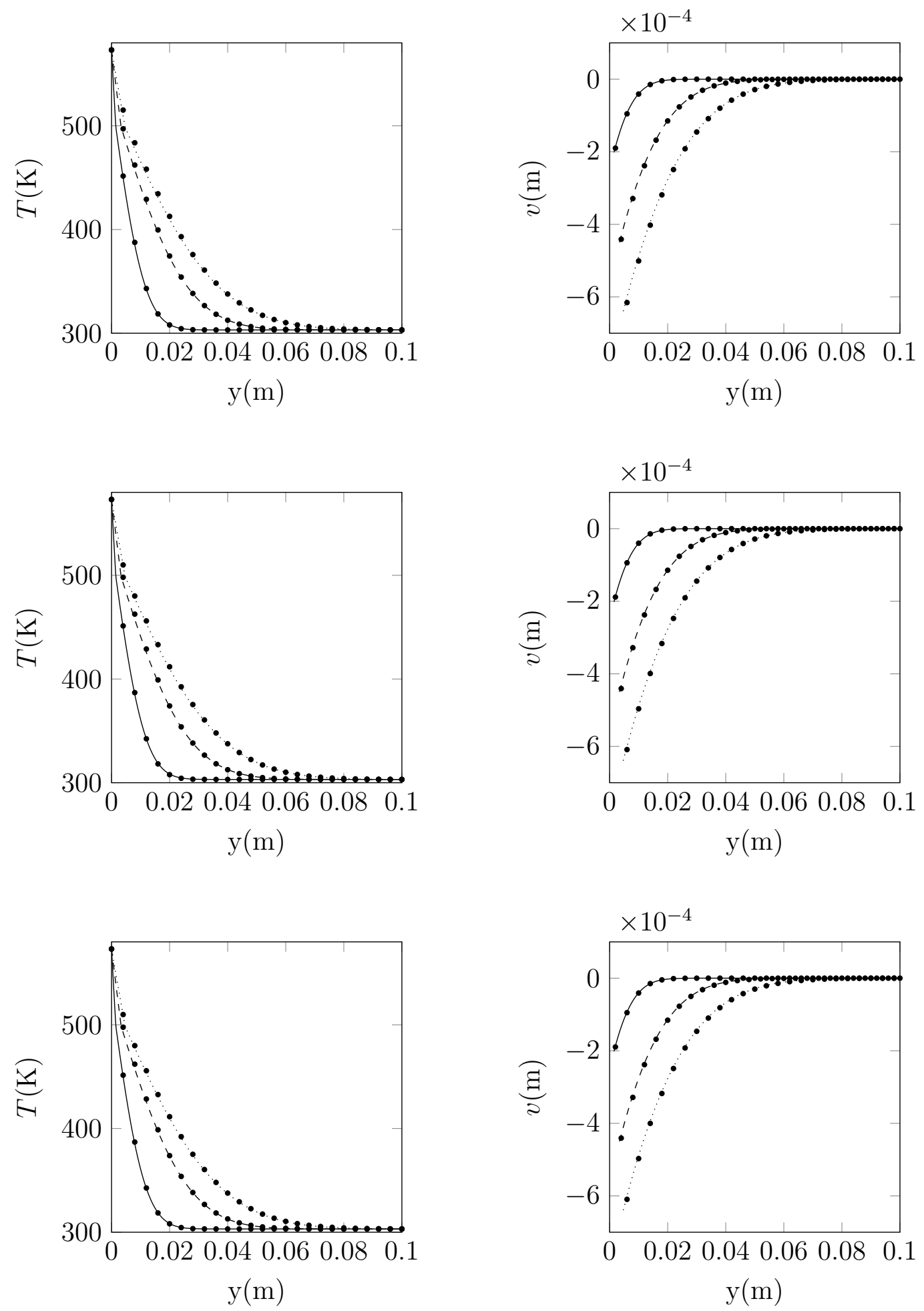

\section{Analytical $t=1 \mathrm{~s} \quad \cdots$ Analytical $t=5 \mathrm{~s} \quad \cdots \cdots$.... Analytical $t=10 \mathrm{~s} \quad \bullet$ Numerical}

Figure 3.3: Comparison of analytical and numerical temperature distributions (left column) and axial displacement (right column) for three different times. The three phase change schemes are considered: heat capacity (top row), heat source (middle row) and enthalpy (bottom row). Analytical solutions in lines and numerical in solid circles. 
Experimentally, materials exhibit temperature-dependency. However, the lack of available data characterising the temperature-dependency over the desired temperature range, the considerable dispersion of the temperature-dependent values reported in literature and the complexity of measuring some of the temperaturedependent properties are the main reasons to consider constant properties in each phase. Nevertheless, the inclusion of temperature-dependent material properties in the numerical formulation would be straightforward in residual-based FE formulations, like the one developed in the present work.

Figure 3.3 compares analytical (solid, dashed and dotted lines) and numerical solutions (solid circles) for temperature distributions (left column) and axial displacements (right column) along the one-dimensional geometry, for the three different phase change schemes -heat capacity (top row), heat source (middle row) and enthalpy (bottom row)- and for three different times: 1, 5, 10 (s). For this comparison, the regularisation parameter is $\epsilon=1.25$.

As observed in Figure 3.3, analytical and numerical solutions are in good agreement with each other for both temperature and axial displacement and for the three phase changes. In particular, the maximum relative error between analytical and numerical results for temperature and axial displacement for each numerical scheme is reported in Table 3.2.

Table 3.2: Maximum relative error (\%) of temperature $(T)$ and axial displacement $(v)$ for each phase change numerical scheme: $h c$ (heat capacity), $h s$ (heat source), $e$ (enthalpy).

$$
\text { hc }(\%) \quad h s(\%) \quad e(\%)
$$

\begin{tabular}{cccc}
\hline \hline$T$ & 1.4 & 1.4 & 1.4 \\
\hline$v$ & 2.6 & 2.1 & 2.1 \\
\hline
\end{tabular}

In conclusion, any of the phase change schemes can be used to solve thermomechanical phase change problems in pure substances.

\subsection{Analyses of thermal stresses in nePCMs}

In this section, the previously formulated and validated numerical tool is applied to simulate four different scenarios in order to determine the temperature distribution on the nePCM shell and to assess the mechanical reliability and energy density of the nePCMs. For this purpose, two geometries and two pairs (core and shell) of materials are considered.

Concerning geometry, spherical and cylindrical nePCM configurations are contemplated, as shown in Figure 3.4. In both geometries, the diameter of the core is $d-2 e_{\text {shell }}$, with $e_{\text {shell }}$ the shell thickness. The height of the cylinder is chosen in such a way to ensure that the total volume (core+shell) of both geometries of nePCMs is the same in order to be able to perform comparative analyses between them.

Regarding material properties, two pair of core@shell materials are considered: tin@tin-oxide $\left(\mathrm{Sn} @ \mathrm{SnO}_{2}\right)$ and aluminium@alumina $\left(\mathrm{Al} @ \mathrm{Al}_{2} \mathrm{O}_{3}\right)$. Core material properties are reported in Table 3.1, while shell properties are given in Table 3.3. Tin 
oxide properties are obtained from [70-74] and alumina ones from [65, 66, 75]. Notice that $\sigma_{t}$ denotes the tensile strength.
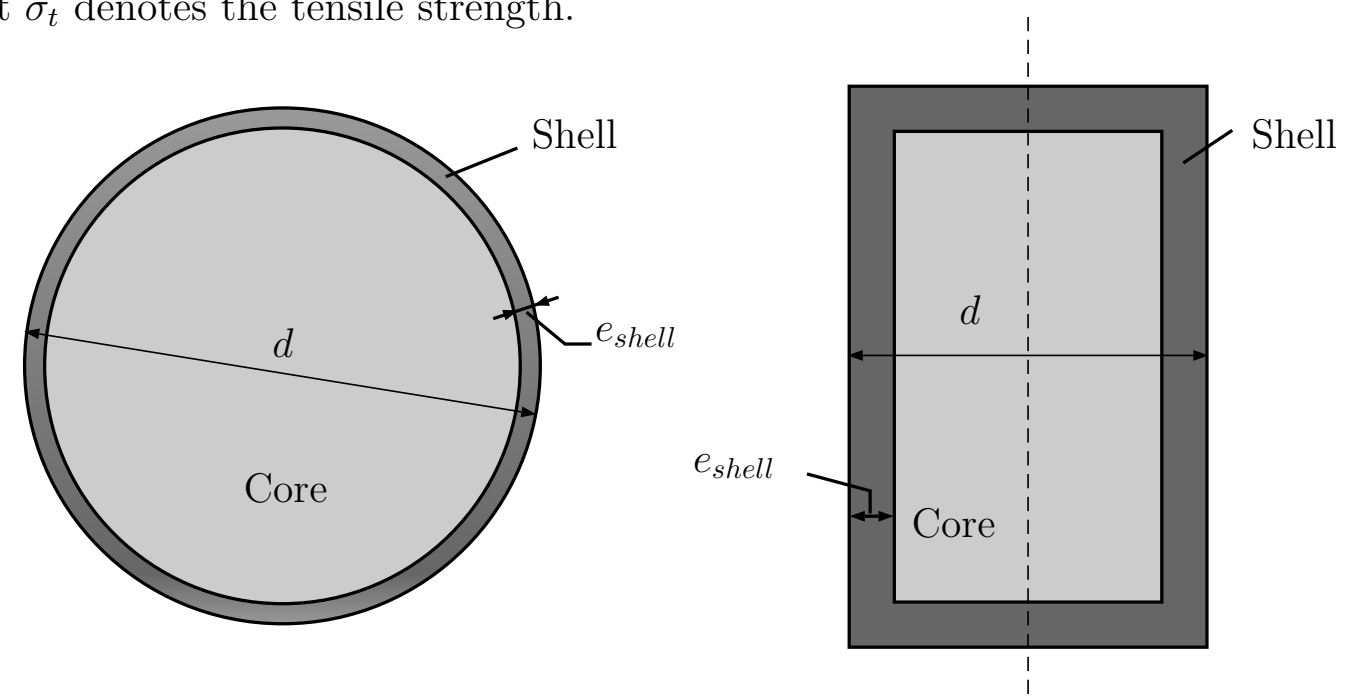

Figure 3.4: Cross-section sketch of the geometry of nanoencapsulated phase change materials: spherical (left) and cylindrical (right). Both are composed of a core of diameter $d-2 e_{\text {shell }}$, filled with a phase change material, and of a shell of thickness $e_{\text {shell }}$ to encapsulate it.

Table 3.3: Material properties of $\mathrm{SnO}_{2}$ and $\mathrm{Al}_{2} \mathrm{O}_{3}$.

\begin{tabular}{|c|c|c|c|}
\hline \multirow{2}{*}{ Property } & $\mathbf{S n O}_{\mathbf{2}}$ & $\mathbf{A l}_{\mathbf{2}} \mathbf{O}_{\mathbf{3}}$ & Units \\
\hline$\rho$ & 7020 & 3970 & $\mathrm{~kg} / \mathrm{m}^{3}$ \\
\hline$c$ & 348.95 & 919.38 & $\mathrm{~J} /(\mathrm{kg} \cdot \mathrm{K})$ \\
\hline$\kappa$ & 40 & 10 & $\mathrm{~W} /(\mathrm{m} \cdot \mathrm{K})$ \\
\hline$E$ & 222.72 & 370 & $\mathrm{GPa}$ \\
\hline$\nu$ & 0.284 & 0.24 & - \\
\hline$\alpha^{\prime}$ & $4 \times 10^{-6}$ & $8.2 \times 10^{-6}$ & $1 / \mathrm{K}$ \\
\hline$T_{m}$ & 1900 & 2273.15 & $\mathrm{~K}$ \\
\hline$\sigma_{t}$ & 803 & 275.9 & $\mathrm{MPa}$ \\
\hline
\end{tabular}

From a FE point of view, structured meshes of 3584 (sphere) and 3840 (cylinder) eight-noded elements are used. With regard to boundary conditions, the nanoparticle is mechanically fixed at its centre and a linearly increasing temperature is prescribed at the outer surface of the shell. The initial temperature of the nanoparticle at $t=0(\mathrm{~s})$ is $T_{i}=303.15(\mathrm{~K})$ and the prescribed temperature is linearly increased with time steps $\Delta t=20(\mathrm{~ns})$ until the final time $t=0.5(\mu \mathrm{s})$. At this time, $T_{0}=573.15$ and $T_{0}=1050.15(\mathrm{~K})$ are reached for $\mathrm{Sn} @ \mathrm{SnO}_{2}$ and $\mathrm{Al}_{\mathrm{A}} \mathrm{Al}_{2} \mathrm{O}_{3}$ nePCMs, respectively. The phase change enthalpy scheme with a regularisation parameter of $\epsilon=1.25$ is applied over the present section.

\subsubsection{Temperature and Rankine's equivalent stress distri- butions}

The first simulation is aimed to obtain temperature and maximum equivalent stress distributions on the nePCM shell. Shells are normally composed of oxides, which 
possess a mechanical behaviour similar to that of ceramics. Despite the fact that the most adequate failure criterion for ceramic materials is not clear in the literature [76], the Rankine's equivalent stress is adopted in the present work given that a shear-insensitive criterion is more adequate than a shear-sensitive one to describe the fracture behaviour of ceramics [77].

Figure 3.5 shows contour plots of temperature and Rankine's equivalent stress distributions on half of the nePCM shell for each of the four scenarios of study. According to the experimental work reported in [17], the diameter $d$ and shell thickness $e_{\text {shell }}$ used in the current section for all the scenarios are: $d=103$ and $e_{\text {shell }}=9.78$ (nm).

In Figure 3.5, firstly, it can be observed that all the nanoparticle shells are at uniform temperature and very low gradients of temperature are appreciated since steady state is reached immediately in nanosolids due to their reduced physical size. Concretely, when the prescribed temperature increases its value, the transient temperature distribution disappears quickly and a new equilibrium state (with low gradients of temperature and consequently negligible heat fluxes) is reached for the new boundary condition.

In the second place, thermal stresses appear due to the difference in the thermal expansion coefficients of the core and shell materials, as was experimentally confirmed in [78]. Notice that this result has also been verified numerically.

Thirdly and with regard to the mechanical reliability of the nePCMs, the maximum numerical values of equivalent stresses are compared with their respective tensile strengths $\sigma_{t}$ given in Table 3.3. From these comparisons, it can be concluded that:

- Spherical and cylindrical $\mathrm{Sn} @ \mathrm{SnO}_{2}$ nePCMs are mechanically reliable during the heating process. In particular, an extra validation has been performed to reproduce the conditions reported in [17] and it is verified that the present numerical tool agrees with the experimental study in that article on the mechanical strength of spherical $\mathrm{Sn} @ \mathrm{SnO}_{2}$ nePCMs.

- Spherical and cylindrical $\mathrm{Al} @ \mathrm{Al}_{2} \mathrm{O}_{3}$ nePCMs are expected to fail.

Finally and for the sake of completeness, Figure 3.6 shows the time evolution of Rankine's equivalent stress at a point at the outer surface of the shell for each scenario of study. Several conclusions are obtained from these curves:

- The equivalent stress increases linearly with temperature until the melting temperature is reached and after that, stress decreases. Consequently, the maximum stress developed in the shell occurs just before melting starts.

- The trend in the time evolution curves is the same regardless of any material property or geometry but the amplitude of the equivalent stresses depends on both these parameters. Stresses in $\mathrm{Al} @ \mathrm{Al}_{2} \mathrm{O}_{3}$ nePCMs are higher than those in $\mathrm{Sn} @ \mathrm{SnO}_{2}$ nePCMs due to their difference in core $T_{m}$, see Table 3.1. For the shell thickness $e_{\text {shell }}=9.78(\mathrm{~nm})$, stresses in cylindrical geometries are higher than those predicted in spherical ones. However, this is not always the case for different values of shell thickness, as shown in Section 3.6.2. 

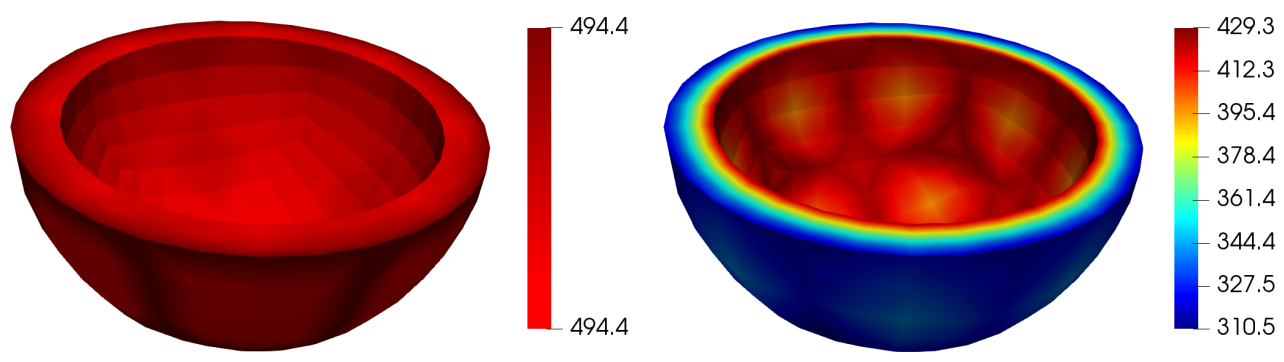

a) $\mathrm{Sn} @ \mathrm{SnO}_{2}$ spherical nePCMs at $t=0.36(\mu \mathrm{s})$

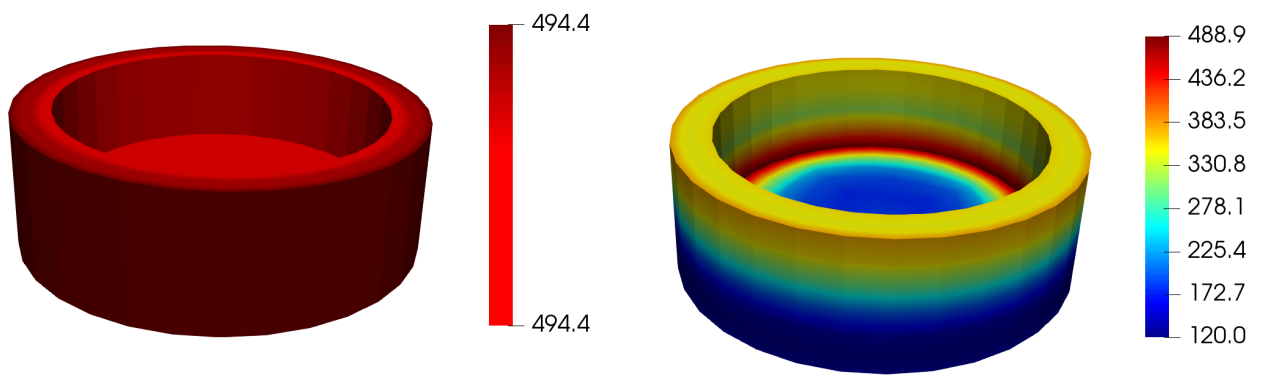

b) $\mathrm{Sn} @ \mathrm{SnO}_{2}$ cylindrical nePCMs at $t=0.36(\mu \mathrm{s})$
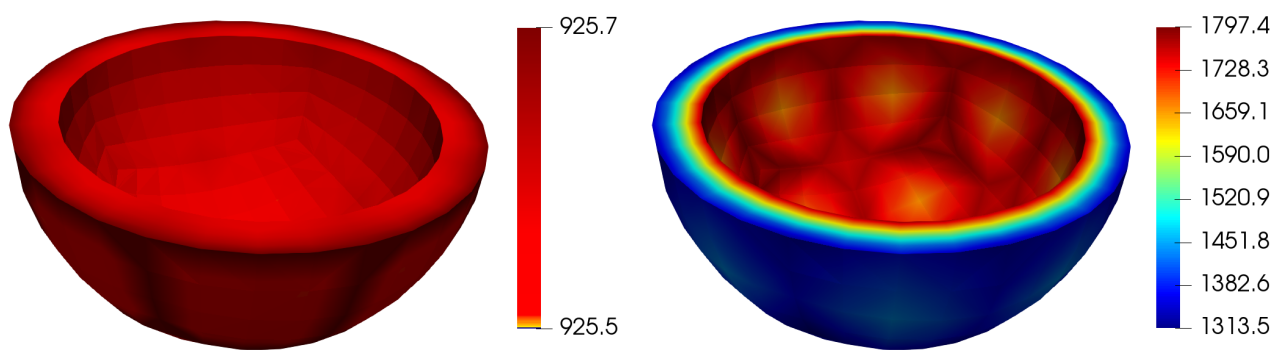

c) $\mathrm{Al} @ \mathrm{Al}_{2} \mathrm{O}_{3}$ spherical nePCMs at $t=0.42(\mu \mathrm{s})$

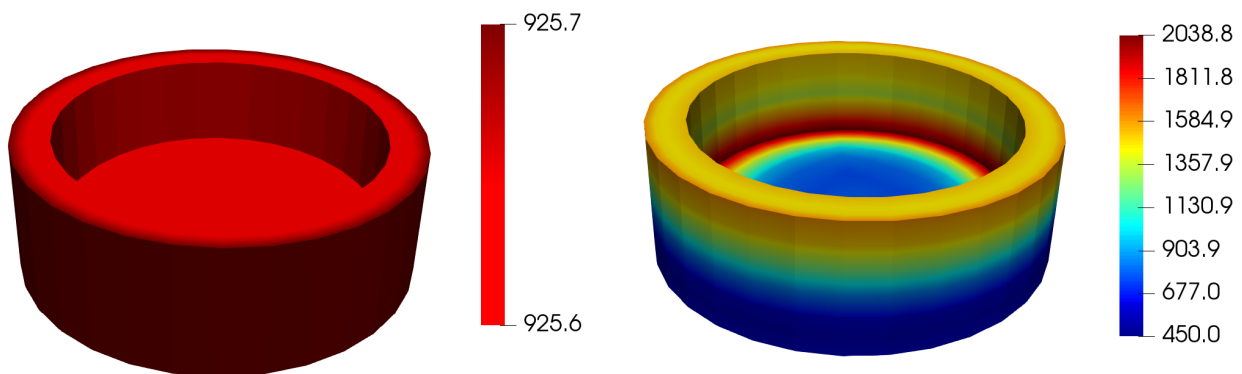

d) $\mathrm{Al} @ \mathrm{Al}_{2} \mathrm{O}_{3}$ cylindrical nePCMs at $t=0.42(\mu \mathrm{s})$

Figure 3.5: Temperature (K) and maximum Rankine's equivalent stress (MPa) distributions developed at the shell for spherical and cylindrical nanoencapsulated phase change materials (neP$\mathrm{CMs})$. 


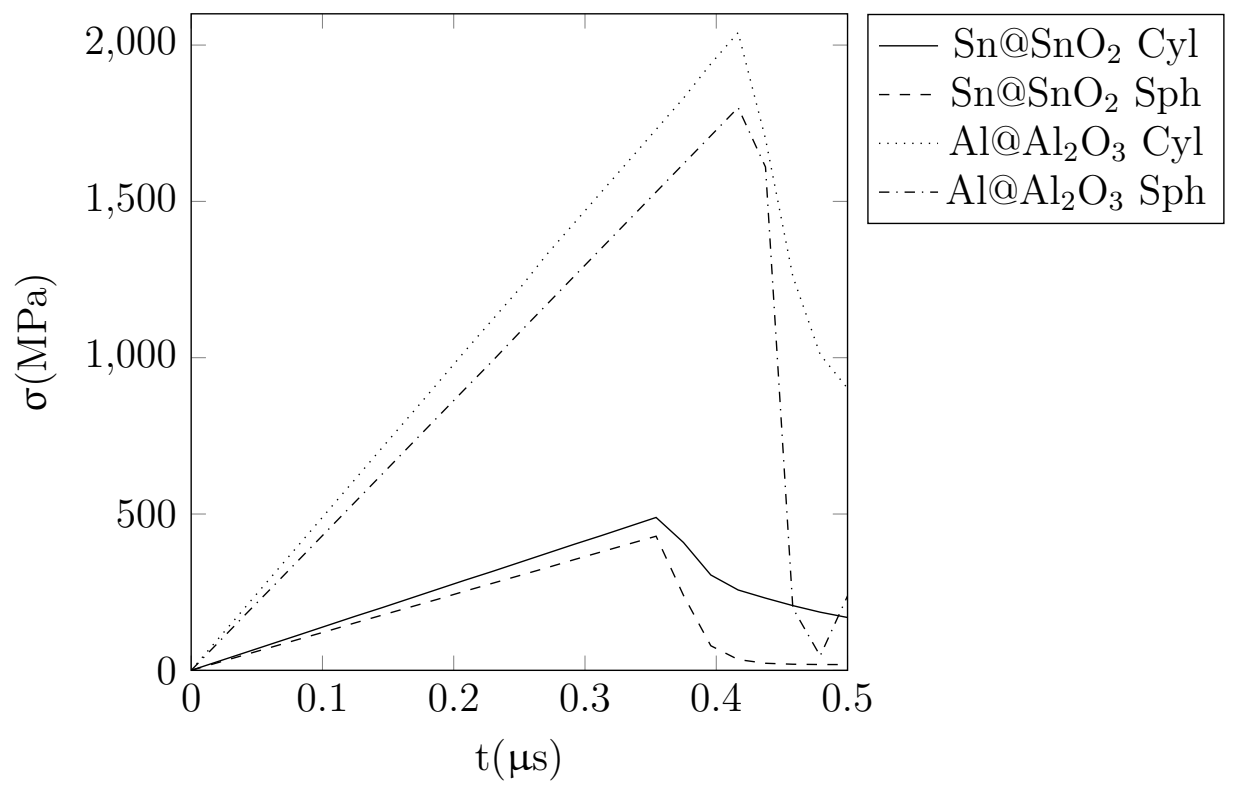

Figure 3.6: Evolution with time of Rankine's equivalent stress at the nanoparticle shell for $\mathrm{Sn} @ \mathrm{SnO}_{2}$ and $\mathrm{Al} @ \mathrm{Al}_{2} \mathrm{O}_{3}$ cylindrical $(\mathrm{Cyl})$ and spherical (Sph) nanoencapsulated phase change materials.

\subsubsection{Analysis of the shell thickness}

The present analysis shows the influence of shell thickness on energy density $\left(E_{d}\right)$ and maximum Rankine's stress developed at the nePCM shell. The energy density measure used in the present analysis is defined as follows:

$$
E_{d}=\rho_{l} L \frac{V_{\text {core }}}{V_{\text {total }}}
$$

where $V_{\text {core }}$ and $V_{\text {total }}$ denote core and total (core+shell) volume of the nePCM, respectively.

Figure 3.7 shows both the variation of the energy density of a single nePCM and of the maximum Rankine's equivalent stress for three different values of the shell thickness $e_{\text {shell }}$, namely: $\{2,5,9.78\}(\mathrm{nm})$. Spherical and cylindrical geometries with the same total volume are considered for comparison purposes.

In the first place, in Figure 3.7, it is observed that both energy density and Rankine's stress decrease with the progressive increase of shell thickness $e_{\text {shell }}$. That decrease in energy density is caused by the reduction in the volume of the available phase change material (core) and, consequently, the energy efficiency of the nePCM is reduced. However, the increase in the shell thickness improves the mechanical reliability of the nePCM, which, as a result, diminishes the thermal stresses developed at the shell.

Secondly, and from a geometrical standpoint, it is observed that:

- The energy density of the spherical nePCMs is higher than that of the cylindrical ones because, for equal total volume of both geometries, the volume of core material inside the nePCM is larger in the spherical geometry.

- The maximum Rankine's stress is slightly higher for spherical nePCMs until a threshold value with increasing shell thickness is overcome and, from that 
point forward, cylindrical nePCMs are the ones undergoing higher thermal stresses for the same shell thickness.

Thirdly, and regarding material properties, it is observed that they exert a direct influence on both energy density and Rankine's stress:

- $\mathrm{Al} @ \mathrm{Al}_{2} \mathrm{O}_{3}$ nePCMs possess an energy density which is nearly twice the value of that of $\mathrm{Sn} @ \mathrm{SnO}_{2}$ nePCMs. The reason of this disparity lies in the difference between the values of latent heat $L$ and mass density $\rho$ of the core materials, see properties in Table 3.1.

- With regard to mechanical reliability, comparing the maximum values of stress in Figure 3.7 with the $\sigma_{t}$ given in Table 3.3, it may be concluded that: whilst $\mathrm{Sn} @ \mathrm{SnO}_{2}$ nePCMs do not fail under thermal stresses, $\mathrm{Al} @ \mathrm{Al}_{2} \mathrm{O}_{3}$ nePCMs are expected to do it.

Finally, spherical $\mathrm{Al} @ \mathrm{Al}_{2} \mathrm{O}_{3}$ nePCMs posses the best energy performance. However, in terms of mechanical strength, $\mathrm{Sn} @ \mathrm{SnO}_{2}$ nePCMs are the only resisting the thermal stresses developed under the previously reported conditions. Since the maximum value of stress is geometry-dependent for a given shell thickness (see Figure 3.7), a compromise between mechanical strength and energy density has to be achieved for each desired application.

In conclusion, mechanical capability of nePCMs highly depends on: i) the difference between the thermal expansion coefficient of the core-shell, ii) the shell thickness and its tensile strength and iii) the melting temperature necessary to reach the liquid state. In turn, energy capability of nePCMs highly depends on: i) the latent heat and mass density of the core and ii) the core volume of the nePCM.

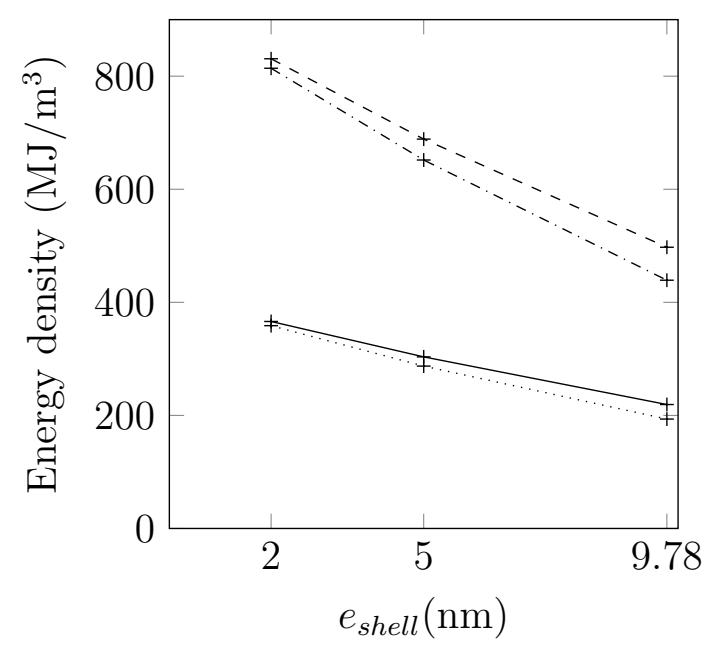

a)

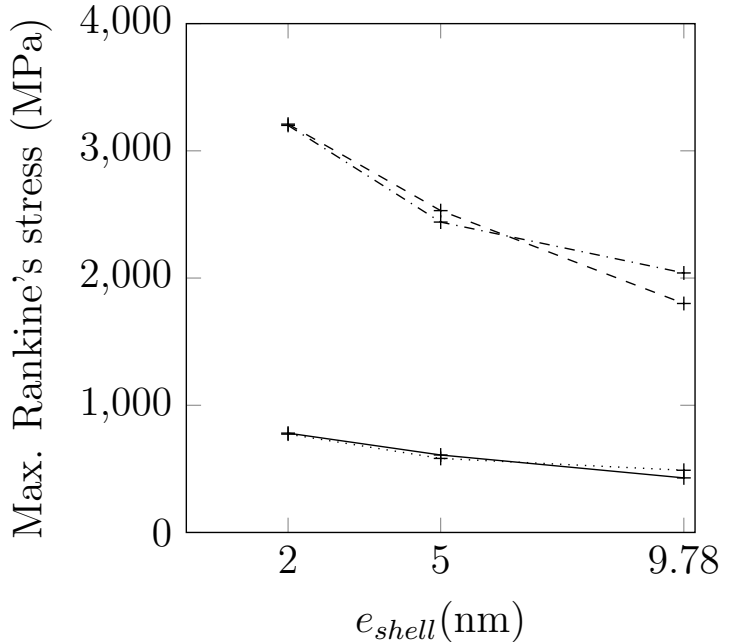

b)

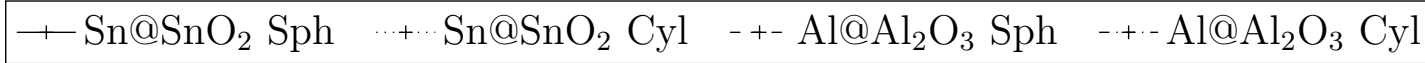

Figure 3.7: Influence of shell thickness $\left(e_{\text {shell }}\right)$ on a) energy density and b) maximum Rankine's equivalent stress for $\mathrm{Sn} @ \mathrm{SnO}_{2}$ and $\mathrm{Al} @ \mathrm{Al}_{2} \mathrm{O}_{3}$ spherical (Sph) and cylindrical (Cyl) nanoencapsulated phase change materials. 


\subsection{Conclusions}

A three-dimensional finite element formulation has been developed to numerically study thermomechanical phase change problems for pure substances. For this purpose, governing equations for mechanical and thermal fields are stated and discretised within the FE context and three different phase change schemes are considered and compared. The numerical formulation is implemented in a research code, which is validated by comparing numerical results against closed solutions extended by the authors of the present work. From these validations, it is concluded that the three phase change schemes are suitable to deal with phase change phenomena on pure substances.

This numerical tool is used to simulate nePCMs in four scenarios of study: two different geometries (spherical and cylindrical) and two core@shell pairs of materials ( $\mathrm{Sn} @ \mathrm{SnO}_{2}$ and $\mathrm{Al} @ \mathrm{Al}_{2} \mathrm{O}_{3}$ ) are considered. For each scenario, three analyses are performed: i) temperature and maximum Rankine's stress distributions on the nePCM shell, ii) time evolution of Rankine's stress and iii) study of the influence of the shell thickness on stress and energy density. From these analyses, it is concluded that the choice of the nePCM geometry and material pair must respond to a compromise between energy density and mechanical strength, which must be thoroughly examined for each desired application.

Despite the uncertainty associated to the values of some material properties, numerical simulations provide a good estimation of the stresses developed in nePCMs during thermal processes. Hence, this framework appears to be a powerful tool, complementary to experiments, to determine the thickness needed for the nanoparticle shells. 


\section{Appendix to Chapter 3}

\section{A. Tangent matrices}

According to [33], tangent matrices are calculated from the residuals of (3.22) and (3.24) by solving:

$$
\mathcal{K}_{a b}^{i j}=-\frac{\partial \mathcal{R}_{a}^{i}}{\partial a_{b}^{j}}, \mathcal{C}_{a b}^{i j}=-\frac{\partial \mathcal{R}_{a}^{i}}{\partial \dot{a}_{b}^{j}}, \mathcal{M}_{a b}^{i j}=-\frac{\partial \mathcal{R}_{a}^{i}}{\partial \ddot{a}_{b}^{j}},
$$

where the indexes $i, j$ refer to the degrees of freedom and $a, b$ to two generic nodes.

Applying (3.28) to (3.22), the mechanical matrices for the solid phase become:

$$
\begin{aligned}
& \mathcal{K}_{a b}^{\underline{u}} \underline{u}=-\frac{\partial \mathcal{R}^{\underline{u}}}{\partial a_{b}^{\underline{u}}}=\int_{\Omega_{e}} \underline{\underline{\mathcal{B}_{a}}} \underline{\underline{\underline{\underline{C}}}} \underline{\underline{\mathcal{B}_{b}}}{ }^{s} \mathrm{~d} \Omega_{e} \\
& \mathcal{K}_{a b}^{\underline{u} T}=-\frac{\partial \mathcal{R} \underline{\underline{u}}}{\partial a_{b}^{T}}=-\int_{\Omega_{e}} \underline{\underline{\mathcal{B}_{a}}} \underline{\underline{\beta}} \underline{\underline{N}} \mathcal{N}_{b} \mathrm{~d} \Omega_{e} \\
& \mathcal{M}_{a b}^{\underline{u}} \underline{u}=-\frac{\partial \mathcal{R} \underline{\underline{u}}}{\partial \ddot{a}_{b}^{\underline{u}}}=-\int_{\Omega_{e}} \underline{\mathcal{N}_{a}} \rho \underline{\mathcal{N}_{b}} \mathrm{~d} \Omega_{e},
\end{aligned}
$$

and, for the liquid phase:

$$
\begin{aligned}
& \mathcal{K}_{a b}^{\underline{u} u}=-\frac{\partial \mathcal{R} \underline{\underline{u}}}{\partial a_{b}^{\underline{u}}}=\int_{\Omega_{e}} \underline{\underline{\mathcal{B}_{a}}}{ }^{s} \frac{1}{3} \operatorname{tr}\left(\underline{\underline{\underline{\underline{C}}}} \underline{\underline{\mathcal{B}_{b}}}\right) \underline{\underline{I}} \mathrm{~d} \Omega_{e}, \\
& \mathcal{K}_{a b}^{\underline{u} T}=-\frac{\partial \mathcal{R} \underline{\underline{u}}}{\partial a_{b}^{T}}=-\int_{\Omega_{e}} \underline{\underline{\mathcal{B}_{a}}}{ }^{s} \frac{1}{3} \operatorname{tr}\left(-\underline{\underline{\beta}} \mathcal{N}_{b}\right) \underline{\underline{I}} \mathrm{~d} \Omega_{e} .
\end{aligned}
$$

Now, applying (3.28) to (3.24), the thermal matrices for the heat capacity $h c$ scheme read:

$$
\begin{aligned}
& \mathcal{K}_{a b}^{T T}=-\frac{\partial \mathcal{R}_{a}^{T, h c}}{\partial a_{b}^{T}}=\int_{\Omega_{e}} \underline{\mathcal{B}}_{a} \underline{\kappa}_{\underline{\mathcal{B}}} \underline{\mathcal{B}}_{b} \mathrm{~d} \Omega_{e} \\
& \mathcal{C}_{a b}^{T T}=-\frac{\partial \mathcal{R}_{a}^{T, h c}}{\partial \dot{a}_{b}^{T}}=\int_{\Omega_{e}} \mathcal{N}_{a} \rho\left[c+L \delta\left(T-T_{m}\right)\right] \mathcal{N}_{b} \mathrm{~d} \Omega_{e}
\end{aligned}
$$


for the heat source $h s$ scheme:

$$
\begin{aligned}
& \mathcal{K}_{a b, n+1}^{T T}=-\frac{\partial \mathcal{R}_{a, n+1}^{T, h s}}{\partial a_{b, n+1}^{T}}=\int_{\Omega_{e}}\left[\underline{\mathcal{B}}_{a, n+1} \underline{\underline{\kappa}} \underline{\mathcal{B}}_{b, n+1} \Delta t+\mathcal{N}_{a, n+1} \rho L \frac{\partial h_{n+1}}{\partial T} \mathcal{N}_{b, n+1}\right] \mathrm{d} \Omega_{e}, \\
& \mathcal{C}_{a b, n+1}^{T T}=-\frac{\partial \mathcal{R}_{a, n+1}^{T, h s}}{\partial \dot{a}_{b, n+1}^{T}}=\int_{\Omega_{e}} \mathcal{N}_{a, n+1} \rho c \mathcal{N}_{b, n+1} \Delta t \mathrm{~d} \Omega_{e},
\end{aligned}
$$

and, finally, for the enthalpy e scheme:

$$
\mathcal{K}_{a b, n+1}^{T T}=-\frac{\partial \mathcal{R}_{a, n+1}^{T, e}}{\partial a_{b, n+1}^{T}}=\int_{\Omega_{e}}\left[\underline{\mathcal{B}}_{a, n+1} \underline{\kappa}_{\underline{\underline{\mathcal{B}}}} \underline{b, n+1} \Delta t+\mathcal{N}_{a, n+1} \frac{\partial H_{n+1}}{\partial a_{j, n+1}^{T}}\right] \mathrm{d} \Omega_{e} .
$$

\section{B. Analytical solution}

This appendix presents an analytical solution for a thermomechanical phase change problem applied to a one-dimensional half-space domain. The analytical solution for the thermal field considering phase change is reported in [79, 80]. The authors of the current work have extended that solution by including the mechanical field. For this purpose, it is assumed that the body is not subjected to any traction and, consequently, the axial displacement $v$ of the solid phase may be calculated as:

$$
v(y)=-\frac{3 \lambda+2 \mu}{\lambda+2 \mu} \alpha^{\prime} \int_{y}^{L_{y}}\left(T-T_{i}\right) \mathrm{d} y
$$

where $L_{y}$ denotes length of the body, as shown in Figure 3.2. Finally, the expression of the axial displacement reads:

$$
\begin{aligned}
v(y)= & -\frac{3 \lambda+2 \mu}{\lambda+2 \mu} \frac{\alpha^{\prime}\left(T_{m}-T_{i}\right)}{\sqrt{\pi} \operatorname{erfc}(\xi)}\left[2\left(e^{-\frac{y^{2}}{4 \beta_{s} t}}-e^{-\frac{L_{y}^{2}}{4 \beta_{s} t}}\right) \sqrt{\beta_{s} t}\right. \\
& \left.+\sqrt{\pi}\left(L_{y} \operatorname{erfc}\left(\frac{L_{y}}{2 \sqrt{\beta_{s} t}}\right)-x \operatorname{erfc}\left(\frac{x}{2 \sqrt{\beta_{s} t}}\right)\right)\right]
\end{aligned}
$$

where $t, \beta_{s}=\kappa_{s} /\left(\rho_{s} c_{s}\right)$, erfc and $\xi$ denote time, thermal diffusivity of the solid phase, the complementary error function and a dimensionless coefficient reported in $[79,80]$, respectively.

Under restrictive assumptions, an analytical solution for a one-dimensional fluid can be obtained. More precisely, an analytical solution for the case of a non-viscous fluid at rest is provided according to the constitutive law in Equation (3.8) (right). In this particular case, pressure in liquid phase can be computed as:

$$
p=\frac{K}{3} \frac{\partial v}{\partial y}-\alpha^{\prime}\left(T-T_{r e f}\right),
$$

where $\mathrm{K}$ denotes bulk modulus.

By considering (3.35), an explicit expression of pressure can be found:

$$
p=\frac{K}{3} \frac{\alpha^{\prime}\left(T_{m}-T_{i}\right)}{\operatorname{erfc}(\xi)} \operatorname{erfc}\left(\frac{x}{2 \sqrt{\beta_{s} t}}\right)-\alpha^{\prime}\left(T-T_{r e f}\right)
$$





\section{Chapter 4: Mechanical reliability analysis of nanoencapsulated phase change materials combining Monte Carlo technique and the finite ele- ment method}

Nanoencapsulated phase change materials (nePCMs) are one of the technologies currently under research for energy storage purposes. These nePCMs are composed of a phase change core surrounded by a shell which confines the core material when this one is in liquid phase. One of the problems experimentally encountered when applying thermal cycles to the nePCMs is that their shell fails mechanically and the thermal stresses arising may be one of the causes of this failure. In order to evaluate the impact of the uncertainties of material and geometrical parameters available for nePCMs, the present work presents a probabilistic numerical tool, which combines Monte Carlo techniques and a finite element thermomechanical model with phase change, to study two key magnitudes of nePCMs for energy storage applications of tin and aluminium nePCMs: the maximum Rankine's equivalent stress and the energy density capability. Then, both uncertainty and sensitivity analyses are performed to determine the physical parameters that have the most significant influence on the maximum Rankine's stress, which are found to be the melting temperature and the thermal expansion of the core. Finally, both a deterministic and a probabilistic failure criterion are considered to analyse its influence on the number of predicted failures, specially when dispersion on tensile strength measurements exists as well. Only $1.87 \%$ of tin nePCMs are expected to fail mechanically while aluminium ones are not likely to resist. 


\subsection{Introduction}

The world demand of energy is estimated to increase by $26 \%$ and $\mathrm{CO}_{2}$ associated emissions will continue rising by $10 \%$ by the year 2040 with respect to those registered in 2017 [81]. In order to reduce the environmental problems, efforts are made by several scientific communities to foster the use of renewable energies, which exploit natural resources -unlimited on a human timescale- without generating polluting emissions. The present work focuses exclusively on solar energy and more precisely, on its application to concentrated solar plants (CSP), since solar energy is the renewable energy presenting the major potential for exploitation of energy [6]. Nevertheless, one of the main cons of solar energy is its intermittence since energy production depends largely on weather/climate conditions. Consequently, owing to the high demand of energy in the electricity market, gaps between generation and supply of energy cannot be tolerated to guarantee the correct operation of the electrical grid. One of the characteristics that makes CSP stand out among other renewable energy technologies is the possibility of incorporating Thermal Energy Storage (TES) systems to mitigate the previously mentioned generation gaps. TES systems appear to be a field of research on its own nowadays for energetic transition towards renewable energies within the context of green policies [41, 82-84].

The focus of the present work lays on one of the technologies under research for TES systems in concentrated solar plants: nanofluids [11], which is the name received by the colloidal suspension of nanoparticles (less than $100 \mathrm{~nm}$ ) in a base fluid to enhance its thermal properties. One of the advantages of these suspensions is that, due to the Brownian motion of the particles within the base fluid, nanofluids combine the good thermal properties of nanosolids with the transport properties of the fluid avoiding clogging or settling problems.

The thermal energy storage capability of the nanofluids is a key parameter of their performance for TES purposes. Although the enhancement of sensible heat storage capability of commonly used nanoparticles (metal oxides or carbon structures) dispersed in ionic liquids still generates controversy [14], it has been recently demonstrated the possible enhancement of thermal energy storage of TES material with the addition of metallic nanoencapsulated Phase Change Materials (nePCMs) [15-18] due to the contribution of the latent heat. NePCMs are composed of a phase change core wrapped in a surrounding shell made of another material with a melting temperature higher than that of the core. The role of the shell is to confine the core material when melting occurs. One of the main features of metallic nePCMs for TES applications is that they contribute considerably to increase the overall energetic performance of the nanofluid thanks to the latent heat absorbed/released during the phase change of their core. Moreover, they can be self-encapsulated with an oxide shell formed by natural passivation during the sintering process that can interact with the base fluid increasing the sensible heat in ionic liquids. In this context, optimising the design of the nePCMs is of key importance given that they play a direct influence on the performance of the nanofluid. One of the main problems encountered when nePCMs undergo thermal cycles is that their shell may fail mechanically, as it has been reported in [17]. The thermal stresses arising in the shells of the nePCMs could be one of the reasons for this failure, as investigated in [85].

Despite the fact that synthesis of nePCMs is performed experimentally with the 
valuable knowledge of the experimental community, the current work presents a numerical tool to analyse the behaviour of nePCMs from a quantitative perspective to get a better understanding of the physical phenomena involved in the failure of the nanoparticle shells. Furthermore, experimental measurements of the different material properties of a substance are not exempt from uncertainties, which are intrinsic to the nature of the measurement process. For this reason, it is important to numerically check the influence and consequences of these uncertainties on the measurements of the material properties by using a probabilistic technique that combines both Monte Carlo (MC) [86] and Finite Element (FE) methods. In the same vein, considerable dispersion exists normally in the mean size of the synthesised nePCMs [17] and despite possessing a spherical morphology, they are not perfect spheres. Therefore, this lack of symmetry could have an impact on the mechanical failure of the shell of the nePCMs, which needs to be quantitatively assessed. Consequently, the study of all the aforementioned uncertainties on the nePCMs highlights the need of considering probabilistic analyses to evaluate the performance of these nanoparticles for TES applications.

Some examples of probabilistic and numerical analyses are reported in the literature to analyse the failure of polymeric nanoparticle composites [87], and to optimise the nanoparticle wet milling process [88]. However, neither their scope of analysis is the same than the one intended in the present work (nePCMs) nor the number of input parameters of their probabilistic analysis is large enough to analyse the influence of different physical parameters on their aim of study. Notice that the present work considers a set of 22 physical parameters (18 material and 4 geometrical parameters) to account for its influence on the failure of the nePCMs and, consequently, the analytical computation of the probability of failure may be complex. Then, the need for numerical methods arises.

MC simulation is a class of algorithms that use statistical sampling techniques to obtain a probabilistic approximation to the solution of a model: the samples previously generated are the inputs of the model and its evaluations provide the probabilistic outputs or responses of the model [89]. The evaluation of the model may be performed by using analytical solutions or numerical methods such as the FE [90-92], finite difference [93], finite volume [94], etc.

On this ground, the aim of the current work is to study two key magnitudes of nePCMs for TES applications: the maximum equivalent stress and the energy density capability and, to achieve this goal, reliability, uncertainty and sensitivity analyses are developed. In particular, two different pairs of nePCM materials are considered: tin encapsulated in tin oxide and aluminium encapsulated in aluminium oxide (alumina). For this purpose, a probabilistic tool is obtained by combining both MC and FE methods. The former considers up to 22 random variables and the input samples are generated by using the Latin Hypercube Sampling (LHS) technique [95], while the latter is a thermomechanical with phase-change FE code previously developed by the authors of the present work [85]. From the uncertainty analysis, distributions of maximum Rankine's equivalent stress -failure criterion for the shell- and of energy density are obtained. Furthermore, the sensitivity analysis permits to assess which of the 22 random variables exerts more influence on both the failure of the nePCM and on its energy density performance. With regard to the reliability analysis, both a deterministic and a probabilistic failure criterion are considered to verify its influence on the number of predicted failures when uncer- 
tainty in tensile strength exists. In conclusion, the results of these analyses may contribute to identify what are the physical parameters to be considered in advance to synthesise mechanically reliable nePCMs.

\subsection{Outline of the problem}

This section briefly reviews the model of the nePCM retained for the probabilistic analyses henceforth.

\subsubsection{Description of the nanoparticle}

The numerical model considers a single three-dimensional ellipsoidal nePCM, as that sketched in Figure 4.1, where the geometry is defined by the three semi-axes $a_{\text {semi }}$, $b_{\text {semi }}$ and $c_{\text {semi }}$ of the outer ellipsoid and the shell thickness $e_{\text {shell }}$. Notice that an ellipsoidal geometry for nePCMs is assumed in the present work for two reasons: i) to consider the influence of the geometrical uncertainty in the probabilistic analyses and ii) given that real nePCMs are not perfectly spherical.

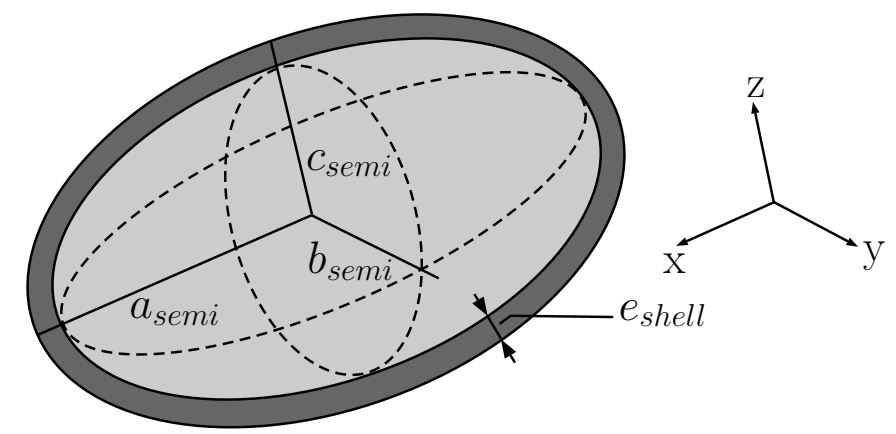

Figure 4.1: Geometry of the ellipsoidal nanoencapsulated phase change material with the three semi-axes $a_{\text {semi }}, b_{\text {semi }}$ and $c_{\text {semi }}$ of the outer ellipsoid and the shell thickness $e_{\text {shell }}$.

Two different pairs of core@shell materials for nePCMs are considered: $\mathrm{Sn} @ \mathrm{SnO}_{2}$ (tin encapsulated in tin oxide) and $\mathrm{Al} @ \mathrm{Al}_{2} \mathrm{O}_{3}$ (aluminium encapsulated in alumina). Their material properties are obtained from [65-69] for $\mathrm{Sn}$, from [70-74] for $\mathrm{SnO}_{2}$, from $[65-67,96]$ for $\mathrm{Al}$ and from $[65,97-99]$ for $\mathrm{Al}_{2} \mathrm{O}_{3}$ and all of them are reported in Table 4.1. The material properties listed in Table 4.1 are mass density $\rho$, specific heat capacity $c$, thermal conductivity $\kappa$, Young's modulus $E$, Poisson's ratio $\nu$, thermal expansion coefficient $\alpha^{\prime}$, melting temperature $T_{m}$ and latent heat $L$. Subscripts $s$ and $l$ denote solid and liquid state, respectively. For the geometry, an order of magnitude of the size of spherical Sn and Al nanoparticles may be obtained from [17] and [18, 100, 101], respectively.

Concerning the boundary and initial conditions, the nePCM is mechanically fixed at its centre and subjected to an initial temperature $T_{i}$. Then, an increasingly linear temperature is applied at the outer surface of the shell until a value of temperature $T_{0}$ (higher than the melting temperature of the core material) is reached. Concretely, $T_{i}=323.15(\mathrm{~K}), T_{0}=523.15(\mathrm{~K})$ for $\mathrm{Sn} @ \mathrm{SnO}_{2}$ and $T_{0}=973.15(\mathrm{~K})$ for $\mathrm{Al} @ \mathrm{Al}_{2} \mathrm{O}_{3}$ nePCMs are considered. 
Table 4.1: Summary of material and geometrical properties of $\mathrm{Sn}_{\mathrm{SnO}} \mathrm{Sn}_{2}$ and $\mathrm{Al} @ \mathrm{Al}_{2} \mathrm{O}_{3}$ (core@shell) nanoencapsulated phase change materials (nePCMs). SRC is the abbreviation of standardised regression coefficients used in the sensitivity analysis and $\sigma$ is the standard deviation for each of the properties with respect to their mean values.

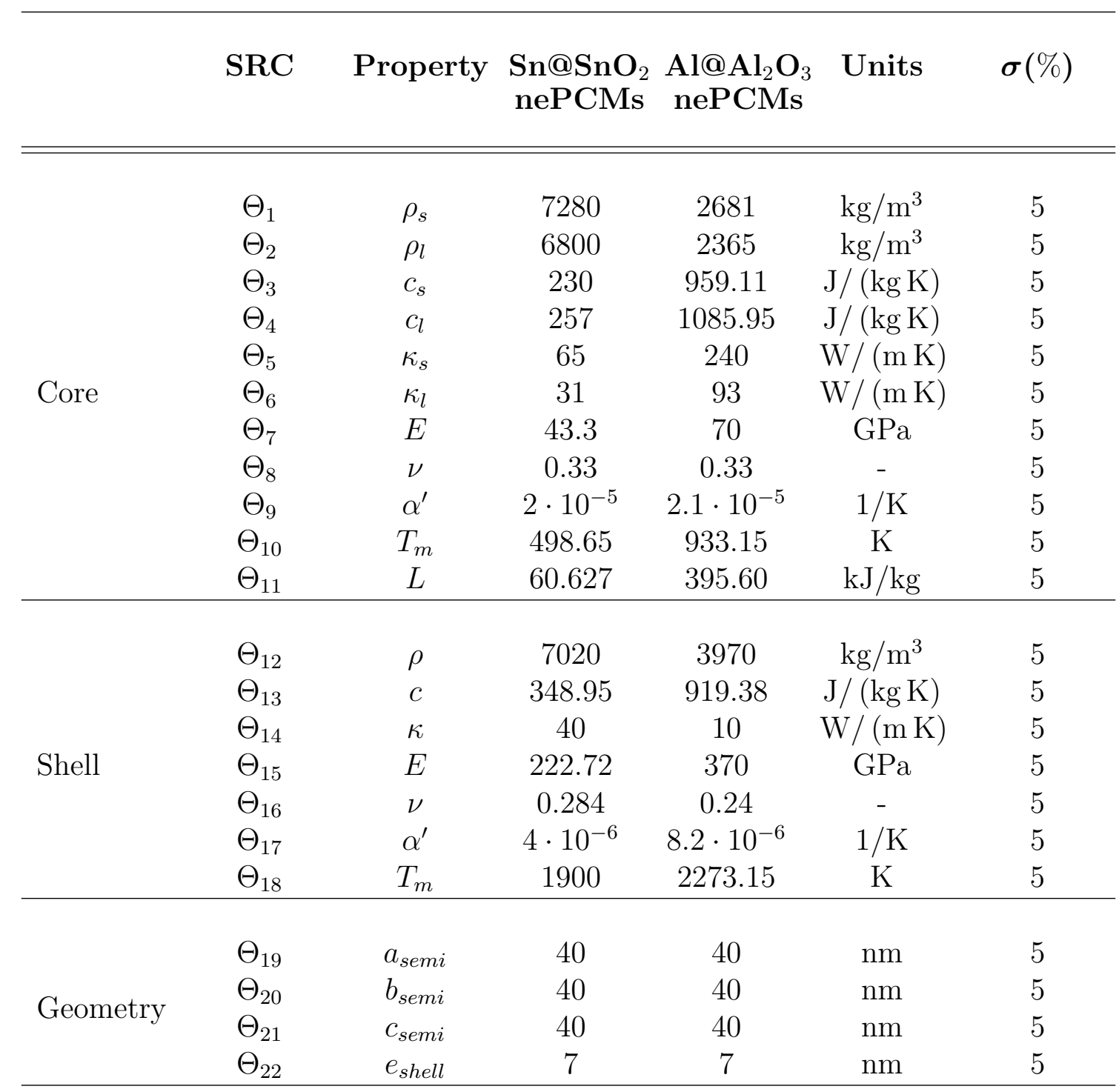

\subsubsection{Description of the finite element model}

The evaluation of the nanoparticle model is performed by a three-dimensional FE code developed by the authors. In particular, a thermodynamically consistent FE formulation was developed in [85] by considering thermomechanical coupling and three phase change approaches: enthalpy, heat source and heat capacity. This formulation was implemented in the research code FEAP [35], which belongs to the University of California at Berkeley (USA).

Numerically, the FE formulation is monolithic and eight-noded with four degrees of freedom (dof) per node:

$$
\operatorname{dof}=\{\underline{u}, T\},
$$

where the first term in brackets represents the three components of the displacement field $\underline{u}=\{u, v, w\}$ and the last term is the temperature. These dofs are discretised by using standard shape functions of Lagrangian type. For the sake of brevity, only 
the tangent matrix is reported in the present work:

$$
\left[\begin{array}{cc}
\mathcal{K}_{a b}^{\underline{u} \underline{u}}+c_{3} \mathcal{M}_{a b}^{\underline{u} \underline{u}} & \mathcal{K}_{a b}^{u} T \\
0 & \mathcal{K}_{a b}^{T T}
\end{array}\right]
$$

where $\mathcal{K}$ and $\mathcal{M}$ denote stiffness and mass matrices, respectively. Subscripts $a$ and $b$ refer to discretization nodes while superscripts denote the dofs. As observed, only a one-way coupling is considered with the term $\mathcal{K}_{a b}^{\underline{u} T}$, which is due to the thermomechanical volumetric expansion. With regard to the time integration scheme, the scalar coefficient $c_{3}$ in (4.2) is associated to the Newmark algorithm. Finally, the enthalpy approach is used in the current work.

\subsection{Probabilisitic analysis}

The present work uses a probabilistic numerical tool that combines the thermomechanical FE method with the MC technique. As shown in Figure 4.2, the working principle of this tool consists of:

1. Identifying the random parameters and their distribution functions.

2. Generating a random sample of size $N$.

3. Performing $N$ evaluations of the model through the FE code.

4. Analyse the $N$ outputs of the FE code: Uncertainty Analysis (UA), Sensitivity Analysis (SA), Probability of Failure (POF) and Energy Density $\left(E_{d}\right)$ distribution.

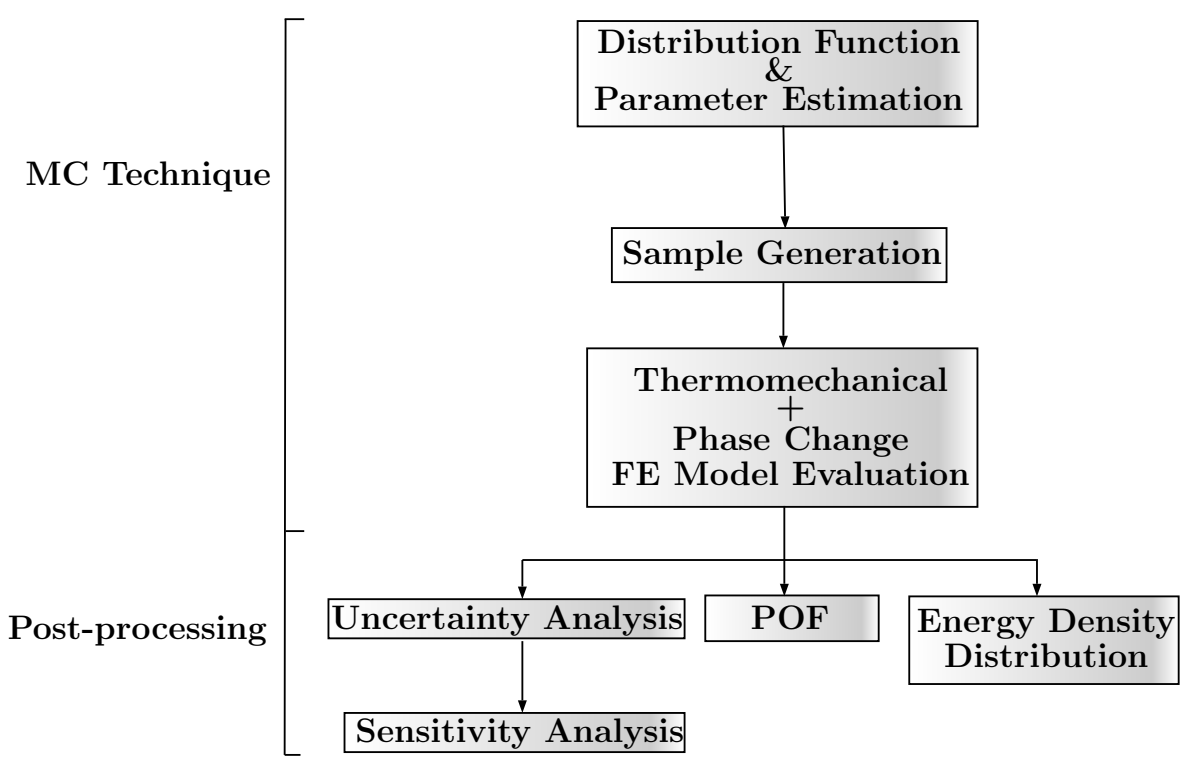

Figure 4.2: Flowchart of the probabilistic numerical tool. 


\subsubsection{Distribution functions and sample generation}

Firstly, the $j$ random variables $\xi_{j}$-commonly called parameters- of the model must be identified and quantified in accordance with experimental observations. In the present work, all the material and geometrical properties $(j=1, \ldots, 22)$ of the nePCM are considered as random variables; their nominal values and standard deviation (uncertainty) of the random variables are shown in Table 4.1.

Secondly, neither the distribution function of the measurements of these variables nor most of uncertainties in the measurement process are available in the literature. However, the experimental values of physical properties are normally obtained as the average of the different measurements and, therefore, according to the central limit theorem, these values can be assumed to be normally distributed even when the original samples themselves do not obey a normal distribution.

According to the orders of magnitude of dispersion in measurements reported in [65], a standard deviation $\sigma$ of $5 \%$ around the nominal value (mean) of each material parameter is considered as a first and good estimation. With regard to geometrical parameters and in agreement with the experimental characterisations available in $[17,18]$, the size of nePCMs is assumed to be log-normally distributed. In particular, the mean size and standard deviation for the semi-axes of the outer ellipsoid are $40(\mathrm{~nm})$ and $40 \%$ around the mean value, respectively. Since experimentally it is observed that nanoparticles are not perfect spheres but quasi-spherical, an ellipsoidal geometry is considered with a standard deviation of $5 \%$ around the log-normal mean values. Notice that the shell thickness is not uniform around the core but normally distributed within a $5 \%$ of uncertainty.

Finally, the LHS technique [95] is used to generate the random samples. LHS is a statistical technique to generate random numbers which consists of dividing the cumulative density function of each random variable into $N$ equal partitions and choosing a random data point in each partition of each random variable. Then, the samples of each random variable are combined in order to create the set of random input vectors of the model. This technique is used in the present work for two reasons: i) it reduces the computational time [102] with respect to the time required for standard random sampling, and ii) the random sample generated is more representative of the variability of the random variables than standard random generations.

\subsubsection{Uncertainty and Sensitivity Analyses}

Consider a generic model $M$ represented by the mathematical expression:

$$
\phi_{i}=M\left(\xi_{j}\right)
$$

where $\phi_{i}$ represents the $i$ outputs and $\xi_{j}$ the $j$ inputs.

On the one hand, the main goal of the UA is to determine the uncertainty in the model output when the uncertainties in the input are known. Concretely, UA allows to calculate the probability distribution of the output and their scalar parameters: mean and standard deviation.

On the other hand, the objective of the SA is to determine the relationship among the uncertainties in input and output variables, namely, SA permits to identify which input variables exert more influence on the response of the model. Although there 
are different techniques to develop a SA [103], multiple linear regression is adopted in the present work. According to $[104,105]$, in multiple linear regression, each output $\phi_{i}$ may be approximated by:

$$
\phi_{i} \approx \theta_{0}+\sum_{j=1}^{N_{\xi}} \theta_{j} \xi_{j}+\Psi,
$$

where $N_{\xi}$ represents the number of random variables (or inputs) of the model, $\theta_{j}$ are the regression coefficients that relate each input $\xi_{j}$ with each output $\phi_{i}, \theta_{0}$ is the intercept term of the linear regression and $\Psi$ represents a random error term.

Regression coefficients $\theta_{0}$ and $\theta_{j}$ are determined by least-square computation from (4.4) and, despite the fact that they provide information on the relationship between the inputs and outputs of the model, according to [103], regression coefficients are not an appropriate sensitivity measure. Instead, another sensitivity measure known as Standardized Regression Coefficients (SRC) is preferred and they are defined as:

$$
\Theta_{j}=\theta_{j} \frac{\sigma_{\xi_{j}}}{\sigma_{\phi_{i}}},
$$

where $\sigma_{\xi_{j}}$ and $\sigma_{\phi_{i}}$ denote the standard deviations of input and output, respectively. SRC are recommended measures for SA since they account not only for raw regression coefficients but also for standard deviations of both inputs and outputs and then provide a normalised measure of the importance of the input parameters on the response of the model [103]. Thus, SRC are the sensitivity measures considered through the present work.

\subsubsection{Probability of Failure}

The POF, which is a statistical indicator of the frequency of occurrence of a considered failure event, is mathematically defined as [106]:

$$
\mathrm{POF}=P\left[G\left(\xi_{j}\right) \leq 0\right]=\int_{G\left(\xi_{j}\right) \leq 0} f_{\xi_{j}}\left(\Xi_{j}\right) \mathrm{d} \Xi_{j},
$$

where $\xi_{j}, G\left(\xi_{j}\right)$ and $f_{\xi_{j}}\left(\Xi_{j}\right)$ represent the vector of input random variables, a limit state function and the joint probability density function of the input random variables, respectively. Therefore, $G\left(\xi_{j}\right) \leq 0$ refers to the region where the limit state violation occurs, i.e. the failure region. In general, equation (4.6) cannot be evaluated analytically, except for some special cases, but the POF can still be determined numerically. One of the existing techniques to compute this POF numerically is MC techniques and according to [106], for these techniques, the POF can be evaluated as:

$$
\mathrm{POF} \approx \frac{n\left[G\left(\hat{\xi}_{j} \leq 0\right)\right]}{N},
$$

where $n\left[G\left(\hat{\xi}_{j} \leq 0\right)\right]$ is the number of trials $n$ for which the limit state function is not satisfied, i.e. $G\left(\hat{\xi}_{j} \leq 0\right)$. In $(4.7), \hat{\xi}_{j}$ is used to represent a sample value of each random variable. 
As well known, the number of total trials $N$ determines the desired accuracy of the POF, which may be measured by the Coefficient of Variation $(\mathrm{CV})$ of the POF [107]:

$$
\mathrm{CV}_{P O F}=\sqrt{\frac{1-\mathrm{POF}}{N \cdot \mathrm{POF}}}
$$

Then, the larger $N$, the most accurate POF is but, in contrast, choosing large values of $N$ increases considerably the computational cost and, therefore, an agreement between accuracy and computation time must be reached. The value of $N$ used in the present work and the time needed to run these simulations is detailed in Section 4.4.1.

\subsection{Results}

This section summarises the results obtained from the probabilistic tool for both $\mathrm{Sn} @ \mathrm{SnO}_{2}$ and $\mathrm{Al} @ \mathrm{Al}_{2} \mathrm{O}_{3}$ nePCMs.

\subsubsection{Uncertainty analysis}

Two UA for two nePCMs - $\mathrm{Sn} @ \mathrm{SnO}_{2}$ and $\mathrm{Al} @ \mathrm{Al}_{2} \mathrm{O}_{3}-$ are conducted in order to obtain two outputs of the model (4.3):

i) The maximum Rankine's equivalent stress $\sigma_{R}$ distribution on the nePCM shell: $\phi_{1}=\sigma_{R}$, see Figure 4.3.

ii) The energy density $E_{d}$ of the nePCMs: $\phi_{2}=E_{d}$, see Figure 4.4.

Notice that these outputs are selected among others since they are key magnitudes in the design and optimisation of nePCMs for TES applications.

With regard to the equivalent stress distribution and in agreement with [85], Rankine's criterion is used to predict the mechanical failure of the nePCM, which usually occurs at the shell.

Figure 4.3 shows the histogram and the statistical scalar values (mean $\mu$ and standard deviation $\sigma$ ) after running the UA. As observed, these scalar values are $\mu=407.25(\mathrm{MPa}), \sigma=71.80(\mathrm{MPa})$ for $\mathrm{Sn}_{\mathrm{SnO}}$ and $\mu=1836.80(\mathrm{MPa}), \sigma=$ $250.62(\mathrm{MPa})$ for $\mathrm{Al} @ \mathrm{Al}_{2} \mathrm{O}_{3}$. Despite the fact that deterministic values do not exist in literature to validate these results, their tendency appear to be logical since larger values of stress are more likely to occur in $\mathrm{Al} @ \mathrm{Al}_{2} \mathrm{O}_{3}$. Notice that the melting temperature of the $\mathrm{Al}$ core is considerably higher than that of $\mathrm{Sn}$; consequently, larger thermal stresses are expected to arise in the $\mathrm{Al} @ \mathrm{Al}_{2} \mathrm{O}_{3}$ nePCMs to reach the liquid state of the core.

In order to measure the accuracy of the predicted $\sigma_{R}$, a bilateral Confidence Interval (CI) around the mean $\mu$ is defined as:

$$
\mathrm{CI}_{1-\alpha}=\mu \pm S E \cdot t_{\alpha, N-1},
$$

where $\alpha$ represents the risk -also called significance level- of the CI and $t_{N-1}$ is the Student's t-distribution with $N-1$ degrees of freedom. The Standard Error (SE) of $\mu$ is defined as: 


$$
\mathrm{SE}=\frac{\sigma}{\sqrt{N}}
$$

$\mathrm{Sn} @ \mathrm{SnO}_{2}$

$$
\mu=407.25 ; \quad \sigma=71.80(\mathrm{MPa})
$$

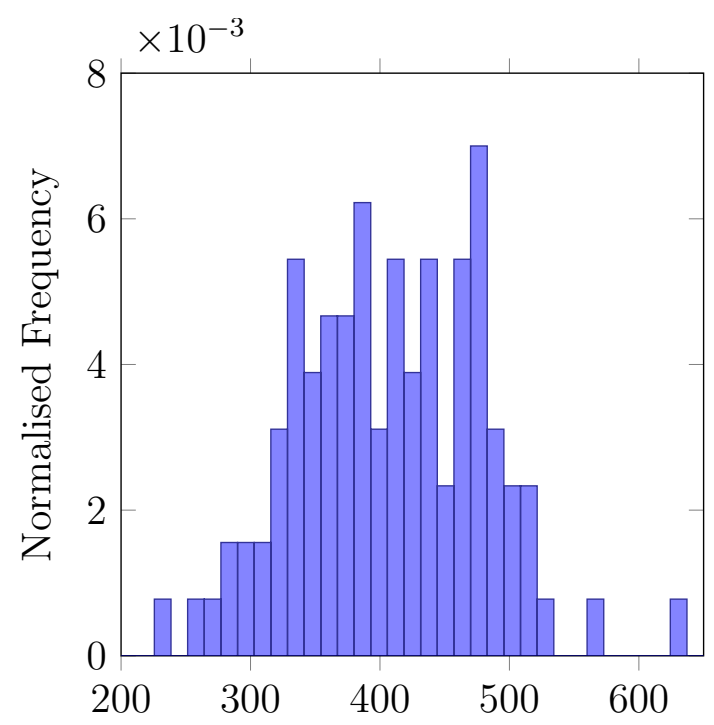

Rankine's equivalent stress $(\mathrm{MPa})$

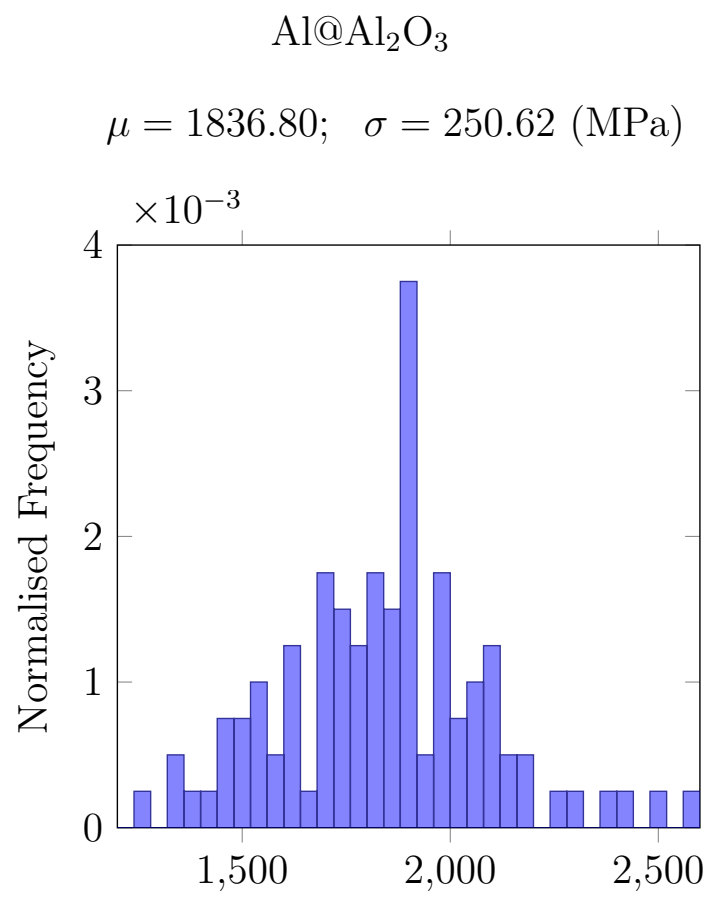

Rankine's equivalent stress (MPa)

Figure 4.3: Histogram of Rankine's equivalent stress for $\mathrm{Sn} @ \mathrm{SnO}_{2}$ nePCMs (left) and $\mathrm{Al}_{0} \mathrm{Al}_{2} \mathrm{O}_{3}$ nePCMs (right) with their respective mean value $\mu$ and standard deviation $\sigma$.

The CI for the equivalent stress at a significance level of $\alpha=5 \%$ is $\{393.03$, $421.47\}(\mathrm{MPa})$ for $\mathrm{Sn} @ \mathrm{SnO}_{2}$ nePCMs and $\{1787.17,1886.42\}$ (MPa) for $\mathrm{Al}_{\mathrm{A}} \mathrm{Al}_{2} \mathrm{O}_{3}$ nePCMs.

Regarding energy density $E_{d}$, which is a relevant magnitude for energy storage purposes, the metric used in the present work for its quantification is defined as:

$$
E_{d}=\rho_{l} L \frac{V_{\text {core }}}{V_{\text {total }}},
$$

where $V_{\text {core }}$ and $V_{\text {total }}$ denote the core and total volume of the nePCM, respectively.

Figure 4.4 represents the histogram and scalar values of $E_{d}$ for $\mathrm{Sn}_{\mathrm{SnO}}$ and $\mathrm{Al} @ \mathrm{Al}_{2} \mathrm{O}_{3}$ nePCMs. From (4.9), the $E_{d}$ for $\mathrm{Sn} @ \mathrm{SnO}_{2}$ nePCMs is found to lie in the confidence interval $C I_{0.95}=\{226.94,234.56\}\left(\mathrm{MJ} / \mathrm{m}^{3}\right)$ with $\mu=230.75\left(\mathrm{MJ} / \mathrm{m}^{3}\right)$, while for $\mathrm{Al} @ \mathrm{Al}_{2} \mathrm{O}_{3}, C I_{0.95}=\{518.43,534.81\}\left(\mathrm{MJ} / \mathrm{m}^{3}\right)$ with $\mu=526.62\left(\mathrm{MJ} / \mathrm{m}^{3}\right)$. From these results, it can be concluded that the energetic performance of $\mathrm{Al}$ nePCMs is better than that of $\mathrm{Sn}$ ones.

Two numerical verifications are performed: statistical and convergence tests. On the one hand, the Jarque-Bera test [108] is used to determine if the null hypothesis -a data sample comes from a normal distribution at a certain significance level- is accepted. The Jarque-Bera test is applied to both $\sigma_{R}$ and $E_{d}$ and it is found that both distributions and both pairs of core@shell materials are normally distributed at a significance level of $1 \%$. Notice that the linearity assumption is not obvious since the present probabilistic analysis combines normal and log-normal distributions. 

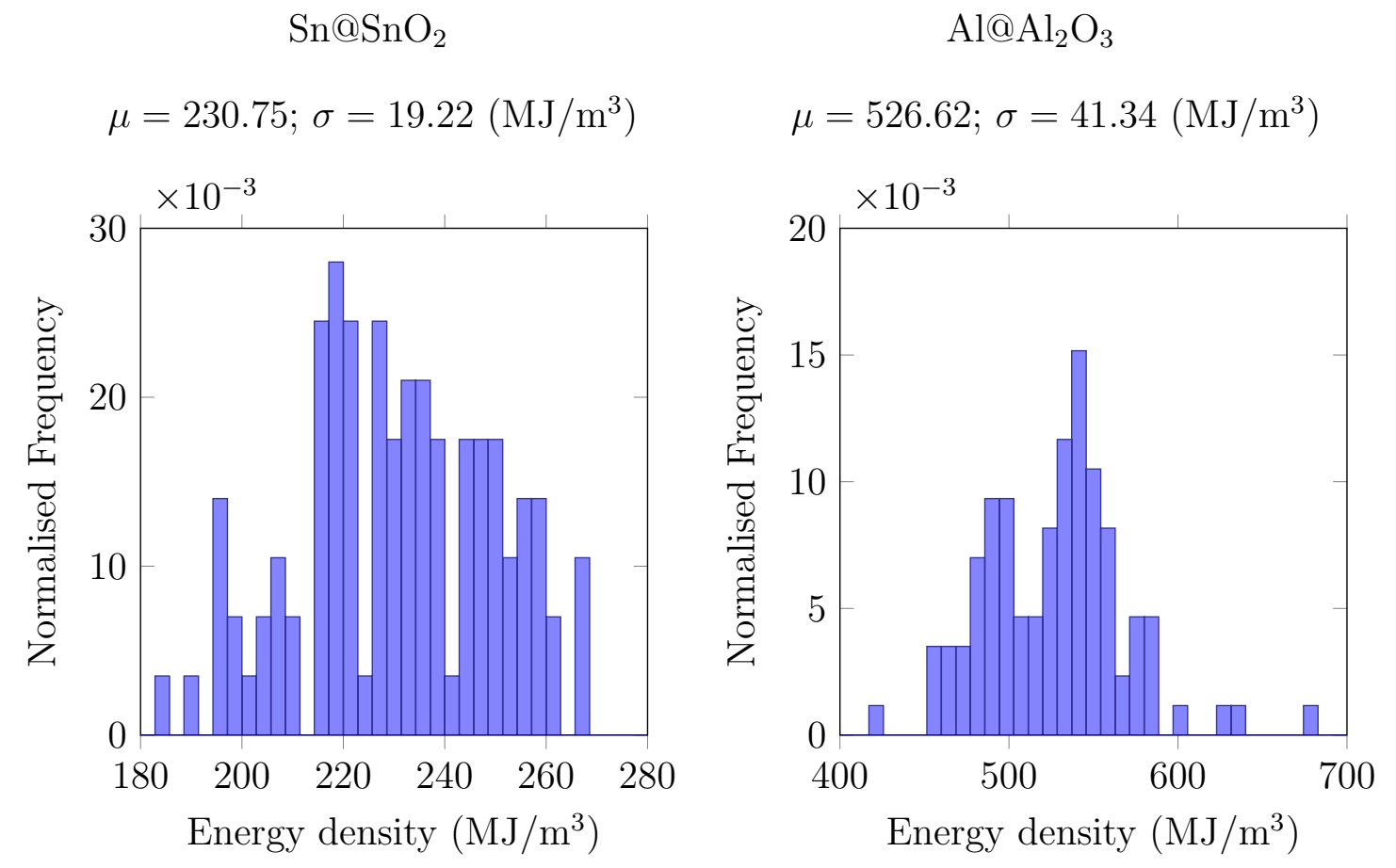

Figure 4.4: Histogram of energy density for $\mathrm{Sn} @ \mathrm{SnO}_{2}$ nePCMs (left) and $\mathrm{Al} @ \mathrm{Al}_{2} \mathrm{O}_{3}$ nePCMs (right) with their respective mean value $\mu$ and standard deviation $\sigma$.
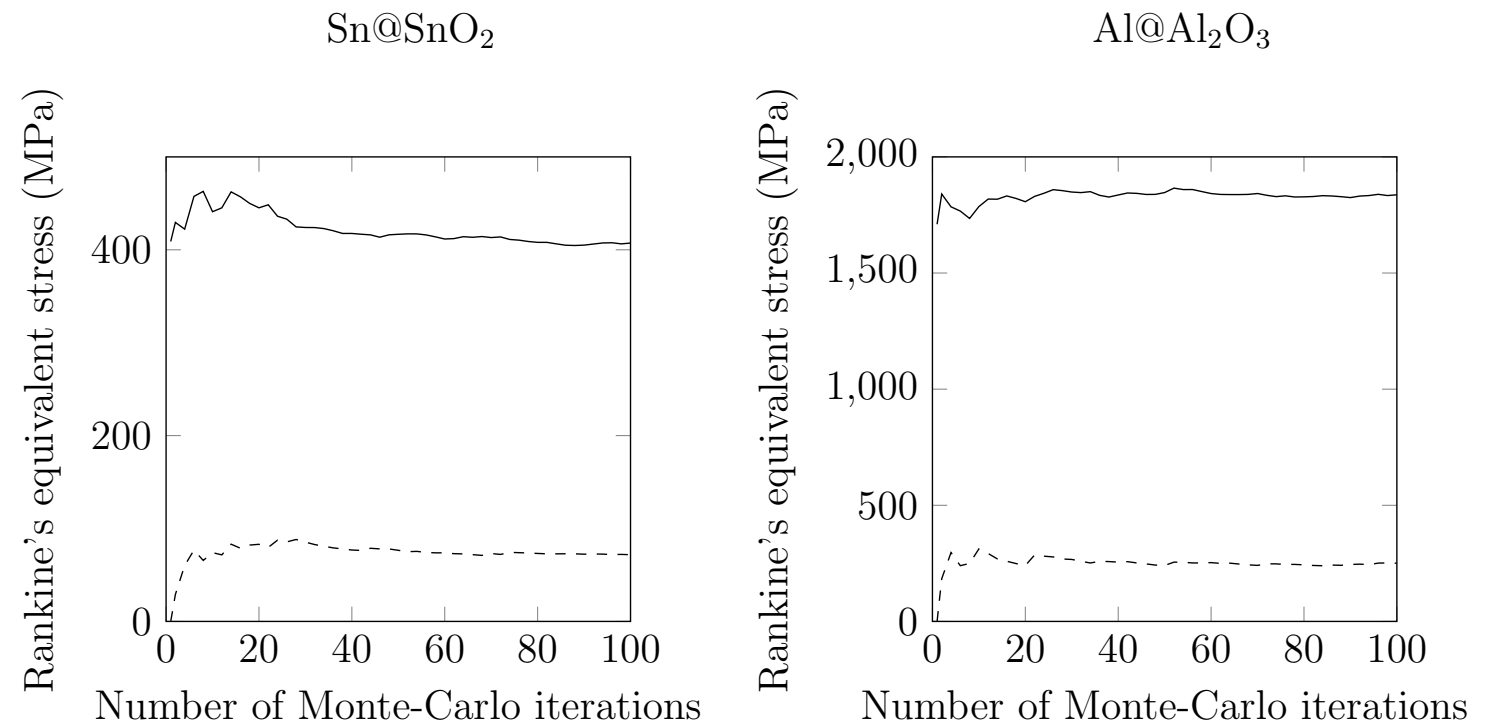

\section{- - - Averaged Standard Deviation $\sigma$ of Rankine's stress}

Figure 4.5: Convergence of Monte Carlo simulation.

On the other hand, the sample size $N$ to guarantee a proper convergence of the $\mathrm{MC}$ is performed by a trial and error numerical test since obtaining a general analytic expression to pre-calculate $N$ for convergence of MC simulations is difficult or even impossible for complex models. The numerical test consists of representing the average evolution of $\mu$ and $\sigma$ versus the number of iterations, as observed in Figure 4.5. From this figure, it can be concluded that the numerical simulation 
converges for $N=100$ iterations and that is the value used through the present work. For this sample size, the computational time is approximately 14 hours for a PC with a processor Intel ${ }^{\circledR}$ Core $^{\text {TM }} \mathrm{i} 7-950$ and 16 GB of RAM.

\subsubsection{Sensitivity analysis}

A multiple linear regression is performed to develop the SA in order to calculate the influence of the random variables $\xi_{j}$ on the $\sigma_{R}$ for both $\mathrm{Sn} @ \mathrm{SnO}_{2}$ and $\mathrm{Al} @ \mathrm{Al}_{2} \mathrm{O}_{3}$ nePCMs. This influence is shown in Figure 4.6 by a bar diagram for the different absolute values of the SRC, see notation in Table 4.1.

\section{$\mathrm{Sn} @ \mathrm{SnO}_{2}$}
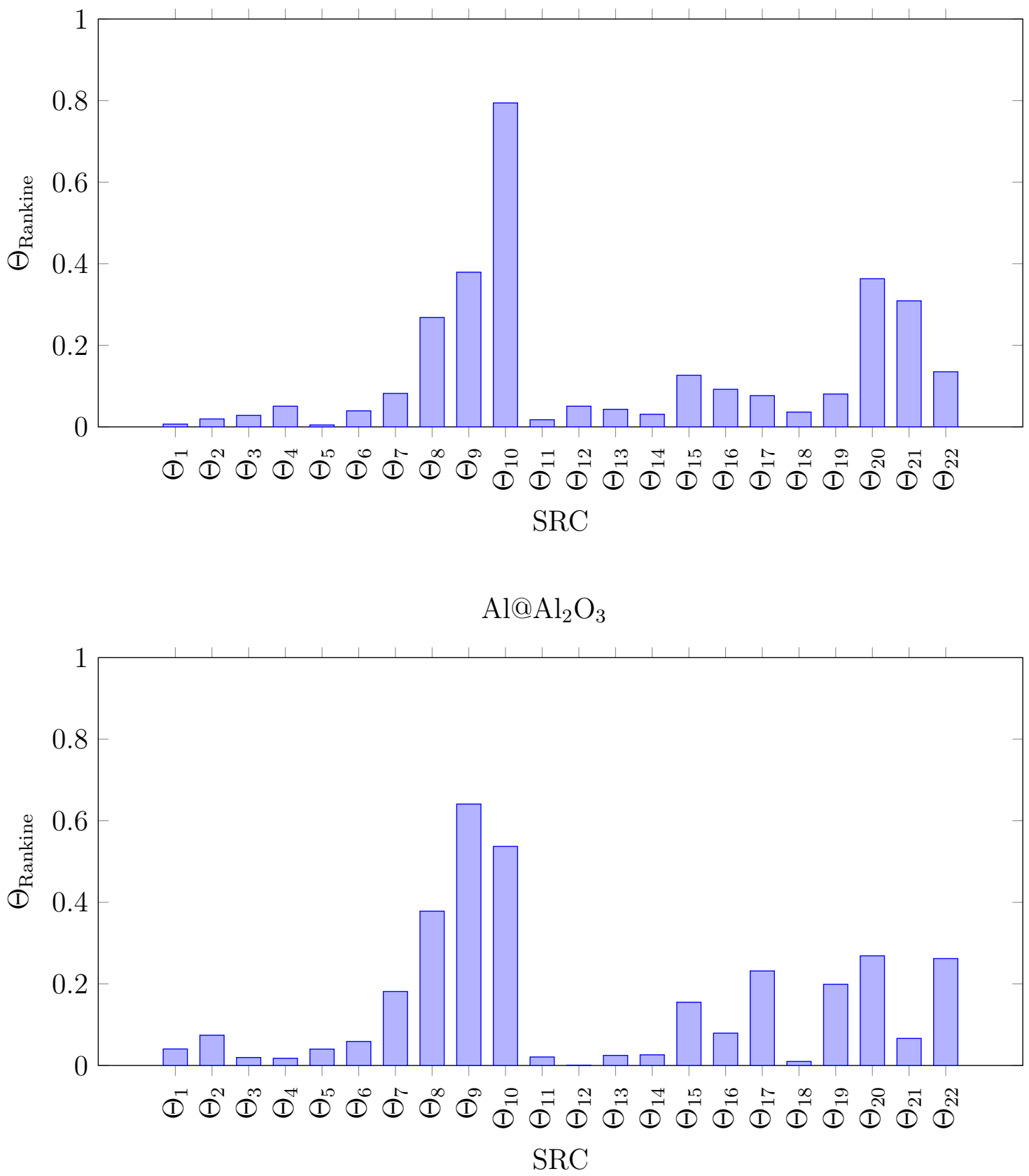

Figure 4.6: Standardized Regression Coefficients (SRC) in absolute value for $\mathrm{Sn}_{\mathrm{S}} \mathrm{SnO}_{2}$ (top) and $\mathrm{Al} @ \mathrm{Al}_{2} \mathrm{O}_{3}$ (bottom) nanoencapsulated phase change materials. Notation in Table 4.1. 
Firstly, the SRC values obtained for each nePCM are not the same given that the material properties are different. However, the same tendency may be observed in both of bar diagrams.

Secondly, the most relevant random values appear to be $\Theta_{8}, \Theta_{9}$ and $\Theta_{10}$, which represent the Poisson's ratio of the core, the thermal expansion coefficient of the core and its melting temperature, respectively. These results seem to be in good agreement with physical intuition: the latter plays a direct role in the maximum value of stress reached until the melting of the core, and the thermal expansion coefficient and the Poisson's ratio are parameters that mechanically govern the volumetric changes in nePCMs.

Thirdly, the next set of parameters having more influence on the failure are the geometrical ones: $\Theta_{19}, \Theta_{20}, \Theta_{21}$ and $\Theta_{22}$. The three first parameters stand for the semi-axes of the ellipsoidal nePCM and the last one represents the shell thickness. The difference in values between $\mathrm{Sn} @ \mathrm{SnO}_{2}$ and $\mathrm{Al} @ \mathrm{Al}_{2} \mathrm{O}_{3}$ nePCMs for the SRC of the three semi-axes in Figure 4.6 is not very significant and could be influenced by randomness in the generation of the random samples.

Finally and since multiple linear regression is applied for this sensitivity analysis, the validity of the hypothesis of linearity must hold true for the results to be acceptable. In order to verify the validity of the SA, the coefficients of determination of the linear regression are $R_{S n}^{2}=0.93$ and $R_{A l}^{2}=0.92$ for the $\mathrm{Sn} @ \mathrm{SnO}_{2}$ and $\mathrm{Al}_{\mathrm{A}} \mathrm{Al}_{2} \mathrm{O}_{3}$, respectively. According to $[109,110]$, as long as the coefficient of determination verifies $R^{2} \geq 0.7$, the linearity hypothesis is satisfied and thus, the present $\mathrm{SA}$ is valid as well.

Notice that the random variables $\xi_{j}$ exerting a major influence on $E_{d}$ can be directly determined from its definition in Equation (4.11) without need of performing a SA. Therefore, the latent heat of the core, the mass density of the liquid core and the geometrical parameters are the variables that have a more relevant impact on $E_{d}$.

\subsubsection{Probability of failure of nePCMs}

In this section, the POF of $\mathrm{Sn} @ \mathrm{SnO}_{2}$ and $\mathrm{Al} @ \mathrm{Al}_{2} \mathrm{O}_{3}$ nePCMs is calculated by using both deterministic and probabilistic failure criteria:

- The deterministic criterion consists of using a tensile strength $\sigma_{t}$ value from literature and studying its position with respect to the $\sigma_{R}$ distribution obtained from the probabilistic simulations.

- The probabilistic criterion is grounded on the uncertainty in the measure of $\sigma_{t}$, resulting in a tensile strength distribution. According to (4.8), by considering a probabilistic criterion to compute the POF, the accuracy of the MC simulation is increased by a factor $\sqrt{N}$-a factor of 10 in the present simulations. Notice that this motivates the need for considering a probabilistic failure criterion.

Concerning $\mathrm{Sn} @ \mathrm{SnO}_{2}$ nePCMs, $\sigma_{t}=803(\mathrm{MPa})$ is assumed for $\mathrm{SnO}_{2}$ [74] for the deterministic case. According to [74], the tensile strength of $\mathrm{SnO}_{2}$ may suffer from fluctuations due to its porosity, which is a hard to control parameter when synthesising nePCMs. Consequently, $\sigma_{t}$ is assumed to be normally distributed with a $20 \%$ of dispersion around $\sigma_{t}=803(\mathrm{MPa})$ for the probabilistic criterion. 


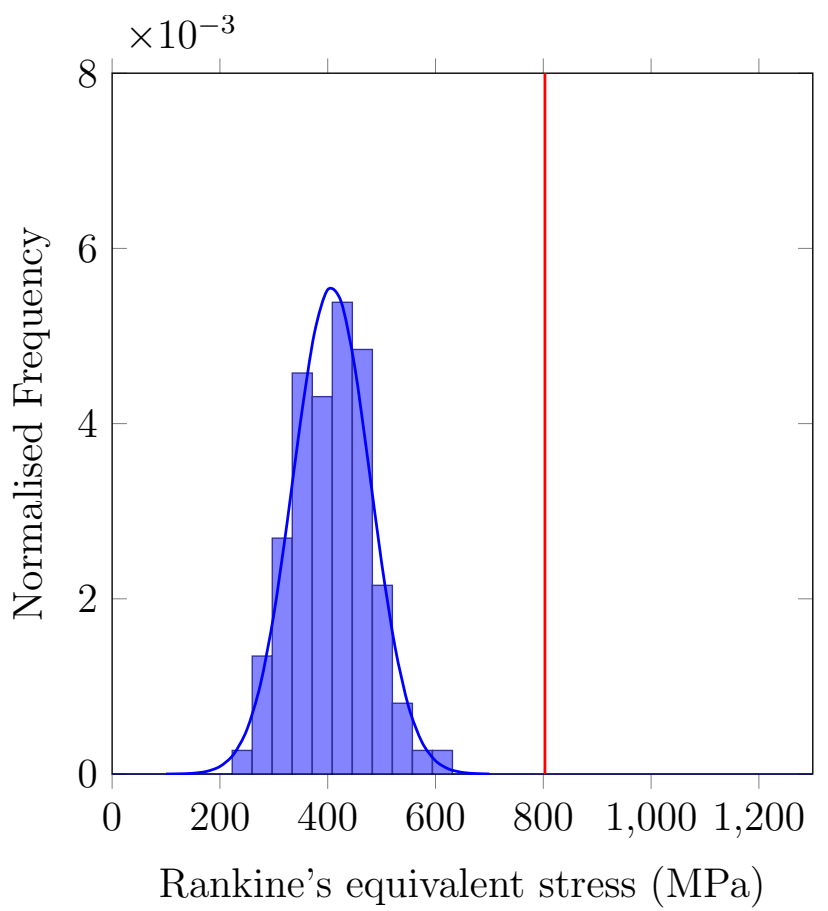

Distribution of Rankine's stress - Fitting of Rankine's stress
Deterministic failure

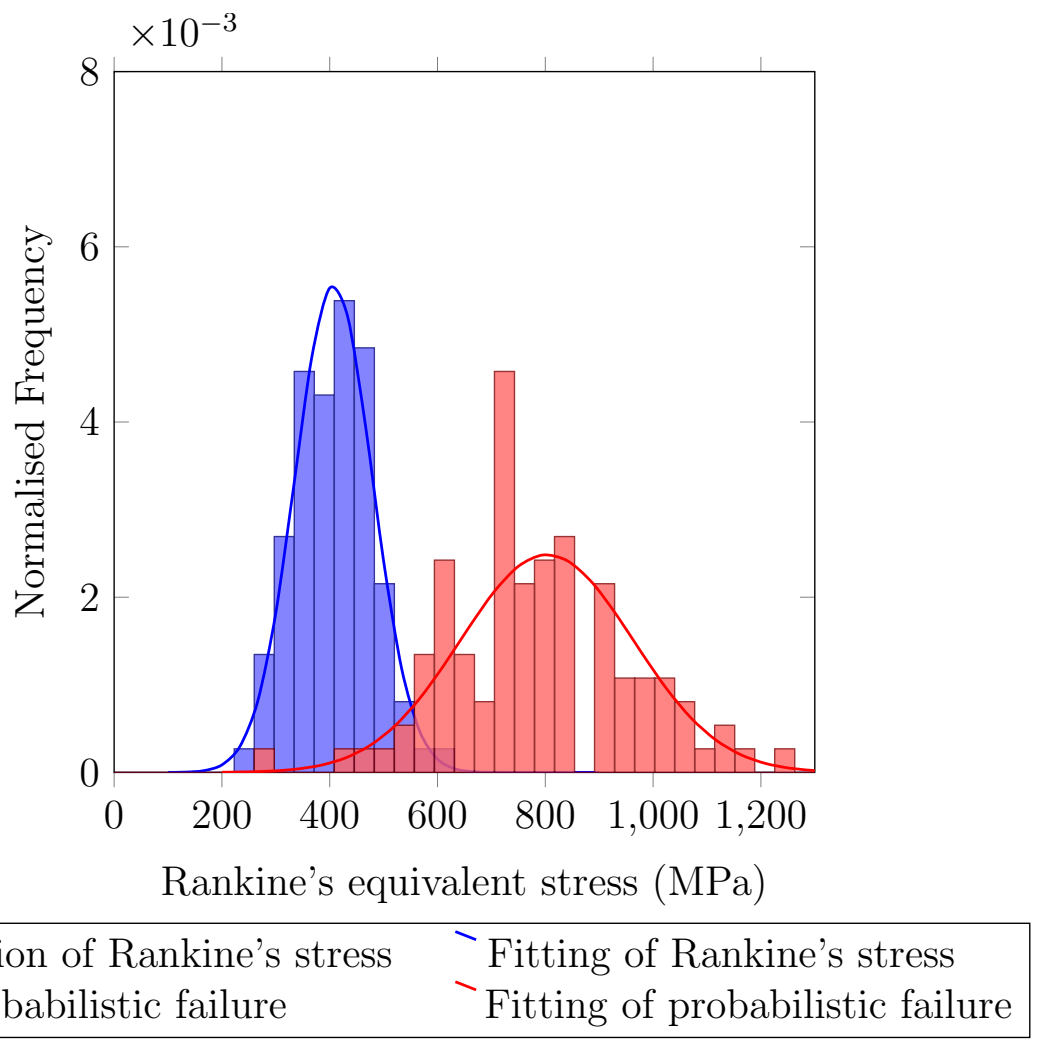

Figure 4.7: Deterministic (top) and probabilistic (bottom) failure criteria compared against the maximum Rankine's equivalent stress obtained from Monte Carlo simulation for $\mathrm{Sn}_{\mathrm{SnO}} \mathrm{Sn}_{2}$ nanoencapsulated phase change materials. 


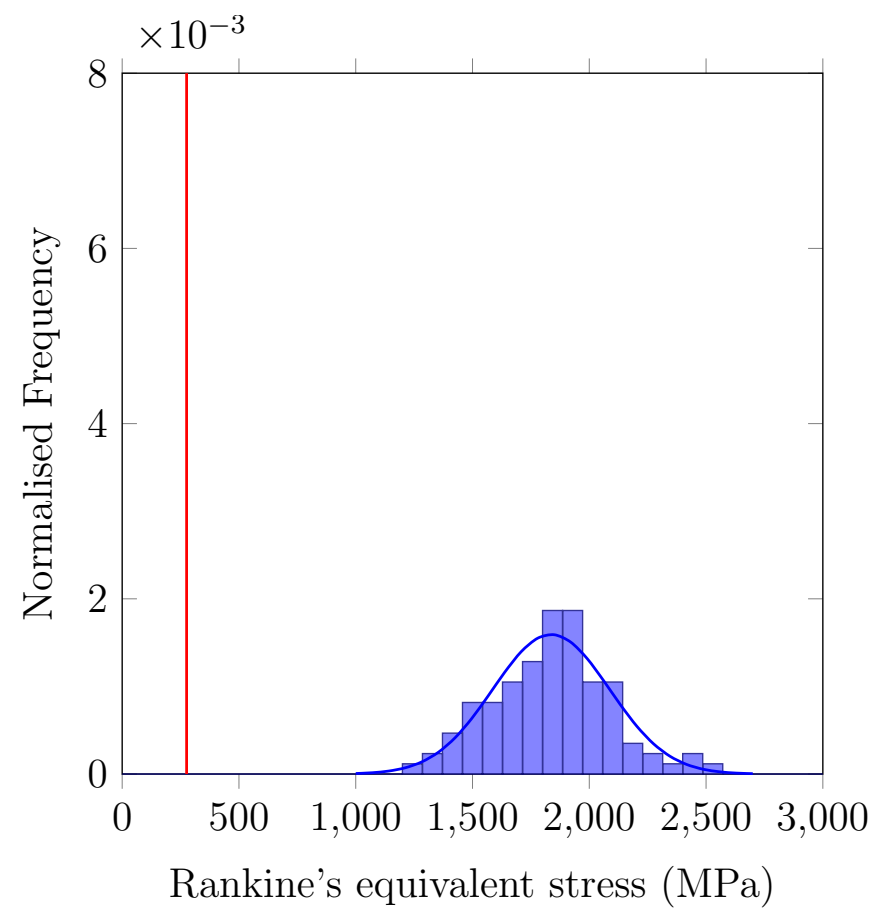

Distribution of Rankine's stress - Fitting of Rankine's stress
Deterministic failure

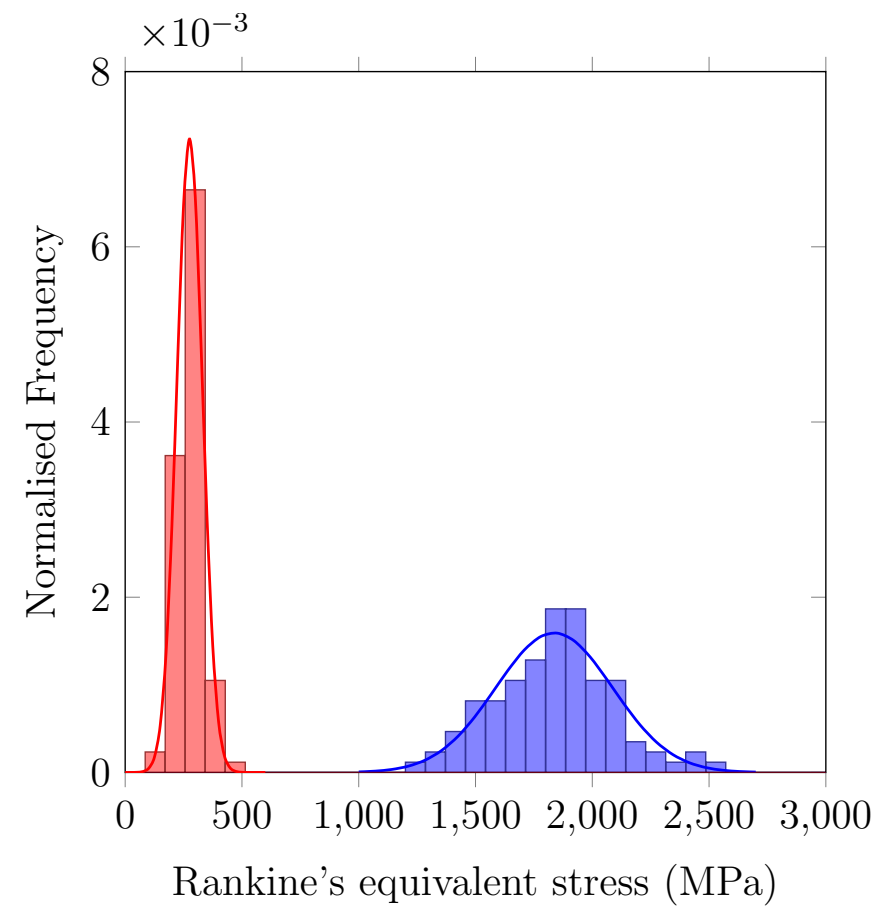

$\square$ Distribution of Rankine's stress - Fitting of Rankine's stress Probabilistic failure Fitting of probabilistic failure

Figure 4.8: Deterministic (top) and probabilistic (bottom) failure criteria compared against the maximum Rankine's equivalent stress obtained from Monte Carlo simulations for $\mathrm{Al}_{2} \mathrm{Al}_{2} \mathrm{O}_{3}$ nanoencapsulated phase change materials. 
Figure 4.7 shows the $\sigma_{R}$ distribution for both deterministic (top) and probabilistic (bottom) criteria. For the deterministic criterion, $\sigma_{R}$ falls below the deterministic $\sigma_{t}$ and, consequently, the POF of $\mathrm{Sn} @ \mathrm{SnO}_{2}$ is $0 \%$ : any nePCM is expected to fail.

On the contrary and for the probabilistic criterion, it can be observed that there is an overlap between the Gaussian curve of the $\sigma_{R}$ distribution and that of the probabilistic $\sigma_{t}$. This overlapping region represents the area in the graph where the nePCMs are likely to fail mechanically. In this case, the POF becomes $1.87 \%$ and this means that it is advisable to account for these type of criterion, especially when dispersion in tensile strength exists.

It is important to highlight that the present results are in accordance with the experimental observations reported in [17], given that only small samples of $\mathrm{Sn} @ \mathrm{SnO}_{2}$ nePCMs were verified to fail mechanically due to thermal stresses.

With regard to $\mathrm{Al} @ \mathrm{Al}_{2} \mathrm{O}_{3}$ nePCMs, to the best author's knowledge, experimental data on the mechanical failure of $\mathrm{Al} @ \mathrm{Al}_{2} \mathrm{O}_{3}$ nePCMs is not available in the literature. In the present work, $\sigma_{t}=275.9(\mathrm{MPa})$ [98] with a Gaussian dispersion of $20 \%$ is considered, as in the previous case.

Figure 4.8 shows the distribution of the $\sigma_{R}$ with the deterministic (top) and the probabilistic (bottom) failure criteria. For this material, the POF predicted for both deterministic and probabilistic criteria is $100 \%$ since the distribution of $\sigma_{R}$ obtained is far above the tensile strength.

In conclusion, despite the fact that $\mathrm{Al} @ \mathrm{Al}_{2} \mathrm{O}_{3}$ nePCMs possess larger energy density storage capabilities than $\mathrm{Sn} @ \mathrm{SnO}_{2}$ nePCMs, the first ones are likely to fail mechanically when they undergo heating cycles.

\subsection{Conclusions}

This chapter has presented a numerical tool, which combines Monte Carlo techniques and a thermomechanical finite element with phase change, in order to conduct probabilistic analyses - uncertainty, sensitivity and reliability- in nanoencapsulated phase change materials (nePCMs). In particular, experimental uncertainties are taken into account to obtain the mechanical probability of failure and this mechanical failure is one of the problems experimentally encountered when the nePCMs undergo thermal processes. In addition, the sensitivity analysis has allowed to quantify the parameters that exert the most significant influence on the mechanical failure of nePCMs. Consequently, these relevant parameters should be closely controlled in the synthesis of nanoparticles.

Specifically, the present work has considered 22 random parameters -18 material properties and 4 geometrical parameters- and has studied the evolution of two variables - Rankine's equivalent stress and energy density - for two nePCMs: Sn@SnO 2 and $\mathrm{Al} @ \mathrm{Al}_{2} \mathrm{O}_{3}$. Firstly and from the sensitivity analysis, it has be concluded that the melting temperature, thermal expansion coefficient and Poisson's rate exert the more relevant influence on the mechanical failure of the nanoparticle shell. In turn, the most influential parameters on the energy density capability of nePCMs are the latent heat of the core, the mass density of the liquid core and the geometrical parameters of the nePCM. Secondly, it has been concluded that the probabilistic failure is $1.87 \%$ and $100 \%$ for $\mathrm{Sn} @ \mathrm{SnO}_{2}$ and $\mathrm{Al} @ \mathrm{Al}_{2} \mathrm{O}_{3}$ nePCMs, respectively. The results 
of the former are verified to be in good agreement with experimental observations while, to the author's knowledge, no data is available for the latter ones.

To sum up, the numerical probabilistic tool allows to estimate the probability of failure of the nePCMs and to determine the parameters having a bigger influence on the failure and energy storage of nePCMs. Therefore, this numerical tool could be used to complement experimental research and to reduce the number of experiments to be conducted to optimise the selection of a pair of core and shell nePCMs by maximising the energy density and by minimising the probability of the failure of the shell. 



\section{Chapter 5: Numerical modelling of the mechanical reliability of multi- coated nanoencapsulated phase change materials with improved thermal per- formance}

Nanoencapsulated phase change materials (nePCMs), which are composed of a phase change material core confined within a shell, are being investigated for enhancing thermal energy storage facilities. However, one of the issues that arises with these nanocapsules is that their shell may fail due to stresses developed during thermal processes, which leads to losses of phase change enthalpy in nePCMs. In order to overcome this problem, multi-coated nePCMs were synthesised by atomic layer deposition (ALD), which enables nanoscale coatings to be deposited on nanoparticles; namely, $\mathrm{SiO}_{2}$ and $\mathrm{Al}_{2} \mathrm{O}_{3}$ coatings on $\mathrm{Sn}$ nanoparticles. With the aim of studying the influence of both shell thickness and composition on the probability of failure of nePCM shells, a probabilistic numerical tool, combining Monte Carlo techniques and a thermomechanical finite element model with phase change, is used to systematically assess the mechanical performance of single-and multi-coated nePCMs. The uncertainties of material and geometrical properties of nePCMs are included into the numerical analysis. Both deterministic and probabilistic failure criteria are also taken into account to consider the effect of dispersion in tensile strength. Finally, Rankine's criterion is used to compute the equivalent stress on shells. The results of this study indicate that multi-coated nePCMs present an enhanced thermal and mechanical performance in relation to their single-coated counterparts and both numerical simulations and experiments confirm that the probability of failure of nePCM shells and the losses in phase change enthalpy in multi-coated nePCMs decrease with the shell thickness, that is directly related to the number of applied ALD cycles. The obtained results indicate that $\mathrm{Al}_{2} \mathrm{O}_{3}$ coatings exhibit a better mechanical and thermal performance than their $\mathrm{SiO}_{2}$ counterparts. 


\subsection{Introduction}

One of the most active research fields today is that of energy conversion, which falls within the context of energy transition from conventional energy sources to renewable energies. From the wide variety of existing renewable energies, a special mention is deserved by solar energy since it represents a reliable and massive energy source. More concretely, and according to the International Energy Agency [6], it is estimated that the Sun takes a little more than two hours to send the necessary amount of energy to meet our planet's annual energy needs by 2035. However, one of the main drawbacks of solar energy is that energy generation is subjected to weather/climate conditions. This unpredictability may cause a mismatch between energy demand and supply, which could entail instability issues for the electrical grid's operation. For this reason, thermal energy storage (TES) systems are particularly important.

In the solar thermal energy context, nanofluids based on molten salts are one of the technologies under study for TES purposes in concentrated solar power (CSP) plants [39]. Nanofluids consist of solid nano-sized particles dispersed in a base fluid [11]. Their ability to store energy traditionally relied on their sensible storage capability, which is limited by the heat capacity and temperature difference undergone by the storage medium. More recently, phase change materials (PCMs) have been used as the solid component of nanofluids to boost its energy storage capability by means of the contribution of the latent heat storage $[15,16]$. However, in order to prevent these PCMs from leaking when molten, they need to be confined within a shell made of a material with a higher melting point than the PCM core. If PCMs fall within the nanometric size range, they receive the name of nanoencapsulated phase change materials (nePCMs). Normally, metallic nanoparticles (NPs) are selfencapsulated by a native oxide layer formed by passivation (metal@metal_oxide), which is not always sufficient to avoid leakage of molten core of nePCMs $[17,18]$.

When going through thermal processes, nanofluids containing nePCMs tend to partially or totally lose the nePCMs phase change enthalpy. The mechanical failure of nePCM shells due to stresses arising during thermal processes has been proposed as one of the causes of such enthalpy loss. Recently, a solution proposed to overcome this issue consisted in creating a multi-coated nePCM, by synthesising a second shell by the cutting-edge technique of atomic layer deposition (ALD) [111]. This technique involves the cyclical exposure of the self-encapsulated nePCMs to two different gas precursors that chemisorb on the available nePCM surface for it to grow an additional inorganic shell with thickness control at the sub-nanometer level by tuning of the number of cycles [112]. ALD of $\mathrm{SiO}_{2}$ and $\mathrm{Al}_{2} \mathrm{O}_{3}$ nanoscale films allowed to improve the thermal energy storage of nePCMs by reducing the enthalpy loss of cores.

The main challenge in the synthesis of single- and multi-coated nePCMs lies in determining the optimal shell thickness confining the core of the nePCMs, since a compromise between mechanical reliability and energy storage has to be reached, which can contribute to reduce the coating cost of nePCMs and to gain control over colloidal stability of nanofluids. Increasing the shell thickness of nePCMs enhances the mechanical strength of the shell but reduces the energy storage density of neP$\mathrm{CMs}$, since the shell material does not contribute to latent heat storage. Besides, increasing the overall nePCM size to enhance the energy density capability of the nanofluid may jeopardise its colloidal stability and cause settling of particles. There- 
fore, understanding the reasons behind the mechanical failure of the nePCM shell is necessary. In this vein, a thermomechanical finite element (FE) model with phase change was developed in a previous work [113] to predict the failure of the nePCM shells during thermal processes. Experimental measurements and characterisation of nePCMs are not exempt from uncertainties, which are intrinsically related to the nature of the measurement process. Therefore, it is of crucial importance to verify the influence that the dispersion in material properties and geometrical parameters of nePCMs can have on their mechanical reliability. Then, the consideration of these uncertainties demonstrates the need to adopt a probabilistic numerical tool to predict the behaviour of nePCMs, as shown in the literature $[114,115]$. For this reason, the thermomechanical phase change FE model is combined with Monte Carlo (MC) techniques, a class of algorithms that use statistically generated samples to approach the solution of a model in a probabilistic sense. These samples are the model's input and the outputs are obtained through evaluation of the FE model.

The objective of the present work consists in obtaining two parameters: the mechanical reliability of multi-coated nePCMs and their loss of enthalpy; with the aim of analysing the effect of adding a second nanoencapsulating coating, the influence of its thickness on both parameters and the possible relationship between them. Specifically, coatings were experimentally synthesised to obtain multi-coated (core@inner_shell@outer_shell materials)nePCMs: Sn@SnO ${ }_{2} @ \mathrm{SiO}_{2}$ and $\mathrm{Sn} @ \mathrm{SnO} @$ $\mathrm{Al}_{2} \mathrm{O}_{3}$ [111]. To achieve this aim, the probabilistic tool combining MC methods and the FE thermomechanical model is used. For the numerical simulations, 30 random variables are defined to characterise the behaviour of the multi-coated nePCMs and the samples are generated by the Latin Hypercube Sampling (LHS) technique [95]. Concerning the reliability analysis, both deterministic and probabilistic failure criteria are considered to also account for the influence of dispersion in tensile strength of the materials forming the shells of the nePCMs and Rankine's criterion is used to compute the equivalent stress in these shells.

\subsection{Materials and methods}

\subsubsection{Materials}

Commercial Sn nanoparticles of nominal size $<300 \mathrm{~nm}$ were purchased from US Research Nanomaterials, Inc. These nanoparticles were produced by the electrophysical fumed combined with strong airflow injection method and were morphologically, chemically and thermally characterised in previous studies $[17,111]$. Experimental results showed self-encapsulated $\mathrm{Sn} @ \mathrm{SnO}$ nePCMs with a mean diameter of $180 \mathrm{~nm}$.

Regarding the ALD process, the Al precursor, trimethylaluminum (TMA), was purchased from Akzo Nobel HPMO in a $600 \mathrm{~mL}$ stainless steel bubbler canister. The Si precursor, silicon tetrachloride $\left(\mathrm{SiCl}_{4}\right)$, was purchased from Sigma-Aldrich. Demineralised water was used as a coreactant for both $\mathrm{SiO}_{2}$ and $\mathrm{Al}_{2} \mathrm{O}_{3}$ ALD. All the precursors were contained in stainless steel bubblers and used as received.

Coatings were synthesised by ALD in a fluidised bed reactor [116] starting from $\mathrm{Sn} @ \mathrm{SnO}$ nePCMs to obtain two different multi-coated nePCMs: $\mathrm{Sn} @ \mathrm{SnO}_{2} @ \mathrm{SiO}_{2}$ and $\mathrm{Sn} @ \mathrm{SnO} @ \mathrm{Al}_{2} \mathrm{O}_{3}$ after 5, 25 and 50 ALD cycles. Table 5.1 shows the evolution of shell thickness of multi-coated nePCMs with the increasing number of ALD cycles. 
These values of shell thickness are determined from the values of growth per cycle (GPC) reported in the work by Navarrete et al. [111] by assuming that the deposition rate was linear. The chemical characterisation of the samples by X-ray diffraction confirmed the existence of two different oxidation states of $\mathrm{Sn}$ in the passivation layer (inner shell) of these multi-coated nePCMs. The characterisation of the nePCMs and the synthesis of their coating by ALD is further detailed in the same previous work [111].

Table 5.1: Summary of shell thickness combinations with respect to the number of atomic layer

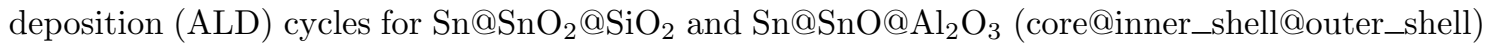
nanoencapsulated phase change materials.

\begin{tabular}{c|c|c}
\multirow{2}{*}{$\begin{array}{c}\text { Number of } \\
\text { ALD cycles }\end{array}$} & \multicolumn{2}{|c}{ Shell thickness } \\
\cline { 2 - 3 } & $\mathbf{S n @ S n O} \mathbf{S n}_{2} @ \mathbf{S i O}_{2}$ & $\mathbf{S n} @ \mathbf{S n O} @ \mathrm{Al}_{2} \mathbf{O}_{3}$ \\
\hline \multirow{2}{*}{5} & $\mathrm{e}_{\mathrm{SnO}_{2}}=12 \mathrm{~nm}$ & $\mathrm{e}_{\mathrm{SnO}}=12 \mathrm{~nm}$ \\
& $\mathrm{e}_{\mathrm{SiO}_{2}}=0.8 \mathrm{~nm}$ & $\mathrm{e}_{\mathrm{Al}_{2} \mathrm{O}_{3}}=1 \mathrm{~nm}$ \\
\hline \multirow{2}{*}{25} & $\mathrm{e}_{\mathrm{SnO}_{2}}=12 \mathrm{~nm}$ & $\mathrm{e}_{\mathrm{SnO}}=12 \mathrm{~nm}$ \\
& $\mathrm{e}_{\mathrm{SiO}_{2}}=4 \mathrm{~nm}$ & $\mathrm{e}_{\mathrm{Al}_{2} \mathrm{O}_{3}}=5 \mathrm{~nm}$ \\
\hline \multirow{2}{*}{50} & $\mathrm{e}_{\mathrm{SnO}_{2}}=12 \mathrm{~nm}$ & $\mathrm{e}_{\mathrm{SnO}}=12 \mathrm{~nm}$ \\
& $\mathrm{e}_{\mathrm{SiO}_{2}}=8 \mathrm{~nm}$ & $\mathrm{e}_{\mathrm{Al}_{2} \mathrm{O}_{3}}=10 \mathrm{~nm}$
\end{tabular}

$\mathrm{Sn} @ \mathrm{SnO}$ and multi-coated $\mathrm{Sn} @ \mathrm{SnO}_{2} @ \mathrm{SiO}_{2}$ and $\mathrm{Sn} @ \mathrm{SnO} @ \mathrm{Al}_{2} \mathrm{O}_{3}$ nePCMs synthesised by 50 ALD cycles were imaged by field emission transmission electron microscopy (TEM). In Figure 5.1, two distinct shells can be clearly observed for each multi-coated nePCM.
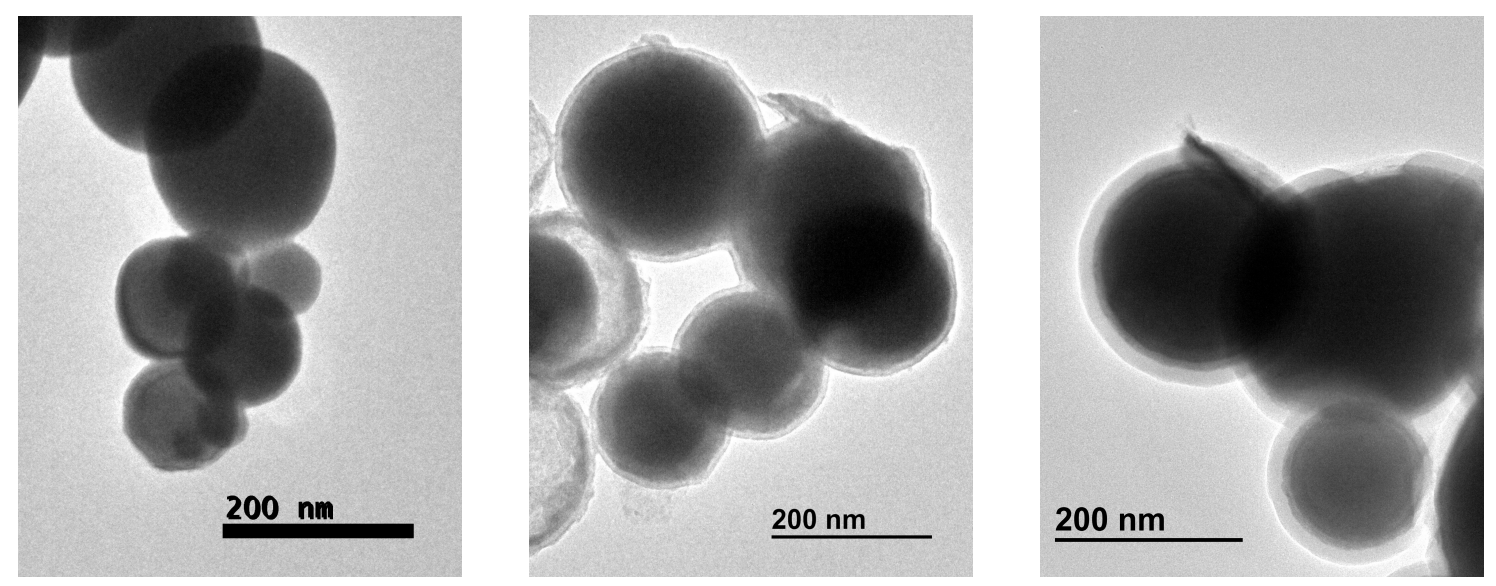

Figure 5.1: TEM images of $\mathrm{Sn} @ \mathrm{SnO}$ (left) and multi-coated $\mathrm{Sn} @ \mathrm{SnO}_{2} @ \mathrm{SiO}_{2}$ (centre) and $\mathrm{Sn} @ \mathrm{SnO} @ \mathrm{Al}_{2} \mathrm{O}_{3}$ (right) nePCMs synthesised by ALD technique after 50 cycles. 
Table 5.2: $\quad$ Summary of material and geometrical properties for $\mathrm{Sn}_{\mathrm{SnO}} \mathrm{Sn}_{2} \mathrm{SiO}_{2}$ (core@inner_shell@outer_shell) nanoencapsulated phase change materials (nePCMs). $\sigma$ is the standard deviation for each of the properties with respect to their mean values.

\begin{tabular}{|c|c|c|c|c|}
\hline & Property & Values & Units & $\boldsymbol{\sigma}(\%)$ \\
\hline \multirow{11}{*}{ Core (Sn) } & $\rho_{s}$ & 7280 & $\mathrm{~kg} / \mathrm{m}^{3}$ & 5 \\
\hline & $\rho_{l}$ & 6800 & $\mathrm{~kg} / \mathrm{m}^{3}$ & 5 \\
\hline & $c_{s}$ & 230 & $\mathrm{~J} /(\operatorname{kg~K})$ & 5 \\
\hline & $c_{l}$ & 257 & $\mathrm{~J} /(\operatorname{kg~K})$ & 5 \\
\hline & $\kappa_{s}$ & 65 & $\mathrm{~W} /(\mathrm{m} \mathrm{K})$ & 5 \\
\hline & $\kappa_{l}$ & 31 & $\mathrm{~W} /(\mathrm{m} \mathrm{K})$ & 5 \\
\hline & $E$ & 43.3 & $\mathrm{GPa}$ & 5 \\
\hline & $\nu$ & 0.33 & - & 5 \\
\hline & $\alpha^{\prime}$ & $2 \times 10^{-5}$ & $1 / \mathrm{K}$ & 5 \\
\hline & $T_{m}$ & 498.65 & $\mathrm{~K}$ & 5 \\
\hline & $L$ & 60.627 & $\mathrm{~kJ} / \mathrm{kg}$ & 5 \\
\hline \multirow{7}{*}{ Inner Shell $\left(\mathrm{SnO}_{2}\right)$} & $\rho$ & 7020 & $\mathrm{~kg} / \mathrm{m}^{3}$ & 5 \\
\hline & $c$ & 348.95 & $\mathrm{~J} /(\operatorname{kg~K})$ & 5 \\
\hline & $\kappa$ & 40 & $\mathrm{~W} /(\mathrm{m} \mathrm{K})$ & 5 \\
\hline & $E$ & 222.72 & $\mathrm{GPa}$ & 5 \\
\hline & $\nu$ & 0.284 & - & 5 \\
\hline & $\alpha^{\prime}$ & $4 \times 10^{-6}$ & $1 / \mathrm{K}$ & 5 \\
\hline & $T_{m}$ & 1900 & $\mathrm{~K}$ & 5 \\
\hline \multirow{7}{*}{ Outer Shell $\left(\mathrm{SiO}_{2}\right)$} & $\rho$ & 2200 & $\mathrm{~kg} / \mathrm{m}^{3}$ & 5 \\
\hline & $c$ & 962.86 & $\mathrm{~J} /(\mathrm{kg} \mathrm{K})$ & 5 \\
\hline & $\kappa$ & 1.7 & $\mathrm{~W} /(\mathrm{m} \mathrm{K})$ & 5 \\
\hline & $E$ & 75 & $\mathrm{GPa}$ & 5 \\
\hline & $\nu$ & 0.17 & - & 5 \\
\hline & $\alpha^{\prime}$ & $5.7 \times 10^{-7}$ & $1 / \mathrm{K}$ & 5 \\
\hline & $T_{m}$ & 1986.15 & $\mathrm{~K}$ & 5 \\
\hline \multirow{5}{*}{ Geometry } & $a_{\text {semi }}$ & 90 & $\mathrm{~nm}$ & 1 \\
\hline & $b_{\text {semi }}$ & 90 & $\mathrm{~nm}$ & 1 \\
\hline & $c_{\text {semi }}$ & 90 & $\mathrm{~nm}$ & 1 \\
\hline & $e_{\text {shell }, i}$ & $(*)$ & $\mathrm{nm}$ & 1 \\
\hline & $e_{\text {shell }, o}$ & $(*)$ & $\mathrm{nm}$ & 1 \\
\hline
\end{tabular}

(*) See Table 5.1 for the shell thickness values, which depend upon the number of ALD cycles. 
Table 5.3: Summary of material and geometrical properties for $\mathrm{Sn} @ \mathrm{SnO} @ \mathrm{Al}_{2} \mathrm{O}_{3}$ (core@inner_shell@outer_shell) nanoencapsulated phase change materials (nePCMs). $\sigma$ is the standard deviation for each of the properties with respect to their mean values.

\begin{tabular}{|c|c|c|c|c|}
\hline & Property & Values & Units & $\sigma(\%)$ \\
\hline \multirow{11}{*}{ Core (Sn) } & $\rho_{s}$ & 7280 & $\mathrm{~kg} / \mathrm{m}^{3}$ & 5 \\
\hline & $\rho_{l}$ & 6800 & $\mathrm{~kg} / \mathrm{m}^{3}$ & 5 \\
\hline & $c_{s}$ & 230 & $\mathrm{~J} /(\operatorname{kg~K})$ & 5 \\
\hline & $c_{l}$ & 257 & $\mathrm{~J} /(\operatorname{kg~K})$ & 5 \\
\hline & $\kappa_{s}$ & 65 & $\mathrm{~W} /(\mathrm{m} \mathrm{K})$ & 5 \\
\hline & $\kappa_{l}$ & 31 & $\mathrm{~W} /(\mathrm{m} \mathrm{K})$ & 5 \\
\hline & $E$ & 43.3 & $\mathrm{GPa}$ & 5 \\
\hline & $\nu$ & 0.33 & - & 5 \\
\hline & $\alpha^{\prime}$ & $2 \times 10^{-5}$ & $1 / \mathrm{K}$ & 5 \\
\hline & $T_{m}$ & 498.65 & $\mathrm{~K}$ & 5 \\
\hline & $L$ & 60.627 & $\mathrm{~kJ} / \mathrm{kg}$ & 5 \\
\hline \multirow{7}{*}{ Inner Shell (SnO) } & $\rho$ & 7020 & $\mathrm{~kg} / \mathrm{m}^{3}$ & 10 \\
\hline & $c$ & 348.95 & $\mathrm{~J} /(\operatorname{kg~K})$ & 10 \\
\hline & $\kappa$ & 40 & $\mathrm{~W} /(\mathrm{m} \mathrm{K})$ & 10 \\
\hline & $E$ & 222.72 & $\mathrm{GPa}$ & 10 \\
\hline & $\nu$ & 0.284 & - & 10 \\
\hline & $\alpha^{\prime}$ & $4 \times 10^{-6}$ & $1 / \mathrm{K}$ & 10 \\
\hline & $T_{m}$ & 1900 & $\mathrm{~K}$ & 10 \\
\hline \multirow{7}{*}{ Outer Shell $\left(\mathrm{Al}_{2} \mathrm{O}_{3}\right)$} & $\rho$ & 3970 & $\mathrm{~kg} / \mathrm{m}^{3}$ & 5 \\
\hline & $c$ & 919.38 & $\mathrm{~J} /(\operatorname{kg~K})$ & 5 \\
\hline & $\kappa$ & 10 & $\mathrm{~W} /(\mathrm{m} \mathrm{K})$ & 5 \\
\hline & $E$ & 370 & $\mathrm{GPa}$ & 5 \\
\hline & $\nu$ & 0.24 & - & 5 \\
\hline & $\alpha^{\prime}$ & $8.2 \times 10^{-6}$ & $1 / \mathrm{K}$ & 5 \\
\hline & $T_{m}$ & 2273.15 & $\mathrm{~K}$ & 5 \\
\hline \multirow{5}{*}{ Geometry } & $a_{\text {semi }}$ & 90 & $\mathrm{~nm}$ & 1 \\
\hline & $b_{\text {semi }}$ & 90 & $\mathrm{~nm}$ & 1 \\
\hline & $c_{\text {semi }}$ & 90 & $\mathrm{~nm}$ & 1 \\
\hline & $e_{\text {shell }, i}$ & $(*)$ & $\mathrm{nm}$ & 1 \\
\hline & $e_{\text {shell }, o}$ & $(*)$ & $\mathrm{nm}$ & 1 \\
\hline
\end{tabular}

(*) See Table 5.1 for the shell thickness values, which depend upon the number of ALD cycles. 
The material and geometrical properties of tin ( $\mathrm{Sn})$ [65-69], $\operatorname{tin}(\mathrm{IV})$ oxide $\left(\mathrm{SnO}_{2}\right)$ [70-74], silica $\left(\mathrm{SiO}_{2}\right)$ [65, 117-120] and alumina $\left(\mathrm{Al}_{2} \mathrm{O}_{3}\right)$ [65, 97-99] used for numerical simulation are reported in Tables 5.2 and 5.3. For the numerical simulation of $\mathrm{Sn} @ \mathrm{SnO}$ nePCMs, data from core and inner shell in Table 5.3 have been used. With regard to the geometry of nePCMs, a single three-dimensional multi-coated ellipsoidal nePCM is considered in order to incorporate the effects of geometrical uncertainty into the current study since not all nePCMs are necessarily perfectly spherical.

The material properties listed in Tables 5.2 and 5.3 are mass density $\rho$, specific heat capacity $c$, thermal conductivity $\kappa$, Young's modulus $E$, Poisson's ratio $\nu$, thermal expansion coefficient $\alpha$, melting temperature $T_{m}$ and latent heat $L$. Subscripts $s$ and $l$ denote solid and liquid state, respectively. Variables $a_{\text {semi }}, b_{\text {semi }}$ and $c_{\text {semi }}$ refer to the three outer semi-axes of an ellipsoidal nePCM and $e_{\text {shell }}$ designates shell thickness. Subscripts $i$ and $o$ denote inner and outer shell, respectively.

For the use of MC techniques in the numerical analysis of multi-coated nePCMs, the model's input parameters (material and geometrical properties) are considered as random variables, whose nominal values and standard deviation with respect to their nominal value are available in Tables 5.2 and 5.3. Taking into consideration the orders of magnitude in measurement dispersion reported in literature [65], an uncertainty of $5 \%$ is considered a good first approximation for errors of material properties of $\mathrm{Sn}, \mathrm{SnO}_{2}, \mathrm{Al}_{2} \mathrm{O}_{3}$ and $\mathrm{SiO}_{2}$. However, to the best authors' knowledge, the complete set of thermomechanical properties of $\mathrm{SnO}$, required for simulations with the present model, are not available in literature. Since both oxidation states of Sn possess a tetragonal crystallographic structure [121, 122], it is considered that material properties of $\mathrm{SnO}$ can be obtained from the normal distribution of $\mathrm{SnO}_{2}$ material properties but with a larger dispersion of $10 \%$. In the present work, all material properties are assumed to be normally distributed except for the size of nePCMs follows a log-normal distribution [17]. More precisely, the mean size of the outer semi-axes of the nePCM and its standard deviation are $90 \mathrm{~nm}$ and $40 \%$, respectively.

While experimentally observed nePCMs are not perfect spheres, their morphology does not significantly differ from particle to particle [111], and therefore a standard deviation of $1 \%$ around the log-normal mean values is considered. Furthermore, shell thickness is normally distributed with an uncertainty of $1 \%$ around its nominal value, which depends upon the number of ALD cycles, as reported in Table 5.1. Finally, the nominal values of tensile strength $\sigma_{t}$ considered for the reliability analysis are: 803, 110, 275.9 $\mathrm{MPa}$ for $\mathrm{SnO}_{2}$ [74], $\mathrm{SiO}_{2}$ [123] and $\mathrm{Al}_{2} \mathrm{O}_{3}$ [98], respectively and, for the probabilistic failure criterion, $\sigma_{t}$ is assumed to be normally distributed with a $20 \%$ of dispersion around the nominal values.

\subsection{Characterisation techniques}

\subsubsection{Thermogravimetric analysis, TGA}

Thermal stability was studied for all the nePCMs by thermogravimetric analysis. A TGA 1 (Mettler Toledo) was used with $\mathrm{N}_{2}$ atmosphere. The temperature of each sample was kept at $343 \mathrm{~K}$ for $5 \mathrm{~min}$, then raised to $553 \mathrm{~K}$ at a $5 \mathrm{~K} / \mathrm{min}$ rate, and held at $553 \mathrm{~K}$ for $30 \mathrm{~min}$, while measuring all the changes in mass taking place. 
Approximately $20 \mathrm{mg}$ of sample were placed inside a $40 \mu \mathrm{l}$ aluminium crucible for each test.

\subsubsection{Differential scanning calorimetry, DSC}

Information about the phase change enthalpies of the nePCMs was obtained by differential scanning calorimetry (DSC2, Mettler Toledo). Samples of around $20 \mathrm{mg}$ of nePCMs were analysed in a $40 \mu \mathrm{l}$ aluminium crucible. 80 thermal cycles from 343 $\mathrm{K}$ to $553 \mathrm{~K}$ were performed under nitrogen atmosphere $\left(25 \mathrm{~mL} / \mathrm{min} \mathrm{N}_{2}\right.$ flow rate), with $20 \mathrm{~K} / \mathrm{min}$ heating and cooling rates and $5 \mathrm{~min}$ isotherms at the maximum and minimum temperatures. More detailed analyses were performed every 10 cycles with the same characteristics but heating and cooling rates of $5 \mathrm{~K} / \mathrm{min}$, in order to obtain more accurate values of the enthalpies.

\section{$5.4 \quad$ Numerical tool}

This section presents the details for the numerical analysis of the mechanical reliability of nePCMs.

\subsubsection{Model description}

In order to perform a reliability analysis and to incorporate the measurement uncertainties into the numerical model, a probabilistic tool is developed by combining a thermomechanical FE code and MC techniques. With regard to the FE model, meshes of 3584 and 5120 8-noded elements with 4 degrees of freedom (dofs) per node are defined for single- and multi-coated nePCMs, respectively.

Concerning boundary and initial conditions, the nePCM is mechanically fixed at its centre and subjected to an initial temperature $\mathrm{T}_{i}$. Then, the prescribed temperature on the outer shell is linearly increased until a value $\mathrm{T}_{0}$ (higher than the melting temperature of the core) is achieved. In this case, $\mathrm{T}_{i}=343.15 \mathrm{~K}$ and $\mathrm{T}_{0}=$ $553.15 \mathrm{~K}$ are considered.

\subsubsection{Probability of failure}

The performance parameter retained for the analysis of mechanical strength of neP$\mathrm{CMs}$ in the present work is their probability of failure (POF), which represents the frequency of occurrence of a given event tagged as failure which, in this case, corresponds to the frequency of mechanical failure of the nePCM shell. The POF is mathematically defined as follows [106]:

$$
\mathrm{POF}=P\left[G\left(\xi_{j}\right) \leq 0\right]=\int_{G\left(\xi_{j}\right) \leq 0} f_{\xi_{j}}\left(\Xi_{j}\right) \mathrm{d} \Xi_{j},
$$

where $\xi_{j}, f_{\xi_{j}}\left(\Xi_{j}\right)$ and $G\left(\xi_{j}\right)$ represent the vector of input random variables, the joint probability density function of the input random variables and a limit state function, respectively. Consequently, situations in which $G\left(\xi_{j}\right) \leq 0$ represent a violation of the limit state, i.e. the failure region. In general, equation (5.1) cannot be analytically evaluated; however, the POF can be computed numerically. One of 
the techniques to numerically determine this POF is $\mathrm{MC}$ techniques and according to Melchers and Beck [106], POF can be evaluated for these techniques as:

$$
\mathrm{POF} \approx \frac{n\left[G\left(\hat{\xi}_{j} \leq 0\right)\right]}{N},
$$

where $n\left[G\left(\hat{\xi}_{j} \leq 0\right)\right]$ is the number of cases $n$ for which the limit state function is violated and $N$ represents the number of MC iterations. In equation (5.2), $\hat{\xi}_{j}$ is used to represent a sample value of the vector of input random variables.

\subsection{Results}

This section presents both the experimental and numerical results obtained for $\mathrm{Sn} @ \mathrm{SnO}, \mathrm{Sn} @ \mathrm{SnO}_{2} @ \mathrm{SiO}_{2}$ and $\mathrm{Sn} @ \mathrm{SnO} @ \mathrm{Al}_{2} \mathrm{O}_{3}$ nePCMs.

\subsubsection{Thermal stability}

In order to test the thermal stability of nePCMs, a TGA analysis on a $\mathrm{N}_{2}$ atmosphere was performed on the samples. Their behaviour when subjected to a progressive increase of temperature from $343 \mathrm{~K}$ until a posterior isotherm at $553 \mathrm{~K}$ is shown in Figure 5.1, where mass variations can be observed.

It is observed that the $\mathrm{Sn} @ \mathrm{SnO}$ nePCMs sample loses some mass at the beginning, likely corresponding to impurities present on commercial nanoparticles, such as anti-agglomerant additives commonly added to industrially produced powders. Above $513 \mathrm{~K}$ however, the sample shows no weight variations, indicating a completely stable behaviour at high temperatures.

A similar trend is observed for multi-coated nePCMs. In $\mathrm{Sn} @ \mathrm{SnO}_{2} @ \mathrm{SiO}_{2}$ samples, the initial weight loss is greater than for the $\mathrm{Sn} @ \mathrm{SnO}$ nePCMs. These mass losses are bigger for the multi-coated nePCMs submitted to a higher number of ALD cycles. Therefore, they can be attributed to the presence of some residual products after the ALD coating (namely chlorine compounds, as was previously observed and reported by Navarrete et al. [111]), apart from the mentioned impurities of commercial nanoparticles. Nevertheless, as previously noted for $\mathrm{Sn} @ \mathrm{SnO}$ nePCMs, $\mathrm{Sn} @ \mathrm{SnO}_{2} @ \mathrm{SiO}_{2}$ samples also show a thermally stable behaviour above $513 \mathrm{~K}$, with only small weight variations in the sample subject to 5 ALD cycles, which is in any case below a $0.1 \%$ variation of the total mass.

Regarding $\mathrm{Sn} @ \mathrm{SnO} @ \mathrm{Al}_{2} \mathrm{O}_{3}$ nePCMs, the initial mass losses are lower than in the other cases and could also be explained by impurities of commercial nanoparticles and ALD ligand leftovers (most likely carbonaceous species from TMA). As seen for $\mathrm{Sn} @ \mathrm{SnO}_{2} @ \mathrm{SiO}_{2}$, nePCMs after 5 ALD cycles undergo a subtle mass increase (smaller than $0.2 \%$ ) when they are exposed to an isotherm of $553 \mathrm{~K}$ during $30 \mathrm{~min}$, whereas the samples coated with 25 and 50 ALD cycles remain completely stable at that temperature.

In any case, the mass variations observed for all the samples analysed are lower than $1 \%$ variation of the total sample weight, accounting for a good thermal stability of multi-coated Sn nePCMs. Moreover, since the thermal stability of the samples is experimentally tested in a $\mathrm{N}_{2}$ atmosphere, the mass fluctuations occurring may not be caused by oxidation. 


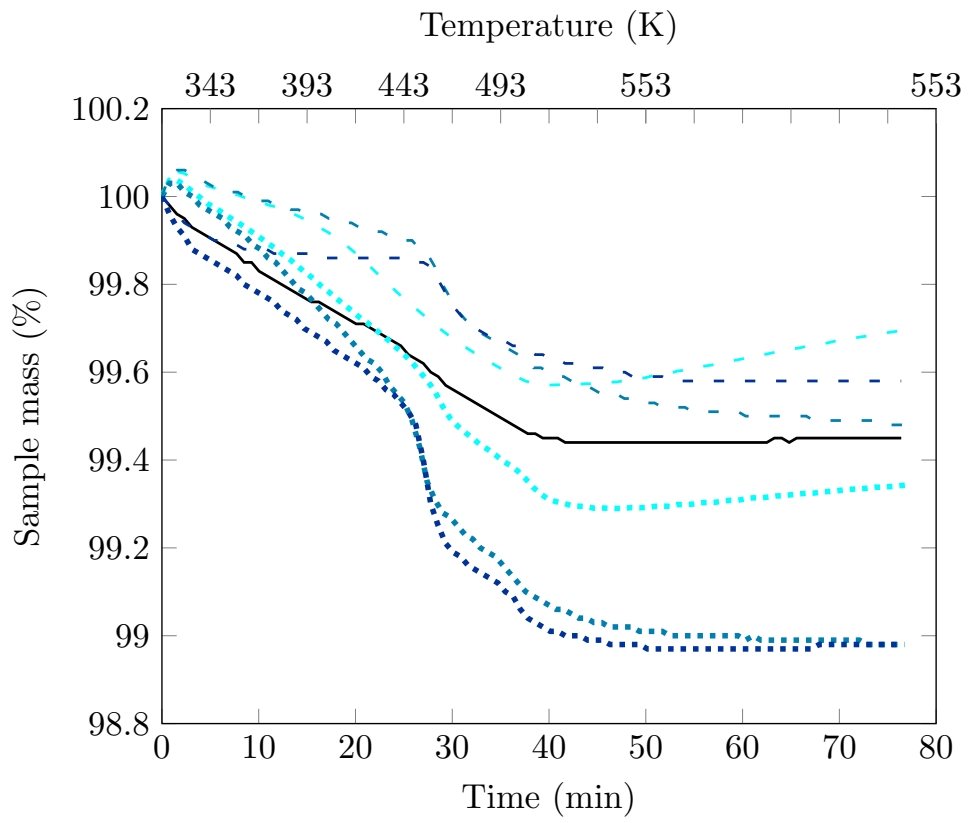

\begin{tabular}{|c|c|c|}
\hline 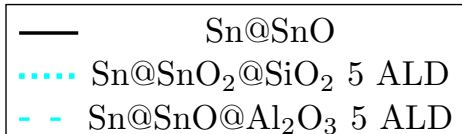 & $\begin{array}{l}\text {... - } \mathrm{Sn} @ \mathrm{SnO}_{2} @ \mathrm{SiO}_{2} 25 \mathrm{ALD} \\
\text { - - } \mathrm{Sn} @ \mathrm{SnO} @ \mathrm{Al}_{2} \mathrm{O}_{3} 25 \text { ALD }\end{array}$ & $\begin{array}{l}\text {..... } \mathrm{Sn} @ \mathrm{SnO}_{2} @ \mathrm{SiO}_{2} 50 \mathrm{ALD} \\
\text { - - } \mathrm{Sn} @ \mathrm{SnO} @ \mathrm{Al}_{2} \mathrm{O}_{3} 50 \mathrm{ALD}\end{array}$ \\
\hline
\end{tabular}

Figure 5.1: TGA analysis of $\mathrm{Sn} @ \mathrm{SnO}, \mathrm{Sn} @ \mathrm{SnO}_{2} @ \mathrm{SiO}_{2}$ and $\mathrm{Sn} @ \mathrm{SnO} @ \mathrm{Al}_{2} \mathrm{O}_{3}$ nanoencapsulated phase change materials subjected to different number of ALD cycles.

\subsubsection{Enthalpy decrease}

The stability of nePCMs to thermal cycling and the suitability of the different ALD coatings as a confining barrier for the molten core of nePCMs were tested in a $\mathrm{N}_{2}$ atmosphere by subjecting the samples to thermal DSC cycles up to $553 \mathrm{~K}$. The enthalpy $(\mathrm{H})$ decrease with the number of the thermal cycles is shown in Figure 5.2, where it can be observed that both ALD-coated nePCMs show higher thermal stability than the $\mathrm{Sn} @ \mathrm{SnO}$ nePCMs surrounded exclusively by the $\mathrm{SnO}$ layer. The decrease in the phase change enthalpy of the $\mathrm{Sn} @ \mathrm{SnO}$ nePCM, almost $7 \%$, is notably

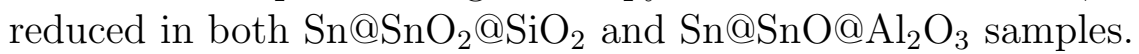

The $\mathrm{Sn} @ \mathrm{SnO} @ \mathrm{Al}_{2} \mathrm{O}_{3}$ nePCMs after 50 ALD cycles exhibit the best resistance to enthalpy losses against thermal cycling, by losing only a $1.1 \%$ of the initial phase change enthalpy. In turn, $\mathrm{Sn} @ \mathrm{SnO}_{2} @ \mathrm{SiO}_{2}$ nePCMs show a higher loss of phase change enthalpy $(3.5 \%)$ under the same conditions.

Therefore, the multi-coated nePCMs coated with $\mathrm{Al}_{2} \mathrm{O}_{3}$ present greater latent heat stability over cycles than their $\mathrm{SiO}_{2}$ counterparts. This translates into a better resistance against enthalpy losses, which implies a better performance as a mean for storing energy in nanofluids. Since the thermal characterisation of multi-coated samples was perfomed under a $\mathrm{N}_{2}$ atmosphere and, consequently, TGA does not reveal any oxidation phenomena when the same thermal cycling is applied, the loss of enthalpy of nePCMs may be due to the mechanical failure of the nePCM coating. 


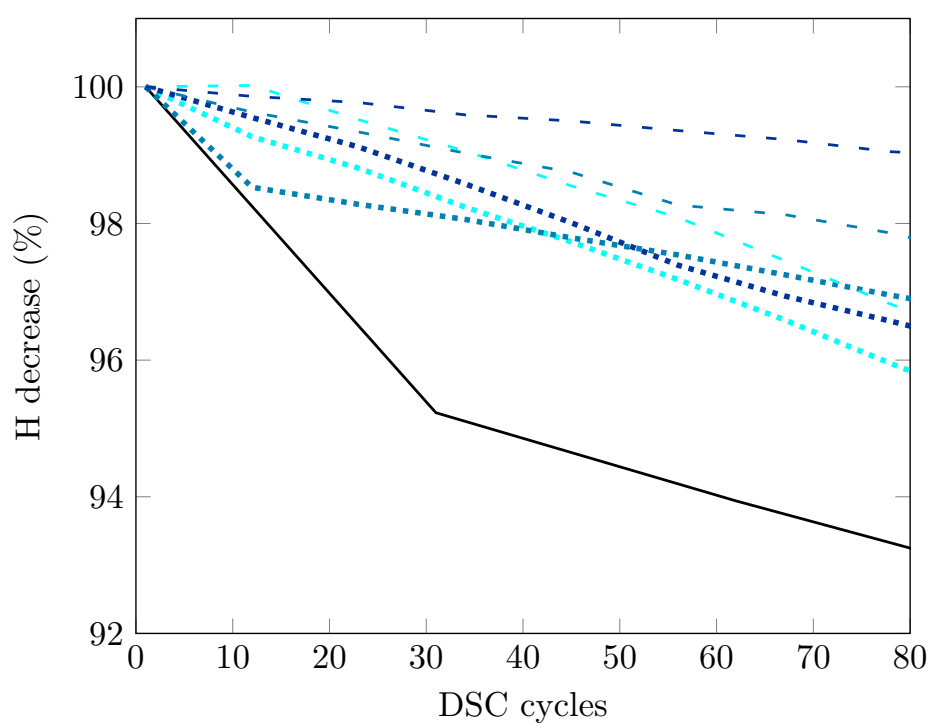

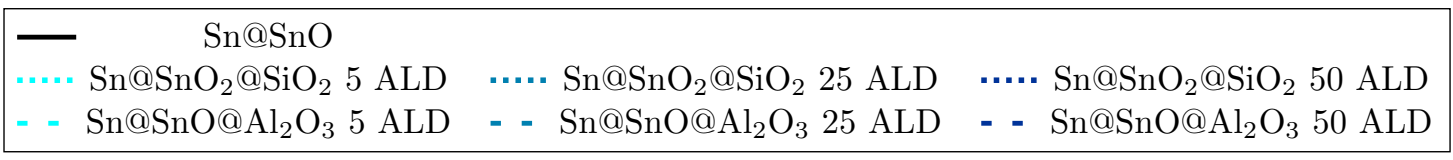

Figure 5.2: Evolution of the phase change enthalpy $(\mathrm{H})$ decrease with thermal cycling in nitrogen $\left(\mathrm{N}_{2}\right)$ atmosphere for $\mathrm{Sn} @ \mathrm{SnO}, \mathrm{Sn} @ \mathrm{SnO}_{2} @ \mathrm{SiO}_{2}$ and $\mathrm{Sn} @ \mathrm{SnO} @ \mathrm{Al}_{2} \mathrm{O}_{3}$ nePCMs subjected to different number of ALD cycles.

\subsubsection{Probability of failure}

Regarding the numerically calculated POF, Figure 5.3 shows the stress distribution for both deterministic (left) and probabilistic (right) failure criteria for $\mathrm{Sn} @ \mathrm{SnO}$, $\mathrm{Sn} @ \mathrm{SnO}_{2} @ \mathrm{SiO}_{2}$ and $\mathrm{Sn} @ \mathrm{SnO} @ \mathrm{Al}_{2} \mathrm{O}_{3}$ nePCMs after 50 ALD cycles. POF values are obtained by comparing the overlapping existing between stress predictions (in blue in Figure 5.3) and deterministic/probabilistic criteria (in red in Figure 5.3). For instance, for Sn@SnO nePCMs, the equivalent stress distribution falls below the deterministic failure criterion. This means that the probability that encapsulation of $\mathrm{Sn} @ \mathrm{SnO}$ fails is $0 \%$ by comparing the numerical predictions of maximum equivalent stress against the deterministic value of tensile strength reported in literature. However, the value provided by the probabilistic failure criterion for $\mathrm{Sn} @ \mathrm{SnO}$ nePCMs is $2.27 \%$. In this case, a probabilistic failure criterion allows to assess the mechanical performance of nePCMs by comparing the predicted maximum equivalent stress against a set of tensile strength values obtained from a probability distribution. The same analysis perfomed for the multi-coated nePCMs shows that in the case of $\mathrm{Sn} @ \mathrm{SnO}_{2} @ \mathrm{SiO}_{2}$ nePCMs after 50 ALD cycles, the deterministic POF of the outer shell is $73 \%$ while the value provided by the probabilistic failure criterion is $72.38 \%$. Finally, for their Sn@SnO@Al2O3 counterparts, the deterministic POF of the outer shell is $0 \%$ whereas the probabilistic POF is $1.66 \%$.

Therefore, these results stress the need to take into account probabilistic failure criteria since not considering them may slightly underestimate the mechanical POF of nePCM shells, which can have consequences on the performance of a nanofluid by reducing its effective energy storage capability if the number of nePCM failures is higher than expected for an application. Furthermore, the use of a probabilistic criterion allows to reduce the number of necessary Monte Carlo iterations to reach numerical convergence [115]. The POF values displayed in Figure 5.4 corresponds to those evaluated through a probabilistic criterion. 
a) $\mathrm{Sn} @ \mathrm{SnO}$
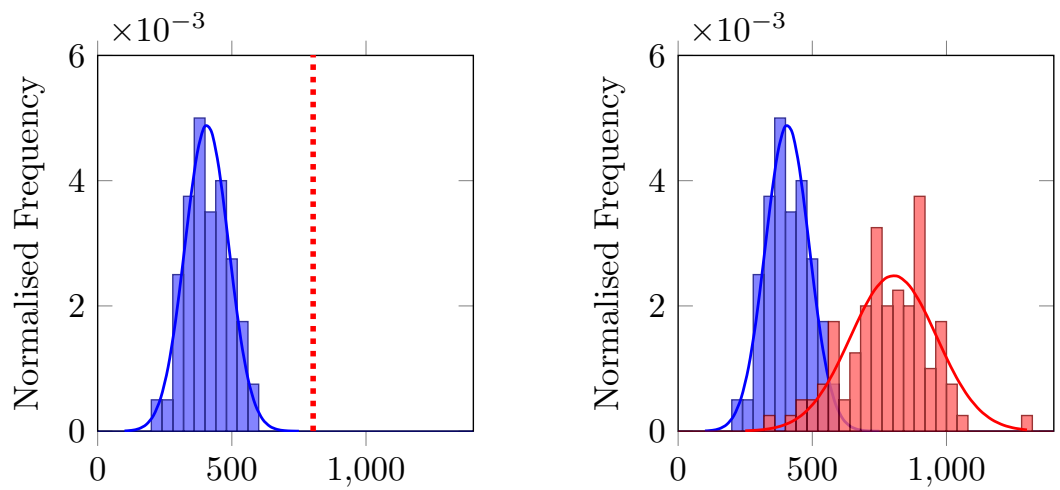

Rankine's equivalent stress ( $\mathrm{MPa})$

Rankine's equivalent stress ( $\mathrm{MPa})$

b) $\mathrm{Sn} @ \mathrm{SnO}_{2} @ \mathrm{SiO}_{2}$
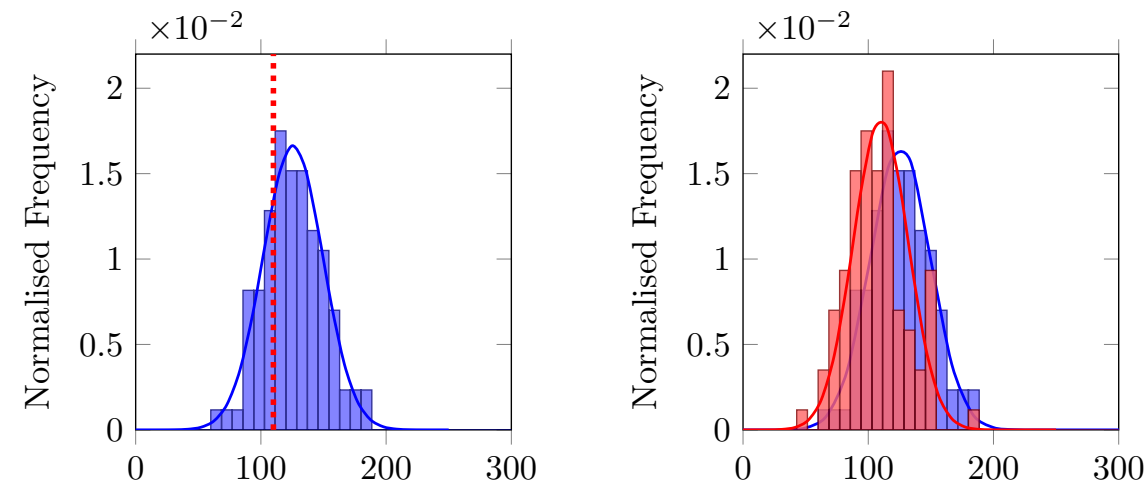

Rankine's equivalent stress (MPa)

Rankine's equivalent stress ( $\mathrm{MPa})$

c) $\mathrm{Sn} @ \mathrm{SnO} @ \mathrm{Al}_{2} \mathrm{O}_{3}$
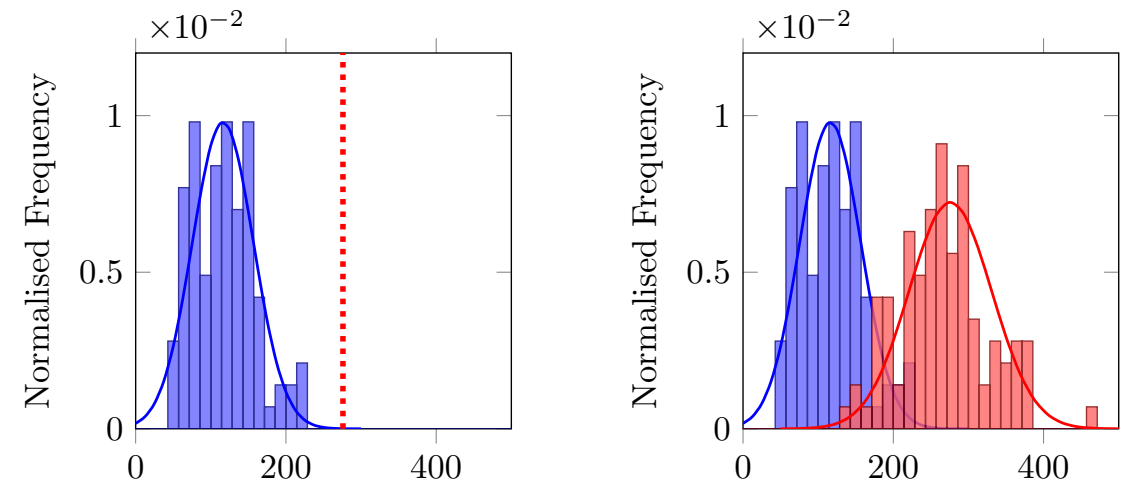

Rankine's equivalent stress ( $\mathrm{MPa}) \quad$ Rankine's equivalent stress ( $\mathrm{MPa})$

\begin{tabular}{|lll}
\hline$\square$ Distribution of Rankine's stress & - Fitting of Rankine's stress \\
$\square \Delta \quad$ Probabilistic failure & Fitting of probabilistic failure & " Deterministic failure \\
\hline
\end{tabular}

Figure 5.3: Deterministic (left) and probabilistic (right) failure criteria compared against the maximum Rankine's equivalent stress obtained from Monte Carlo simulation for a) Sn@SnO, b) $\mathrm{Sn} @ \mathrm{SnO}_{2} @ \mathrm{SiO}_{2}$ and c) $\mathrm{Sn} @ \mathrm{SnO}_{\mathrm{Al}_{2}} \mathrm{O}_{3}$ nanoencapsulated phase change materials. 
a) $\mathrm{Sn} @ \mathrm{SnO}_{2} @ \mathrm{SiO}_{2}$

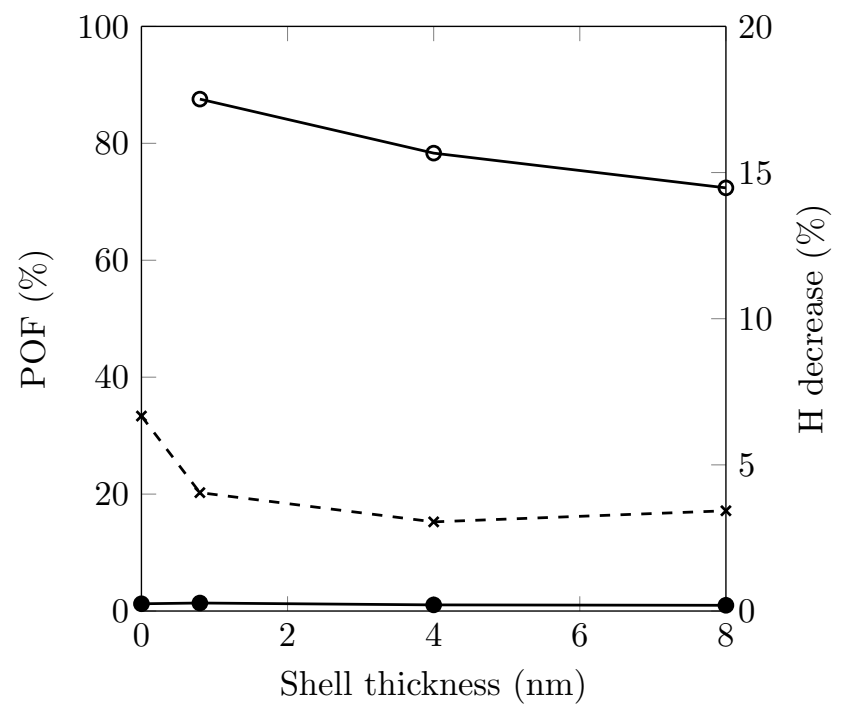

$\rightarrow-\mathrm{POF} \mathrm{SnO}_{2} \quad \multimap-\mathrm{POF} \mathrm{SiO}_{2} \quad-\star-\mathrm{H}$ decrease

b) $\mathrm{Sn} @ \mathrm{SnO} @ \mathrm{Al}_{2} \mathrm{O}_{3}$

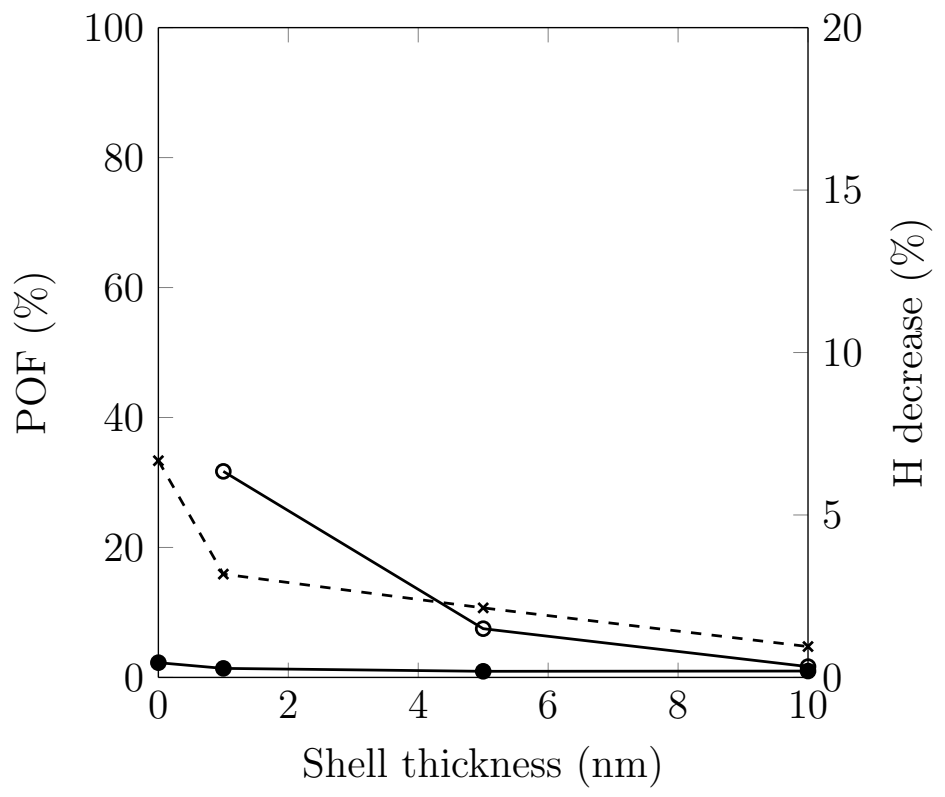

- $\mathrm{POF} \mathrm{SnO} \rightarrow \mathrm{POF} \mathrm{Al}_{2} \mathrm{O}_{3}-*-\mathrm{H}$ decrease

Figure 5.4: Evolution of the probability of failure (POF) of the inner and outer shells and of the enthalpy $(\mathrm{H})$ decrease with the outer shell thickness of multi-coated a) $\mathrm{Sn}_{\mathrm{SnO}} @ \mathrm{SnSiO}_{2}$ and b) $\mathrm{Sn} @ \mathrm{SnO} @ \mathrm{Al}_{2} \mathrm{O}_{3}$ nanoencapsulated phase change materials. 
The influence of the outer coating shell thickness of multi-coated nePCMs, which is directly related to the number of ALD cycles, on the POF of the shells and the enthalpy decrease of the nePCMs is also studied, as shown in Figure 5.4. Notice that the values of phase change enthalpy decrease displayed in these Figures correspond to those experimentally obtained after 80 DSC cycles.

From Figure 5.4 a), it can be observed that the POF of the inner shell $\left(\mathrm{SnO}_{2}\right)$ of $\mathrm{Sn} @ \mathrm{SnO}_{2} @ \mathrm{SiO}_{2}$ remains nearly constant regardless of the number of ALD cycles while the POF of the outer shell $\left(\mathrm{SiO}_{2}\right)$ reduces with increasing thickness of the outer shell until a value of POF of $72.38 \%$ is reached for 50 ALD cycles. The constant trend of the inner shell $\left(\mathrm{SnO}_{2}\right)$ POF with its thickness does not affect mechanical reliability since the POF value is low. However, a decrease in POF of $\mathrm{SiO}_{2}$ coating is observed with increasing number of ALD cycles; in absolute terms, the POF of the outer shell is still extremely high even for 50 ALD cycles. With respect to phase change enthalpy decrease, a clear reduction is observed between the case when nePCMs are single-coated (null shell thickness) and when the extra coating is synthesised by ALD. However, the shell thickness of the outer coating does not exert a big influence in the evolution of this enthalpy decrease. Therefore, all these results confirm that although $\mathrm{SiO}_{2}$ coatings prevent to some extent the enthalpy loss of the nePCMs, their performance is still not optimal for their use in multi-coated Sn nePCMs for energy storage purposes.

From Figure $5.4 \mathrm{~b}$ ), it can be concluded that the POF of the inner shell ( $\mathrm{SnO}$ ) of $\mathrm{Sn} @ \mathrm{SnO} @ \mathrm{Al}_{2} \mathrm{O}_{3}$ does not notably change with the number of ALD cycles but the POF of the outer shell $\left(\mathrm{Al}_{2} \mathrm{O}_{3}\right)$ considerably reduces until attaining a value of $1.66 \%$ for 50 ALD cycles. This sharp decrease in the POF of the outer shell means that $\mathrm{Sn} @ \mathrm{SnO} @ \mathrm{Al}_{2} \mathrm{O}_{3}$ are likely to resist the thermal stresses developed when undergoing thermal processes. Furthermore, the $\mathrm{H}$ decrease significantly diminishes to a value of $0.95 \%$ for 50 ALD cycles. Consequently, the good mechanical and thermal performance of $\mathrm{Al}_{2} \mathrm{O}_{3}$ makes it a good material candidate as a coating for multi-coated nePCMs in energy storage applications.

From these results, a certain agreement seems to exist between the POF and the $\mathrm{H}$ decrease of nePCMs and, since oxidation phenomena cannot take place in a $\mathrm{N}_{2}$ atmosphere, the mechanical failure of the nePCM coating could be a possible cause for their loss enthalpy. Therefore, numerically predicting the outer shell POF of multi-coated nePCMs in advance can contribute to reduce their enthalpy losses, which have a direct impact on the energy storage performance of the application (nanofluids), by precisely tuning the coating thickness by ALD.

\subsection{Conclusions}

This chapter presents a study about the mechanical reliability of experimentally synthesised multi-coated nePCMs by making use of a probabilistic numerical tool combining MC methods with a FE thermomechanical model with phase change.

Starting with self-encapsulated Sn NPs, additional coatings were synthesised on nePCMs by the ALD technique to obtain multi-coated nePCMs, i.e., $\mathrm{Sn} @ \mathrm{SnO}_{2} @ \mathrm{SiO}_{2}$ and $\mathrm{Sn} @ \mathrm{SnO} @ \mathrm{Al}_{2} \mathrm{O}_{3}$. Their behaviour was experimentally characterised to study their thermal stability over heating cycles and to assess the stability of their phase change enthalpy with the thickness of the outer shell of multi-coated nePCMs, i.e. with the number of ALD cycles. It was found that $\mathrm{Al}_{2} \mathrm{O}_{3}$ coatings resist better 
thermal cycling than their $\mathrm{SiO}_{2}$ counterparts. Furthermore, the POF of the outer shells is studied to asses the mechanical strength for $\mathrm{Sn} @ \mathrm{SnO}, \mathrm{Sn} @ \mathrm{SnO}_{2} @ \mathrm{SiO}_{2}$ and $\mathrm{Sn} @ \mathrm{SnO} @ \mathrm{Al}_{2} \mathrm{O}_{3}$ nePCMs. Numerical predictions confirm the experimental trend that the thicker the shell (and hence the higher the number of ALD cycles), the more marked the reduction in both the POF and phase change enthalpy decrease of nePCM cores. Therefore, numerical simulations and thermal characterisation seem to indicate that the POF of outer shells and the enthalpy decrease of nePCMs are related phenomena. From the studied materials, $\mathrm{Al}_{2} \mathrm{O}_{3}$ coatings present the most suitable mechanical and thermal performance for their use in energy storage applications.

In short, the coatings synthesised by ALD to obtain multi-coated nePCMs permit to enhance their mechanical and thermal properties by precisely controlling the outer shell thickness. Numerical simulations may be used to determine the optimal thickness of the coating for a desired thermal energy storage application, which can contribute to reduce the coating cost of nePCMs and to gain more control over colloidal stability of nanofluids. Furthermore, the numerical tool used in the present work can be employed to make numerical predictions in an attempt to reduce the number of experiments to be conducted to mechanically characterise multi-coated nePCMs. 



\title{
Chapter 6: Non-linear finite element modelling of light-to-heat energy con- version applied to solar nanofluids
}

\begin{abstract}
Nanoparticles (NPs) exhibit remarkable photothermal conversion efficiency under optical illumination. This light-induced heating on NPs is interesting in many different applications, such as solar radiation absorption in nanofluids, which the present work focuses on. Consequently, mastering the temperature increase undergone by NPs and the surrounding media is extremely relevant today. As nanothermometry measurements of a single NP are hard to obtain, numerical simulations can contribute to better understand the physical phenomena involved in light-induced heating. In this vein, the current work presents theoretical and numerical formulations to predict the heating of optically excited NPs. Theoretically, a thermodynamic approach is conducted to obtain balance and constitutive equations. These equations are numerically discretised in the finite element method and implemented into a research code. The main novelty of the present work lies in developing, from a multiphysics perspective, a time domain formulation capable of modelling instantaneous dissipation that can be easily extended to account for more physical phenomena. Finally, the numerical model is validated by comparing analytical and numerical results, and maximum values of 0.0014 (\%) of relative error between them are reached. Then some different analysis are performed for gold, silver and graphite NPs of $20(\mathrm{~nm})$ in diameter to characterise the temperature increase they produce in the surrounding medium (water) when optically excited at a wavelength of $400(\mathrm{~nm})$ and a laser intensity of $5 \times 10^{4}\left(\mathrm{~W} / \mathrm{cm}^{2}\right)$-silver NPs exhibiting the most significant temperature increase. The influence of NP concentration on the increase of temperature in nanofluids is numerically assessed as well by testing values of NP concentration up to a maximum of $0.052(\%)$, which considerably enhances temperature increase. In conclusion, the present numerical tool could be used to predict light-induced heating in NPs, which could complement and reduce the number of experiments for optimising the photothermal efficiency of solar nanofluids.
\end{abstract}




\subsection{Introduction}

Nowadays, society's development is directly related to consumption of energy: generating and supplying energy are vital for human current lifestyle. However, producing that energy sustainably is of key importance to stop climate change and to preserve our natural environment for future generations. For this reason, use of renewable energies is increasing to take advantage of natural resources (inexhaustible on the human timescale) to produce clean energy. Of the wide variety of renewable energies, solar energy is particularly interesting for its enormous potential; for instance, it is estimated that little more than one hour and a half of solar irradiation on Earth equals one-year of the world's energy demand [6]. Although there are several solar energy technologies, the current work focuses on solar thermal energy.

Solar thermal energy is the name given to the thermal energy obtained from solar radiation. Its working principle consists of capturing the energy of light on an absorbing surface to transfer that energy to a heat carrier fluid [124]. One of the most widely used technologies to harness solar energy by converting light into thermal energy is solar collectors, for which two main collector configurations exist [125]:

- Tube-in-plate collectors [126], composed of selective absorbing surfaces that transfer solar-radiated heat to the working fluid. However, this technology has one main drawback: the maximum temperature is reached on the collector's surface, which increases thermal losses [124]. Then the configuration of this collector cannot be optimal because the biggest differences in temperature appear between the surface collector and the carrier fluid flowing inside the tubes beneath. Therefore, tube-in-plate collectors present low thermal conversion efficiency.

- Volumetric collectors [127], which absorb solar energy directly within the fluid itself. For this purpose, thermal trapping tubes [128] are designed to allow light to pass through them but to prevent radiation from leaving them. Thus better thermal efficiencies can be achieved with this configuration due to less thermal losses.

Recently, nanoparticles (NPs) in dispersion in a base fluid have been used as the effective absorption media in Direct Absorption Solar Collectors (DASC) [129]. More precisely, remarkable photothermal conversion efficiency has been observed for gold [130-132] and silver [133-135] NPs owing to their surface plasmon resonance $[133,136]$. Other non-metallic materials, such as carbon, are also used as NPs as well because they present good light absorbance throughout the solar spectrum [137].

This dispersion of nanoparticles in a base fluid receives the name of nanofluids [11], which are one of the technologies being investigated in DASC systems. Commonly, conventional base fluids (water and oils) are transparent, and hence, present low light absorption. For this reason, NPs are dispersed inside fluid to enhance the mixture's optical properties. Currently, a specific branch of nanofluids, solar nanofluids $[21,138]$, in which low concentrations of NPs absorb solar radiation, is being investigated for DASC applications. Further details of using nanofluids in solar collectors are reported in [137, 139-144].

Briefly, light-to-heat conversion in NPs may contribute to increase the efficiency of volumetric collectors, and presently constitutes an active research line. Yet, des- 
pite the fact that different nanoscale thermometry techniques are reported in the literature [145-147], the light-induced heat transfer of a single NP cannot be easily measured experimentally given the complexity of isolating a single NP and measuring the heat transfer produced by light irradiation [148]. Therefore, numerical simulations can contribute to predict the temperature increase generated by the incident radiation on NPs and its surroundings to obtain the optimal solar nanofluid in volumetric collector applications.

Accordingly, the present work aims to state both theoretical and numerical formulations to study and understand light-to-heat energy conversion.

Light-to-heat conversion in NPs appears to be governed by the same physics that govern electromagnetic heating [149-151]. In this context, a sensible amount of the literature on light-to-heat conversion addresses the solution of this problem by adopting a frequency-domain approach, as is often the case with electrical engineering and telecommunication communities.

The expression of power dissipation, $P_{d}$, produced by light-to-heat in the frequency domain and usually found in the literature reads [149, 152-154]:

$$
P_{d}=\frac{1}{2}\left[\frac{\gamma}{\omega \epsilon_{0}}+\epsilon^{\prime \prime}\right] \omega \epsilon_{0}\left|\hat{E}_{0}\right|^{2},
$$

where $\gamma, \omega, \epsilon^{\prime \prime}$ and $\left|\hat{E}_{0}\right|$ denote electric conductivity, excitation pulsation, imaginary part of the complex relative permittivity and modulus of the complex amplitude of the sinusoidal electric field, respectively. Parameter $\epsilon_{0}=8.854 \cdot 10^{-12}(\mathrm{~F} / \mathrm{m})$ is vacuum permittivity. Note that: i) this expression is valid only for sinusoidal excitations; ii) the term corresponding to Joule's dissipation [155] is often omitted from the literature but is added in the present work for the sake of completeness. In fact, equation (6.1) is the root mean square (RMS) value of the power dissipation for sinusoidal excitation and, consequently, provides a term-averaged dissipation instead of an instantaneous one.

Although both temporal and frequency domain approaches are valid, only one of both formalisms should be used for the sake of consistency in coupled problems. Consequently, the novelty of the present work lies in developing a thermodynamically consistent framework in the time domain from a multiphysics perspective to account for time-instantaneous dissipation. Therefore, the present formalism can be extended easily to include more phenomena.

Three approaches exist in the literature to derive the source term in the energy balance responsible for light-to-heat conversion, often referred to as power loss term:

- The electrodynamic approach [154], which considers that the total current displacement stems from two different contributions: one due to the electric field and the other resulting from the remnant displacement current. The latter accounts for both partial energy storage in the medium and the power loss term behind microwave heating.

- The equivalent circuit approach [154], which is mainly used by the electric engineering community and establishes an analogy between the energy of an electric field and that of an electric circuit composed of capacitors and a resistor. The latter stands for the dissipation term in light-to-heat conversion. 
- Non-equilibrium thermodynamic (NET) formalism, for which two different techniques can be contemplated:

- The standard NET $[29,31,156]$, based on the local equilibrium assumption and the formulation of the entropy balance to derive transport equations.

- The hidden variable technique [157, 158], which consists of enlarging the set of thermodynamic variables of the problem to include further irreversible contributions in the formalism at the expense of increasing the number of phenomenological coefficients to be experimentally measured.

The standard NET approach is retained in this work; more precisely, the Debye model [159] is used to describe the source of irreversibilities associated with the time lag between polarisation and the electric field and, thus, responsible for light-to-heat conversion.

From a theoretical point of view, a robust thermodynamically consistent formulation based on both the Equilibrium Thermodynamics (ET) [28] and the NET formalisms is herein developed. In particular, the electric charge balance is obtained from Maxwell's laws and, afterwards, energy and entropy balances are stated to obtain transport (also called constitutive) equations.

In numerical terms, the set of two coupled partial differential equations is discretised in the Finite Element (FE) method [33]. Indeed, a three-dimensional, monolithic and non-linear formulation based on residuals is developed by using eight-noded brick elements with two degrees of freedom per node, namely voltage and temperature. Then the non-linearities due to quadratic dependence on the electric field are solved by the Newton-Raphson algorithm and the time integration by the standard Newmark implicit scheme.

Finally, the numerical formulation is implemented into the research code FEAP [35] and is validated against one-dimensional closed solutions. Then, a three-dimensional model of a single gold, a silver and a graphite nanoparticle (Au, Ag and G NP) is studied to demonstrate the capabilities of the present formulation for studying light-to-heat energy conversion.

The present work considers the following assumptions: i) NPs are poor light emitters, namely the quantity of light-induced heat in the NP is generated mainly by light absorption, as argued in [131]; ii) the scattering of incident light on NPs is negligible as long as the size of NPs is small compared to the incident light wavelength [160]; iii) lack of magnetic fields.

\subsection{Theoretical formulation}

For the theoretical formulation, a material that couples thermal and electrical energies and fills a body of domain $\Omega$ and boundary $\Gamma$, with its outward normal $\underline{n}$ is considered. Light-to-heat energy conversion is described by a set of two coupled differential equations, which are obtained from electromagnetism and thermodynamics formalisms. 


\subsubsection{Electromagnetism}

Electromagnetism studies the interaction between electric $\underline{E}$ and magnetic $\underline{H}$ fields with their sources and is grounded on a set of four empirical equations called Maxwell's laws, from which the following two are needed to establish the present formalism:

$$
\underline{\nabla} \times \underline{E}=-\underline{\dot{B}}, \quad \underline{\nabla} \times \underline{H}=\underline{j}+\underline{\dot{D}} .
$$

From left to right, the first and second equations (Faraday's and Ampère's laws) relate the corresponding physical field to their vector sources: magnetic induction $\underline{B}$, free electric currents $j$ and electric displacement $\underline{D}$.

The electromagnetic formalism is completed by introducing three new equations, which can be directly obtained from (6.2):

- Despite the fact that the electric field may derive from either vectorial or scalar potentials, as argued in [30], the present work uses the scalar potential, -commonly called voltage- $V$. This potential is obtained by applying the fundamental theorem of vector calculus to Faraday's law of (6.2) when magnetic fields are absent:

$$
\underline{\nabla} \times \underline{E}=0 \Rightarrow \underline{E}=-\underline{\nabla} V .
$$

- Polarisation vector $\underline{P}$, which takes into account the average of the electric dipolar momentum in polarisable media, reads:

$$
\underline{P}=\underline{D}-\epsilon_{0} \underline{E} .
$$

- The electric charge balance, which is obtained from Ampère's law and by using a vector calculus relation, which states that the divergence of the curl is always zero for any vector field:

$$
\underline{\nabla} \cdot(\underline{j}+\underline{\dot{D}})=0 .
$$

Note that, despite term $\underline{\dot{D}}$ often being called displacement current, its physical nature is not that of an electric current, but merely represents a time-varying electric field.

\subsubsection{Thermodynamics}

Within the continuum thermodynamics framework, light-to-heat energy conversion is a coupled interaction that deals with both reversible and irreversible processes; consequently, both ET and NET formalisms are herein used.

In this context, electric displacement is decomposed as the sum of its reversible (superscript $r$ ) and irreversible (superscript $i$ ) contributions: $\underline{D}=\underline{D}^{r}+\underline{D}^{i}$.

\subsubsection{Equilibrium thermodynamics (ET)}

Within the ET framework, the differential form of the energy balance reads:

$$
\mathrm{d} \mathcal{U}=T \mathrm{~d} \mathcal{S}+\mathrm{d} \mathcal{W}
$$

where $\mathcal{U}, T, \mathcal{S}$ and $\mathcal{W}$ denote internal energy, temperature, entropy and work, respectively. 
According to [30], $\mathrm{d} \mathcal{W}$ may be expressed as the product between intensive variable $\underline{E}$ and its conjugate extensive variable $\underline{D}^{r}$ so that (6.6) becomes:

$$
\mathrm{d} \mathcal{U}\left(\mathcal{S}, \underline{D}^{r}\right)=T \mathrm{~d} \mathcal{S}+\underline{E} \cdot \mathrm{d} \underline{D}^{r} .
$$

In order to obtain an amenable displacement-based FE formulation, a Legendre transformation is applied to (6.7) and the Gibbs-like energy $\mathcal{G}$ becomes [161]:

$$
\mathrm{d} \mathcal{G}(T, \underline{E})=-\mathcal{S} \mathrm{d} T-\underline{D}^{r} \cdot \mathrm{d} \underline{E} .
$$

In a first and good approximation, the explicit expression of $\mathcal{G}(T, \underline{E})$ may be obtained by Taylor's expansion as in [30] to give:

$$
\mathcal{G}(T, \underline{E})=-\frac{1}{2} \underline{\underline{E}} \cdot \underline{\underline{\epsilon}}^{r} \cdot \underline{E}-C\left[T \ln \left(\frac{T}{T_{r e f}}\right)-\left(T-T_{r e f}\right)\right],
$$

where $C, T_{\text {ref }}$ and $\underline{\epsilon}^{r}$ denote heat capacity, reference temperature and the reversible part of the permittivity of the medium, respectively. Note that pyroelectric coupling is neglected in the present study.

Finally, the reversible constitutive equations are calculated from (6.8) and (6.9) by using standard ET procedures to give:

$$
\mathcal{S}=-\left.\frac{\partial \mathcal{G}(T, \underline{E})}{\partial T}\right|_{\underline{E}}=C \ln \left(\frac{T}{T_{r e f}}\right), \quad \underline{D}^{r}=-\left.\frac{\partial \mathcal{G}(T, \underline{E})}{\partial \underline{E}}\right|_{T}=\underline{\epsilon}^{r} \cdot \underline{E} .
$$

\subsubsection{Non-equilibrium thermodynamics (NET)}

The NET formalism deals with irreversible processes and, consequently, the energy rate balance of (6.7) becomes:

$$
\frac{\mathrm{d}}{\mathrm{d} t} \mathcal{U}=T \frac{\mathrm{d}}{\mathrm{d} t} \mathcal{S}+\frac{\mathrm{d}}{\mathrm{d} t}\left(\mathcal{W}^{r}+\mathcal{W}^{i}\right)
$$

where $t$ denotes time. Furthermore, NET works with continuum equations and the three terms of (6.11) must be expressed in continuum forms:

- The term on the left-hand side of (6.11) reads:

$$
\frac{\mathrm{d}}{\mathrm{d} t} \mathcal{U}=\int_{\Omega} \rho \dot{\mathrm{u}} \mathrm{d} \Omega
$$

where $\rho$ and $\dot{\mathbf{u}}$ denote mass density and the specific internal energy rate, respectively.

- The first term on the right-hand side of (6.11) may be expressed in a continuum form by introducing heat flux $\underline{q}$ to give:

$$
T \frac{\mathrm{d}}{\mathrm{d} t} \mathcal{S}=-\int_{\Gamma} \underline{q} \cdot \underline{n} \mathrm{~d} \Gamma=-\int_{\Omega} \underline{\nabla} \cdot \underline{q} \mathrm{~d} \Omega
$$

where the divergence theorem has been used. Note that this equation represents the reversible entropy, which is the heat flux exchanged through the boundary $\Gamma$. 
- The second term on the right-hand side of (6.11) becomes:

$$
\frac{\mathrm{d}}{\mathrm{d} t}\left(\mathcal{W}^{r}+\mathcal{W}^{i}\right)=-\int_{\Gamma} \underline{S} \cdot \underline{n} \mathrm{~d} \Gamma+\int_{\Omega} r \mathrm{~d} \Omega,
$$

where $\underline{S}=\underline{E} \times \underline{H}$ is the Poynting vector and $r$ is the heat source/sink term. By applying the divergence theorem to the term on the right-hand side of (6.14) and taking into account the vector identity $\underline{\nabla} \cdot(\underline{E} \times \underline{H})=\underline{H} \cdot(\underline{\nabla} \times \underline{E})-\underline{E} \cdot(\underline{\nabla} \times \underline{H})$ and Ampère's law of (6.2), the electromagnetic power, the first term on the right-hand side of (6.14), reads when magnetic field is absent:

$$
\int_{\Gamma} \underline{S} \cdot \underline{n} \mathrm{~d} \Gamma=-\int_{\Omega}[\underline{j} \cdot \underline{E}+\underline{\dot{D}} \cdot \underline{E}] \mathrm{d} \Omega .
$$

As observed, the reversible power is given by $\underline{\dot{D}}^{r} \cdot \underline{E}$, while the irreversible one is due to two contributions: Joule's heating, mathematically represented by $\underline{j} \cdot \underline{E}$, and polarisation heating, $\underline{\dot{D}}^{i} \cdot \underline{E}$.

By combining (6.15), (6.14), (6.13), (6.12) and (6.11), the NET energy balance when magnetic fields are lacking becomes:

$$
\int_{\Omega} \rho \dot{\mathrm{u}} \mathrm{d} \Omega=-\int_{\Omega}(\underline{\nabla} \cdot \underline{q}-\underline{j} \cdot \underline{E}-\underline{\dot{D}} \cdot \underline{E}-r) \mathrm{d} \Omega .
$$

The energy balance is expressed in terms of temperature for its numerical implementation by substituting the rate of (6.7) and (6.10) (left) into (6.16):

$$
\int_{\Omega} \rho c \dot{T} \mathrm{~d} \Omega=-\int_{\Omega} \underline{\nabla} \cdot \underline{q} \mathrm{~d} \Omega+\int_{\Omega}\left(\underline{j}+\underline{\dot{D}}^{i}\right) \cdot \underline{E} \mathrm{~d} \Omega+\int_{\Omega} r \mathrm{~d} \Omega
$$

where $c$ represents the specific heat capacity.

At this point, the entropy balance must be calculated to obtain the material constitution. For this purpose, the reversible energy rate given in (6.7) is inserted into (6.16) to obtain:

$$
\int_{\Omega} \rho \dot{\mathrm{s}} \mathrm{d} \Omega=-\int_{\Omega} \underline{\nabla} \cdot\left(\frac{\underline{q}}{T}\right) \mathrm{d} \Omega+\int_{\Omega}\left[-\underline{q} \cdot\left(\frac{\underline{\nabla} T}{T^{2}}\right)+\frac{\underline{j} \cdot \underline{\underline{E}}}{T}+\frac{\underline{\dot{D}}^{i} \cdot \underline{E}}{T}+\frac{r}{T}\right] \mathrm{d} \Omega,
$$

where s refers to specific entropy and the chain rule is used for convenience to rewrite the heat flux term.

According to $[29,31]$, the entropy balance in the NET context reads:

$$
\int_{\Omega} \rho \dot{\mathrm{s}} \mathrm{d} \Omega=-\int_{\Omega} \underline{\nabla} \cdot \underline{j_{s}} \mathrm{~d} \Omega+\int_{\Omega} \sigma_{s} \mathrm{~d} \Omega,
$$

consequently, by comparing (6.18) and (6.19), entropy flux $j_{s}$ and entropy production $\sigma_{s}$ may be explicitly expressed as:

$$
\underline{j_{s}}=\frac{\underline{q}}{T}, \quad \sigma_{s}=-\underline{q} \cdot\left(\frac{\underline{\nabla} T}{T^{2}}\right)+\frac{j \cdot \underline{E}}{T}+\frac{\underline{D}^{i} \cdot \underline{E}}{T}+\frac{r}{T} \geq 0 .
$$

From $\sigma_{s}$ of $(6.20)$, it is concluded that entropy sources are due to three irreversible processes: 
- Heat conduction, the first term on the right-hand side of the second equation

- Joule's heating, the second term

- Polarisation heating, the third term

Finally, to obtain the material constitution (known as transport equations in the NET context), the entropy production of (6.20) may be expressed in a first good and reasonable approximation as a linear combination of fluxes and driving forces $[29,31]$ :

$$
\underline{j}=\underline{\underline{\gamma}} \cdot \underline{E}, \quad \underline{q}=-\underline{\underline{\kappa}} \cdot \underline{\nabla} T, \quad \underline{\dot{D}}^{i}=\underline{\underline{\epsilon}}^{i} \cdot \underline{\ddot{E}},
$$

where $\underline{\underline{\gamma}}$ and $\underline{\underline{\kappa}}$ denote electrical and thermal conductivity, respectively. Coefficient $\underline{\underline{\epsilon}}^{i}$ represents the irreversible part of the permittivity of the medium. This irreversible permittivity depends on $\epsilon_{s}$ and $\epsilon_{\infty}$, which are known as static and high-frequency relative permittivity, respectively. In turn these two parameters are directly related to complex relative permittivity $\epsilon_{r}(\lambda)$, which is the measurement generally provided in the material databases. The relation among $\epsilon_{s}, \epsilon_{\infty}$ and $\epsilon_{r}(\lambda)$ is explicitly reported in Appendix A. The detail of the derivation of the Debye relaxation law in the time domain in (6.21) (right) and the definition of $\underline{\underline{\epsilon}}^{r}$ and $\underline{\underline{\epsilon}}^{i}$ are explicitly reported in Appendix B.

Solving coupled physical phenomena of different nature in a numerical and monolithic approach, which is the intention of this work, could lead to accuracy issues given the very different orders of magnitude of the involved physical quantities. Some numerical problems regarding accuracy arise in the present formulation if (6.21) (right) is directly used. Therefore, for the sake of numerical accuracy, this equation is re-expressed to avoid such errors.

As the excitation electric field is assumed to be harmonic, the following relation between the electric field and its second-time derivative holds:

$$
\underline{\ddot{E}}=-\omega^{2} \underline{E} .
$$

By substituting (6.22) in (6.21) (right), the Debye relaxation law can be reexpressed as:

$$
\underline{\dot{D}}^{i}=-\omega^{2} \underline{\underline{\epsilon}}^{i} \cdot \underline{E}=\underline{\epsilon}^{i *} \cdot \underline{E},
$$

where the new coefficient $\underline{\epsilon}^{i *}$ is defined for the sake of compactness in the notation as:

$$
\underline{\underline{\epsilon}}^{i *}=\epsilon_{0} \frac{\epsilon_{s}-\epsilon_{\infty}}{1+\omega^{2} \tau^{2}} \tau \omega^{2} \underline{\underline{I}}
$$

where $\underline{\underline{I}}$ is the identity tensor.

Hence, equation (6.23) proves more convenient numerically and will be henceforth used even though, in essence, both (6.21) (right) and (6.23) describe the same physical phenomenon. 


\subsubsection{Boundary conditions}

The boundary conditions for the two degrees of freedom, namely $T$ and $V$, are composed of Dirichlet and Neumann expressions:

$$
\begin{array}{ll}
\text { Dirichlet: } & T=\bar{T}, \quad V=\bar{V}, \\
\text { Neumann: } & \underline{q} \cdot \underline{n}=\bar{q}, \quad \underline{j} \cdot \underline{n}=\bar{j}, \quad \underline{D} \cdot \underline{n}=\bar{D},
\end{array}
$$

where $\bar{T}, \bar{V}, \bar{q}, \bar{j}$ and $\bar{D}$ are the prescribed temperature, voltage, thermal flux, electric flux and electric displacement, respectively.

\subsection{Finite element formulation}

This section presents a variational approach in the FE context [33] to numerically express the governing equations of light-to-heat conversion. For this purpose: i) the balance equations are multiplied by test functions; ii) isoparametric discretisations are introduced; iii) a residual-based formulation is obtained to solve the problem's non-linearity (thermal sources quadratically depend on the electric field); iv) tangent matrices are calculated.

\subsubsection{Weak forms}

As previously mentioned, weak forms are obtained by multiplying (6.5) and (6.17) by test functions $(\delta T, \delta V)$ respectively, and by applying the divergence theorem and introducing the Neumann boundary conditions of (6.25):

$$
\begin{gathered}
\int_{\Omega} \underline{\nabla} \delta T \cdot \underline{q} \mathrm{~d} \Omega-\int_{\Omega} \delta T \rho c \dot{T} \mathrm{~d} \Omega-\int_{\Gamma} \delta T \underline{q} \cdot \underline{n} \mathrm{~d} \Gamma+\int_{\Omega} \delta T\left(\underline{j}+\underline{\dot{D}}^{i}\right) \cdot \underline{E} \mathrm{~d} \Omega \\
+\int_{\Omega} \delta T r \mathrm{~d} \Omega=0, \\
\int_{\Omega} \underline{\nabla} \delta V \cdot(\underline{j}+\underline{\dot{D}}) \mathrm{d} \Omega-\int_{\Gamma} \delta V(\underline{j}+\underline{\dot{D}}) \cdot \underline{n} \mathrm{~d} \Gamma=0 .
\end{gathered}
$$

\subsubsection{Discretisations}

At this point, continuum domain $\Omega$ with boundary $\Gamma$ is discretised by using $n$ elements of domain $\Omega_{e}$ and boundary $\Gamma_{e}$. For this purpose, the present work uses eight-noded brick elements with standard Lagrange-type shape functions $\mathcal{N}$ to interpolate the degrees of freedom and spatial coordinates.

$$
\begin{array}{lll}
T \approx \mathcal{N}_{b} a_{b}^{T}, & \delta T \approx \mathcal{N}_{b} \delta a_{b}^{T}, & \underline{\nabla} T \approx \underline{\mathcal{B}}_{b} a_{b}^{T},
\end{array}
$$


where the Einstein summation convention is used, $\underline{\mathcal{B}}$ represents the shape function gradient matrix, and $a_{b}^{j}$ denotes the nodal values in a generic node $b$ for each degree of freedom $j=\{T, V\}$.

\subsubsection{Residuals}

The discretisations of (6.27) are introduced into (6.26) to obtain the residuals in a generic node $a$ :

$$
\begin{aligned}
\mathcal{R}_{a}^{T}= & \int_{\Omega_{e}} \underline{\mathcal{B}}_{a} \underline{q} \mathrm{~d} \Omega_{e}-\int_{\Omega_{e}} \mathcal{N}_{a} \rho c \mathcal{N}_{i} \dot{a}_{i}^{T} \mathrm{~d} \Omega_{e}-\int_{\Gamma_{e}} \mathcal{N}_{a} \underline{q} \underline{n} \mathrm{~d} \Gamma_{e} \\
& -\int_{\Omega_{e}} \mathcal{N}_{a}\left(\underline{j}+\underline{\dot{D}}^{i}\right) \cdot \underline{\mathcal{B}}_{i} a_{i}^{V} \mathrm{~d} \Omega_{e}+\int_{\Omega_{e}} \mathcal{N}_{a} r \mathrm{~d} \Omega_{e}, \\
\mathcal{R}_{a}^{V}= & \int_{\Omega_{e}} \underline{\mathcal{B}}_{a} \cdot(\underline{j}+\underline{\dot{D}}) \mathrm{d} \Omega_{e}-\int_{\Gamma_{e}} \mathcal{N}_{a}(\underline{j}+\underline{\dot{D}}) \cdot \underline{n} \mathrm{~d} \Gamma_{e},
\end{aligned}
$$

where $\underline{q}=-\underline{\underline{\kappa}} \cdot \underline{\mathcal{B}}_{i} a_{i}^{T}, \underline{j}=-\underline{\underline{\gamma}} \cdot \underline{\mathcal{B}}_{i} a_{i}^{V}$ and $\underline{\dot{D}}=\underline{\dot{D}}^{r}+\underline{\dot{D}}^{i}$, where $\underline{\dot{D}}^{r}=-\underline{\underline{\epsilon}}^{r} \cdot \underline{\mathcal{B}}_{i} \dot{a}_{i}^{V}$ and $\underline{\dot{D}}^{i}=-\underline{\underline{\epsilon}}^{i *} \cdot \underline{\mathcal{B}}_{i} a_{i}^{V}$.

\subsubsection{Tangent matrices}

Tangent matrices are obtained by standard FE procedures:

$$
\mathcal{K}_{a b}^{i j}=-\frac{\partial \mathcal{R}_{a}^{i}}{\partial a_{b}^{j}}, \mathcal{C}_{a b}^{i j}=-\frac{\partial \mathcal{R}_{a}^{i}}{\partial \dot{a}_{b}^{j}}, \mathcal{M}_{a b}^{i j}=-\frac{\partial \mathcal{R}_{a}^{i}}{\partial \ddot{a}_{b}^{j}},
$$

where $\mathcal{K}, \mathcal{C}$ and $\mathcal{M}$ denote the tangent stiffness, capacity and mass matrices, respectively. Indices $i$ and $j$ refer to degrees of freedom and $a$ and $b$ to two generic nodes.

For the sake of clarity, tangent matrices are explicitly reported in Appendix C. Finally, the monolithic assembled matrix becomes:

$$
\left[\begin{array}{cc}
\mathcal{K}_{a b}^{T T}+c_{2} \mathcal{C}_{a b}^{T T} & \mathcal{K}_{a b}^{T V} \\
0 & \mathcal{K}_{a b}^{V V}+c_{2} \mathcal{C}_{a b}^{V V}
\end{array}\right]\left\{\begin{array}{l}
\mathrm{d} a_{b}^{T} \\
\mathrm{~d} a_{b}^{V}
\end{array}\right\}=\left\{\begin{array}{c}
\mathcal{R}_{b}^{T} \\
\mathcal{R}_{b}^{V}
\end{array}\right\},
$$

where coefficient $c_{2}$ is a scalar involving the parameters of the time integration scheme as reported in [162].

The present FE formulation is implemented into the research code FEAP [162], which belongs to the University of California at Berkeley (USA). This software holds dummy subroutines to add elements, while non-linear solvers and time integration algorithms are already implemented. In particular, the present work uses the standard Newton-Raphson algorithm to solve non-linearities and backward differences for the time integration. 


\subsection{Results}

This section presents a validation of the present formulation to ensure proper implementation and, in addition, several study scenarios are presented to provide profounder physical insight into the comprehension of light-to-heat conversion in solar nanofluids.

\subsubsection{One-dimensional validation}

In this section, the numerical code is compared to a simple one-dimensional, timeindependent excitation and steady-state analytical solution developed by the authors and reported in Appendix D. The one-dimensional domain and its boundary conditions are shown in Figure 6.1:

- The length of the domain is $L=0.1(\mathrm{~m})$.

- $T_{1}=303.15(\mathrm{~K})$ and $V_{1}=0(\mathrm{~V})$ denote prescribed values on the left-end.

- $T_{2}=353.15(\mathrm{~K})$ and $V_{2}=\{0.05,0.1,0.2\}(\mathrm{V})$ on the right-end.

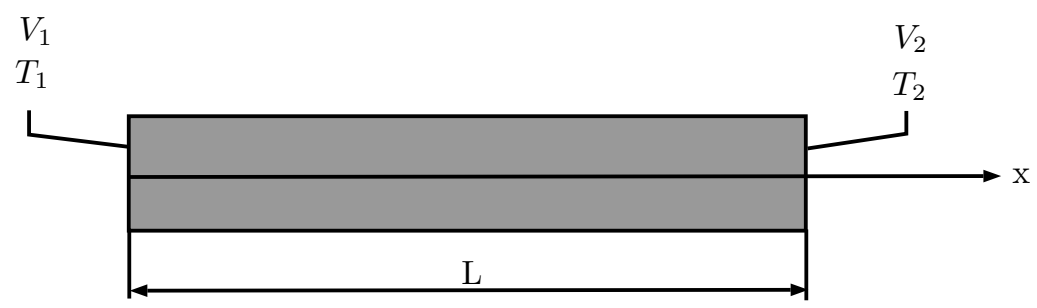

Figure 6.1: Geometry and boundary conditions of the one-dimensional domain used for the validation of the numerical model.

For the validation, gold $(\mathrm{Au})$ is considered because it is one of the most frequently used materials for light-to-heat conversion in NPs. The material properties of $\mathrm{Au}$ are obtained from $[65,66,163-165]$ and summarised in Table 6.1. Note that the relative permittivity values $\epsilon_{r}(\lambda)=\epsilon / \epsilon_{0}$ provided in Table 6.1 are expressed in complex form, as in the literature, at a wavelength $\lambda=400(\mathrm{~nm})$ and $i$ represents the imaginary unit.

Figure 6.2 compares the analytical (solid lines) and numerical solutions (solid circles) for $T$ and $V$ distributions in the study domain. As observed, an excellent agreement is reached between the analytical and numerical solutions for this simple validation; the maximum relative error is $0.0014(\%)$. In addition, the non-linearity due to the quadratic dependence of Joule's heating is solved by 3 iterations of the Newton-Raphson algorithm. This non-linearity can be observed in the quadratic distribution of temperature shown in Figure 6.2 (left). 
Table 6.1: Material properties for different materials.

\begin{tabular}{|c|c|c|c|}
\hline Material & Properties & Value & Units \\
\hline \multirow{6}{*}{ Gold $(\mathrm{Au})$} & $\rho$ & 19320 & $\mathrm{~kg} / \mathrm{m}^{3}$ \\
\hline & $c$ & 131.4 & $\mathrm{~J} /(\mathrm{kg} \cdot \mathrm{K})$ \\
\hline & $\kappa$ & 312 & $\mathrm{~W} /(\mathrm{m} \cdot \mathrm{K})$ \\
\hline & $\gamma$ & $3.17 \cdot 10^{7}$ & $(\Omega \cdot \mathrm{m})^{-1}$ \\
\hline & $\epsilon_{r}(\lambda)$ & $-1.4421-6.3962 i$ & - \\
\hline & $n(\lambda)$ & $1.5992+1.9998 i$ & - \\
\hline \multirow{6}{*}{ Silver (Ag) } & $\rho$ & 10490 & $\mathrm{~kg} / \mathrm{m}^{3}$ \\
\hline & $c$ & 240.49 & $\mathrm{~J} /(\mathrm{kg} \cdot \mathrm{K})$ \\
\hline & $\kappa$ & 420 & $\mathrm{~W} /(\mathrm{m} \cdot \mathrm{K})$ \\
\hline & $\gamma$ & $4.42 \cdot 10^{7}$ & $(\Omega \cdot \mathrm{m})^{-1}$ \\
\hline & $\epsilon_{r}(\lambda)$ & $-3.3668-0.7122 i$ & - \\
\hline & $n(\lambda)$ & $0.1930+1.8450 i$ & - \\
\hline \multirow{6}{*}{ Graphite $(\mathrm{G})$} & $\rho$ & 2100 & $\mathrm{~kg} / \mathrm{m}^{3}$ \\
\hline & $c$ & 1041.36 & $\mathrm{~J} /(\mathrm{kg} \cdot \mathrm{K})$ \\
\hline & $\kappa$ & 390 & $\mathrm{~W} /(\mathrm{m} \cdot \mathrm{K})$ \\
\hline & $\gamma$ & $2 \cdot 10^{3}$ & $(\Omega \cdot \mathrm{m})^{-1}$ \\
\hline & $\epsilon_{r}(\lambda)$ & $2.2285-3.1024 i$ & - \\
\hline & $n(\lambda)$ & $1.7390+0.8920 i$ & - \\
\hline \multirow{6}{*}{ Water $\left(\mathrm{H}_{2} \mathrm{O}\right)$} & $\rho$ & 988.037 & $\mathrm{~kg} / \mathrm{m}^{3}$ \\
\hline & $c$ & 4176.84 & $\mathrm{~J} /(\mathrm{kg} \cdot \mathrm{K})$ \\
\hline & $\kappa$ & 0.645 & $\mathrm{~W} /(\mathrm{m} \cdot \mathrm{K})$ \\
\hline & $\gamma$ & $5.5 \cdot 10^{-6}$ & $(\Omega \cdot \mathrm{m})^{-1}$ \\
\hline & $\epsilon_{r}(\lambda)$ & $1.7929-5 \cdot 10^{-9} i$ & - \\
\hline & $n(\lambda)$ & $1.3390+1.9 \cdot 10^{-9} i$ & - \\
\hline
\end{tabular}
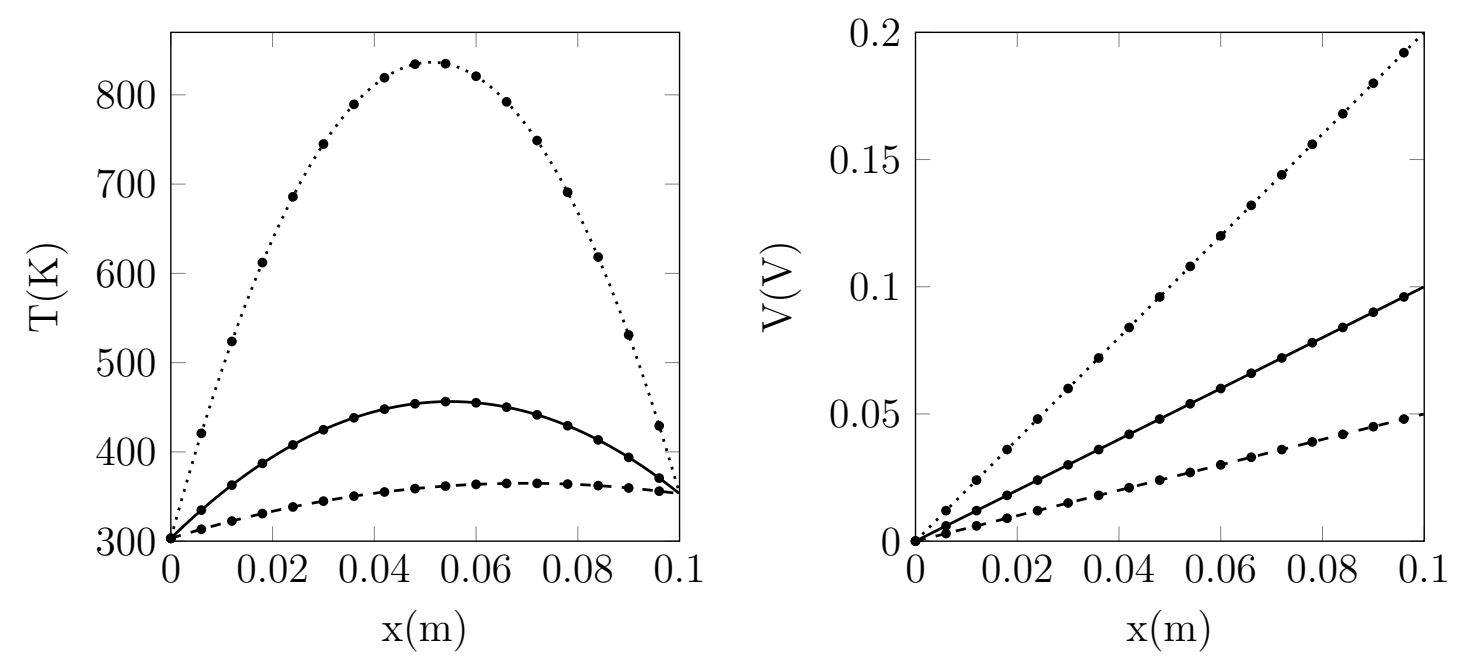

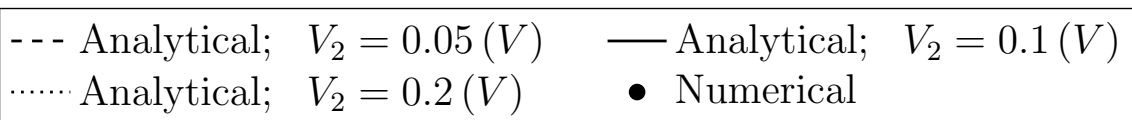

Figure 6.2: Comparison of the steady-state analytical and numerical distributions of temperature (left) and voltage (right) along the one-dimensional domain shown in Figure 6.1 for three different values of prescribed voltage $V_{2}=\{0.05,0.1,0.2\}(\mathrm{V})$ at the right end of the geometry. 


\subsubsection{Three-dimensional simulation}

This section presents a three-dimensional simulation of an Au NP surrounded by water and irradiated by a laser beam to determine the instantaneous heat dissipation in the surroundings of a single NP. Figure 6.3 shows the domain with its boundary conditions: the voltage reference is set at $V_{0}=0(\mathrm{~V})$ at $x=L / 2$ and a time-dependent voltage $V(t)=V_{0} \sin (\omega t)$, with $V_{0}$ denoting voltage amplitude, is prescribed at $x=-L / 2$. Temperature boundary conditions are set at a constant fixed value for each side of the cube in Figure 6.3. The centre of the NP is located at the origin of the reference system.

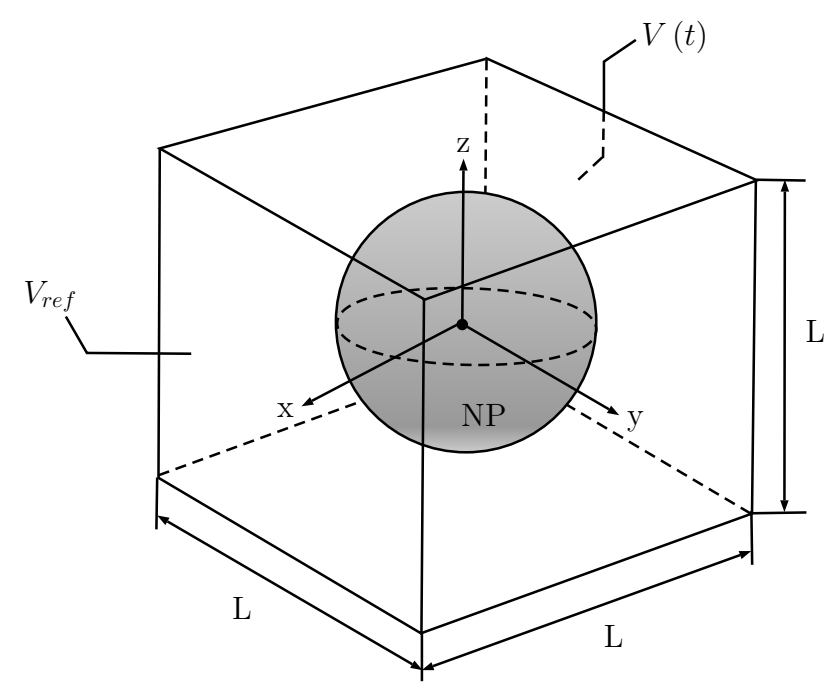

Figure 6.3: Geometry and boundary conditions of the three-dimensional simulation.

The Au NP is excited by a laser beam at $400(\mathrm{~nm})$ and amplitude $V_{0}$ is computed from the definition of the RMS value of laser intensity [131] as follows:

$$
V_{0}=\sqrt{\frac{2 I_{\text {laser }}}{c_{\text {light }} \epsilon_{0}\left\|n_{H_{2} O}(\lambda)\right\|}} L,
$$

where $I_{\text {laser }}, c_{\text {light }}$ and $\left\|n_{H_{2} O}(\lambda)\right\|$ denote the RMS value of the laser flux, speed of light and the norm of the wavelength-dependent complex refractive index of water, respectively. Note that the laser flux considered for the simulations is obtained from the literature [131]: $I_{\text {laser }}=5 \times 10^{4}\left(\mathrm{~W} / \mathrm{cm}^{2}\right)$.

Excitation pulsation $\omega$ can be determined from wavelength $\lambda$ of incident excitation as follows:

$$
\omega=\frac{2 \pi c_{\text {light }}}{\lambda\|n(\lambda)\|}
$$

where $\|n(\lambda)\|$ denotes the norm of the complex refractive index.

For the sake of completeness for the parameter calibration in the present model, relaxation time $\tau$ is necessary for the Debye law and is computed as follows ([166]):

$$
\tau=\frac{\lambda_{c}\left\|n\left(\lambda_{c}\right)\right\|}{2 \pi c_{\text {light }}}
$$

where subscript $c$ denotes the critical point in the wavelength spectrum at which the relaxation phenomenon occurs. According to [167], this critical point can be 
determined as the intersection between the real and imaginary part functions of the complex relative permittivity. Once the critical point is found, the optical material properties at the critical wavelength such as the refractive index can be determined.

For the geometrical dimensions, the diameter of the Au NP is 20 (nm) and the length of the surrounding medium, controlled by $L$, is chosen to be large enough to avoid edge effects. For this first study, L is taken to be 10-fold bigger than the diameter of the NP. Finally, the material properties of gold and water, which are obtained from $[65,165,168,169]$ for water, are reported in Table 6.1.

The increase in temperature, namely, light-to-heat conversion, is shown in Figure 6.4 for the different sinusoidal excitation function values at four different times. As expected, the parabolic temperature increase profiles are obtained around the NPs, where the maximum temperature increase is reached at the centre of the NP and is directly proportional to the amplitude of the prescribed voltage. Note also that although sinusoidal excitation may take negative values as in Figure 6.4, as the dissipation due to polarisation phenomena responds to a quadratic effect, the sinusoidal excitation sign has no influence on dissipation.

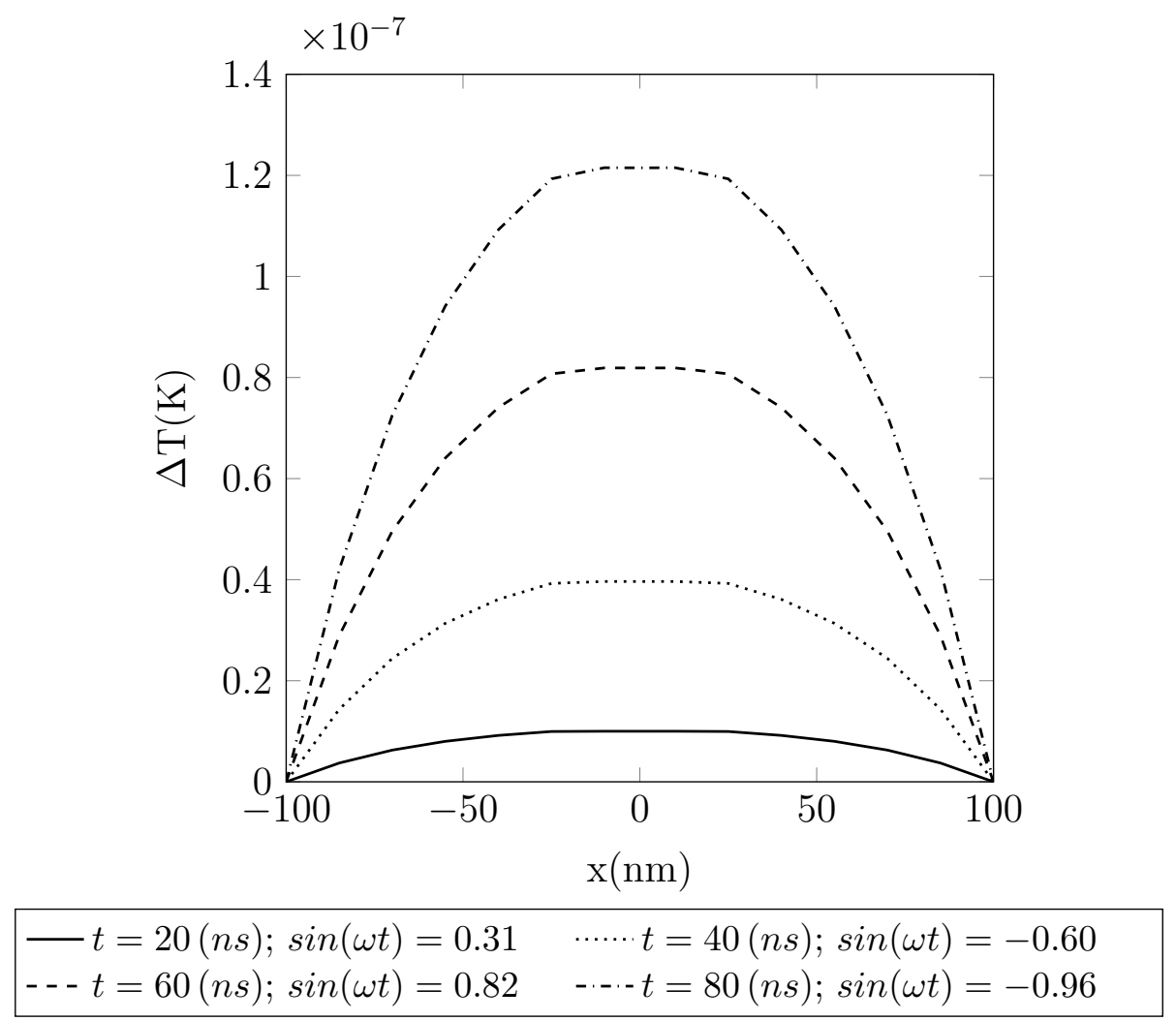

Figure 6.4: Temperature increase across the diameter of a gold nanoparticle centred at $x=$ 0 (see Figure 6.3) for four different values of amplitude of sinusoidal excitation $\sin (\omega t)=$ $\{0.31,-0.60,0.82,-0.96\}$ at four different times $t=\{20,40,60,80\}(n s)$. The nanoparticle is 20 $(\mathrm{nm})$ in diameter and is irradiated by a laser flux of $5 \times 10^{4}\left(\mathrm{~W} / \mathrm{cm}^{2}\right)$ at a wavelength $\lambda=400$ $(\mathrm{nm})$.

For dissipation terms in the energy balance (6.17), two main terms contribute to light-to-heat conversion: Joule's and polarisation effects. The former is governed by the material's electrical conductivity, and the latter by the irreversible part of relative permittivity.

Concerning Joule's heating, this source is relevant for low-frequency excitations, 
but not for high-frequencies, which are those at which light-to-heat conversion takes place; at approximately $560(\mathrm{THz})$ for the simulations presented in this Section. Note that electrodynamics can be approximated to quasi-static phenomena until frequency of the order of $10(\mathrm{GHz})$ or lower is reached, as indicated in [170].

Regarding polarisation heating and by considering high-frequencies, it is numerically verified that the temperature increase produced by Joule's heating is much lower than that generated by polarisation heating. Therefore, the effects of Joule's heating are included in the theoretical formulation for the sake of framework's generality but are omitted from the subsequent examples to study light-to-heat conversion in NPs.

\subsubsection{Light-to-heat conversion for different NPs}

This section compares heating in nanofluids due to the light-to-heat conversion for different materials used as NPs; namely gold $(\mathrm{Au})$, silver $(\mathrm{Ag})$ and graphite $(\mathrm{G})$. The properties of $\mathrm{Ag}$ are taken from $[65,66,163,165,171]$ and those of $\mathrm{G}$ are obtained from $[65,165,172,173]$. Both are reported in Table 6.1 along with properties of $\mathrm{Au}$ and $\mathrm{H}_{2} \mathrm{O}$.

Studying a model that considers fluid dynamics is beyond the scope of the present work. However, the model introduced in this work (see Figure 6.3) permits the simulation of the medium surrounding a NP. Similarly, by considering that the surrounding medium (or base fluid in the nanofluids context) can be assumed to behave as a liquid at rest, this model can be used to simulate light-to-heat in nanofluids. Hence different concentrations of NPs in suspension in the base fluid can be reproduced by varying the volume ratio of the sphere representing the NP and the cube representing the base fluid. Hence volumetric concentration $\phi$ used henceforth in this work is defined as follows:

$$
\phi=\frac{V_{\text {sphere }}}{V_{\text {cube }}},
$$

where $V_{\text {sphere }}$ and $V_{\text {cube }}$ represent the volume of the sphere and the cube of our model, respectively.

Figure 6.5 shows the progressive temperature increase with time for water only, and for the $\mathrm{Au}, \mathrm{Ag}$ and $\mathrm{G}$ NPs dispersed in water, to compare the different evolution of temperature increase of nanofluids. Note that the diameter considered for the simulation of the different NPs is $20(\mathrm{~nm})$. Four different concentration values are retained: $\phi=\{0.0034,0.0065,0.016,0.052\}(\%)$ and, as experimentally confirmed, temperature increase is related to the concentration of the NPs in the base fluid.

Unlike the simulation presented in Section 6.4.2, the boundary conditions on temperature are not set at a fixed constant value, but are left unconstrained so that the temperature increase in the surrounding medium (water) can evolve with time. Note also that a unitary sinusoidal amplitude value is adopted for the simulations in this Section and that temperature increase is predicted on the outer surface of the NP that comes into contact with the base fluid.

Figure 6.5 depicts that for an excitation wavelength $\lambda=400(\mathrm{~nm})$, the temperature increase numerically predicted for the Ag NPs is greater than that for $\mathrm{G}$ NPs, and the latter is still larger than that predicted for the Au NPs. This trend coincides with the literature [174-177] because for $\lambda=400$ (nm), the absorption 
coefficient (directly related to light-to-heat conversion) of the Ag NPs dispersed in water is higher than that of the $\mathrm{G}$ and $\mathrm{Au}$ NPs dispersed in water. This heating enhancement in the Ag NPs versus the other NPs occurs because they are irradiated with an excitation wavelength $\lambda=400(\mathrm{~nm})$, which matches the surface plasmon resonance of $\mathrm{Ag}$.
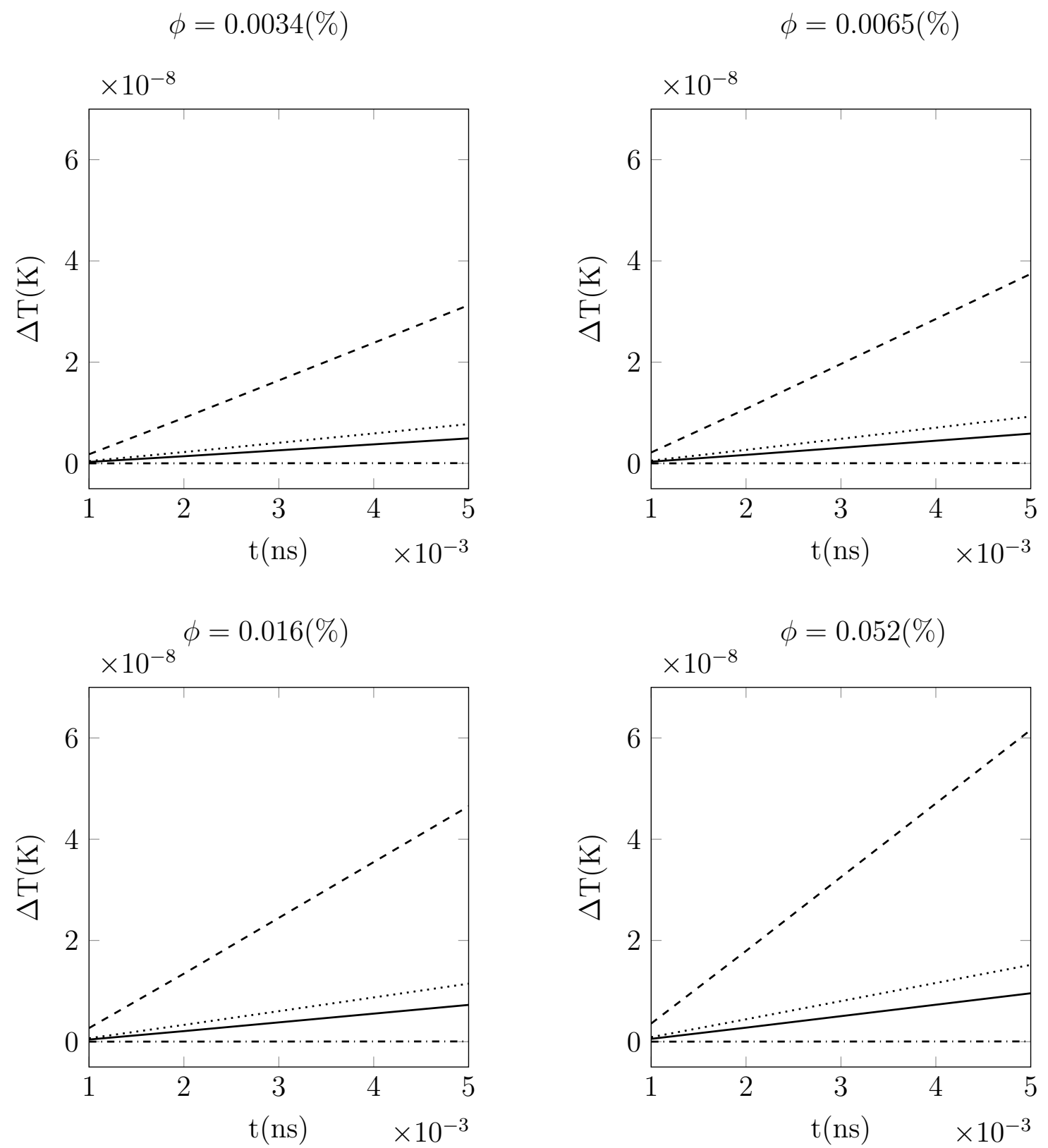

$-\mathrm{Au}+\mathrm{H}_{2} \mathrm{O} \quad-\cdots \mathrm{Ag}+\mathrm{H}_{2} \mathrm{O} \quad \cdots \cdots \mathrm{G}+\mathrm{H}_{2} \mathrm{O} \quad \cdots \cdots \mathrm{H}_{2} \mathrm{O}$

Figure 6.5: Time evolution of the temperature increase of different nanofluids for a laser flux $I_{\text {laser }}=5 \times 10^{4}\left(\mathrm{~W} / \mathrm{cm}^{2}\right)$ at a wavelength $\lambda=400(\mathrm{~nm})$ for four different volumetric concentrations $\phi=\{0.0034,0.0065,0.016,0.052\}(\%)$. The media considered for simulation are only water $\left(\mathrm{H}_{2} \mathrm{O}\right)$ and three different nanofluids composed of: gold nanoparticles dispersed in water $\left(\mathrm{Au}+\mathrm{H}_{2} \mathrm{O}\right)$, silver nanoparticles dispersed in water $\left(\mathrm{Ag}+\mathrm{H}_{2} \mathrm{O}\right)$ and graphite nanoparticles dispersed in water $\left(\mathrm{G}+\mathrm{H}_{2} \mathrm{O}\right)$. 


\subsubsection{Evolution of temperature increase with concentration}

This section presents a study on the influence of concentration on the temperature increase of nanofluids. For this purpose, a new metric that eliminates the effect of heating of the base fluid (water in this case) is defined in line with the dimensionless temperature increase below:

$$
\Delta T_{d l}=\frac{\frac{\Delta T_{N F}}{\Delta t_{N F}}}{\frac{\Delta T_{H_{2} O}}{\Delta t_{H_{2} O}}},
$$

where the numerator in (6.35) represents the slope of the temperature increase in the nanofluid and the denominator denotes the slope of the temperature increase in the base fluid.

Several numerical simulations are performed for different nanofluids, namely Au, $\mathrm{Ag}$ and G NPs in suspension in water, to assess the influence of different volumetric concentrations on the predicted temperature increase. Figure 6.6 shows this evolution.

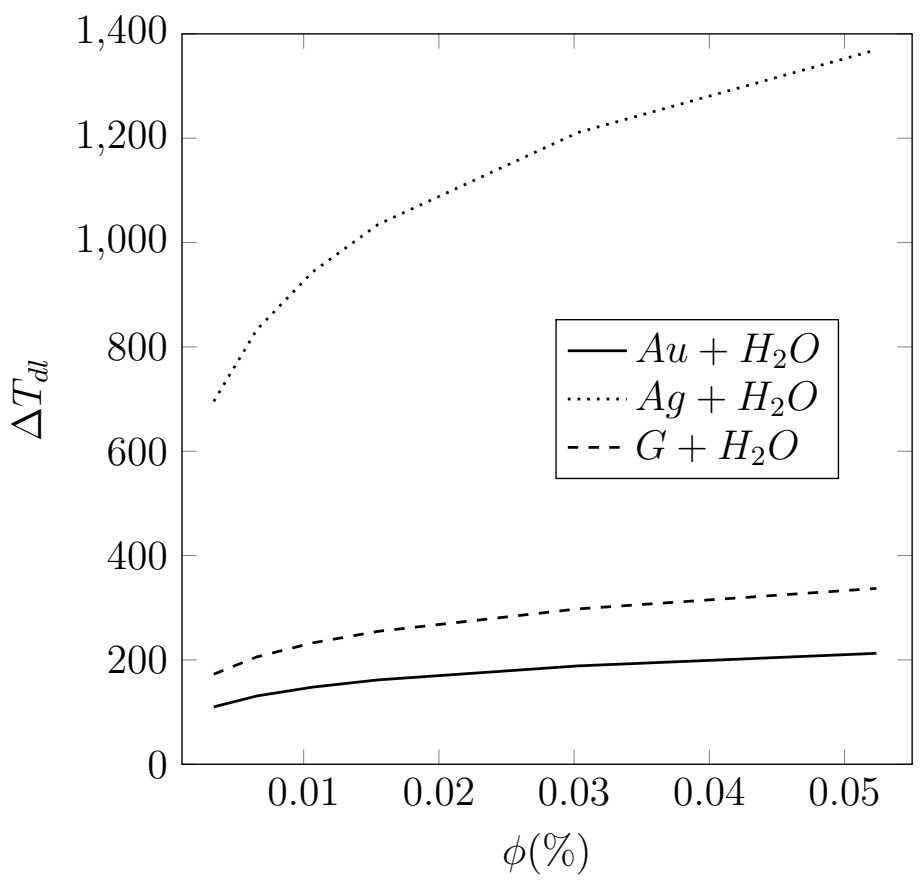

Figure 6.6: Evolution of the dimensionless temperature increase in relation to the volumetric concentration of the NPs in the nanofluid for three different nanofluids composed of: gold nanoparticles dispersed in water $\left(\mathrm{Au}+\mathrm{H}_{2} \mathrm{O}\right)$, silver nanoparticles dispersed in water $\left(\mathrm{Ag}+\mathrm{H}_{2} \mathrm{O}\right)$ and graphite nanoparticles dispersed in water $\left(G+H_{2} O\right)$ for a laser flux $I_{\text {laser }}=5 \times 10^{4}\left(\mathrm{~W} / \mathrm{cm}^{2}\right)$ at a wavelength $\lambda=400$ (nm).

The trend observed in Figure 6.6 is that the higher the NPs concentration in the nanofluid, the more marked the predicted temperature increase. However in real applications, increasing the NPs concentration is not exempt of drawbacks as such a choice entails an upsurge in viscosity [178] and, consequently, more difficulty to pump the nanofluid in flow system applications. Another inconvenience of incrementing concentration is that the colloidal stability of the nanofluid is not guaranteed [179, 180], thus it is more likely to precipitate and then lose the working principle of the 
nanofluid. Moreover, continuously increasing the NPs concentration in the base fluid does not guarantee better light absorption as light-to-heat conversion is limited to top layers in solar nanofluids with high NPs concentrations [181].

Therefore, Figure 6.6 can be used by the experimental community to select the most convenient combination of NPs and their concentration for a desired application.

\subsection{Conclusions}

This chapter presents a non-linear, three-dimensional, dynamic and thermodynamically consistent formulation applied to light-to-heat conversion for optically excited NPs. Theoretically, equilibrium and non-equilibrium thermodynamic formalisms are used to obtain the set of two coupled governing equations. Numerically, a finite element formulation for a light-to-heat problem is developed by using residuals due to the problems' non-linearities. Note that heat sources quadratically depend on the electric field. Finally, the numerical formulation is coded in a research software, is validated against a one-dimensional simulation and is used to perform several studies on light-to-heat conversion in solar nanofluids.

A good agreement is reached between the one-dimensional analytical solution and the numerical results, which permits to validate the present formulation. Furthermore, different numerical analyses are conducted for light-to-heat conversion in solar nanofluids. Firstly, the temperature increase around a single Au NP is obtained to verify the parabolic distribution of temperature for the different sinusoidal excitation values of a laser. Afterwards, the time evolution of the temperature increase for water and three different nanofluids is analysed: Au NPs dispersed in water, Ag NPs dispersed in water and graphite $(G)$ NPs dispersed in water. The numerical simulations predict a major heating enhancement for the Ag NPs than for the $\mathrm{G}$ and $\mathrm{Au}$ NPs, respectively, which agrees with the experimental trends when these nanofluids are excited at a wavelength of $400(\mathrm{~nm})$ because this wavelength matches the surface plasmon resonance of Ag. Finally, a study on the influence of NP concentration in nanofluids is performed. It is concluded that the temperature increase due to light-to-heat conversion depends on the charge of NPs in the nanofluids but the concentration cannot be increased indefinitely as other practical issues, such as the lack of stability, the incremented viscosity of the nanofluid or the limitation of light absorption to top nanofluid layers become apparent.

In short, this numerical model can be used as a virtual laboratory to better understand the physical phenomena involved in light-to-heat conversion in NPs due to the complexity of measuring the temperature increase in a single NP from an experimental point of view. Therefore, this numerical tool can be used to make predictions to help select a certain combination of base fluid, NPs and their concentration in the nanofluid for a desired application by reducing the number of experiments to be conducted and consequently their cost. 


\section{Appendix to Chapter 6}

\section{A. Static and high-frequency relative permittivity}

This appendix provides the relation between the measured complex relative permittivity $\epsilon_{r}(\lambda)$ and parameters $\epsilon_{s}$ and $\epsilon_{\infty}$, used in the present work for the Debye relaxation model.

Pulsation-dependent relative permittivity can be written in the form of a complex number:

$$
\epsilon_{r}(\lambda)=\epsilon^{\prime}+i \epsilon^{\prime \prime}
$$

where $\epsilon^{\prime}$ and $\epsilon^{\prime \prime}$ denote the real and imaginary part of complex permittivity, respectively.

The real and imaginary parts of complex relative permittivity in (6.39) are separated and the obtained expression is:

$$
\epsilon_{r}(\lambda)=\epsilon_{\infty}+\frac{\epsilon_{s}-\epsilon_{\infty}}{1+\omega^{2} \tau^{2}}-\frac{\left(\epsilon_{s}-\epsilon_{\infty}\right) i \omega \tau}{1+\omega^{2} \tau^{2}},
$$

where $\tau$ represents the relaxation time.

By equalling the real and imaginary parts from (6.36) and (6.37), explicit algebraic expressions of $\epsilon_{s}$ and $\epsilon_{\infty}$ are obtained in terms of the experimentally measured coefficients:

$$
\epsilon_{s}=\epsilon^{\prime}-\epsilon^{\prime \prime} \omega \tau, \quad \epsilon_{\infty}=\epsilon^{\prime}+\frac{\epsilon^{\prime \prime}}{\omega \tau}
$$

\section{B. Debye relaxation law}

The Debye relaxation law is usually provided in the frequency domain in literature $[153,154,182]$ as follows:

$$
\underline{D}(\omega)=\epsilon_{0}\left(\epsilon_{\infty}+\frac{\epsilon_{s}-\epsilon_{\infty}}{1+i \omega \tau}\right) \underline{\underline{I}} \cdot \underline{E}(\omega) .
$$

As a multiphysics time domain formulation is intended in the present work, and as the electric-field excitation is assumed to be monochromatic and harmonic to behave like a laser, the Debye relaxation model can be re-expressed analytically in the time domain by the inverse Fourier transform. More specifically, the following transforms are needed: 
i) Rational function of pulsation

$$
\frac{1}{2 \pi} \int_{-\infty}^{+\infty} \frac{1}{a+i \omega} e^{i \omega t} \mathrm{~d} \omega=e^{-a t} h(t)
$$

where $a$ is a constant so that $\operatorname{Re}(a)>0$ and $h(t)$ represents the Heaviside step function.

ii) Convolution in time

$$
\frac{1}{2 \pi} \int_{-\infty}^{+\infty} \hat{f}(\omega) \hat{g}(\omega) e^{i \omega t} \mathrm{~d} \omega=(f * g)(t)
$$

where symbol $*$ represents the convolution product.

By using properties (6.40) and (6.41), and by enforcing the sinusoidal electric field condition, the time domain expression of the Debye relaxation model is finally derived:

$$
\underline{D}=\epsilon_{0}\left[\left(\epsilon_{\infty}+\frac{\epsilon_{s}-\epsilon_{\infty}}{1+\omega^{2} \tau^{2}}\right) \underline{\underline{I}} \cdot \underline{E}-\frac{\epsilon_{s}-\epsilon_{\infty}}{1+\omega^{2} \tau^{2}} \tau \underline{\underline{I}} \cdot \underline{\dot{E}}\right] .
$$

Thus the reversible and irreversible parts of electric displacement and permittivity can be identified as:

$$
\begin{aligned}
& \underline{D}^{r}=\epsilon_{0}\left(\epsilon_{\infty}+\frac{\epsilon_{s}-\epsilon_{\infty}}{1+\omega^{2} \tau^{2}}\right) \underline{I} \cdot \underline{E}=\underline{\epsilon}^{r} \cdot \underline{E}, \\
& \underline{D}^{i}=-\epsilon_{0} \frac{\epsilon_{s}-\epsilon_{\infty}}{1+\omega^{2} \tau^{2}} \tau \underline{\underline{I}} \cdot \underline{\dot{E}}=\underline{\epsilon}^{i} \cdot \underline{\dot{E}} .
\end{aligned}
$$

\section{Tangent matrices}

This appendix reports the explicit form of tangent matrices.

$$
\begin{aligned}
& \mathcal{K}_{a b}^{T T}=-\frac{\partial \mathcal{R}_{a}^{T}}{\partial a_{b}^{T}}=\int_{\Omega_{e}} \underline{\mathcal{B}}_{a} \underline{\underline{\kappa}} \underline{\mathcal{B}}_{b} \mathrm{~d} \Omega_{e}, \\
& \mathcal{K}_{a b}^{T V}=-\frac{\partial \mathcal{R}_{a}^{T}}{\partial a_{b}^{V}}=-\int_{\Omega_{e}} \mathcal{N}_{a} 2\left(\underline{\underline{\gamma}}+\underline{\underline{\epsilon}}^{i}\right) \underline{\mathcal{B}}_{i} a_{i}^{V} \underline{\mathcal{B}}_{b} \mathrm{~d} \Omega_{e}, \\
& \mathcal{C}_{a b}^{T T}=-\frac{\partial \mathcal{R}_{a}^{T}}{\partial \dot{a}_{b}^{T}}=\int_{\Omega_{e}} \mathcal{N}_{a} \rho c \mathcal{N}_{b} \mathrm{~d} \Omega_{e}, \\
& \mathcal{K}_{a b}^{V V}=-\frac{\partial \mathcal{R}_{a}^{V}}{\partial a_{b}^{V}}=\int_{\Omega_{e}} \underline{\mathcal{B}}_{a}\left(\underline{\underline{\gamma}}+\underline{\underline{\epsilon}}^{i}\right) \underline{\mathcal{B}}_{b} \mathrm{~d} \Omega_{e}, \\
& \mathcal{C}_{a b}^{V V}=-\frac{\partial \mathcal{R}_{a}^{V}}{\partial \dot{a}_{b}^{V}}=\int_{\Omega_{e}} \underline{\mathcal{B}}_{a} \underline{\epsilon}^{r} \underline{\mathcal{B}}_{b} \mathrm{~d} \Omega_{e} .
\end{aligned}
$$




\section{One-dimensional analytical solution}

This appendix reports the steady-state, time-independent excitation and one-dimensional analytical solution used to validate the numerical code. For this purpose, balance equation (6.5) in the absence of transient terms and constitutive law (6.21) (left) are expressed in one-dimensional form:

$$
\frac{\partial j_{x}}{\partial x}=0 \quad, \quad j_{x}=-\gamma \frac{\partial V}{\partial x} .
$$

Now by considering the boundary conditions shown in Figure 6.1 , the voltage distribution reads:

$$
V=\frac{V_{2}-V_{1}}{L} x+V_{1}
$$

where $L$ denotes the length of the one-dimensional geometry.

For the thermal field, balance equation (6.17) in the absence of transient terms and constitutive law (6.21) (middle) are expressed in one-dimensional form as:

$$
\frac{\partial q_{x}}{\partial x}=-j_{x} \frac{\partial V}{\partial x} \quad, \quad q_{x}=-\kappa \frac{\partial T}{\partial x} .
$$

Finally, by enforcing the boundary conditions shown in Figure 6.1, the temperature distribution becomes:

$$
T=-\frac{\gamma}{\kappa}\left(\frac{V_{2}-V_{1}}{L}\right)^{2} \frac{x^{2}}{2}+\frac{1}{L}\left[T_{2}-T_{1}+\frac{\gamma}{\kappa}\left(\frac{V_{2}-V_{1}}{L}\right)^{2} \frac{L^{2}}{2}\right] x+T_{1} .
$$





\section{Chapter 7: General discussion and conclusions}

This thesis deals with the theoretical and numerical formulations of physical phenomena in nanoparticles for their use in nanofluids. In particular, the focus of the present work has been put in developing different numerical tools to perform simulations that reproduce the behaviour of nanoparticles for TES purposes and DASC. Therefore, these computational tools may contribute to better understand the behaviour of nanofluids for their use in solar thermal energy plants and contribute to optimise the selection of nanoparticles for the desired application.

In this thesis, a compendium of four different journal articles is presented, each one of them tackling different aspects related to the formulation of theoretical and numerical models for the prediction of physical behaviour of NPs in nanofluids. The most relevant conclusions from numerical simulations in this thesis can be grouped into three main categories, in which the most relevant results are summarised next as the main contributions of the present work:

- Thermomechanical modelling with phase change:

- With the aim of predicting thermal stresses in nePCMs, a thermodynamically consistent thermomechanical formulation with phase change is developed by implementing three regularisation algorithms for phase change. Numerical simulations with this model can be applied to different geometries (spherical and cylindrical) and different pairs of core@shell materials ( $\mathrm{Sn} @ \mathrm{SnO}_{2}$ and $\mathrm{Al} @ \mathrm{Al}_{2} \mathrm{O}_{3}$ ).

- The selection of a nePCM geometry and materials must respond to a compromise between energy density capability and mechanical strength, which depend upon the shell thickness of the nePCM. A compromise between these two features must be reached when defining the shell thickness value, which must be carefully studied for each desired application.

- Energy density of spherical nePCMs is higher than that of cylindrical ones for equal total volume of nePCMs.

- The maximum equivalent stress on the nePCM shell is higher for spherical nePCMs until a threshold shell thickness is attained. From that point forward, with increasing shell thickness, cylindrical nePCMs experience higher thermal stresses.

- Although, Al@ $\mathrm{Al}_{2} \mathrm{O}_{3}$ nePCMs possess an energy density capability which is nearly twice that of $\mathrm{Sn} @ \mathrm{SnO}_{2}$, numerical simulations predict that $\mathrm{Sn} @ \mathrm{SnO}_{2}$ nePCMs are likely to resist when exposed to thermal processes 
while $\mathrm{Al} @ \mathrm{Al}_{2} \mathrm{O}_{3}$ nePCMs are expected to fail mechanically due to the thermal stress arising in their shell.

- According to numerical simulations, the maximum stress in nePCMs appears just before melting of core starts.

- Probabilistic numerical modelling:

- Measurement uncertainty on material properties and on geometry dimensions of $\mathrm{Sn} @ \mathrm{SnO}_{2}$ and $\mathrm{Al} @ \mathrm{Al}_{2} \mathrm{O}_{3}$ nePCMs can be incorporated into the numerical analysis due to the probabilistic numerical tool developed by combining MC techniques with a FE model.

- The physical parameters exhibiting a major influence on the mechanical failure of the nePCM shell are Poisson's ratio of the core, thermal expansion coefficient of the core and its melting temperature.

- The parameters exhibiting a major influence on the energy density capability of nePCMs are the latent heat of the core, mass density of the liquid core and geometrical parameters of nePCMs.

- Both deterministic and probabilistic failure criteria are defined to consider the effects of uncertainty on the tensile strength of shells in their eventual mechanical failure. The probability of failure of $\mathrm{Sn} @ \mathrm{SnO}_{2}$ and $\mathrm{Al} @ \mathrm{Al}_{2} \mathrm{O}_{3}$ nePCMs is $1.87 \%$ and $100 \%$ respectively by considering a probabilistic failure criterion and is $0 \%$ and $100 \%$ by considering a deterministic failure criterion. This confirms that most of $\mathrm{Sn} @ \mathrm{SnO}_{2}$ nePCMs are not likely to fail under thermal stresses and that only considering a deterministic failure criterion can slightly underestimate the mechanical failure in the case of $\mathrm{SnO}_{2}$ shells.

- Numerically, considering a probabilistic failure criterion permits to increase the accuracy of the MC simulation by a factor $\sqrt{N}$ in comparison to the accuracy obtained by a deterministic criterion.

- The mechanical performance of multi-coated nePCMs, experimentally synthesised by the technique of ALD: $\mathrm{Sn} @ \mathrm{SnO}_{2} @ \mathrm{SiO}_{2}$ and $\mathrm{Sn} @ \mathrm{SnO} @$ $\mathrm{Al}_{2} \mathrm{O}_{3}$, is numerically assessed and it is observed that their probability of failure and the enthalpy decrease of nePCM cores reduces with the increasing number of ALD cycles, i.e., with the thickness of the outer shell.

- Numerical simulations and thermal characterisation of multicoated nePCMs seem to indicate that the POF of outer shells and the enthalpy decrease of nePCMs are related phenomena.

- $\mathrm{Al}_{2} \mathrm{O}_{3}$ coatings of multi-coated $\mathrm{Sn}$ nePCMs exhibit better thermal and mechanical performance than their $\mathrm{SiO}_{2}$ counterparts.

- High-frequency thermoelectric modelling:

- With the aim of avoiding frequency domain approaches for the study of multiphysics phenomena, a thermodynamically consistent time domain thermoelectric model is formulated for the numerical simulation of lightto-heat conversion in $\mathrm{Au}, \mathrm{Ag}$ and Graphite NPs, which are excited at a wavelength of $\lambda=400(\mathrm{~nm})$. 
- Parabolic distributions of temperature are obtained around the NPs, where the maximum temperature is predicted at its centre and is proportional to the prescribed voltage.

- Joule's heating dissipation can be neglected when compared to polarisation heating since the former is only relevant for low-frequency excitations.

- The temperature increase predicted for Ag NPs is greater than in Graphite and $\mathrm{Au}$ NPs, respectively for $\lambda=400(\mathrm{~nm})$ since this excitation matches the surface plasmon resonance of Ag.

- The temperature increase due to light-to-heat conversion depends on the load of NPs in the nanofluid. The trend is that the higher the NP concentration in the nanofluid, the higher the temperature increase.

Overall, this thesis lays the foundations of some theoretical and numerical frameworks to gain a deeper understanding in the physical phenomena involved around the use of NPs in nanofluids in solar thermal energy applications. From numerical results presented throughout this thesis, it can be claimed that the formulations developed in this work provide results which are in good agreement with experimental tendencies, within the unavoidable limitations of theoretical and numerical models with respect to reality. Then, these models appear to be as powerful computational tools which can be used as a virtual laboratory to complement experimental characterisations and to reduce the number of experiments to be conducted. In short, the intention of this work is to contribute to the improvement and optimisation of solar thermal energy technology to do my bit to boost the use of renewable energies to live in a cleaner world. 



\section{Chapter 8: Gaps and future research works}

Theoretical and numerical formulations of models to predict reality is a hard and continuously improving task because it is difficult to cast the complexity of reality into the form of equations. In the present thesis, several frameworks are developed dealing with mechanical, thermal and electric physical fields, which permit to obtain predictions of the behaviour of NPs in nanofluids. These numerical results already appear to be in good agreement with experimental tendencies reported in literature. In short, a thesis offers a view on the research carried out during a certain lapse of time but this does not mean that all the work in that field is already done. Indeed, there is still much more to discover and some of the remaining knowledge gaps and continuity lines that the present work may offer are:

- Use of other advanced regularisation techniques for the formulation of phase transition phenomena such as the phase-field method.

- Extension of the mechanical field from the formalism of small displacements or perturbations to the framework of finite strains.

- Inclusion of further material couplings and scale effects into the formulation of physical phenomena such as pyroelectricity or Cattaneo's heat conduction.

- Exploring more advanced theories of generalised continuum mechanics such as Cosserat's.

- Extension of the present formalisms to incorporate further physical fields like, for instance, magnetism or chemical reactions.

- Simulation of NPs dispersed within a base fluid to consider the interaction between them under conditions approaching those of industrial scale applications.

- Formulation of inverse problems based on models for estimation of homogenised thermal and optical properties of nanofluids from experimental measurements.

- Experimental characterisation of scale-dependent material properties of NPs to avoid using bulk properties for model calibration.

- Need for further experimental testing for validation of numerical models of NPs and nanofluids. 



\section{Chapter 9: Scientific production}

\subsection{Journal Contributions}

- N. Navarrete, A. Gimeno-Furió, J. Forner-Escrig, J.E. Juliá and R. Mondragón. Colloidal stability of molten salt-based nanofluids: Dynamic Light Scattering tests at high temperature conditions, Powder Technology, vol. 352, pp. 1-10, 2019.

DOI: $10.1016 /$ j.powtec.2019.04.045

- J. Forner-Escrig, R. Palma and R. Mondragón. Finite element formulation to study thermal stresses in nanoencapsulated phase change materials for energy storage, Journal of Thermal Stresses, vol. 43, no. 5, pp. 543-562, 2020.

DOI: $10.1080 / 01495739.2020 .1718045$

- J. Forner-Escrig, R. Mondragón, L. Hernández, R. Palma. Non-linear finite element modelling of light-to-heat energy conversion applied to solar nanofluids, International Journal of Mechanical Sciences, vol. 188, pp. 105952, 2020 .

DOI: $10.1016 /$ j.ijmecsci.2020.105952

- J. Forner-Escrig, R. Mondragón, L. Hernández, R. Palma. Mechanical reliability analysis of nanoencapsulated phase change materials combining Monte Carlo technique and the finite element method, Submitted for publication.

- J. Forner-Escrig, N. Navarrete, R. Palma, D. La Zara, A. Goulas, D. Valdesueiro, J. R. van Ommen, L. Hernández, R. Mondragón. Numerical modelling of the mechanical reliability of multi-coated nanoencapsulated phase change materials with improved thermal performance, Submitted for publication.

\subsection{Book Chapters}

- R. Palma, E. Moliner, J. Forner-Escrig. Chapter 13: Computational Thermoelectricity Applied to Cooling Devices. Bringing Thermoelectricity into Reality. (P. Aranguren, ed.). pp. 269 - 288. London (UK): IntechOpen, 2018. ISBN: 978-1-83881-565-3.

DOI: $10.5772 /$ intechopen.75473 


\subsection{Contribution to International Conferences}

- J. Forner-Escrig, R. Mondragón, R. Palma. Mechanical Reliability of CoreShell Nanoparticles for thermal energy storage by Finite Element Method. $1^{\text {st }}$ International Conference on Nanofluids (ICNf2019), $2^{\text {nd }}$ European Symposium on Nanofluids (ESNf2019), $26^{\text {th }}-28^{\text {th }}$ June 2019, Castelló de la Plana (Spain). Ed. Bubok Publishing, ISBN: 9788468539171, (2019).

- J. Forner-Escrig, R. Mondragón, R. Palma. Finite element formulation of Heat propagation in Nanoencapsulated Phase Change Materials. $1^{\text {st }}$ International Conference on Nanofluids (ICNf2019), $2^{\text {nd }}$ European Symposium on Nanofluids (ESNf2019), 26 $6^{\text {th }}-28^{\text {th }}$ June 2019, Castelló de la Plana (Spain). Ed. Bubok Publishing, ISBN: 9788468539171, (2019).

- J. Forner-Escrig, R. Mondragón, R. Palma. Non-linear finite element modelling of light-to-heat energy conversion applied to nanoencapsulated phase change materials. VIII International Conference on Computational Methods for Coupled Problems in Science and Engineering, COUPLED2019, $3^{\text {rd }}-5^{\text {th }}$ June 2019, Sitges (Spain). Ed. International Centre for Numerical Methods in Engineering (CIMNE), ISBN: 9788494919459, (2019).

- J. Forner-Escrig, R. Mondragón, R. Martínez-Cuenca, R. Palma. Phasechange-thermoelastic modelling for nanoencapsulated phase change materials. Eurotherm Seminar \#112: Advances in Thermal Energy Storage, $15^{\text {th }}-17^{\text {th }}$ May 2019, Lleida (Spain). Ed. Universitat de Lleida, ISBN: 9788491441557, (2019). 


\section{Bibliography}

[1] World Bank, International Energy Agency, Energy Sector Management Assistance Program, "Renewable energy consumption (\% of total final energy consumption)." https://data.worldbank.org/indicator/EG.FEC.RNEW.ZS. Last Accessed: 24-07-2020.

[2] H. Ritchie, "Fossil fuels," Our World in Data, 2017. https://ourworldindata.org/fossil-fuels. Last Accessed: 24-07-2020.

[3] Intergovernmental Panel on Climate Change (IPCC) SR15, "Summary for Policymakers." https://www.ipcc.ch/sr15/, 2018. Last Accessed: 23-07-2020.

[4] International Renewable Energy Agency (IRENA), "Renewable energy highlights," 2020.

[5] European Commission, "2030 climate \& energy framework. Climate strategies \& targets." https://ec.europa.eu/clima/policies/strategies/2030_en. Last Accessed: 02-09-2020.

[6] International Energy Agency. (IEA), Solar energy perspectives. Paris: International Energy Agency, 2011.

[7] International Energy Agency. (IEA), Technology Roadmap. Concentrating Solar Power. Paris: International Energy Agency, 2010. https://www.iea.org/reports/technology-roadmap-concentrating-solar-power. Last Accessed: 01-09-2020.

[8] P. Breeze, Solar Power Generation. Cambridge, Massachusetts: Academic Press, 2016.

[9] A. G. Fernández, J. Gomez-Vidal, E. Oró, A. Kruizenga, A. Solé, and L. F. Cabeza, "Mainstreaming commercial CSP systems: A technology review," Renewable Energy, vol. 140, pp. 152 - 176, 2019.

[10] J. A. Duffie and W. A. Beckman, Solar Engineering of Thermal Processes. New York: John Wiley \& Sons, Inc., 2013.

[11] S. Choi and J. Eastman, "Enhancing thermal conductivity of fluids with nanoparticles," Proceedings of the ASME International Mechanical Engineering Congress and Exposition, San Francisco, CA, USA, 1995.

[12] J. C. Maxwell, A Treatise on Electricity and Magnetism. Oxford, UK: Clarendon Press, 1873. 
[13] D. Shin and D. Banerjee, "Enhanced Specific Heat of Silica Nanofluid," Journal of Heat Transfer, vol. 133, 11 2010. 024501.

[14] H. Riazi, T. Murphy, G. B. Webber, R. Atkin, S. S. M. Tehrani, and R. A. Taylor, "Specific heat control of nanofluids: A critical review," International Journal of Thermal Sciences, vol. 107, pp. 25 - 38, 2016.

[15] S. Cingarapu, D. Singh, E. V.Timofeeva, and M. R. Moravek, "Nanofluids with encapsulated tin nanoparticles for advanced heat transfer and thermal energy storage," International Journal of Energy Research, vol. 38, pp. 51-59, 2013.

[16] S. Cingarapu, D. Singh, E. V.Timofeeva, and M. R. Moravek, "Use of encapsulated zinc particles in a eutectic chloride salt to enhance thermal energy storage capacity for concentrated solar power," Renewable Energy, vol. 80, pp. 508-516, 2015.

[17] N. Navarrete, A. Gimeno-Furió, R. Mondragón, L. Hernández, L. Cabedo, E. Cordoncillo, and J. E. Juliá, "Nanofluid based on self-nanoencapsulated metal/metal alloys phase change materials with tuneable crystallisation temperature," Scientific Reports, vol. 7, p. Article number: 17580, 2017.

[18] N. Navarrete, R. Mondragón, D. Wen, M. E. Navarro, Y. Ding, and J. E. Juliá, "Thermal energy storage of molten salt -based nanofluid containing nanoencapsulated metal alloy phase change materials," Energy, vol. 167, pp. 912 920, 2019.

[19] E. Alehosseini and S. M. Jafari, "Nanoencapsulation of phase change materials (PCMs) and their applications in various fields for energy storage and management," Advances in Colloid and Interface Science, vol. 283, p. 102226, 2020 .

[20] Nuria Navarrete Argilés, Thesis: Development of Nanofluids based on Nanoencapsulated Phase Change Materials. 2020.

[21] T. P. Otanicar, P. Phelan, and J. S. Golden, "Optical properties of liquids for direct absorption solar thermal energy systems," Solar Energy, vol. 83, no. 7, pp. 969-977, 2009.

[22] M.-K. Lee, T. G. Kim, W. Kim, and Y.-M. Sung, "Surface Plasmon Resonance (SPR) Electron and Energy Transfer in Noble Metal-Zinc Oxide Composite Nanocrystals," The Journal of Physical Chemistry C, vol. 112, pp. 1007910082, 2008.

[23] A. A. Minea, B. Buonomo, J. Burggraf, D. Ercole, K. R. Karpaiya, A. Di Pasqua, G. Sekrani, J. Steffens, J. Tibaut, N. Wichmann, P. Farber, A. Huminic, G. Huminic, R. Mahu, O. Manca, C. Oprea, S. Poncet, and J. Ravnik, "NanoRound: A benchmark study on the numerical approach in nanofluids' simulation," International Communications in Heat and Mass Transfer, vol. 108, p. 104292, 2019. 
[24] O. Mahian, L. Kolsi, M. Amani, P. Estellé, G. Ahmadi, C. Kleinstreuer, J. S. Marshall, R. A. Taylor, E. Abu-Nada, S. Rashidi, H. Niazmand, S. Wongwises, T. Hayat, A. Kasaeian, and I. Pop, "Recent advances in modeling and simulation of nanofluid flows - part ii: Applications," Physics Reports, vol. 791, pp. $1-59,2019$.

[25] Y.-T. Yang, K.-T. Tsai, Y.-H. Wang, and S.-H. Lin, "Numerical study of microchannel heat sink performance using nanofluids," International Communications in Heat and Mass Transfer, vol. 57, pp. 27 - 35, 2014.

[26] A. Kamyar, R. Saidur, and M. Hasanuzzaman, "Application of Computational Fluid Dynamics (CFD) for nanofluids," International Journal of Heat and Mass Transfer, vol. 55, no. 15, pp. 4104 - 4115, 2012.

[27] Roberto Palma Guerrero, Thesis: Thermodynamic formulation for non-linear finite element applied to multi-coupled materials. 2011.

[28] H. B. Callen, Thermodynamics and an Introduction to Thermostatistics. New York: John Wiley and Sons, Inc., 1985.

[29] S. R. de Groot and P. Mazur, Non-Equilibrium Thermodynamics. New York: Dover Publications, Inc., 1984.

[30] J. Pérez-Aparicio, R. Palma, and R. Taylor, "Multiphysics and Thermodynamic Formulations for Equilibrium and Non-equilibrium Interactions: Nonlinear Finite Elements Applied to Multi-coupled Active Materials," Archives of Computational Methods in Engineering, vol. 23, no. 3, pp. 535-583, 2016.

[31] G. Lebon, D. Jou, and J. Casas-Vázquez, Understanding Non-equilibrium Thermodynamics. New York: Springer-Verlag Berlin Heidelberg, 2008.

[32] X. Oliver Olivella and C. Agelet de Saracíbar Bosch, Mecánica de medios continuos para ingenieros. Barcelona: Edicions UPC, 2000.

[33] O. Zienkiewicz and R. Taylor, The Finite Element Method 7th Edition. Oxford: Butterworth-Heinemann, 2013.

[34] T. J. R. Hughes, The Finite Element Method. Linear Static and Dynamic Finite Element Analysis. New Jersey: Prentice-Hall, Inc., 1987.

[35] R. Taylor, FEAP. A Finite Element Analysis Program: User Manual. University of California, Berkeley, 2013.

[36] G. Tyler Miller Jr. and S. Spoolman, Essentials of Ecology, 5th Edition. Belmont: Cengage Learning, 2008.

[37] S. Zhang and Z. Wang, "Thermodynamics behavior of phase change latent heat materials in micro-/nanoconfined spaces for thermal storage and applications," Renewable and Sustainable Energy Reviews, vol. 82, pp. 2319-2331, 2018.

[38] G. Alva, Y. Lin, and G. Fang, "An overview of thermal energy storage systems," Energy, vol. 144, pp. 341-378, 2018. 
[39] B. Muñoz-Sánchez, J. Nieto-Maestre, I. Iparraguirre-Torres, A. GarcíaRomero, and J. M. Sala-Lizarraga, "Molten salt-based nanofluids as efficient heat transfer and storage materials at high temperatures. an overview of the literature," Renewable and Sustainable Energy Reviews, vol. 82, pp. 3924-3945, 2018.

[40] L. F. Cabeza, E. Galindo, C. Prieto, C. Barreneche, and A. I. Fernández, "Key performance indicators in thermal energy storage: Survey and assessment," Renewable Energy, vol. 83, pp. 820-827, 2015.

[41] R. Mondragón, N. Navarrete, A. Gimeno-Furió, L. Hernández, L. Cabedo, and J. E. Juliá, "New high-temperature heat transfer and thermal storage molten salt-based nanofluids: Preparation, stabilization, and characterization," in Advances in New Heat Transfer Fluids: From Numerical to Experimental Techniques (A. A. Minea, ed.), ch. 11, Boca Raton: CRC Press, 2017.

[42] N. Bozorgan and M. Shafahi, "Performance evaluation of nanofluids in solar energy: a review of the recent literature," Micro and Nano Systems Letters, vol. 3, p. 5, 2015.

[43] V. Sridhara and L. Satapathy, "Effect of Nanoparticles on Thermal Properties Enhancement in Different Oils - A Review," Critical Reviews in Solid State and Materials Sciences, vol. 40, pp. 399-424, 2015.

[44] S. U. Ilyas, R. Pendyala, and N. Marnen, "Preparation, sedimentation, and agglomeration of nanofluids," Chemical Engineering \&6 Technology, vol. 37, pp. 2011-2021, 2014.

[45] S. U. Ilyas, R. Pendyala, and N. Marnen, "Stability and agglomeration of alumina nanoparticles in ethanol-water mixtures," Procedia Engineering, vol. 148, pp. 290-297, 2016.

[46] Q. Yu, A. Romagnoli, B. Al-Duri, D. Xie, Y. Ding, and Y. Li, "Heat storage performance analysis and parameter design for encapsulated phase change materials," Energy Conversion and Management, vol. 157, pp. 619-630, 2018.

[47] V. R. Voller, "Fast implicit finite-difference method for the analysis of phase change problems," Numerical Heat Transfer, Part B: Fundamentals, vol. 17, pp. 155-169, 1990.

[48] V. R. Voller, "Implicit Finite - difference Solutions of the Enthalpy Formulation of Stefan Problems," IMA Journal of Numerical Analysis, vol. 5, pp. 201214, 1985.

[49] B. Nedjar, "An enthalpy-based finite element method for nonlinear heat problems involving phase change," Computers \& Structures, vol. 80, pp. 9-21, 2002.

[50] L. A. Crivelli and S. R. Idelsohn, "A temperature-based finite element solution for phase-change problems," International Journal for Numerical Methods in Engineering, vol. 23, pp. 99-119, 1986. 
[51] M. Truex, "Numerical simulation of liquid-solid, solid-liquid phase change using finite element method in $\mathrm{h}, \mathrm{p}, \mathrm{k}$ framework with space-time variationally consistent integral forms," Master's thesis, University of Kansas, Lawrence, 2010 .

[52] V. Voller, "An overview of numerical methods for solving phase change problems," in Advances In Numerical Heat Transfer, 1st Edition (W. Minkowycz, ed.), ch. 9, Washington, D.C.: CRC Press, 1996.

[53] S. R. Idelsohn, M. A. Storti, and L. A. Crivelli, "Numerical methods in phasechange problems," Archives of Computational Methods in Engineering, vol. 1, pp. 49-74, Mar 1994.

[54] A.A.Samarskii, P.N.Vabishchevichand, O.P.Iliev, and A.G.Churbanov, "Numerical simulation of convection/diffusion phase change problems - a review," International Journal of Heat and Mass Transfer, vol. 36, pp. 4095-4106, 1993.

[55] W. D. Callister Jr. and D. G. Rethwisch, Materials Science and Engineering: An Introduction, 9th Edition. New York: Wiley, 2013.

[56] A. Anca, A. Cardona, J. Risso, and V. Fachinotti, "Finite element modeling of welding processes," Applied Mathematical Modelling, vol. 35, pp. 688-707, 2011.

[57] R. Aris, Vectors, Tensors and the Basic Equations of Fluid Mechanics. New York: Dover Publications, Inc., 1989.

[58] J. Pérez-Aparicio, R. Palma, and P. Moreno-Navarro, "Elasto-thermoelectric non-linear, fully coupled, and dynamic finite element analysis of pulsed thermoelectrics," Applied Thermal Engineering, vol. 107, pp. 398-409, 2016.

[59] R. Palma, E. Moliner, and J. Pérez-Aparicio, "Elasto-thermoelectric beam formulation for modeling thermoelectric devices," Finite Elements in Analysis and Design, vol. 129, pp. 32-41, 2017.

[60] M. A. Biot, "Thermoelasticity and irreversible thermodynamics," Journal of Applied Physics, vol. 27, no. 3, pp. 240-253, 1956.

[61] E. W. V. Chaves, Mecánica del Medio Continuo. Conceptos básicos-3 $3^{a}$ Edición. Barcelona: CIMNE, 2012.

[62] C. Swaminathan and V. Voller, "A general enthalpy method for modeling solidification processes," Metallurgical Transactions B, vol. 23, no. 5, p. 651-664, 1992.

[63] G. Meyer, "Multidimensional Stefan problems," SIAM Journal on Numerical Analysis, vol. 10, no. 3, pp. 688-707, 1973.

[64] R. Palma, J. Pérez-Aparicio, and R. Taylor, "Dissipative Finite-Element Formulation Applied to Piezoelectric Materials With the Debye Memory," IEEE/ASME Transaction on Mechatronics, vol. 23, pp. 856-863, 2018. 
[65] R. H. Perry, D. W. Green, and J. O. Maloney, Perry's Chemical Engineers' Handbook. New York: McGraw-Hill, 2008.

[66] ASM Handbook Volume 2: Properties and Selection: Nonferrous Alloys and Special-Purpose Materials. Materials Park: ASM International, 1990.

[67] F. Cverna, ASM Ready Reference: Thermal Properties of Metals. Materials Park: ASM International, 2002.

[68] S. V. Stankus and R. A. Khairulin, "The density of alloys of tin-lead system in the solid and liquid states," High Temperature, vol. 44, p. 389-395, 2006.

[69] M. J. Assael, A. Chatzimichailidis, K. D. Antoniadis, W. A. Wakeham, M. L. Huber, and H. Fukuyama, "Reference correlations for the thermal conductivity of liquid copper, gallium, indium, iron, lead, nickel and tin," High Temperatures-High Pressures, vol. 46, p. 391-416, 2017.

[70] Landolt-Börnstein. Semiconductors. Non-Tetrahedrally Bonded Elements and Binary Compounds I, vol. 41C. New York: Springer-Verlag Berlin Heidelberg, 1998.

[71] R. Gaillac and F.-X. Coudert, "ELATE elastic tensor analysis." http://progs.coudert.name/elate/mp?query=mp-856. Last Accessed: 18-072018 .

[72] R. Gaillac, P. Pullumbi, and F.-X. Coudert, "Elate: an open-source online application for analysis and visualization of elastic tensors," Journal of Physics: Condensed Matter, vol. 28, no. 27, p. 275201, 2016.

[73] United States National Institutes of Health (NIH), "PubChem open chemistry database." https://pubchem.ncbi.nlm.nih.gov/compound/29011. Last Accessed: 24-10-2018.

[74] K. Nam, J. Wolfenstine, H. Choi, R. Garcia-Mendez, J. Sakamoto, and H. Choe, "Study on the mechanical properties of porous tin oxide," Ceramics International, vol. 43, pp. 10913-10918, 2017.

[75] J. F. Shackelford and W. Alexander, eds., CRC Materials Science and Engineering Handbook. Boca Raton: CRC Press, 2001.

[76] S. Nohut, A. Usbeck, H. Özcoban, and D. Krause, "Determination of the multiaxial failure criteria for alumina ceramics under tension-torsion test," Journal of the European Ceramic Society, vol. 30, pp. 3339-3349, 2010.

[77] A.Brückner-Foit, T.Fett, K.-S.Schirmer, and D.Münz, "Discrimination of multiaxiality criteria using brittle fracture loci," Journal of the European Ceramic Society, vol. 16, pp. 1201-1207, 1996.

[78] K. Yang, K. Cho, S. Kim, and K. Im, "Influence of thermal stress on heatgenerating performance of indium tin oxide nanoparticle thin films," Journal of Vacuum Science $\&$ Technology B, vol. 34, p. 06KA02, 2016. 
[79] D. A. Tarzia, "Explicit solutions to phase-change problems and applications," Arlington, VA (USA), 2016 Computational Mathematics Annual Program Review.

[80] D. A. Tarzia, "Relationship between Neumann solutions for two-phase LameClapeyron-Stefan problems with convective and temperature boundary conditions," Thermal Science, vol. 21, pp. 187-197, 2017.

[81] International Energy Agency (IEA), "World energy outlook." https://www.iea.org/weo/. Last Accessed: 11-07-2019.

[82] A. Gil, M. Medrano, I. Martorell, A. Lázaro, P. Dolado, B. Zalba, and L. F. Cabeza, "State of the art on high temperature thermal energy storage for power generation. part 1-concepts, materials and modellization," Renewable and Sustainable Energy Reviews, vol. 14, no. 1, pp. 31 - 55, 2010.

[83] B. Xu, P. Li, and C. Chan, "Application of phase change materials for thermal energy storage in concentrated solar thermal power plants: A review to recent developments," Applied Energy, vol. 160, pp. 286 - 307, 2015.

[84] B. Akhmetov, A. G. Georgiev, A. Kaltayev, A. A. Dzhomartov, R. Popov, and M. S. Tungatarova, "Thermal energy storage systems - review," Bulgarian Chemical Communications. Special Issue E, vol. 48, pp. 31-40, 2016.

[85] J. Forner-Escrig, R. Palma, and R. Mondragón, "Finite element formulation to study thermal stresses in nanoencapsulated phase change materials for energy storage," Journal of Thermal Stresses, vol. 43, no. 5, pp. 543-562, 2020.

[86] D. P. Kroese, T. Taimre, and Z. I. Botev, Handbook of Monte Carlo Methods. New York: John Wiley \& Sons, Inc., 2011.

[87] K. M. Hamdia, M. Silani, X. Zhuang, P. He, and T. Rabczuk, "Stochastic analysis of the fracture toughness of polymeric nanoparticle composites using polynomial chaos expansions," International Journal of Fracture, vol. 206, no. 2, pp. 215-227, 2017.

[88] T.-H. Hou, C.-H. Su, and W.-L. Liu, "Parameters optimization of a nanoparticle wet milling process using the Taguchi method, response surface method and genetic algorithm," Powder Technology, vol. 173, no. 3, pp. 153 $162,2007$.

[89] A. Aderibigbe, "A Term Paper on Monte Carlo Analysis/Simulation," Department of Electrical and Electronic Engineering. Faculty of Technology. University of Ibadan, 2014.

[90] J. Pérez-Aparicio, R. Palma, and R. Taylor, "Finite element analysis and material sensitivity of peltier thermoelectric cells coolers," International Journal of Heat and Mass Transfer, vol. 55, no. 4, pp. 1363 - 1374, 2012.

[91] R. Palma, J. Pérez-Aparicio, and R. Bravo, "Study of hysteretic thermoelectric behavior in photovoltaic materials using the finite element method, extended thermodynamics and inverse problems," Energy Conversion and Management, vol. 65 , pp. $557-563,2013$. 
[92] R. Palma, J. Torrent, J. L. Pérez-Aparicio, and L. Ripoll, "Reliability-based dynamical design of a singular structure for high energy physics experiments," Archives of Civil and Mechanical Engineering, vol. 18, no. 1, pp. 256 - 266, 2018.

[93] X. Li and S. E. Rankin, "Multiscale dynamic Monte Carlo/continuum model of drying and nonideal polycondensation in sol-gel silica films," American Institue of Chemical Engineers Journal, vol. 56, no. 11, pp. 2946-2956, 2010.

[94] S. Bhoi and D. Sarkar, "Hybrid finite volume and Monte Carlo method for solving multi-dimensional population balance equations in crystallization processes," Chemical Engineering Science, vol. 217, p. 115511, 2020.

[95] M. D. McKay, R. J. Beckman, and W. J. Conover, "A comparison of three methods for selecting values of input variables in the analysis of output from a computer code," Technometrics, vol. 21, no. 2, pp. 239-245, 1979.

[96] The Engineering ToolBox. https://www.engineeringtoolbox.com. Last Accessed: 18-08-2019.

[97] C. T. Lynch, ed., Practical Handbook of Materials Science. Boca Raton: CRC Press, 1989.

[98] J. F. Shackelford, Y.-H. Han, S. Kim, and S.-H. Kwon, CRC Materials Science and Engineering Handbook, Fourth Edition. Boca Raton: CRC Press, 2015.

[99] Accuratus Corporation, "Aluminum oxide, $\mathrm{Al}_{2} \mathrm{O}_{3}$ ceramic properties." https://accuratus.com/alumox.html. Last Accessed: 18-08-2019.

[100] R. Sarathi, T. Sindhu, and S. Chakravarthy, "Generation of nano aluminium powder through wire explosion process and its characterization," Materials Characterization, vol. 58, no. 2, pp. 148 - 155, 2007.

[101] R. K. Sahu and S. S. Hiremath, "Synthesis of Aluminium Nanoparticles in A Water/Polyethylene Glycol Mixed Solvent using $\mu$-EDM," IOP Conference Series: Materials Science and Engineering, vol. 225, p. 012257, 2017.

[102] A. Olsson, G. Sandberg, and O. Dahlblom, "On Latin hypercube sampling for structural reliability analysis," Structural Safety, vol. 25, no. 1, pp. 47 - 68, 2003.

[103] A. Saltelli, M. Ratto, T. Andres, F. Campolongo, J. Cariboni, D. Gatelli, M. Saisana, and S. Tarantola, Global Sensitivity Analysis. The Primer. New York: John Wiley \& Sons, Ltd., 2008.

[104] D. C. Montgomery and G. C. Runger, Applied Statistics and Probability for Engineers, 3rd Edition. New York: John Wiley \& Sons, Inc., 2003.

[105] R. Palma, G. Rus, and R. Gallego, "Probabilistic inverse problem and system uncertainties for damage detection in piezoelectrics," Mechanics of Materials, vol. 41, no. 9, pp. 1000 - 1016, 2009. 
[106] R. E. Melchers and A. T. Beck, Structural Reliability Analysis and Prediction, 3rd Edition. New York: John Wiley \& Sons, Ltd., 2018.

[107] B. P. Smarslok, R. T. Haftka, L. Carraro, and D. Ginsbourger, "Improving accuracy of failure probability estimates with separable monte carlo," International Journal of Reliability and Safety, vol. 4, no. 4, pp. 393 - 414, 2010.

[108] C. M. Jarque and A. K. Bera, "A test for normality of observations and regression residuals," International Statistical Review / Revue Internationale de Statistique, vol. 55, no. 2, pp. 163-172, 1987.

[109] F. Pan, J. Zhu, M. Ye, Y. A. Pachepsky, and Y.-S. Wu, "Sensitivity analysis of unsaturated flow and contaminant transport with correlated parameters," Journal of Hydrology, vol. 397, no. 3, pp. 238 - 249, 2011.

[110] A. Saltelli, M. Ratto, S. Tarantola, and F. Campolongo, "Sensitivity analysis practices: Strategies for model-based inference," Reliability Engineering 86 System Safety, vol. 91, no. 10, pp. 1109 - 1125, 2006. The Fourth International Conference on Sensitivity Analysis of Model Output (SAMO 2004).

[111] N. Navarrete, D. La Zara, A. Goulas, D. Valdesueiro, L. Hernández, J. R. van Ommen, and R. Mondragón, "Improved thermal energy storage of nanoencapsulated phase change materials by atomic layer deposition," Solar Energy Materials and Solar Cells, vol. 206, p. 110322, 2020.

[112] H. Van Bui, F. Grillo, and J. R. van Ommen, "Atomic and molecular layer deposition: off the beaten track," Chemical Communications, vol. 53, pp. 45$71,2017$.

[113] J. Forner-Escrig, R. Palma, and R. Mondragón, "Finite element formulation to study thermal stresses in nanoencapsulated phase change materials for energy storage," Journal of Thermal Stresses, vol. 43, no. 5, pp. 543-562, 2020.

[114] J. Forner-Escrig, R. Mondragón, and R. Palma, "Mechanical Reliability of Core-Shell Nanoparticles for thermal energy storage by Finite Element Method," in Conference Proceedings 1st Internationational Conference on Nanofluids (ICNf2019), 2nd European Symposium on Nanofluids (ESNf2019), pp. 258-261, Bubok Publishing S.L, 2019.

[115] J. Forner-Escrig, R. Mondragón, L. Hernández, and R. Palma, "Mechanical reliability analysis of nanoencapsulated phase change materials combining Monte Carlo technique and the finite element method," 2020. Submitted.

[116] J. van Ommen and A. Goulas, "Atomic layer deposition on particulate materials," Materials Today Chemistry, vol. 14, p. 100183, 2019.

[117] MNX Mems \& Nanotechnology Exchange, "MEMSnet ${ }^{\circledR}$." https://www.memsnet.org/material/silicondioxidesio2film/. Last Accessed: 1106-2020.

[118] Massachusetts Institute of Technology, "Thermal silicon oxide." http://www.mit.edu/ 6.777/matprops/sio2.htm. Last Accessed: 13-062020 . 
[119] Translume, "Fused silica material properties." https://www.translume.com/index.php/resources/

item/186-fused-silica-material-properties. Last Accessed: 13-06-2020.

[120] W. M. Haynes, CRC Handbook of Chemistry and Physics (92nd ed.). Boca Raton: CRC Press, 2011.

[121] K. Persson, "Materials Data on SnO (SG:129) by Materials Project," 2014. https://materialsproject.org/materials/mp-2097/. Last Accessed: 10-08-2020.

[122] K. Persson, "Materials Data on SnO2 (SG:136) by Materials Project," 2014. https://materialsproject.org/materials/mp-856/. Last Accessed: 10-08-2020.

[123] Massachusetts Institute of Technology (MIT), "Thermal silicon oxide." http://www.mit.edu/ 6.777/matprops/sio2.htm. Last Accessed: 11-08-2020.

[124] Q. He, S. Wang, S. Zeng, and Z. Zheng, "Experimental investigation on photothermal properties of nanofluids for direct absorption solar thermal energy systems," Energy Conversion and Management, vol. 73, pp. 150 - 157, 2013.

[125] H. Jin, G. Lin, L. Bai, M. Amjad, E. P. Bandarra Filho, and D. Wen, "Photothermal conversion efficiency of nanofluids: An experimental and numerical study," Solar Energy, vol. 139, pp. 278 - 289, 2016.

[126] S. A. Kalogirou, "Solar thermal collectors and applications," Progress in Energy and Combustion Science, vol. 30, no. 3, pp. 231 - 295, 2004.

[127] A. Lenert and E. N. Wang, "Optimization of nanofluid volumetric receivers for solar thermal energy conversion," Solar Energy, vol. 86, no. 1, pp. 253 $265,2012$.

[128] N. Arai, Y. Itaya, and M. Hasatani, "Development of a "volume heat-trap" type solar collector using a fine-particle semitransparent liquid suspension (FPSS) as a heat vehicle and heat storage medium Unsteady, one-dimensional heat transfer in a horizontal FPSS layer heated by thermal radiation," Solar Energy, vol. 32, no. 1, pp. 49 - 56, 1984.

[129] S. K. Verma and A. K. Tiwari, "Progress of nanofluid application in solar collectors: A review," Energy Conversion and Management, vol. 100, pp. 324 $-346,2015$.

[130] H. H. Richardson, Z. N. Hickman, A. O. Govorov, A. C. Thomas, W. Zhang, and M. E. Kordesch, "Thermooptical properties of gold nanoparticles embedded in ice: characterization of heat generation and melting," Nano Letters, vol. 6 , pp. $783-788,2006$.

[131] H. H. Richardson, M. T. Carlson, P. J. Tandler, P. Hernandez, and A. O. Govorov, "Experimental and Theoretical Studies of Light-to-Heat Conversion and Collective Heating Effects in Metal Nanoparticle Solutions," Nano Letters, vol. 9, pp. 1139 - 1146, 2009. 
[132] M. Chen, Y. He, J. Huang, and J. Zhu, "Investigation into Au nanofluids for solar photothermal conversion," International Journal of Heat and Mass Transfer, vol. 108, pp. 1894 - 1900, 2017.

[133] S. Eustis and M. A. El-Sayed, "Why gold nanoparticles are more precious than pretty gold: Noble metal surface plasmon resonance and its enhancement of the radiative and nonradiative properties of nanocrystals of different shapes," Chemical Society Reviews, vol. 35, pp. 209-217, 2006.

[134] M. Chen, Y. He, J. Zhu, and D. Wen, "Investigating the collector efficiency of silver nanofluids based direct absorption solar collectors," Applied Energy, vol. 181, pp. $65-74,2016$.

[135] S. Polvongsri and T. Kiatsiriroat, "Performance Analysis of Flat-Plate Solar Collector Having Silver Nanofluid as a Working Fluid," Heat Transfer Engineering, vol. 35, no. 13, pp. 1183-1191, 2014.

[136] J. Pérez-Juste, I. Pastoriza-Santos, L. M. Liz-Marzán, and P. Mulvaney, "Gold nanorods: Synthesis, characterization and applications," Coordination Chemistry Reviews, vol. 249, no. 17, pp. 1870 - 1901, 2005. 36th International Conference on Coordination Chemistry, Merida, Mexico, July 2004.

[137] A. Gimeno-Furio, L. Hernandez, N. Navarrete, and R. Mondragon, "Characterisation study of a thermal oil-based carbon black solar nanofluid," Renewable Energy, vol. 140, pp. 493 - 500, 2019.

[138] T. P. Otanicar, P. E. Phelan, R. S. Prasher, G. Rosengarten, and R. A. Taylor, "Nanofluid-based direct absorption solar collector," Journal of Renewable and Sustainable Energy, vol. 2, no. 3, p. 033102, 2010.

[139] R. Taylor, S. Coulombe, T. Otanicar, P. Phelan, A. Gunawan, W. Lv, G. Rosengarten, R. Prasher, and H. Tyagi, "Small particles, big impacts: A review of the diverse applications of nanofluids," Journal of Applied Physics, vol. 113, no. 1, p. 011301, 2013.

[140] R. A. Taylor, P. E. Phelan, T. P. Otanicar, R. Adrian, and R. Prasher, "Nanofluid optical property characterization: towards efficient direct absorption solar collectors," Nanoscale Research Letters, vol. 6, p. 225, 2011.

[141] A. Gimeno-Furió, E. Juliá, S. Barison, F. Agresti, C. Friebe, and M. Buschmann, "Nanofluids as Direct Solar Energy Absorbers," Journal of Nanofluids, vol. 8, no. 1, pp. 17-29, 2019.

[142] N. Hordy, D. Rabilloud, J.-L. Meunier, and S. Coulombe, "High temperature and long-term stability of carbon nanotube nanofluids for direct absorption solar thermal collectors," Solar Energy, vol. 105, pp. 82 - 90, 2014.

[143] F. Javadi, R. Saidur, and M. Kamalisarvestani, "Investigating performance improvement of solar collectors by using nanofluids," Renewable and Sustainable Energy Reviews, vol. 28, pp. 232 - 245, 2013. 
[144] C. L. Beicker, M. Amjad, E. P. Bandarra Filho, and D. Wen, "Experimental study of photothermal conversion using gold/water and mwcnt/water nanofluids," Solar Energy Materials and Solar Cells, vol. 188, pp. 51 - 65, 2018.

[145] J. Lee, A. O. Govorov, and N. A. Kotov, "Nanoparticle assemblies with molecular springs: a nanoscale thermometer," Angewandte Chemie International Edition in English, vol. 44, no. 45, pp. 7439-7442, 2005.

[146] C. Gota, K. Okabe, T. Funatsu, Y. Harada, and S. Uchiyama, "Hydrophilic Fluorescent Nanogel Thermometer for Intracellular Thermometry," Journal of the American Chemical Society, vol. 131, no. 8, pp. 2766-2767, 2009.

[147] C. M. Tan, J. Jia, and W. Yu, "Temperature dependence of the field emission of multiwalled carbon nanotubes," Applied Physics Letters, vol. 86, p. 263104, 2005 .

[148] M. Honda, Y. Saito, N. I. Smith, K. Fujita, and S. Kawata, "Nanoscale heating of laser irradiated single gold nanoparticles in liquid," Optics Express, vol. 19, pp. 12375-12383, Jun 2011.

[149] F. Torres and B. Jecko, "Complete FDTD analysis of microwave heating processes in frequency-dependent and temperature-dependent media," IEEE Transactions on Microwave Theory and Techniques, vol. 45, pp. 108-117, 1997.

[150] Y. Alpert and E. Jerby, "Coupled thermal-electromagnetic model for microwave heating of temperature-dependent dielectric media," IEEE Transactions on Plasma Science, vol. 27, pp. 555-562, 1999.

[151] L. Acevedo, S. Usón, and J. Uche, "Exergy transfer analysis of microwave heating systems," Energy, vol. 68, pp. 349 - 363, 2014.

[152] L. Landau and E. Lifshitz, Electrodynamics of Continuous Media. Oxford: Pergamon, 1984.

[153] X. Zhao, L. Yan, and K. Huang, "Review of Numerical Simulation of Microwave Heating Process," in Advances in Induction and Microwave Heating of Mineral and Organic Materials (S. Grundas, ed.), ch. 2, London: IntechOpen, 2011.

[154] K. Huang and Y. Liao, "Transient Power Loss Density of Electromagnetic Pulse in Debye Media," IEEE Transactions on Microwave Theory and Techniques, vol. 63, pp. 135-140, 2015.

[155] P. Castiglione and P. Shouse, "The effect of ohmic cable losses on time-domain reflectometry measurements of electrical conductivity," Soil Science Society of America Journal, vol. 67, pp. 414-424, 2003.

[156] F. Bresme, A. Lervik, D. Bedeaux, and S. Kjelstrup, "Water Polarization under Thermal Gradients," Physical Review Letters, vol. 101, p. 020602, 2008.

[157] L. Restuccia and G. A. Kluitenberg, "On the heat dissipation function for dielectric relaxation phenomena in anisotropic media," International Journal of Engineering Science, vol. 30, no. 3, pp. 305 - 315, 1992. 
[158] F. Farsaci and P. Rogolino, "An alternative dielectric model for low and high frequencies: A non-equilibrium thermodynamic approach," Journal of NonEquilibrium Thermodynamics, vol. 37, pp. 27-41, 2012.

[159] P. Debye, Polar Molecules. New York: The Chemical Catalog Company, Inc., 1929.

[160] S. Bruzzone and M. Malvaldi, "Local Field Effects on Laser-Induced Heating of Metal Nanoparticles," The Journal of Physical Chemistry C, vol. 113, no. 36, pp. 15805-15810, 2009.

[161] R. Tinder, Tensor Properties of Solids: Phenomenological Development of the Tensor Properties of Crystals. San Rafael (California): Morgan and Claypool Publishers, 2008.

[162] R. Taylor, FEAP. A Finite Element Analysis Program: Programmer Manual. University of California, Berkeley, 2014.

[163] S. Kasap, C. Koughia, and H. E. Ruda, "Electrical conduction in metals and semiconductors," in Springer Handbook of Electronic and Photonic Materials (S. Kasap and P. Capper, eds.), ch. 2, New York: Springer International Publishing, 2017.

[164] D. I. Yakubovsky, A. V. Arsenin, Y. V. Stebunov, D. Y. Fedyanin, and V. S. Volkov, "Optical constants and structural properties of thin gold films," Optics Express, vol. 25, no. 21, pp. 25574-25587, 2017.

[165] M. Polyanskiy, "Refractiveindex.info website." https://refractiveindex.info/. Last Accessed: 18-02-2020.

[166] K. M. Chew, R. Sudirman, N. Seman, and C. Y. Yong, "Relaxation frequency and relaxation time estimation for phantom modeling by proposed fitting linear models," in 2012 IEEE-EMBS Conference on Biomedical Engineering and Sciences, pp. 911-915, 2012.

[167] R. Richert, A. Agapov, and A. P. Sokolov, "Appearance of a Debye process at the conductivity relaxation frequency of a viscous liquid," The Journal of Chemical Physics, vol. 134, no. 10, p. 104508, 2011.

[168] Lenntech, "Water conductivity." https://www.lenntech.com/applications/ ultrapure/conductivity/water-conductivity.htm. Last Accessed: 18-07-2018.

[169] G. M. Hale and M. R. Querry, "Optical Constants of Water in the 200-nm to 200- $\mu$ m Wavelength Region," Applied Optics, vol. 12, no. 3, pp. 555-563, 1973.

[170] J. P. A. Bastos and N. Sadowski, Electromagnetic Modeling by Finite Element Methods. Washington, D.C.: CRC Press, 2003.

[171] A. Ciesielski, L. Skowronski, M. Trzcinski, and T. Szoplik, "Controlling the optical parameters of self-assembled silver films with wetting layers and annealing," Applied Surface Science, vol. 421, pp. 349 - 356, 2017. 7th International Conference on Spectroscopic Ellipsometry. 
[172] H. O. Pierson, Handbook of Carbon, Graphite, Diamonds and Fullerenes. New Jersey: Noyes Publications, 1994.

[173] M. R. Querry, Optical Constants. Kansas City: Defense Technical Information Center. Department of Defense, USA, 1985.

[174] Y. J. Zhang, "Investigation of Gold and Silver Nanoparticles on Absorption Heating and Scattering Imaging," Plasmonics, vol. 6, no. 2, pp. 393-397, 2011.

[175] J. Theerthagiri, R. Sudha, K. Premnath, P. Arunachalam, J. Madhavan, and A. M. Al-Mayouf, "Growth of iron diselenide nanorods on graphene oxide nanosheets as advanced electrocatalyst for hydrogen evolution reaction," International Journal of Hydrogen Energy, vol. 42, no. 18, pp. 13020 - 13030, 2017.

[176] M. Mehrali, M. K. Ghatkesar, and R. Pecnik, "Full-spectrum volumetric solar thermal conversion via graphene/silver hybrid plasmonic nanofluids," Applied Energy, vol. 224, pp. 103 - 115, 2018.

[177] T. B. Gorji and A. Ranjbar, "A numerical and experimental investigation on the performance of a low-flux direct absorption solar collector (DASC) using graphite, magnetite and silver nanofluids," Solar Energy, vol. 135, pp. 493 $505,2016$.

[178] S. S. Murshed and P. Estellé, "Rheological characteristics of nanofluids for advance heat transfer," in Advances in New Heat Transfer Fluids: From Numerical to Experimental Techniques (A. A. Minea, ed.), ch. 9, Boca Raton: CRC Press, 2017.

[179] F. Yu, Y. Chen, X. Liang, J. Xu, C. Lee, Q. Liang, P. Tao, and T. Deng, "Dispersion stability of thermal nanofluids," Progress in Natural Science: Materials International, vol. 27, no. 5, pp. 531 - 542, 2017.

[180] S. U. Ilyas, R. Pendyala, M. Narahari, and L. Susin, "Stability, rheology and thermal analysis of functionalized alumina- thermal oil-based nanofluids for advanced cooling systems," Energy Conversion and Management, vol. 142, pp. $215-229,2017$.

[181] N. Singh and V. Khullar, "Efficient volumetric absorption solar thermal platforms employing thermally stable - solar selective nanofluids engineered from used engine oil," Scientific Reports, vol. 9, no. 1, p. 10541, 2019.

[182] M. Onimisi and T. Ikyumbur, "Comparative analysis of dielectric constant and loss factor of pure butan-1-ol and ethanol," American Journal of Condensed Matter Physics, vol. 2015, pp. 69-75, 2015. 